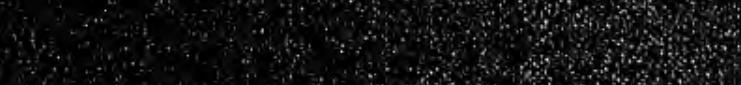
$\therefore \%$, d

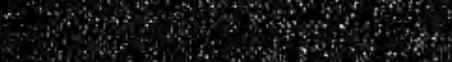
(4) Sitis

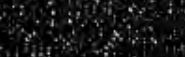

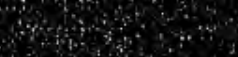




$$
\text { - }
$$



THE AMERICAN MIDLAND NATURALIST

Monograph No. 1 


\section{THE AMERICAN MIDLAND NATURALIST \\ Monograph Series}

\section{EDITORIAL STAFF}

ThEodor JUST

Editor, University of Notre Dame

Botan:

Edward A. Chapin

Entomolog!

U. S. National Museum, Washington, D. C.

Kenneth W. Cooper.

Cytology and Genetics Princeton University, Princeton, New Jersey

Carroll Lane Fenton Invertebrate Paleontologe Rutgers University, New Brunswick, N. J.

JoHn Hobart Hoskins Paleobotany University of Cincinnati, Cincinnati, Ohio

Remington Kellogg Mammaloge

U. S. National Museum, Washington, D. C.

Jean Mrron Linsdale. Ornithologe

Hastings Reservation. Monterey, California

George Willard Martin Mycologe State University of lowa, Iowa City, lowa

Karl Patterson Scilmidt. Ichthuology and Herpetologe Chicago Natural History Museum, Chicago, Illinois

Harley Jones Van Cleave

University of Illinois. Urbana. Illinois Invertebrate Zoology 


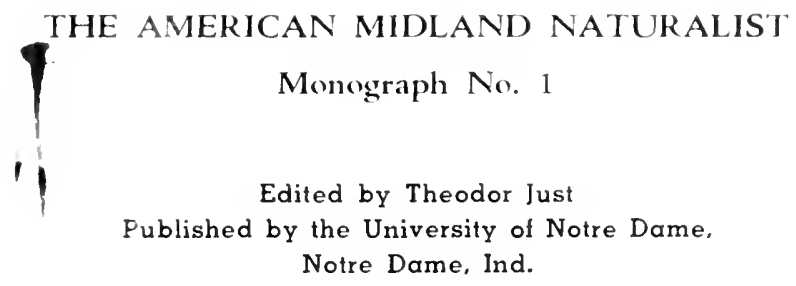

\title{
The Argasidae of North America, Central America and Cuba
}

\author{
By R. A. COOLEY \\ (Senior Entomologist) \\ and \\ GLFN M. KOHLS \\ Associate Entomologist)
}

Contribution from the Rocky Mountain Laboratory, Hamilton, Montana. Division of Infectious Diseases, National Institute of Health. United States Public Health Service. 
Copyright, 1944

by

The American Midland Naturalist

University of Notre Dame

Notre Dame, Ind. 


\section{CONTENTS}

Introduction

The Medical and Veterinary Importance of the Argasidae 3

Explanation of Terms

Principal Characters of Argasidae, Figure 1 .................

Methods _..................................................... 7

Family Argasidae Canestrini ……............................... 11

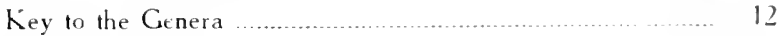

Genus Argas Latreille ..........................................................

Key to Species of Argas ......................... 13

Argas reflexus (Fabricius) ……................................... It

Argas persicus (Oken) ........................................... 17

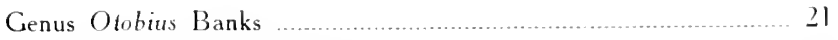

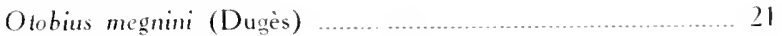

Otobius lagophilus Cooley and Kohls ............................ 32

Genus Ornithodoros Koch ................................................. 37

Key to Species of Ornithodoros ....................................... 37

Ornithodoros savignvi (Audouin) .................................... 38

Ornithodoros eremicus Cooley and Kohls .......................... ti)

Ornithodoros coriaceus Koch ...................................... t2

Ornithodoros hermsi Wheeler, Herms, and Meyer ................. 46

Ornithodoros nicollei Mooser ........................................ 50

Ornithodoros coolevi Mclvor ………............................. 52

Ornithodoros turicata (Dugès) …........................................... 56

Ornithodoros parkeri Cooley .......................................... 62

Ornithodoros yumatensis Cooley and Kohls ......................... 74

Ornithodoros brodyi Matheson ……................................ 80)

Ornithodoros talaje (Guérin-Méneville) ……..................... 82

Ornithodoros concanensis Cooley and Kohls ....................... 88

Ornithodoros stageri Cooley and Kohls ........................... 91

Ornithodoros dycri Cooley and Kंohls.............................. 95

Ornithodoros amblus Chamberlin ........................................ 99

Ornithodoros rudis Karsch ................................................... 101

Ormithodoros dunni Matheson ........................................ 103

Ornithodoros viguerasi Cooley and Kohls ........................... 106

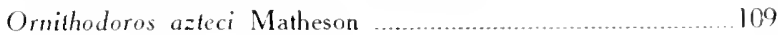

Genus Antricola Cooley and Kohls _..........................................118

Key to Species of Antricola _..................................... 118

Antricola coprophitus (McIntosh) …….......................... 11 s

Antricola marginatus (Banks) ….......................................

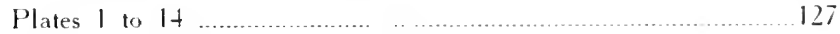

Classified List of Hosts ...................................................... $1+1$

Geographical Distribution of Species ……......................... Itt

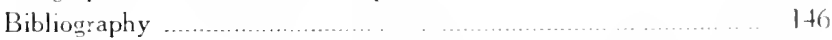

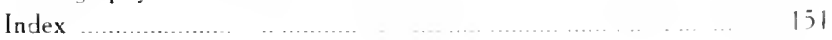





\section{The Argasidae of North America, Central America and Cuba}

\section{Introduction}

The taxonomic study of the Argasidae has been beset with difficult problems, some of which are still unsolved. The principal difficulty has been and still is the lack of adequate generic characters. Some of the earlier species were described from very few specimens and frequently with very little knowl. edge of their biologies. By 1908, Neumann and Nuttall had notably improved the situation by better generic definitions and the use of new specific characters. Both retained as genera only Argas and Ornithodoros. In 1912 Banks added the genus Otobins, and in 1942 Antricola was added by the authors.

In 1908 only some twenty species were known. Now in North America alone there are at least twenty-five species and about thirty new species have been described from other countries. The characters exhibited by these new species have served to clarify certain of the taxonomic problems; they have made others more confusing. Some specific distinctions have found corroborative support in the biologies. With the increasing number of new species, it has become more and more difficult to separate Argas and Ornithodoros and we have found it necessary to change the previcus conceptions of these genera. However, no genera have been synonymized. It is probable that subsequent workers will find others necessary but it is earnestly hoped that none will be erected until reliable generic criteria have been clearly established. The present names serve the purpose and should be changed only for permanent reasons.

In a previous paper ${ }^{1}$ the senior author emphasized the importance of variation within species. This occurs principally in the ornamentation, and the morphology is reasonably constant. In the Argasidae it is perhaps too early to evaluate fully the variation within species, but at least it is evident that it is of little importance in the genus Ornithodoros. Ornamentation is absent in the known species of the Argasidae except in Ornithodoros coriaceus.

Where confusion has arisen in specific identities, it has been due largely to overlooking characters in the mammillae and hypostome, some of which are not very easily detected, and the very distinct ones found in the larval stage which heretofore has not been thoroughly studied.

Host specificity varies in the numerous species. So far as known several

1 Cooley, R. A. The Genera Dermacentor and Otocentor (Ixodidae) in the United States, with studies in variation. National Institute of Health Bulletin No. 171. Government Printing Office, 1938. 
are host specific for bats though the bat tick, Ornithodoros stageri, also attacks man readily. Nymphs and adults of $O$. dunni feed readily on guinea pigs and white rats, and the larvae of $O$. kelleyi feed on guinea pigs. Species which are found in the burrows and retreats of animals other than bats will apparently attack any available host. Still others have been recorded from restricted lists.

During recent years a surprising number of new American species have been found on bats. The original one, Antricola marginatus (Banks), was described from Cuba in 1910. The new ones have been described during the past six years. In 1935, Dr. Robert Matheson, of Cornell University, described three from Panama and the Canal Zone and Mr. Allen McIntosh, of the Bureau of Animal Industry, United States Department of Agriculture, described one from bat guano from Mexico and Arizona. We have recently described a new species from Utah and Colorado, four others from Southern States and one from Cuba. There are likely still others that infest bats in the United States and probably in Mexico and Central America. We already have larval specimens of undescribed species from Southwestern States of which the adult and nymph are unknown.

Most of the material studied has been collected by staff members of the Rocky Mountain Laboratory. Dr. Gordon E. Davis, in connection with his studies on Ornithodoros as vectors of relapsing fever, has made many collections in the field and has furnished valuable laboratory-reared specimens.

The authors wish to express their appreciation for the assistance given by various persons and institutions and especially the following: Dr. Jos. C. Bequaert. Harvard University, for valuable specimens and for bringing to our attention certain items of taxonomy and synonymy: Dr. Robert Matheson, Cornell University, Dr. William A. Riley, University of Minnesota, Dr. C. A. Herrick, University of Wisconsin, and Dr. W. B. Herms, University of California, for very useful materials and helpful cooperation: Drs. B. Schwartz, E. W. Price and Mr. Allen McIntosh, Bureau of Animal Industry, United States Department of Agriculture, for cooperation and facilities for study while in Washington and for permission to use illustrations from the Seventeenth Report of the Bureau of Animal Industry, for assistance in many ways while the senior author was a visitor at his laboratories and for permission to use his drawings of Antricola coprophilus; Drs. E. A. Chapin and H. E. Ewing for facilities and assistance while at the National Museum; Dr. F. C. Bishopp, for assistance in locating critical material; Dr. Barbara C. Mclvor for lending very valuable specimens; Dr. Chas. M. Wheeler, Dr. D. E. Howell, and Mr. Thomas F. Kelley for sending ticks on various occasions: Mr. Kenneth E. Stager, Los Angeles County Museum of History, Science and Art, for assistance and materials; Dr. J. M. Linsdale. University of California, for opportunity to study the collection of the Hastings Natural History Reservation; Mr. Robert Holdenried. for opportunity to study the collection of the Hooper Foundation; Dr. Charles T. Vorhies and Mr. R. A. Flock, University of Arizona. for specimens and assistance; Mr. Robert Traub, University of Illinois, for valuable specimens; Dr. I. Pérez Vigueras, for several collections of ticks from Cuba; and Dr. E. Brumpt for especially valuable and critical materials.

In the tables of collection data the following abbreviations have been used: R.M.L. - Rocky Mountain Laboratory; B.A.I. - Bureau of Animal Industry, United States Department of Agriculture; U.S.N.M. - United States National Mureum; A - adult: N. - nymph; L. - larva; spec. - specimens. 


\section{The Medical and Veterinary Importance of the Argasidae}

Several species of the Argasidae are of known medical or veterinary im. Fortance.

Five species of Ornithodoros in this hemisphere, bermsi, turicata, parkert, talaje, and rudis, are proved vectors of relapsing fever spirochetes. O. hermsi is present in California, Nevada, Idaho, Oregon, and Colorado. O. turicata is found in California, Arizona, New Mexico, Texas, Oklahoma, Kansas, Colo. rado, Utah, Florida, and in Mexico. O. parkeri is present in Washington, Oregon, California, Idaho, Nevada, Montana, Wyoming, Utah, and Colorado. O. talaje is present in California, Arizona, Nevada, Texas, Kansas. Florida, and Central America. O. rudis is known in Panama, Mexico, and South America.

Other species may prove to be of importance as disease vectors. Davis has reported (Section VII, Sixth Pacific Science Congress, Berkeley, Calif., July 1939) the experimental transmission of Rocky Mountain spotted fever by $O$. parkeri and has also demonstrated similar transmission of this disease and American Q fever by $O$. hermsi.

O. corraceus, of California and Mexico, while not known: to be a vector of any specific disease agent, readily attacks man. Its "bite" is quite painful. Herms, who has studied this species. considers it to be one of the most venomous of our ticks.

O. nicollci, a Mexican species of which we have ene record from the United States (from snakes in a St. Louis, Missouri, zoo), was reported by Mooser as occurring in native huts and fecding on man in Mexico.

Brumpt was unable to tiansmit turicata strains of relapsing fever spirochetes with nicollei but found that the species would transmit experimentally the 1 elapsing fever of Turkestan.

Very little is known conccrning the several species in the Southwest recently described from bats and bat retreats. One of these, O. stagiri, promptly attacks man when opportunity permits. While its "bites" are rather severe, the species is not known to be concerned in the transmission of any disease. Another, O. kelleyi, probably primerily associated with bats, has been found in houses in Minnesota, Iowa, Wisconsin, Illinois, New York, and Pennsylvania but is not known to attack man. Further settlement in Western States may increase the possibilities of association of the various bat-infesting species with man.

Argas persicus, of almost world-wide distribution in warm climates, is a notorious pest of poultry. It is the vector of avian spircchetosis in many Old World regions and in the $\mathrm{Ncw}$ World the disease has been reported from Brazil, Panama, and Cuba. Brown and Cross (1941) published results of experiments indicating that the species may be a vector of fowl paralysio in Texas.

Otobius megnimi, the spinose ear tick, is a serious pest of cattle in most of 
the Southwestern United States and parts of Mexico. While not known to be concerned in the transmission of any disease, the habit of the immature stages of feeding deep in the ears of the host results in intense irritation. Heavily infested animals, especially calves, are often in poor condition and deaths of cattle have been attributed to gross infestations of this tick. Several instances have been reported of the occurrence of nymphs of this species in the ears of man. Medical attention is usually required to effect the removal of the tick.

\section{Explanation of Terms}

Fig. 1

Anterior Projection: The projection of the dorsal body wall at the anterior end. It may extend horizontally or may be curved ventrad and be continuous with or separate from the hood.

Anus: The external evidence of the termination of the alimentary tract. located on the venter back of the coxae. It consisls of two eversible flaps enclosed in a continuous ring or frame.

Apical Ventral Spur: A ventral spur on the distal end of the tarsus in some species. Figure 53, D and $\mathrm{E}$.

Article: A distinct articulating portion of a leg or palpus. The sequence of the articles is indicated by Arabic numerals 1, 2, 3 and 4 , I being proximal.

Attenuated: To become thin, fine, or less.

Basts CAPITUli: The basal portion of the capitulum which is movably articulated with the body and to which the mouth parts are attached. The "basal ring" of some authors.

Buttons: In the genus Argus, circular elevations found on the integument, each with a central pit and often with a hair in the pit, and distinguishable from the discs and "wrinkles."

BARBED Halrs: Tapering hairs with barbs on their sides. The barbs may be numerous and found on all sides or few in number and present on one side only, and may be long or very short. Fig. $52 \mathrm{H}$.

Camerostome: The depression or cavity in which the capitulum lies, and usually less definite in much engorged specimens.

CAPITUlum: The movable anterior portion of the body including the mouth parts. The "head" or "false head" of some authors.

CHEEks: Paired flaps at the sides of the camerostome, which may be either fixed or movable; the "movable cheeks" of some writers. Fig. I, C.

Chelicerae: Paired mouth parts for piercing the skin, lying dorsally on the hypostome and completing the more or less cylindrical mouth parts that are inserted when the tick feeds.

Clubbed Hairs: Hairs which do not taper and are terminally enlarged.

Color: The color is greatly affected by ingested blood. At first there is a reddish tinge resulting from the fresh haemoglobin but in a few hours this changes to dark gray. During the subsequent process of depletion the changing color of the blood gradually loses its effect and only the natural color of the body wall remains. Color is much affected when the specimen is placed in preserving fluid: also those preserved soon after feeding appear different from those preserved after having been depleted for weeks or months. Thus. since the color is not dependable, it is usually not mentioned in describing the Argasidae.

CORONA: The apical portion of the hypostome which is differentiated from the remainder by having very small denticles which may be numerous or few in number.

COXAE: The sequence of the coxae from anterior to posterior is indicated in Romav numerals thus, I, II, III, and JV. Fig. I, B. 
Denticles: The "teeth" on the ventral side of the hypostome. Usually arranged in parallel, longitudinal rows or files. They may be only slight elevations or they may be definitely raised. sharp, recurved and with distinct "over-hang" which makes them more effective in clinging to the host.

Depletion: A term applied to the progressive changes within each stage, between feedings, in nymphs and adults of the Argasidac. When fully fed, many species are much distended and as depletion progresses the shape, color, depth of grooves, elevation of folds, and the appearance of the mammillae are affected making it difficult to recognize or adequately describe some species. The shape changes progressively from "rotund" to "flat" without greatly changing the length and width and the grooves become more pronounced. The dorsal surface may even become concave. In a few species (notably Antricola coprophilus) the shape may become much distorted. In distended specimens the mammillae may become much flattened and show only as sclerotized spots. Some grooves may disappear completely and reappear during depletion. The folds usually persist through complete feeding but sometimes become difficult to see. See "Color."

Discs: Limited areas or spots which are the external evidence of modification of the structure of the body wall at the points of attachment of the dorso-ventral muscles. They are usually in a nearly symmetrical pattern and may or may not be evident on the venter. They vary structurally in the numerous species and may be superficial or depressed, faint, or distinct. The authors piefer to accept the term "disc" as appropriate in defining any structural modification of the body wall at the points of attachment of dorso-ventral muscles. The "obvious discs," "foveolae," "pits," "scutella," and "patellae" of some authors. Fig. I, A.

Dorsal Humps: Humps or elevations on the dorsal walls of the articles of the legs and not including the subapical dorsal protuberance. Fig. I, D and E.

Dorsal Plate: The unwrinkled spot in or near the middle of the dorsum in some larvae. Examples are fig. 35, G and fig. 51. G.

Dorsum: The entire dorsal surface in contra-distinction to the venter.

Folds: Constant ridges of the integument found on the venter in Argasidae and, like grooves, much influenced by the degree of engorgement. Fig. I. B.

Frame of The Anus: The continuous circular or oval ring which encloses the eversible flaps of the anus.

Granulations: Irregular elevations on the surface of the integument in adults of Otobius, in contra-distinction to tubercles in Antricola and mammillae in Ornithodoros, and "elevations" or wrinkles in Argas. Also used in describing the very small elevations, similar to micromammillae, found in some species.

Grooves: Lineal depressions or furrows, mainly on the ventral surface. Their depths and widths are much influenced by the degree of engorgement. See Fig. I, B.

HaIrs: Hairs found on the body or appendages of the Argasidae have been spoken of by authors as barbed. clubbed. truncated spines, or simple hairs. In the descriptions the authors have disregarded for the most part the character of the hairs or spines because more useful characters are available.

Hoon: The anterior projection of the integument forming in part the walls of the camerostome, if present. Fig. I, A, B and C.

Hypostome: The median ventral mouth part which is immovably attached to the basis capituli and usually bearing "teeth" or denticles. The dentition is indicated by numerals either side of a line. Thus 33 means that there are three longitudinal files on each half of the hypostome. Measurements are made from the posthypostomal hairs to the anterior extremity. Fig. 1, F.

LEgs: The sequence of the legs from anterior to posterior is indicated in Roman numerals, thus, I, II, III, and IV. Fig. I, D and E.

Mammillae: Elevations of various forms found on the integument in Ornithodoros in contra-distinction to the granulations in Otobius, tubercles in Antricola, and "elevations" or wrinkles in Argas. Previous authors have used the term to designate the conical or hemispherical elevations found especially in such species 
as savignyi and turicala but with the increased numbers of species now known it is more appropriate to include under the term all similar structures on the integument in Ornithodoros. Fig. I, A.

Measurements: All measurements are recorded in millimeters. The articles of the legs are measured dorsally. The articulations "telescope" on the ventral side but are fixed or hinged dorsally. The length of the hypostome is measured from the posthypostomal hairs to the tip of the hypostome.

Micromammillae: V'ery small, rounded elevations of nearly uniform size on the surface of the legs, and sometimes on the capitulum as in Ornithodoros talaje and $O$. rudis.

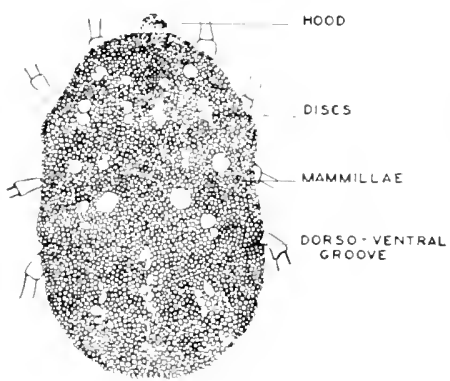

A
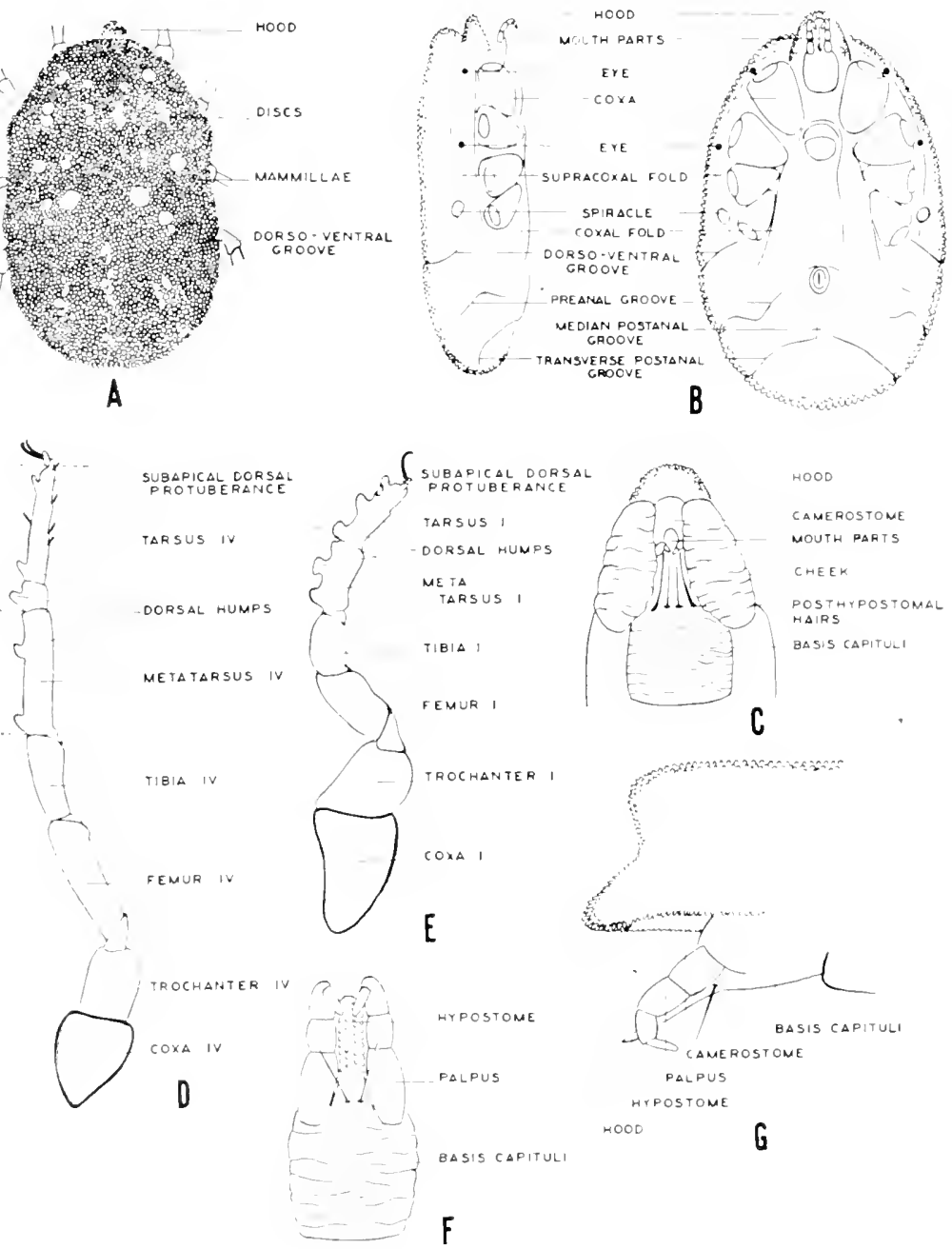

Fig. 1. Principal characters of Argasidae. A, Dorsal. B, Lateral and ventral. C. ventral, anterior. D, Leg IV. E. Leg I. F, Capitulum, ventral. G, lateral, anterior. 
Ornate: Ornate ticks are common in Dermacentor and Amblyomma which have a symmetrical pattern of color usually spoken of as "white" or "gray," "rosetinted." etc., superimposed over the base color of the chitin. In the Argasidae ornamentation is lacking except in $O$. coriaceus in which the mammillae are crowned with "white," "cream." or faint iridescent colors.

PANDCRIFORM: Obovate, with a concavity on each side, like a violin.

Postpalpal Hairs: A pair of hairs placed posterior to the palpi, more or less in line with the posthypostomal hairs.

Posthypostomal Hatrs: A pair of hairs on the ventral surface at the base of the hypostome.

SEX OPEning: The external evidence of the sexual organs of either sex found on the ventral median line posterior to the capitulum.

SIMILAR: The sexes are similar if separable only by size and the differences in the morphology of the sex openings, and dissimilar if there are other morphological differences of the body or appendages, as in Antricola coprophilus. Adults and nymphs are similar if separable only by the presence of the mature sex openings in adults which are absent in nymphs, and dissimilar if, as in Otohius, the adults and nymphs have differences in body structures.

SIMPLE HAIRS: Smooth, tapering hairs which terminate in a point.

SPIRACLE: Paired organs, one on each side; the external openings of the respiratory system which communicate with the tracheae.

Strbapical Dorsal Protuberance: The protuberance sometimes present distad of Haller's organ and when much drawn out produces the bifurcate termination of the tarsus, mentioned by some authors. It should be distinguished from dorsal humps. The protuberance appears to be different in origin or purpose from the dorsal humps. Thus, the species of Argas and those species of Ornithodoros which have cheeks, and micromammillae on the legs seldom have dorsal humps, but may have the subapical dorsal protuberance. Fig. I, D and E.

Sutural Line: A definite line of cleavage around the periphery in Argas separating the dorsal and ventral surfaces. Fig. 2, D and Fig. 4, G.

Tubercles: The elevations on the integument in Antricola comparable to the mammillae of Oruithodoros.

Truncated Hairs: Hairs which do not taper and are terminally truncated.

V'ENTER: The entire ventral surface in contra-distinction to the dorsum.

\section{Methods}

The characters in the Argasidae are definite and little difficulty should be encountered in recognizing most species. The methods of study here outlined are applicable also to various genera of the Ixodidae.

Dissecting microscope.-A primary need is a satisfactory dissecting mictoscope with low, intermediate, and high power objectives. Very satisfactory types are: first, one with a stage that can be placed directly on the surface of the desk; second, one with a heavy base placed well away from the worker and with a horizontal arm supporting the body of the microscope, thus leaving a clear working space around and under the instrument.

Lighting.- Adequate lighting is about as necessary as a suitable microscope. Desk and microscope lamps of numerous forms are available but a type producing a bright beam and on a stand which can be placed well away from the microscope is particularly useful. It should be possible to adjust the intensity of the light and to avoid heating the specimen. Both aims can be accomplished by placing a piece of rice paper or ground glass in the beam of light. 
Preserving fluid.-It is a distinct advantage to use as a preserving fluid one that will dry quickly, thus making the surface characters visible with as little delay as possible. Fluids containing glycerine have the disadvantage of leaving a "moist" or "tacky" surface which obscures the details of the surface parts. However, glycerine can be removed by washing with 70 percent alcohol. This takes time and subjects the specimen to some danger of injury. Carbon ictrachloride preserves the true colors in ornate ticks to a remarkable degree but makes the specimens very hard and brittle. At the Rocky Mountain Laboratory 70 percent alcohol is used. This evaporates rapidly and we have not detected that specimens so preserved are more brittle than those placed in fluids containing glycerine.

When ticks are kept out of the alcohol for some time and also subjected to the heat of a light, it is very desirable to put a drop of alcohol on the specimen occasionally.

Cleaning.-Cleaning should be avoided if possible, but is sometimes necessary, since argasid ticks are often encrusted with coxal fluid which serves as a mild glue. For cleaning it is useful to have at hand a series of small, artist's red sable brushes, the tips of which have been cut off at different lengths, thus affording various degrees of severity for "scrubbing." The cleaning is done under low magnification with the tick immersed in 70 percent alcohol. Care must be taken not to break parts or remove hairs.

In examining the hypostome in situ it is frequently desirable to remove matter from the mouth parts with a soft brush from which the tip has not been removed.

When especially clean specimens are needed, as for photographing, it is preferable to use ticks that have recently molted in a clean container.

Posing.-The specimens are removed from 70 percent alcohol, pressed lightly on soft, absorbent paper (such as is used as a substitute for handkerchiefs) and are then transferred on a microscopical slide to the field of the microscope for examination dorsally and ventrally. When special positions are wanted other aids are used. When working with Dr. Nuttall in England, the senior author saw him using small lumps of modeling clay or "plasticine" which could be stuck to a glass slide and shaped to fit the need - a point, a ridge, a sloping surface, or a groove. Without some such refinement of technique there is danger of failing to make some characters visible. It is common practice in museums and laboratories to hold the tick under the microscope between the points of forceps. This has resulted in injuring valuable specimens. Because of this practice some types which we have seen have lost part or all of the appendages. Parts broken off by manipulation should be put in "micro vials," labelled, and dropped into the larger museum vial along with the dismembered specimen.

Dissection.-We have found that it is not always sufficient to study the hypostome and some other parts in situ. Even with good vision and a satisfactory microscope it is frequently impossible to see the essential characters clearly. Dissection and mounting of parts then become necessary. 
Dissections are made in a small, Syracuse watch glass (U.S. Bureau of Fiant Industry Model; diameter of 27 millimeters) under a microscope, with the specimen immersed in alcohol. The watch glasses are improved if the bottom is coated with collodion to prevent the dulling of sharp instruments.

The hypostome is readily removed from adults and nymphs. The specimen is carefully held in position with slender forceps. A transverse incision is made a short distance posterior to the posthypostomal hairs with a very small, sharp, iris scalpel; also two longitudinal ones, one on either side of the hypostome, each starting at the point where the palpus meets the base of the hypostome. This usually permits the removal of a part of the basis capituli with the liypostome attached, 'but if not yet free, insert the iris knife horizontally between the hypostome and the stalks of the chelicerae and cut through any pieces of chitin still attached to the base of the hypostome. It is important that this final incision be made with the point of the knife held horizontally to insure that the hypostome will be flat when mounted in balsam and not raised on one side.

It is necessary to sharpen the scalpel frequently on a marble stone. This is done under the microscope. For some dissections a blunt, rather than a pointed, scalpel may be advantageously used.

Care is needed to avoid losing dissected parts, hence the need for the very small dishes. The parts to be mounted are readily transterred to the next liquid by the use of a small brush of which most of the tapered portion has been removed.

In the study of the larvae it is sometimes necessary only to clear and mount them if the specimens are unfed, but if critical studies are required the more difficult manipulation of separating the hypostone from the chelicerae becomes necessary. This dissection can usually be accomplished best by removing first only the chelicerae, leaving the hypostome and palpi in position. This is often difficult and is usually best done with a fine needle point and a sharp-pointed, iris scalpel. Finally, the entire capitulum is severed, cieared in xylol and mounted in balsam with the venter up.

Four percent potassium hydroxide is sometimes used as a clearing agent. However, critical parts, particularly hypostomes, are sometimes obscured by gas appearing within the specimen immediately after being placed in balsam. This may happen even if preparation has included thorough washing to remove the potassium hydroxide. It may be prevented by passing the specimen through a series of xyld-balsam mixtures of increasing density. The first should be very fluid. This requires about twenty-four hours.

Rearing.--It is sometimes difficult or impossible to identify immature specimens, especially earily stage nympins. If alive, such ticks can be reared through one or more stages as desired, feeding being permitted as necessary.

To facilitate holding living ticks in the laboratory for observation or ecdysis various facilities have been used such as paper or wooden boxes held over wet sand, test tubes with cotton plugs placed in covered jars, etc. The 
essential conditions for keeping the ticks alive for prolonged periods are (a) containers that permit the maintenance of a higher humidity than is usual in room atmosphere, (b) sufficient air, and (c) avoidance of over-heating. The container should be such as to facilitate frequent examinations of the specimens. We have used two methods successfully.

For one method we employ desiccator jars that provide a space for containing a fluid below and for holding vials of ticks above. A "floor" for the upper space can be made of cardboard sacurated with melted paraffin. Pill boxes containing ticks direct from the field may be placed temporarily in the upper chamber. A relative humidity of 92 percent is maintained by a saturated solution of ammonium chloride $\left(\mathrm{NH}_{4} \mathrm{Cl}\right)$ in the lower chamber." Paper pill boxes become moist and soft if held in the desiccator jars very long. On the other hand, ticks in glass vials with cotton plugs may be held indefinitely. The jars are kept at room temperature and out of the sunlight. Mold sometimes develops but causes very little difficulty if the ticks are held in glass vials and can be further prevented or reduced by using only sterile vials.

Various modifications of the "Hixson jar" are also useful. We have found the modification described below to be of value in holding a few living ticks in the laboratory and also in collecting critical material in the field. Hixson (1932) described and figured a small $3 / 4$ inch cork-stoppered shell vial "jar" with wet sand in the bottom. The tick or ticks are placed in a $1 / 4$ inch tube plugged with cellu-cotton at both ends. The latter is held in a fixed position in the jar by inserting one end in a central hole through the stopper.

For our purposes we have modified the "jar" by using a wide-mouthed bottle, 2 inches in diameter by 4 inches tall, with plaster of paris in place of the sand. The plaster of paris is allowed to set in the bottom of the bottle. The jat is then placed in a watming oven with the mouth open until the plaster is thoroughly dry. Six to ten drops of water are added to the plaster to maintain a moderate decree of humidity. The inside tube should have a diameter of about $1 / 3$ of an inch, should be clean and sterile and should not reach the plaster of paris.

Critical living specimens may be placed singly in the inner glass tubes and when ecdysis occurs the molted skin is available. The latter is often of special value because the hypostome or other parts are available for comparison with the same parts in the subsequent stage. The cast skin of the hypostome may be placed in absolute alcohol, then tran sferred to xylol and when mounted in balsam is nearly as useful as the actual tick of the stage concerned. These small jars have several advantages when it is desirable to keep living ticks and make daily ebservations and tecords of their development. They are also used in the field when especially interesting lots of ticks are collected and when shipped they are put in double mailing tubes.

2 See International Critical Tables, vol. 1, p. 67, for information on maintaining constant humidities. 


\section{Family, Argasidae Canestrini, 1890}

Non-scutate Ixodoidea with sexual dimorphism slight. Integument of adults and nymphs leathery, wrinkled, granulated, mammillated or with tubercles. Capitulum in adults and nymphs either subterminal or distant from the anterior margin; in larvae subterminal or terminal. Capitulum, especially in depleted adults and nymphs, in a more or less marked depression (camerostome). Articulations of the palpi of all stages free (never fused). Porose areas absent in both scxes. Eyes when present placed on the supracoxal folds. Spiracles in adults and nymphs usualiy placed anterior to coxae IV. Pulvilli usually rudimentary or absent in adults and nymphs; sometimes well developed (functional) in larvae. Nymphal stages plural and the number variable.

Type genus, Argas Latreille, 1796.

The number of genera that should be recognized in the Argasidae has long been a matter of doubt. Nuttall et al. (1908) and Neumann (1911) recog. nized Argas and Ornithodoros, although Nuttall stated that "we are by no means sure that the family Argasidae contains more than one genus, Argas." Banks (1912) erected the genus Otobius for a species formerly included in Ornithodoros. This we recognize as valid.

Pocock (1907) advocated the revival of Carios Latreille, 1796 for Argas respertilionis, an Old World species associated with bats, because this species possesses a "conspicuous transverse, lightly curved groove just behind the anus." As pointed out by Nuttall, this structure is not peculiar to vespertilionis. It is present in other species also, though modified, and is the character usually referred to as the transverse postanal groove. However, the species is aberrant. The capitulum is situated far forward and would be visible from above were it not for the prominent hood. The sutural line on the margins of the body, a character used by Neumann (1911) to characterize the genus Argas, is absent. Yet by the other characters it appears to be clearly an Argas, and until further information is available, we consider it best to refer the species to this genus.

Also in 1907 Pocock erected the genus Alectorobius for Ornithodoros talaje on account of the presence of lateral wings (cheeks) on the camerostome. If Alectorobius were to be reestablished, it would be desirable to find correlating characters. While talaje and some other known species have cheeks, dorsal humps on the tarsi, and micromammillae on the legs, certain species lack the dorsal humps or the micromammillae, or both.

The New World species of Argas and Ormithodoros can best be distinguished by the presence of the sutural line in the former, its absence in the latter. Bedford (1932) made Ornithodoros Koch a synonym of Argas, stating that he could not consider "having the margin of the body differing in structure from the rest of the integument" as being of generic importince. He was influenced in his decision by Ornithodoros perengueyi Bedford and Hewitt, 1925. In this species, as well as in $O$. dunni Matheson, 1935 and O. stageri Cooley and Kohls, 1941, the flattened margins persist even in well fed specimens but the sutural line is absent. While these species serve to show that the genera 
grade into each other, the great majority of the species can be assigned generically with little or no difficulty.

We accept as of good standing the following genera:

1. Argas Latreille, 1795

3. Otobius Banks, 1912

2. Ornithodoros Koch, $184 t$

4. Antricola Cooley and Kohls, 1942

\section{Ney to the Genera}

1. With a definite sutural line separating dorsal and ventral surfaces (see fig. 4. G)

Lacking a definite sutural line separating dorsal and ventral surfaces.

2. Nymphs with integument beset with spines, hypostome well developed; adults with integument granular, hypostome vestigial (see fig. 6, C) Ototius

Integument of adults and nymphs essentially alike, mammillated or tuberculated, and lacking spines: hypostome of various forms in nymphs and adults but not vestigial

3. Hypostome broad at the base and scoop-like (see fig. 53, B) (Associated with bats.)

Antricola

Hypostome of various forms but never scoop-like (Associated with various classes of animals and including bats.)

Ornithodoros 
Genus Argas Latreille, 1796

1796. Argas Latreille, original description, p. 18. The generic synonymy to 1850 is reviewed in detail in Oudemans "Kritisch Historisch Overzicht der Acarologie," part 2, pp. $135-137$ (1929) and part 3. B, pp. $7+6-755$ (1936). See also Nuttall el al. (1908) pp. t-5.

1932. Argas Latreille: Bedford, p. 275. Ornithodoros made a synonym of Argas.

1934. Argas Latreille: Bedford, p. 60.

1936. Argas Latreille: Brumpt, p. 1186.

Sexes similar; nymphs and adults similar.

Body flattened, dorsal and ventral surfaces about equal in area; margin distinctly flattened, made up of radial striae or quadrangular plates. Sutural line present. Flattened margins not obliterated even when tick is fully fed. Capitulum either distant from or near the anterior border. Integument leathery, minutely wrinkled in folds of many shapes often intermingled with small, rounded "buttons" each with a pit on top and often bearing a hair in the pit. Discs present on both dorsal and ventral surfaces and placed in more or less radial lines. Eyes absent.

Genotype, Acarus reflexus Fabricius, 1794, as designated by Latreille (1802). Nuttall et al. while admitting that reflexus had been the accepted type preferred to take persicus as the type because of its world-wide distribution and its having been better studied. We regard these reasons as being insufficient for changing the genotype.

Two species occur in North America, reflexus (Fabricius) 1794 (see discussion page 16) and persicus (Oken), 1818. A third species, A. brevipes Banks 1908, described from Arizona, must remain in doubt since no specimens so labelled by Banks are available and the description is inadequate.

Key to Species of Argas

(Adults and Nymphs)

Flattened margins striate; postpalpal hairs absent; hypostome apically rounded. reflexus (p. 17)

Flattened margins having quadrangular plates; post-palpal hairs present; hypostome apically notched persicus (p. 17) 


\title{
Argas reflexus (Fabricius), 1794
}

\author{
Plate 1. Figs. 2 and 3
}

1793. Acarus columbarum Shaw, in Shaw and Nodder, original description, 4, pl. 128. (nomen nudum).

1794 Acarus reflexus Fabricius, p. 426.

1802. Argas reflexus (Fabricius): Latreille, p. 66.

1804. Rhynchoprion columbae Hermann, p. 69.

1805. Ixodes reflexus and lxodes colmbae Fabricius, p. 353 and 356.

1815. Argas marginatus Oken, p. 402.

1816. Rhunchoprion marginatum Olfers, p. 75.

1827. Lxodes hispanus and Ixodes espagnol. Brebisson, p. 267.

1828. Acarus marginatus. Guérin-Méneville, p. 300.

1829. Argas reflexus. Latreille, p. 289.

1896. Argas magnus Neumann, p. 14. Degraded to Argas reflexus var. magnus, Neumann, 1905, p. 239.

1929. Argas columbarum (Shaw): Oudemans, part 2, p. 138.

1936. Argas reflexus (Fabricius): Brumpt pp. $1187-1188$.

\section{ADULT}

Body.- Oval, often distinctly narrower in front. Margin irregularly striate with the striae varying in width in different specimens. Margin slightly turned up (whence reflexus). Often larger than persicus and may reach $9.0 \times 5.0$ (Nuttall et al. 1908). Specimens may be as small as $6.25 \times 3.75$.

Integument.-Integument on dorsum and venter raised into irregular, sinuous wrinkles which may be short or long. Nuttall et al. (1908) state that the integument is much more finely wrinkled than in persicus. Specimens from the Americas show the wrinkles to be coarser.

Discs.-Variable; may be either large and numerous or small and few; when numerous arranged radially.

Buttons.-Absent or few in number, often each with a short, fine hair arising from the pit.

Legs.-Moderate in length and size. Surface irregular -- nearly granular. Subapical dorsal protuberances well developed, about equal on all the legs. Length of tarsus I (in larger specimens), 0.78; metatarsus, 0.78. Length of tarsus IV, 0.96; metatarsus, 0.93 .

Coxae.-Coxae I and II separated; all others contiguous. (Nuttall et al (1908) state that coxae I and II are contiguous.)

Folds.-Coxal and supracoxal folds present; all other folds absent.

Capitulum.-Removed from the anterior margin by about its own length (including the palpi). Basis capituli nearly twice as wide as long; lateral margin with a group of short, fine, erect hairs at about the middle. Entire length of palpal article 1 in contact with and overlapping the base of the hypostome as a knife-edge flange. Postpalpal hairs absent.

Hypostome. - Mildly tapering; apex rounded. The larger denticles arranged 2 , with about 3 or 4 in each file. Numerous very fine denticles in the middle arranged in diagonal rows (more numerous than in persicus) 
Corona with only a very few fine denticles. Long posthypostomal hairs are present. Length 0.30 to 0.39 .

Camerostome.-Short and indefinite.

Sexual opening.- Placed at the level of the intervals between coxae I and II.

Anus.-In an elliptical pattern placed nearly central on the venter.

This species is readily separated from persicus by its striated margins, its well developed subapical dorsal protuberances on all legs, the absence of the apical notch on the hypostome, and absence of postpalpal hairs.

\section{DISTRIBUTION AND HOSTS}

In the Old World Nuttall et al. (1908) record this species from England, France, Germany, Italy, Russia, Rumania, and Algeria. Because of its association with pigeons, Columba domestica, it is commonly known as the pigeon
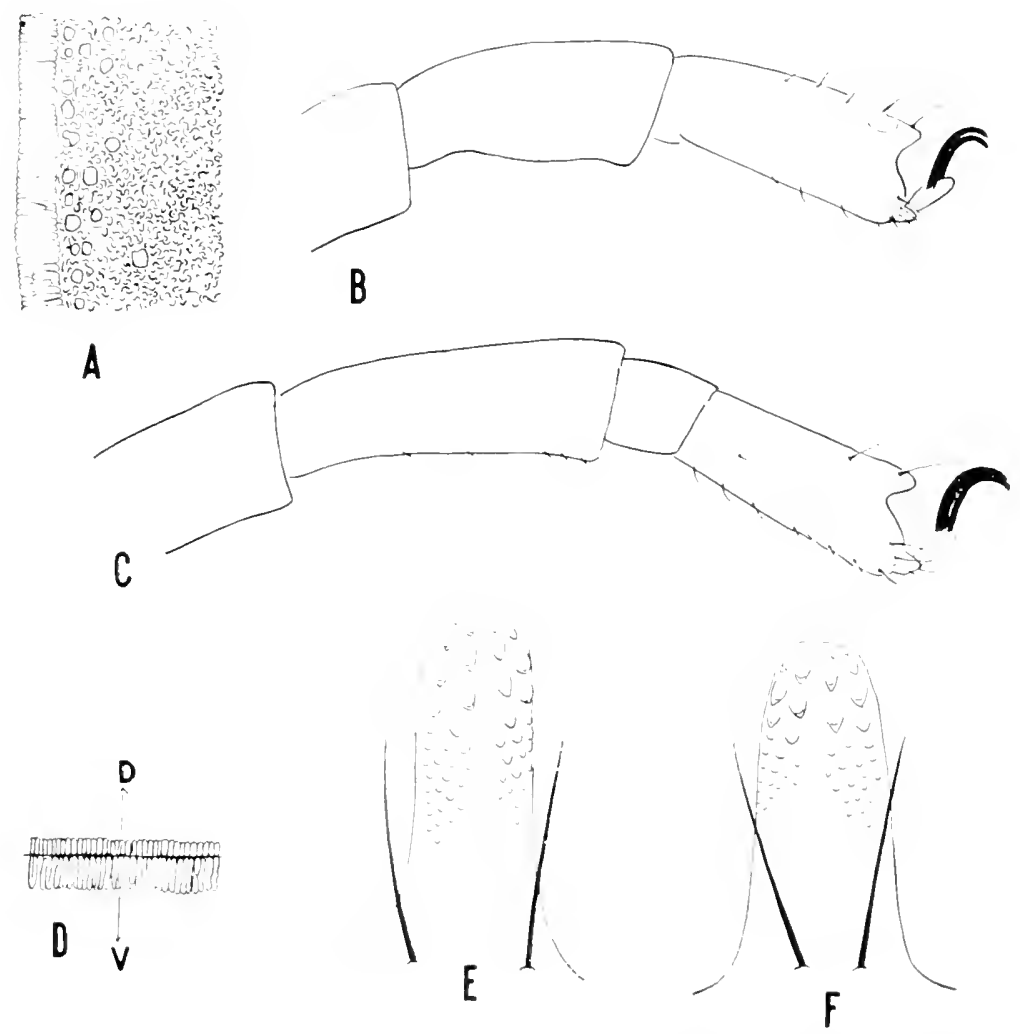

Fig. 2. Argas reflexus (Fabricius). A, Margin of adult or nymph. B, I Leg I of female. C. Leg IV of female. D. Lateral view of edge showing sutural line. E. Hypostome of female. F. Hypostome of male. 
tick. Other hosts mentioned are Gallus domesticus, man, and a single record of larvae from Equus caballus reported by Starcovici in Rumania.

As for the New World, Dr. J. Bequaert has sent us specimens from Bogotá, Colombia. South America, collected in chicken coops. Neumann (1911) recorded $A$. reflexus magnus from California without mention of host. Osborn (1896) stated that, "It is common, I believe as far north as St. Louis." How. ever, no records substantiating this statement have appeared. The only United States records we have are the following:

California. 17018, near nest of California condor, Gymnogyps californianus, September 18, 1939, and 1787, May 24, 1940, both lots from Santa Paula Canyon, Ventura County, 41 nymphs and adults (Thomas F. Kelley); 17395, "nest in cave," April 8, 1939, Mt. Diablo, Contra Costa County, 1 male (D. E. Howell); 17556, nesting hole of Inyo screech owl, Otus asio inyoensis. November 1940, Inyo County, 1 nymph, also 5 nymphs of Argas persicus (Kenneth E. Stager).

Montana. 15195, October 1928, Haxhy. 1 female. This specimen had been sent to Dr. H. B. Mills, State Entomologist, with the information that it and two others were "found in the bedroom on my bed." During the summer, 10 or 15 swallow nests were built under the eaves of this bedroom. It appears likely that the swallows were the source of the infestation.

Assignment of the United States specimens to reflexus is made with some hesitation. We believe it advisable to refer the specimens listed to this species until more information is available. While they are smaller than Old World and South American specimens and lack the pronounced reflexed margins of the latter, they agree very closely in other morphological characteristics. However, it is surprising that there are no definite records of the species from pigeons and other domestic birds in this country.

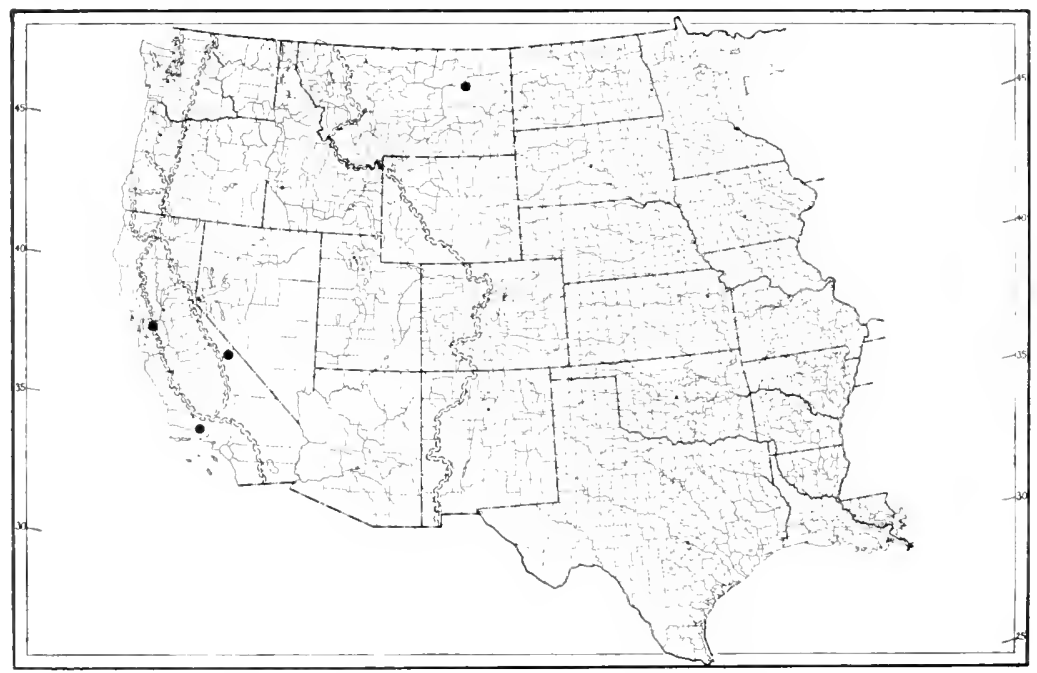

Fig. 3. Distribution of Argas reflexus (Fabricius). 


\author{
Argas plesicus (Oken), 1818 \\ Plate 1. Figs. $t$ and 5
}

1818. Rhunchoprion persicum Oken, orginal description, p. 1568.

1823. Argas persicus Fischer de Waldheim, p. 282.

184t. Aigas mauritianus Guérin-Meneville, p. 17.

1844. Argas chinche Goudot: Gervais, in Walckenaer, p. 462.

1844. Argas miniatus Koch, p. 219.

1872. Argas americana Packard. p. 740.

1891. Argas sanchezi Alfred Dugès, p. 20.

1893. Argas radialus Raillict. p. 718; for americana Packard. preoccupied.

1901. Argas miniatus Koch: Neumann, p. 255, = americana Packard, sanchezi Dugès and radiatus Railliet, synonyms. P. 34t. = chinche Goudot, synonym.

1901. Argas persicus Fischer: Neumann, p. 253, 256, = Argas mauritianus GuérinMéneville, synonym.

1905. Argas persicus var. miniatus: Neumann, pp. $2+0-2+1$.

1908. Argas persicus (Oken): Nuttall, et al., p. $9=$ Argas persicus var. miniatus, synonym.

1932. Argas persicus (Oken): Bedford, p. 281.

1934. Argas persicus (Oken): Bedford, pp. 65-69.

1936. Argas persicus (Oken): Brumpt, pp. $1189-1192$.

\title{
ADUET
}

Body.-Usually oval, wider behind; sometimes almost elliptical. Margins composed of irregular quadrangular plates or cells which often have one or more circular pits. In some specimens a very small, short, fine hair is visible arising frcm some of the pits. Like reflexus this species varies greatly in size. Nuttall et al. give size ranging from $4.0 \times 2.5$ to 12.7 long. Specimens in the collections of the Rocky Mountain Laboratory show sizes within the range published.

Integument.- Surface of dorsum and venter with numerous rounded or sinuous, shining wrinkles. In some specimens the sinuous elevations are unusually long.

Discs.-Numerous, large, variable in size, oval or circular, and radially arranged. Other discs not radially arranged are found in the submarginal areas.

Buttons.-Usually numerous but faint and sparse in some specimens.

Legs.-Moderate in length and size. Some specimens from Southern United States have the legs short and small. Surface irregular with hairs short and fine. Subapical dorsal protuberances mild or absent on tarsi I to III: absent on tarsus IV. Length of tarsus I, 0.57 to 0.75 ; metatarsus, 0.51 to 0.81 . Length of tarsus IV, 0.72 to 0.81 ; metatarsus, 0.66 to 0.78 .

Coxae.-Coxae I and II well separated; all others contiguous; surfaces longitudinally wrinkled.

Folds.-Coxal and supracoxal folds present.

Capitulum.--Removed from the anterior margin of the body by about the 
length of the capitulum including the palpi. Basis capituli with its width greater than its length; surface transversely wrinkled. Postpalpal hairs present, about in line with the posthypostomal hairs. Entire length of article 1 of the palpus in contart with the hypostome and with a knife-edge flange overlapping it.

Hypostome.-Sides a little tapering; apex notched. Larger denticles few in number and arranged ${ }^{2}, 2$; smaller ones, in middle portion, arranged $3{ }_{3}$. Corona with very small denticles. Length of female hypestome 0.315 to 0.36 ; male about 0.30 .

Camerostome.-Short, indefinite, and affording little protection for the mouth parts.

Sexual opening.-At the level of the intervals betweeen coxae I and II.

Anus.-In an elliptical pattern; placed nearly central.

This species is readily separated from reflexus by having the hypostome terminally notched, the margins with quadrangular cells in place of striae, and postpalpal hairs present.

\section{GEOGRAPHICAL DISTRIBUTION}

Argas persicus occurs in Europe, Asia, Africa, America, and Australia. In general it is restricted to the warm, dry regions.

Bishopp (1927) stated that

The present distribution of the tick in the United States may be said to extend throughout the western three-fourths of Texas, from approximately the longitude of Dallas, westward: the southern half of New Mexico and Arizona; southwestern Oklahoma; three-fourths of southwestern California; and the major part of Florida. During the last few years it appears that the pest has extended its range northward in the Sacramento Valley of California a considerable distance, as R. W. Wells has found it to be firmly established in Shasta County. * * The tick has undoubtedly been shipped with fowls into many parts of the United States and specimens have been taken in States as far removed from the normally infested areas as Iowa. It has not established itself generally, however, in the more humid and cooler parts of the country. It has been thought that the tick would not become a pest in such regions and in the higher mountain areas, but its continued spread indicates that it has considerable adaptability, and thai it will ultimately infest a much larger part of the country than it does at present.

The map showing the distribution of Argas persicus is after Bishopp (1927) with the following records added:

California. 17556, nesting hole of Inyo screech owl, Otus asio invoensis, Inyo County, December 1940, 5 nymphs, also 1 nymph of Argas columbarum (Kenneth E. Stager).

Georgia. 42331 B. A. I., Callus domesticus, chicken house, Feb. 18, 1936, Atlanta, 16 specimens (W. R. Baynes).

Louisiana. 30307 B. A. 1., host not stated. Oct. 27. 1940. Jeanerette, few specimens (C. W. Rees).

Nevada. Many specimens without host or date. Reno (S. B. Doten). Record from U. S. National Museum. 
Utah. Many specimens, said to be killing chickens near St. Ceorge, 1936 (F) W. Davis). Record from U.S. National Museum.

Canada. 17496, golden-crowned sparrow, Zonotrichia coronata (Pallas), May 2. 1931. Vancouver, B.C. t nymphs (1 tearle, 1938).

In Mexico, Hoffman (I930) stated:

It is found in all of the hot and dry States of the North and extending throughout the regions consisting of the Central Plateau toward the south and west to the Pacific Coast. In the more humid zone along the Gulf Coast and in the humid districts of the south it occurs only exceptionally and then as a result of fowls being brought in from infested places. Apparently it is unable to survive in these regions. It easily adapts itself to the chicken houses which are protected against the cold of our Central Plateau. for example, I have seen infested chicken houses at Tlálpam. D. F.. which is some 2300 meters above sea level. (Translation.)

According to Dunn (1923) the species is "very abundant throughout Panama, the majority of chicken houses and other places where fowls commonly roost in the cities of Panama and Colon, villages in the Canal Zone and native villages in the interior being usually infested with them."
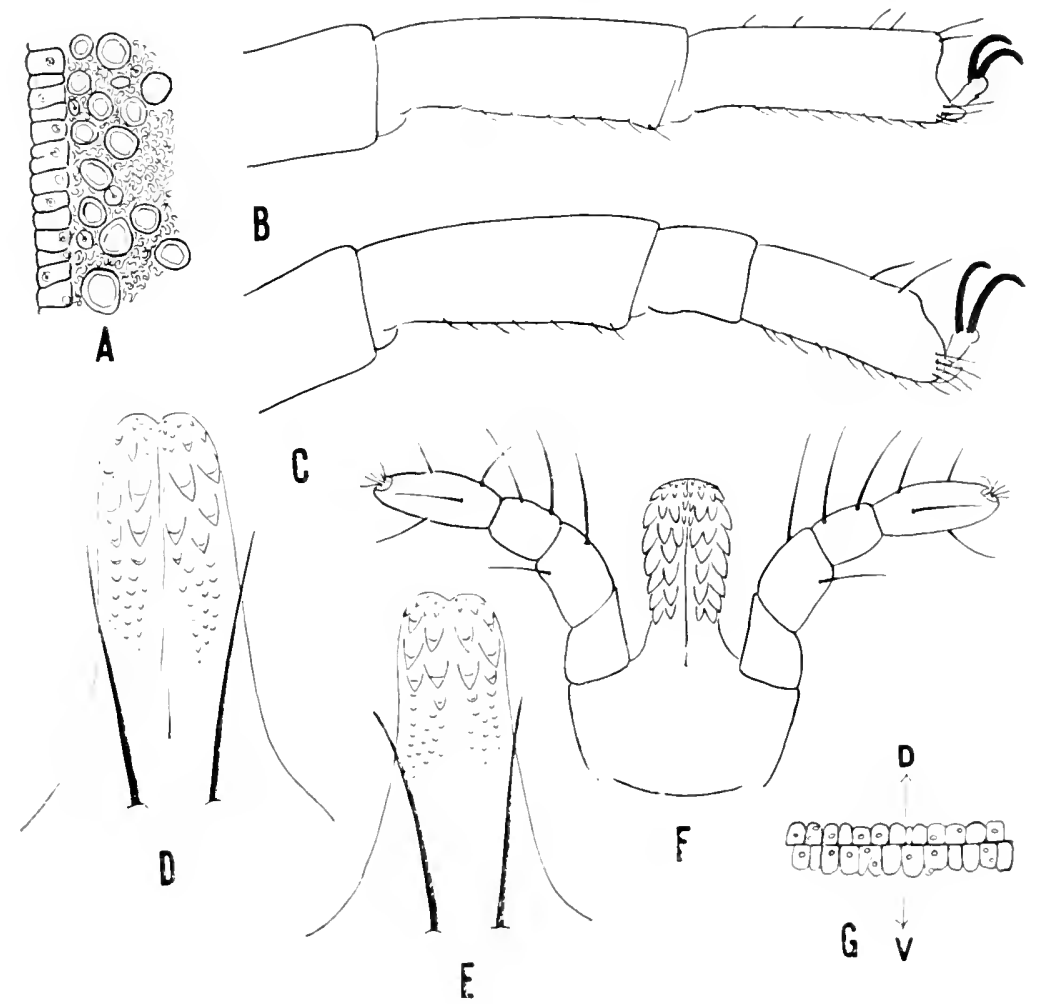

Fig. 4. Argas persicus (Oken). A. Margin of adult or nymph. B. Leg 1 of female. C. Leg $\mathrm{W}$ of female. D. Hypostome of female. E. Hypostome of male. F. Capitulum of larva, ventral view. G, Lateral view of edge showing sutural line. 
In the West Indies the species has been found at Trinidad and at Antigur.

Vigueras (1934) stated that Argas persicus has been known in Cuba for many years, and listed the following localities: Provinces of Havana, Matan. zas and Santa Clara.

Koch's type of $A$. miniatus came from Demerara, British Guiana.

HOSTS

Argas persicus is preeminently a fowl tick. It attacks practically all species of domestic fowls, but the chicken appears to be the preferred host. It has been found in limited numbers on a wide variety of wild brids including quail, wild doves, wild turkeys, vultures, golden-crowned sparrow (Zonotrichia coronata), and Inyo screech owl (Otus asio inyoensis). It is said to attack man commonly in Persia, producing serious symptoms. Hoffman (1930) stated that in Mexico it attacks man only exceptionally, with more or less disagreeable local effects, and as a rule only in houses where it cannot reach its natural hosts.

Economic losses occasioned by this tick are considerable. Fowls are weakened through loss of blood and annoyance and when attacked by large numbers the effects are sufficient to result in death.

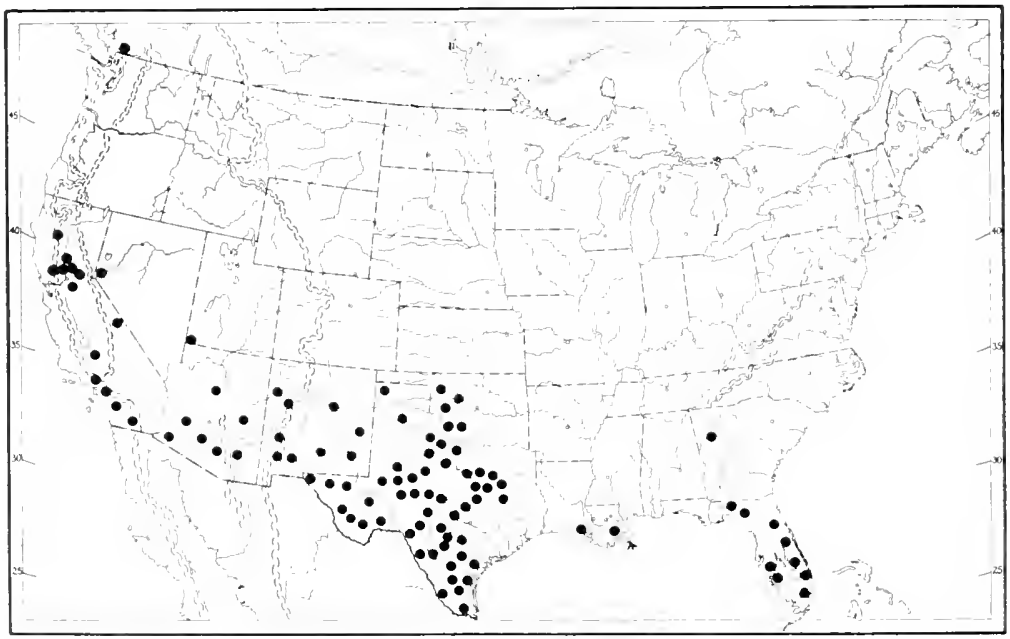

Fig. 5. Distribution of Argas persicus in the United States and Canada. Adapted from Bishopp (1927), with additions. 


\title{
Genus Otobius Banks, 1912
}

1912 Otohius Banks. p. 99, original description.

Adults and nymphs dissimilar and with sexes similar. Adults with the integument granulated; nymphs striated and with spines. Without change of pattern of the integument at the sides. Capitulum distant from the anterior margin in adults; near the margin in nymph. Hood and eyes absent. Hypostome of nymphs well developed; vestigial in adults.

Genotype: Argas megnini Dugès, 1884, original monotype.

$$
\text { Key to Species of Otobius }
$$

Adults

The numerous pits on the dorsum separated by a distance of twice or more the diameter of one pit ...............................................................nini (p. 21)

The numerous pits on the dorsum separated by a distance of the diameter or less. of one pit lagophilus (p. 32)

\section{Nymphs}

Integument with numerous heavy spines anteriorly and lighter spines posteriorly; hypostome with denticles 4 ; spiracles conical mignini (p. 23) Integument with numerous spines all of one size: hypostome with denticles 3 ' 3 ; spiracles convex lagophitus (p. 34)

\section{Otobius Megnini (Dugès), 1884}

\author{
Plate 2. Fig. 6, 7. 8, 9 and 10
}

1884. Argas megnini Dugés, original description, pp. 197-198, with figures.

1885. Argas megnini Alf. Dugès: Mégnin, redescribed, pp. 466, 472-475, with figures. 1893. "Argas americana Packard": Townsend. p. 50.

1895 Rhynchoprium spinosum G. Marx, figures only, p. 199, Marx obituary notice.

1896. Ornithodoros megnini (Alf. Dugès): Neumann, redescribed pp. 42-44.

1901. Ornithodoros megnini (Dugès): Salmon and Stiles, redescribed, pp. $408-414$. with figures.

1908. Ornithodoros negnini Dugès: Banks, redescribed, p. 17, with figures.

1908. Ornithodoros megnini (Dugès) 1883: Nuttall, Warburton, Cooper and Robinson, redescribed, pp. 7l-77, with figures.

1911. Ornithodoros megnini (Alf. Dug.): Neumann, p. 125.

1912. Otobius megnini Dugès: Banks, new genus proposed, p. 99.

1930. Ornithodoros (Otobius) megnini Dugès, 1882: Hoffman, redescribed, pp. 151155, with fogures.

1932. Argas megnini Dugès: Bedford. p. 280.

1934. Argas megnimi Dugès: Bedford, pp. 77-81.

1936. Ornithodorus megnini (A. Dugès): Brumpt, p. 1209.

\section{ADULT}

Body.--Panduriform, rounded behind and slightly attenuated anteriorly; broadest at legs 11 and III, constricted just behind leg IV. Both Salmon and Stiles (1901) and Nuttall et al. (1908) give as the size of the female, $6.0 \mathrm{x}$ 4.0 to $5.0 \times 3.0$. In the collections of the Rocky Mountain Laboratory we have females as large as $8.25 \times 6.00$. Males are a little smaller. Specimens of adults preserved in alcohol are enclosed by a thin. translucent covering which is easily 
temoved in part by the use of a needle point. The true character of the integument is better seen after the removal of the covering.

Mammillae.--True mammillae as defined in Ornithodoros by authors appear to be absent. Dorsal and ventral surfaces have the integument granulated, and with numerous circular depressions, each depression with a central tubercle.

Discs.-The discs are easily overlooked but are present as small, slightly

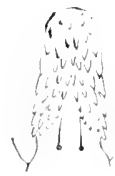

A

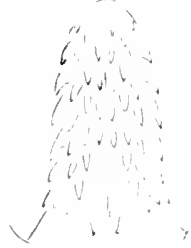

B

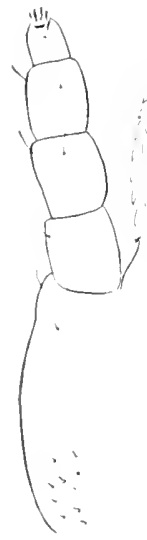

0
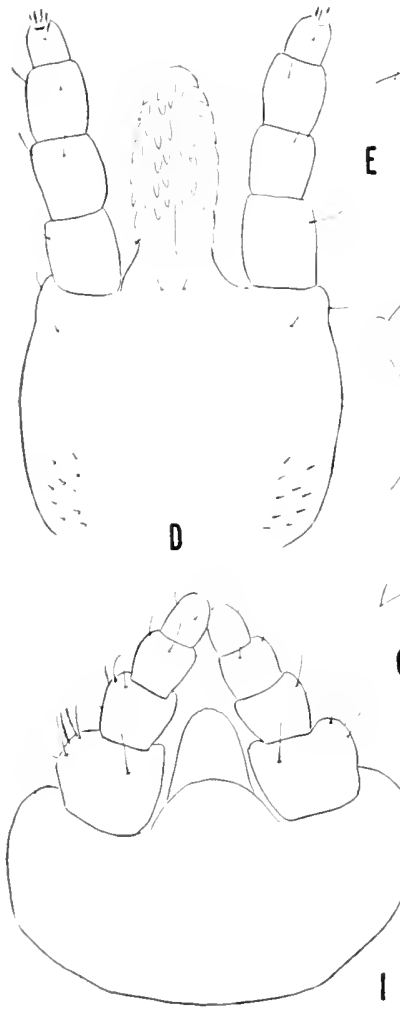

1
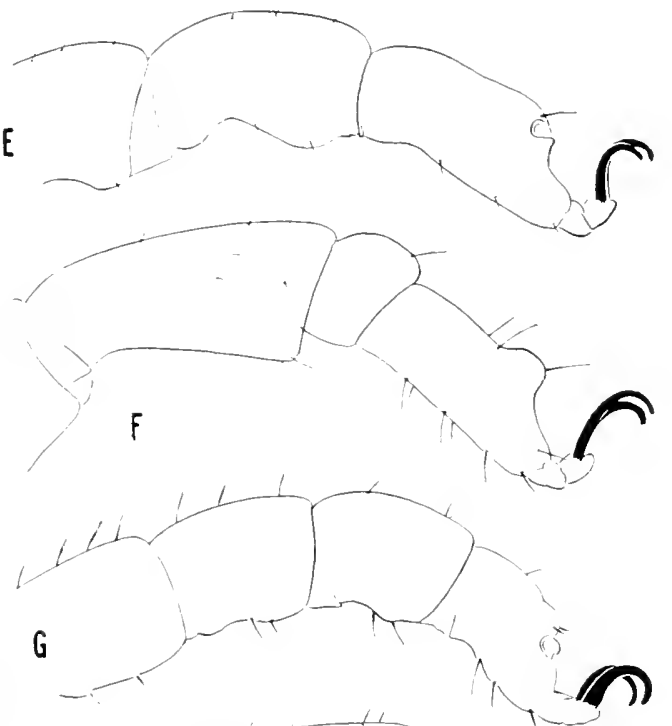

Fig. 6. Otobius megnini (Dugès). A, Hypostome of first-stage nymph. B, Hypostome of second-stage nymph. C. Hypostome of adult. D. Capitulum of nymph, ventral view. E, Leg I of adult. F, Leg IV of adult. G. Leg I of nymph. H. Leg IV of nymph. I. Capitulum of adult, ventral view. 
depressed areas in a symmetrical pattern; the individual discs have their surfaces only a little changed over the general granulated surface, and are les; distinct on the ventral side.

Hairs.-A few very fine hairs, easily overlooked, arise from some of the tubercles and are more apparent at the anterior end.

Legs.-Short and heavy. Tarsi II, III, and IV with the subapical dorsal protuberance moderate, negligible on I. Length of tarsus I about 0.48 ; metatarsus about 0.48. Length of tarsus IV about 0.72; metatarsus, about 0.69. Hairs on the legs few, short, inconspicuous.

Coxae.-Each coxa with an elongated smooth sclerite which, together with deep invaginations on the posterior side mark the position of the coxa. Coxa IV also has such an invagination on the anterior side.

Hood and Camerostome.- Hood very short and broad-a curved elevation anterior to the mouth parts. Camerostome lined with numerous fine, long hairs.

Capitulum.-Basis very broad and short, curved, approaching a reniform shape with the convexity behind.

Palpi.-Short and heavy; article 1 swollen ventrally and laterally; hairs on the palpi fine and long.

Hypostome.-Vestigial in marked contrast with the well developed hypostome of the nymph. Short, broad, with the sides converging anteriorly, concave dorsally and convex ventrally; without denticles and with the apical margin curved and thin. Length in the female 0.135.

Folds.-Coxal and supracoxal folds are present but in well engorged specimens the coxal fold is not much in evidence.

Grooves.-A short postanal groove present near the posterior end of the body. Median postanal groove present only anterior to the postanal groove, fáint. Other grooves are negligible or absent.

Sexual opening.-At the level of the posterior ends of coxae I.

Spiracle.-Circular, mildly convex.

Eyes.-Absent.

Anus.-Circular, very small.

\section{SECOND NYMPH}

This tick is ordinarily seen only in the second nymphal stage, which is the stage commonly found in the ears of domestic animals, and is the stage in which the species is most easily distinguished from other ticks.

Body.- When fully fed a little larger than that of the adult. Shape of fed specimens much as in the adult but with the lateral constrictions a little less 
pronounced. Unfed specimens much narrowed posteriorly, constriction beginning at about the fourth pair of legs; broadest at about the third pair of legs; rounded anteriorly.

Discs.-The integumental markings of the nymph are very different from
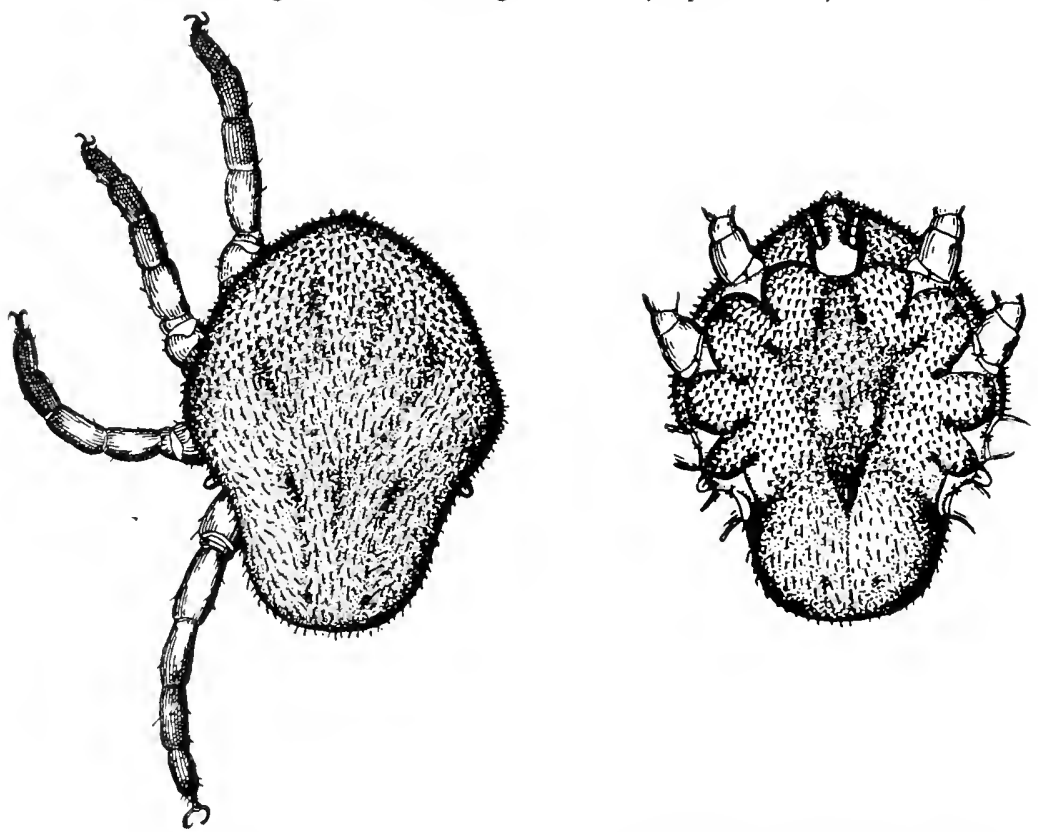

Fig. 7. Otobius megnini (Dugès) nymph, only a little fed: dorsal and ventral views, showing spines. After Marx (1895).
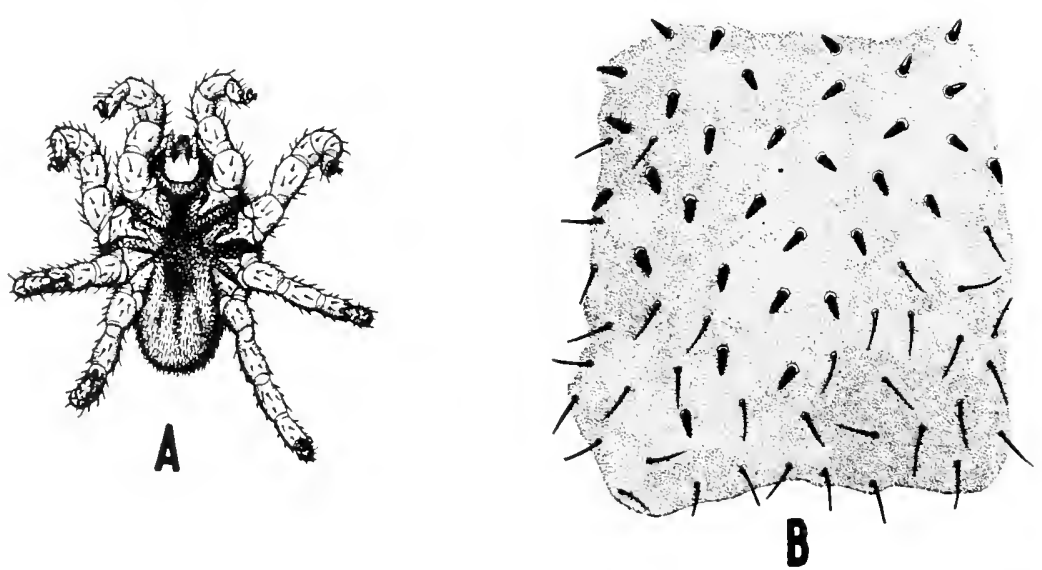

Fig. 8. Otobius megnini (Dugès). A, Nymph, unfed, ventral view, B, Nymph. "Portion of skin, showing spines and hairs. Greatly enlarged." From Salmon and Stiles (1901). 
those of the adult. The entire surface, shining and with fine reticulations or striae which are continuous over depressed areas which are the counterpart of discs. These disc areas lack spines.

Spines.-Spines conspicuous, of two kinds (see figures 7 and $8, \mathrm{~B}$ ); those with heavier bases confined to an anterior dorsal crescentic area which extends over the sides and backward to a short distance in front of the spiracle and is continuous with the anterior ventral area which reaches posteriorly about to the anus; the more slender spines occupy the posterior dorsal, lateral and ventral areas not detailed ahove. The line of demarcation between the two kinds of spines is definite. Spines absent in the area surrounding the capitulum.

Legs.- Short and heavy. Tarsi II, III, and IV with the subapical dorsal protuberance absent or very small; absent on I. Length of tarsus I, 0.48 ; metatarsus, 0.42. Length of tarsus IV, 0.6; metatarsus, 0.6. Hairs on the legs a little longer than those on the legs of the adults.

Coxne.-Indefinite; trochanters of the legs arise from a circular opening in the body wall which is modified only by a short, V-shaped sclerite in the usual position of the coxa.

Spiracle-Conical.

Folds and Grooves. - Coxai and supracoxal folds are faint or absent in the nymphs. True grooves are absent.

Capitulum.-Subrectangular, about as broad as long, ventrally tumescent; surface smooth and shining; a few hairs at the sides in front, and with a group of short, heavy spines on each side behind.

Hood and Camerostome.-Absent.

Hypostome--Large, tapering, and with long, sharp denticles arranged $t_{4}$, with about 8 in each file. Denticles about as large and prominent in basal as in apical portion, with no fine denticles in the corona. Posthypostomal hairs absent. Length about 0.36 .

\section{FIRST NYMPH}

The first nymphal stage is very much like the newly emerged second stage, but is smaller, has more slender legs and the hypostome measures only 0.195 . Posthypostomal hairs absent. (See also Brumpt [1936] p. 648)

\section{LARVA}

Unfed larva measures 0.66 from tip of hypostome to posterior extremity. Body oval; two pairs of hemispherical, ocellus-like eyes present. Integument thin, striated, and with a few bristle-like hairs arranged symmetrically. Capitulum visible in both dorsal and ventral views; hypostome and palpi very long. Hypostome with the denticles arranged 2 . Palpi with articles 2 and 3 about equal and with 1 and 4 short. Legs long; stalk of pulvillus long; pulvillus 
small. Fed larva much distended, broader in front; the capitulum also distended as a conical anterior projection. Length 4.00, width 2.5 .

Salmon and Stiles (1901), p. 410, state:

Some of our specimens of this species show a pupa-like stage. They are about $4 \mathrm{~mm}$.
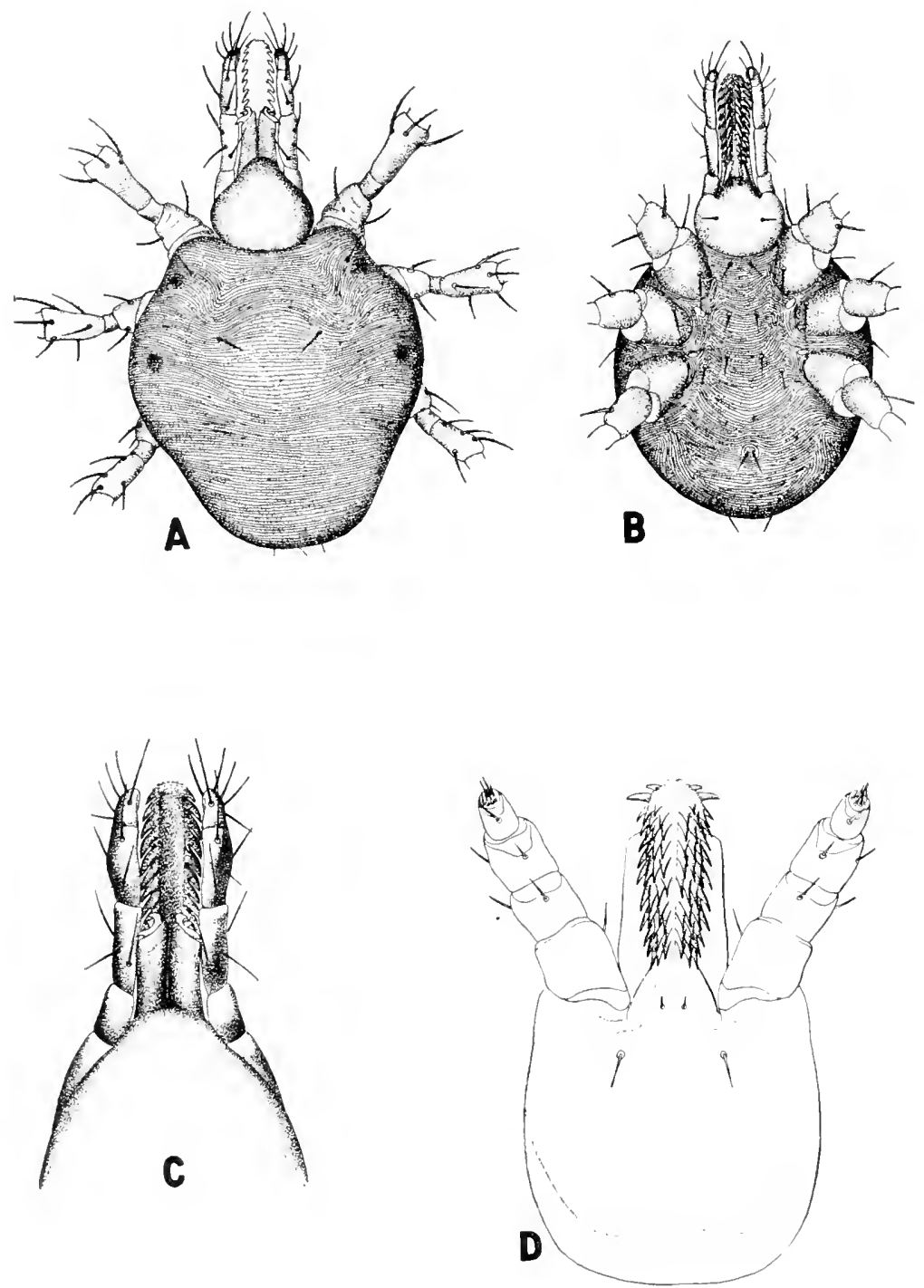

Fig. 9. Otobius megnini (Dugès). A. larva, dorsal view. B, larva, ventral view. C, Capitulum, dorsal view. D, Capitulum, ventral view. From Salmon and Stiles (1901). 
long by about $2 \mathrm{~mm}$. broad, rounded, white pyriform structures with one end elongate...

We have not seen this stage alive, but from the general structure it is apparent that in changing from the hexapod to the octopod stage $O$. megnini passes a resting pupa-like stage. This is by no means surprising, since the differences between the hexapod and the octopod stages of the Argasidae are far greater than those between the corresponding stages of the Ixodidae. This is apparently the stage which Townsend (1893) interpreted as an egg.

Brumpt (1936), p. 647, gives the following:

From the cat $\left(693 \mathrm{XV}^{\prime}\right)$ I collected two types of nymphs (Ist and 2d. n.). The engorged nymphs in the last stage dropped on the 38th day.

The last molt, which produces the adults, is effected in the exterior environment. From the hexapod larva to the adult according to me there certainly are three molts and not two as claimed by others.

In February, 1940, many larvae of megnimi from females, Douglas, Arizona, 16128, were placed in the ears of rabbits and soon engorged. Some of the engorged larvae were removed and held for molting while others were left attached. Fourteen days after the rabbit was infested with larvae, a comparison was made of the nymphs resulting from the engorged larvae removed from the host and the nymphs that were now present on the rabbit. The two nymphs were found to be distinctly different, showing that the nymphs on the host had undergone a molt; thus our findings are in conformity with those of Dr. Brumpt. The hypostome of the first nymph measured 0.195 , the coxae were smaller, and the legs not as heavy. The hypostome of the second nymph measured 0.33 , the coxae were larger, and the legs heavier.

Otobius megnimi has only three molts in its development from egg to adult - 1 larval and 2 nymphal stages. The larva becomes very large during its feeding and is what was spoken of as the "pupa-like stage" by Salmon and Stiles (1901, p. 410). Whether nymph 1 ever feeds is not evident.

Nymph 2 is the stage usually seen and from it has arisen the name "spinose ear tick." This stage is small when it emerges but during its prolonged feeding it becomes very large and it appears that its striated integument is correlated with its phenomenal extensibility. When ecdysis takes place there is a complete change of character of the integument, the spines are lost and the large hypostome is replaced by a vestigial one.

The adult does not feed.

\section{HOSTS}

O. megnini appears to be largely restricted to domestic animals and most of the records are from cattle and horses. Other animals known to be attacked include mules, asses, sheep, goats. hogs, dogs, cats, coyotes, deer, mountain sheep (Ovis canadensis), cottontail rabbit (Sylvilagus sp.), jackrabbit (Lepus californicus nalla nalla), and ostrich. There are several records of occurrence of nymphs in the ears of man. 


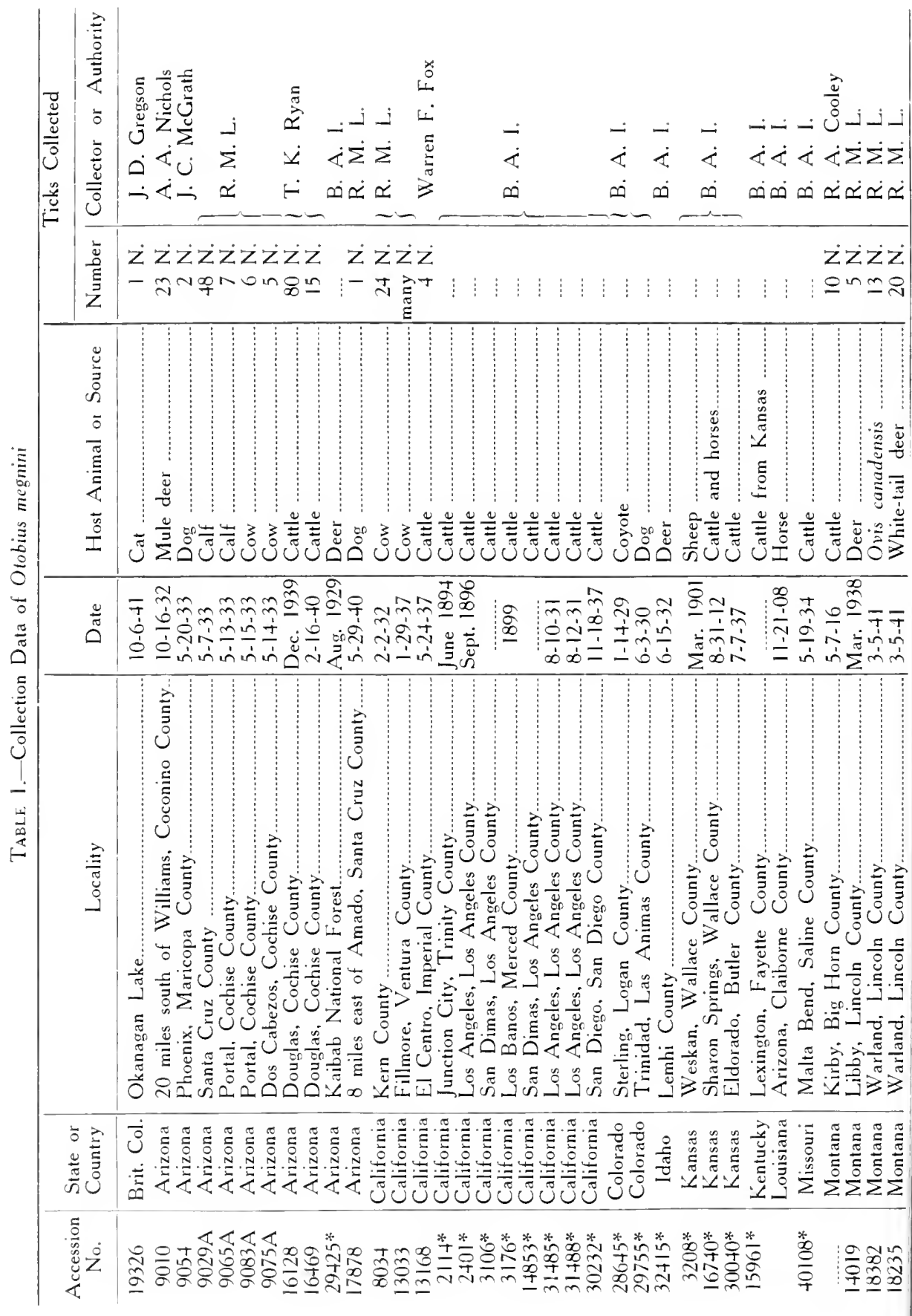




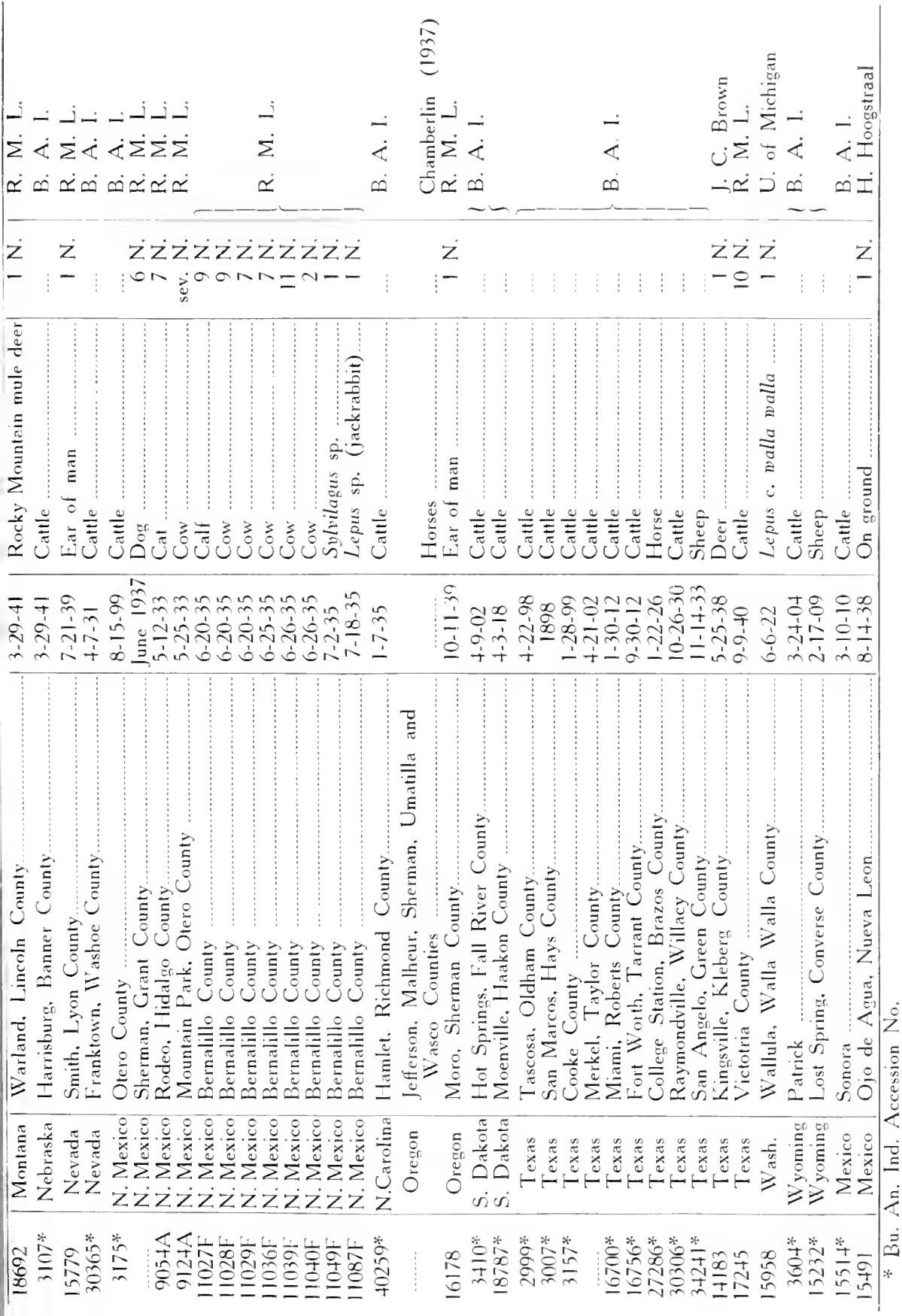




\section{DISTRIBUTION}

Otobius megnini (Dugès) was originally described from Guanajuato, Mexico, and is common in that country as reported by Valdez (1923), Hooker, Bishepp and Wood (1912), and Hoffman (1930), who states (translation) :

O. megnini is a typical inhabitant of our arid and semi-arid regions of the central plateau of the southern part of the country and the Pacific Coast. In the central plateaus 1 have found the species at an altitude of 2500 meters above the sea. At these elevations they apparently develop from the eggs only in the hot months following the rainy season.

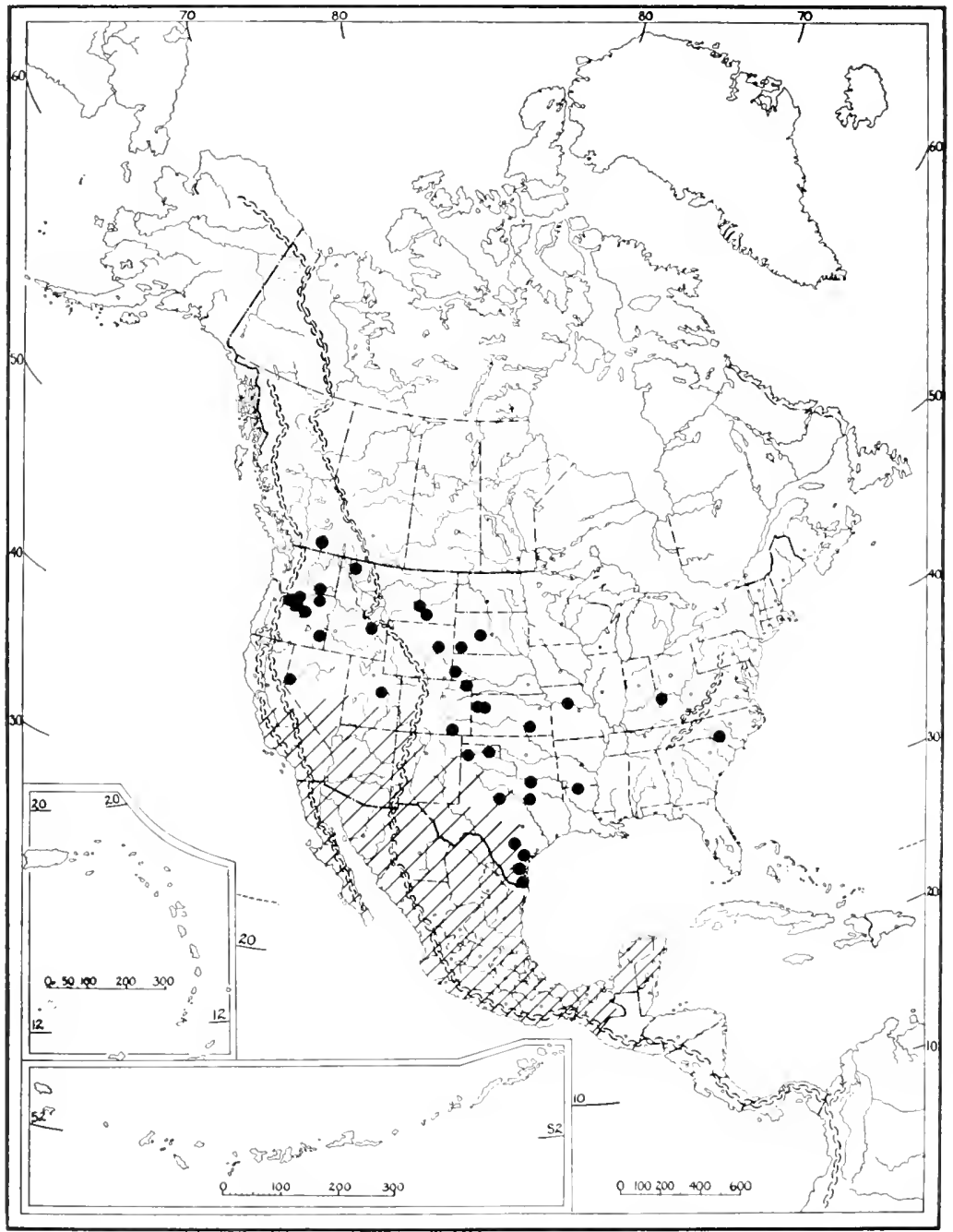

Fig. 10. Distribution of Otobius megnini (Dugès). 
In the humid regions the species does not exist since the larva is quite sensitive in humidity.

While the species may occur in Central America, we have no records from that region.

It has been reported in Argentina by Aragao (1935), in Brazil by Pinto (1930), and there are specimens from Chile in the Bureau of Animal Indus. try (40809). In South Africa it has been reported by Bedford (1912), and Kingston (1936) reported it from India in the ear of a gelding that had been bred and reared in Queensland, Australia.

In the United States, O. megnini appears to be rather common in parts of Texas, New Mexico, Arizona, and southern California. We have never made an effort to determine the definitely infested areas in the United States but from the extensive records of occurrence in Hooker, Bishopp and Wood (1912), the Bureau of Animal Industry, the United States National Museum, as well as from the records of the Rocky Mountain Laboratory, we are able to map the occurrence of this species in this country in a general way. (See figure 10.) The circular spots on the map indicate records from the Focky Mountain Laboratory, Bureau of Animal Industry, and the United States National Museum. The species because of its long feeding period is particularly subject to introduction into new areas even over long distances. Occurrences in Northern, Central, and Eastern States are probably the results of livestock shipments.

We know that it has persisted for at least several years in eastern Montana. On April 27, 1916, Cooley wrote to Mr. Al Young, Kirby, Big Horn County, and received his reply dated May 5, 1916, as follows:

In reply to yours of April 27 concerning ticks, in February and March 1912 a great many cattle died in this neighborhood. While skinning these we found the ear tick. We talked the matter (over) with our neighbors and one man said he had seen them two years before. I only have his statement for it. But since that time (1912) I know the ticks have been in the ears of our cattle. Ours are native cattle. The ticks I am sending today were taken from the ear of one of my cows. Respectfully yours. 
Otobius lagophilus Cooley and Kohls, 1940

Plate 3, Figs. II and 12

1940. Otobius lagophilus, Cooley and Kohls; original description, p. 928-933, with figures.

\section{ADULT}

Body.- Rounded on both ends and but little constricted at the sides just behind legs IV (less panduriform than in megnimi); widest at legs II and III. Length of female, 5.40 to 6.25 ; width, 3.60 to 4.00 . Length of male, 4.75 to 5.00 ; width, 2.90 to 3.50 .

Integument ${ }^{3}$ on both dorsal and ventral surfaces granular with numerous intermingled circular depressions or pits and each pit with a single small central elevation. Very short, fine hairs present on the elevations in the circular depressions, less apparent on the venter except near the mouth parts.

Discs.-Indefinite, yet evident as symmetrical patterns of small depressions, the floors of which are irregular.

Legs.-Short, moderately heavy, and with hairs few and small. All tarsi with moderate subapical dorsal protuberances, more pronounced on tarsus IV. Length of tarsus I. 0.45; metatarsus, 0.39. Length of tarsus IV. 0.54; metatarsus, 0.525 .

Coxae.-Coxae III and IV contiguous, the others separated. There are deep invaginations between the coxae which are shown by dissection to be the surface indications of large apodemes. Coxae I, II, and III each with an elongated, smooth sclerite.

Hood and Camerostome.-Definite hood and camerostome are not apparent, though there is a moderate swelling ventrally excavated, just anterior to the mouth parts.

Capitulum.-Basis capituli very broad and short, curved, approaching a reniform shape with the convex border behind. Surface irregular, with fine hairs at the sides near the palpi and two groups, one on each side, near the posterior margin. Palpi moderately heavy, with article 1 a little more swollen than the others. Palpal hairs fine, moderate in length.

Hypostome.-Vestigial, in marked contrast with the well developed hynostome of the nymph. Broad, short, tapering, withcut denticles, concave dorsally, convex ventrally; bluntly rounded or partly bilobed apically. Length about 0.10 .

Folds. - Coxal and supracoxal folds present though less in evidence in well engorged specimens.

Grooves.-A short, transverse postanal groove present near the posterior end. Median postanal groove faint. All other grooves are absent or negligible.

3 Specimens of adults and nymphs preserved in alcohol are enclosed in a brittle. thin, translucent covering which when dried is easily removed with a needle. The true character of the integument of the body wall is better seen after this covering is removed. 
Sexual opening.- In line with the postertor ends of coxae I.

Spiracle.-Ovate, with surface convex.

Eyes.-Absent.

Anus.-Small, nearly circular.
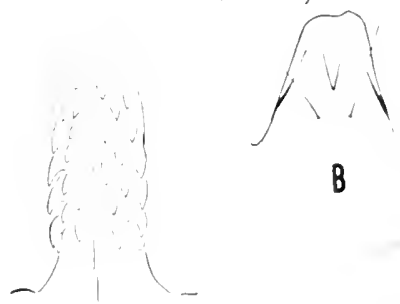

B

A
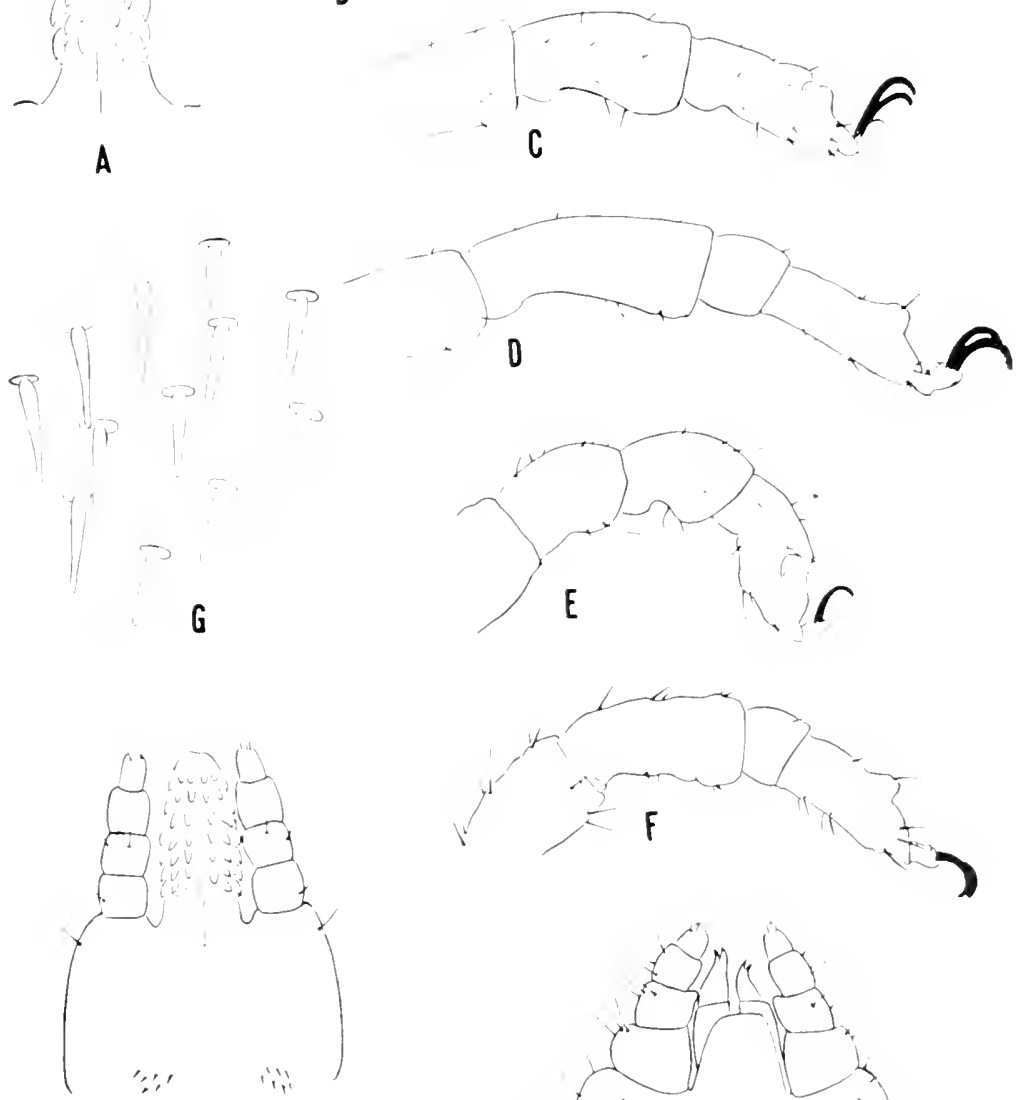

H

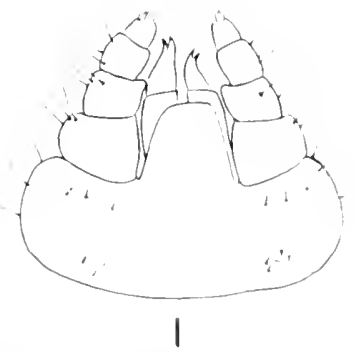

Fig. 11. Otobius lagophilus Cooley and Kohls. A, Hypostome of nymph. B. Hypostome of adult. C. Leg I of adult. D. Leg IV of adult. E. Leg I of nymph. F, Leg IV of nypmh. G. Spines from anterior portion of the nymph. H. Capitulum of nymph. ventral view. I. Capitulum of adult, ventral view. 


\section{NYMPH}

Shape and size about as in the adult.

The integumental markings of the nymph very different from those of the adult. Entire surface, dorsal and ventral, smooth and shining, with fine reticulations and transverse striae, similar to the body wall of larval Argasidae.

Spines.-Spines or hairs are present over the entire surface of the body except in the area immediately surrounding the mouth parts; more abundant and longer at the anterior end; progressively smaller toward the posterior end; less numerous on the ventral surface.

Discs.-Definite discs are absent but corresponding depressions are sometimes evident. These depressions are free of spines and in some a few fine punctations are visible.

Legs.-Short and moderately heavy. Subapical protuberances absent or small on tarsi I, II, and III, but distinct on IV. Length of tarsus I, 0.36; metatarsus, 0.30. Length of tarsus IV, 0.45; metatarsus, 0.45 .

Coxae.-Present as inconspicuous sclerites.

Hood and Camerostome.-Absent.

Capitulum. - In ventral view the capitulum is in a depression formed by a circular tumescence which makes it difficult to get a true impression of the shape of the basis capituli unless it is dissected out. Broader than long. Palpi moderately heavy (more slender than in megnini), and with article 1 lacking the distinct ventral swelling found in the adult. Hairs small and few in number.

Hypostome.-Large, with sides nearly parallel, denticles long and sharp, in a $3 / 3$ arrangement with the denticles about equally long in the basal and apical regions; denticles in the corona absent or $f \in w$ in number. Marginal denticles absent in the subapical region. Length, 0.30 .

Folds.-Coxal and supracoxal folds are faint or absent.

Grooves.- True grooves are absent but the preanal and median postanal grooves are indicated by shallow, elongated depressions.

Spiracle.-Circular, mildly convex.

This species resembles the well-known spinose ear tick, O. megnini, but is readily separated by the following characters: its smaller size; the heavy $\mathrm{V}$ shaped spines found on the anterior surfaces in megnmi are replaced in lagophilus by slender spines which are the same as those on the posterior parts; denticles on the hypostome in a $3: 3$ pattern instead of $4_{4}$; legs more slender; spiracles of the nymph mildly convex instead of conically protuberant.

In common with megnini, the adults of lagophilus are not parasitic. In our cxperience the nymphs are attached in the fur on the face of the rabbit near the vibrissae. One living adult (17850) was found at the entrance of a rodent burrow; another $(19270)$ was found well down in a burrow. 


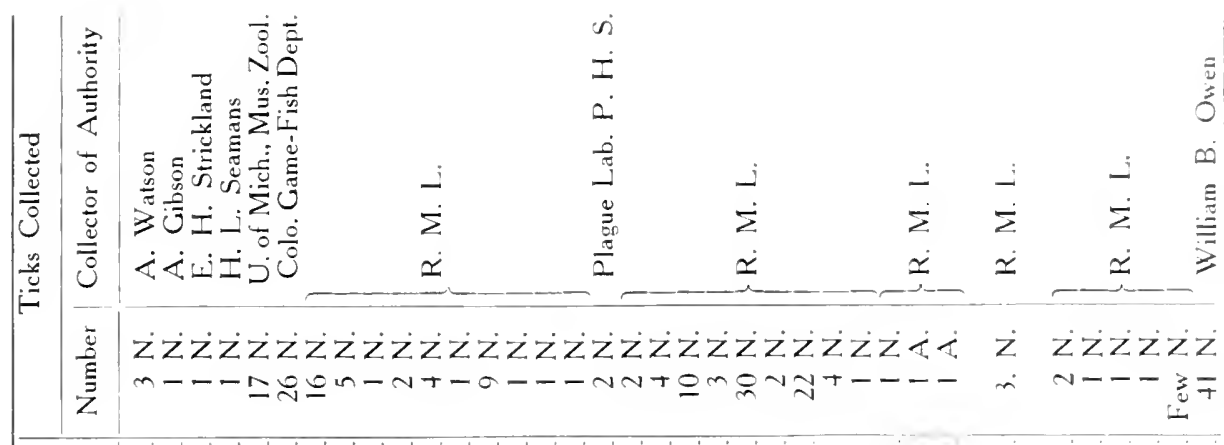

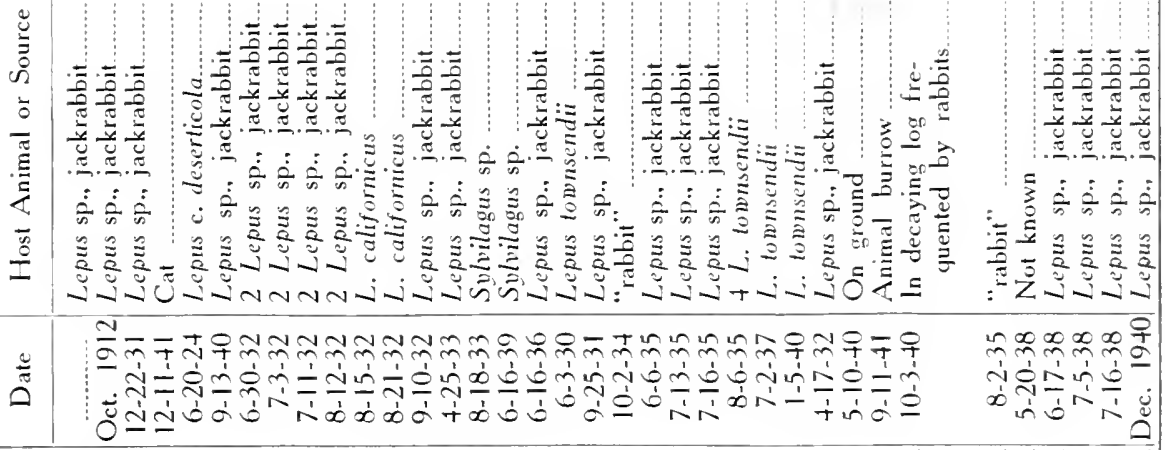

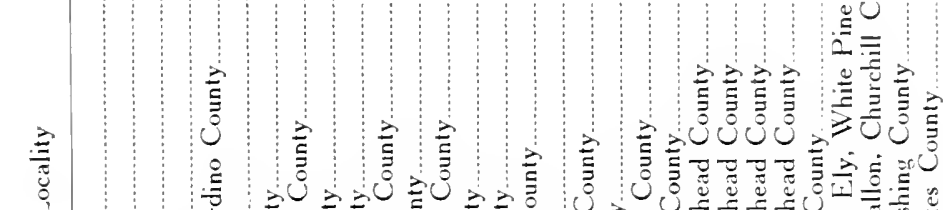

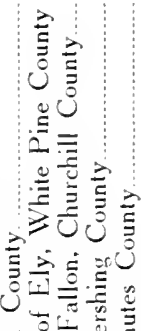

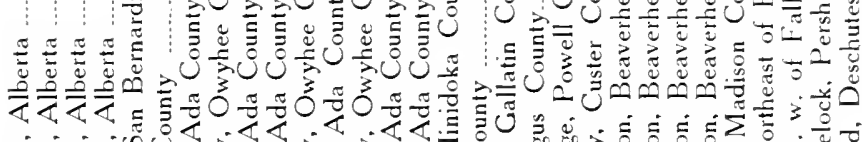

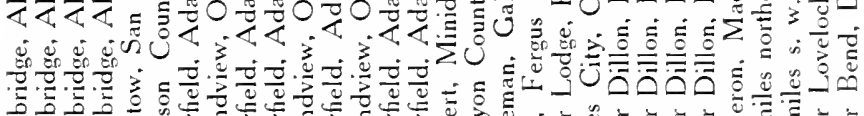

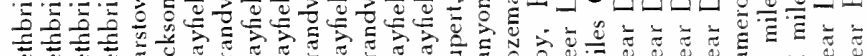

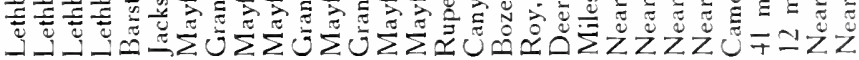

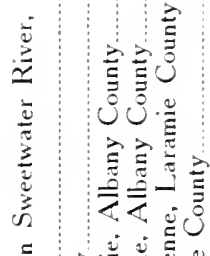
5 : 总

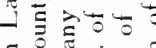

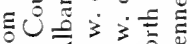

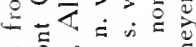

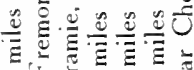
ๆ

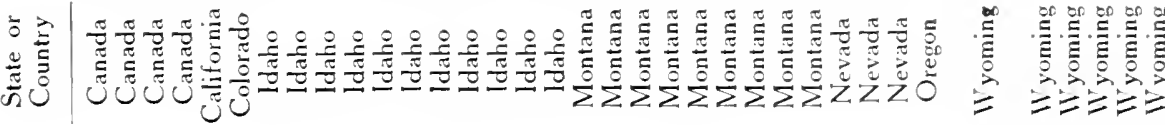

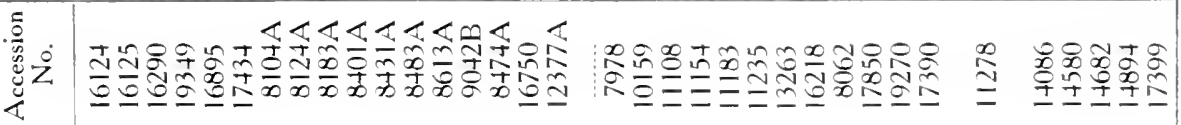




\section{DISTRIBUTION AND HOSTS}

This species is known from Alberta, Canada, and from the following States: California, Colorado, Idaho, Montana, Nevada, Oregon, and Wyoming. Except for a single record from a cat, the only known hosts are cottontail rabbits, Sylvilagus sp., and jack rabbits, Lepus sp., including L. tow'nsendii, and L. californicus deserticola.

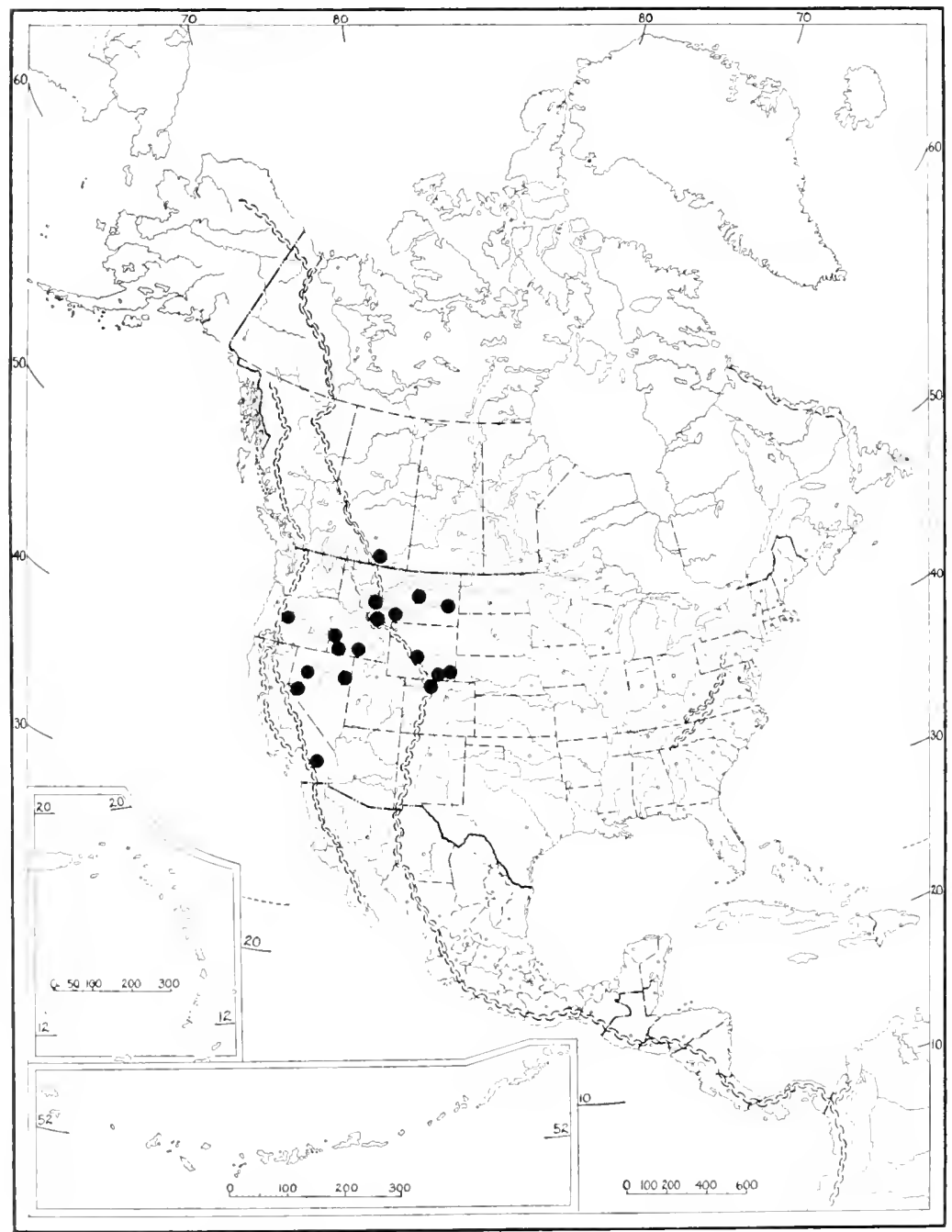

Fig. 12. Distribution of Otobius lagophilus Cooley and Kohls. 


\section{Genus Ornithodoros C. L. Koch, 1844}

1844. Ornithodoros Koch, original description, p. 219.

1845. Ornithodorus Koch: Erickson, in Agassiz Nom. Zool. (spelling emended).

1877. Argas (Ornithodoros) Murray, p. 183.

1895. Rhynchoprium Marx, p. 199. Misprint for Rhynchoprion Hermann, 1804, a synonym of Argas Latreille.

1896. Ornithodoros Koch: Neumanu, redescribed, p. 25-26.

1907. Alcctorobius Pocock, original description, p. 189 (new genus proposed for $O$. talaje).

1908. Ornithodoros Koch: Nuttall et al., redescribed p. 39-40.

1911. Ornithodoros Koch: Neumann, redescribed, p. 122.

1932. Argas Latreille: Bedford, p. 280; in part.

1934. Argas Latreille: Bedford, p. 60; in part.

1936. Ornithodorus Koch: Brumpt, p. 1180 and p. 1192.

Body more or less flattened but never marginated (except $d v e r i$ ) and with the pattern of integumental strucrures continuous over the sides from dorsal to ventral surfaces. Sutural line separating dorsal and ventral surfaces absent. Usually very convex on dorsal surface when distended. Norsal humps and subapical dorsal protuberances on legs progressively more prominent in the successive nymphal stages. Capitulum either subterminal or distant from the anterior margin. Hypostome well developed and usually essentially alike in the sexes and in nymphs and adults. Integument with discs and mammillae commingling in a variety of patterns. Hood, camerostome, and cheeks present or absent. Eyes present or absent.

Genotype: Argas savignyi Audouin, 1826, designated by Nuttall et al. (1908) not $O$. coriaceus Koch designated by Oudemans (1936).

\section{Key to Species of Ornithodoros}

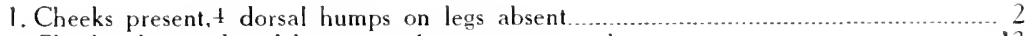

Cheeks absent, dorsal humps on legs present or absent $\ldots \ldots \ldots \ldots \ldots \ldots \ldots$

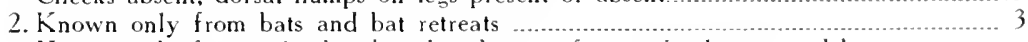

Known only from animals other than bats or from animal nests and burrows, or

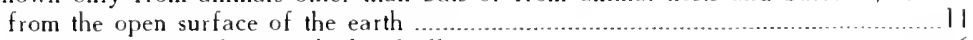

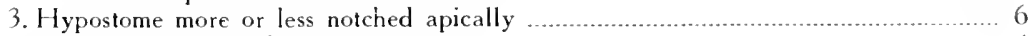

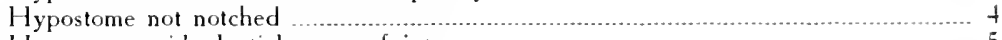

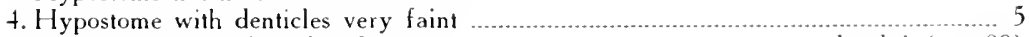

Hypostome with denticles distinct...................................... 80)

5. Hypostome long, attenuated …...............................................teci (p. 109) Hypostcme short. broad, and pointed .................................... viguerasi (p. 106)

6. Body unusually long in proportion to width and with two parallel ridges following the periphery ................................................................. 95)

Body not unusually long and lacking two parallel ridges on the periphery ........... 7

7. Legs notably long Legs not notably long

8. A small species with short legs (known from Panama) dunni (p. 103) Species of moderate size or larger and with legs of about the usual length........... 9

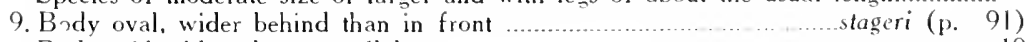

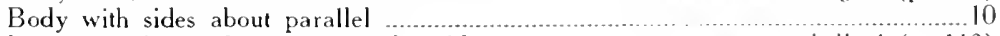

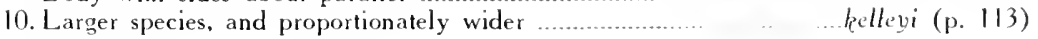

$\$$ One species, stageri, lacks the cheeks in nymphs and males. 
Smaller species, and proportionately narrower .............................concanensis (p. 88)

11. Discs large and noticeable

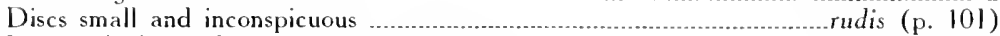

12. Legs with the surfaces micromammillated. talaje (p. 82)

Legs with the surfaces without micromammillae...............................amblus (p. 99)

13. Dorso-ventral grooves present, capitulum subapical

Dorso-ventral grooves absent, capitulum distant from the anterior margin

14. Dorsal humps on tarsi I present cooleyi (p. 52)

Dorsal humps on tarsi I absent

hermsi (p. 46)

15. Eyes absent

Eyes present coriaceus (p. 42)

16. Subapical dorsal protuberance on leg IV absent

Subapical dorsal protuberance on leg $\mathrm{IV}$ present nicollei (p. 50)

17. Dorsal humps absent on tarsus IV

Dorsal humps present on tarsus IV

8. Mammillae large, relatively few in number, not crowded.

eremicus (p. 40)

Mammillae small, many, and somewhat crowded. turicala (p. 56)

Ornithodoros Savigní (Audouin), 1826

Plate 4, Fig. 13

1826. Argas savignyi Audouin, p. 183, original description. (See Oudemans Part III. B, p. $789,1936$.

1844. Ornithodoros savignvi (Audouin): Koch, p. 219.

1873. (?) Ornithodoros morbillosus Gerstaecker, p. 464: Nuttall et al. (1908, p. 42).

1889. Argas schinzii Berlese, p. 289.

1896. Ornilhodoros savignyi (Audouin): Neumann, p. 26.

1908. Ornithodoros savignyi (Audouin): Nuttall et al., p. 42.

1911. Ornithodorus savignyi (Audouin): Neumann, p. 123.

1932. Argas savignyi Audouin: Bedford, p. 282.

1934. Argas savignvi Audouin: Bedford, p. 86.

1936. Ornithodorus savignvi (Audouin): Brumpt, pp. 1196-1197.

Sexes similar; adults and nymphs similar.

\section{ADULT}

Body.-Short, oval, broader behind, rounded on both ends. Size $10.0 \times 7.5$ to $13.0 \times 9.0$.

Mammillae.-Numerous, moderate in size, and of about equal size on all parts of the tick. Individual mammillae, convex on top (some on the venter are nearly flat on top) and with irregular, radiating ridges on their bases. Under higher magnification some mammillae show faint, small pits on the convex surface. Hairs smooth, tapering, arising from smalles mammillae; fewer on the dorsum, more abundant on the venter and most abundant and longer on the anterior and above the mouth parts.

Discs.-Distinct, small and placed in depressions; in a nearly symmetrical pattern but more numerous than in many species of the genus.

Legs.-Short, moderately large; surface smooth (not granulated). Hairs on the legs few in number, longer on the dorsal surface of the articles and on anterior legs. All femora distinctly larger distally than proximally. All tarsi with the subapical dorsal protuberances pronounced and with 2 pronounced dorsal humps. Metatarsi I, II, and III with 3 pronounced dorsal humps; IV with 2. Length of tarsus I, 1.2; metatarsus, 0.96. Length of tarsus IV, 2.04; metatarsus I.725. 
Coxae. Coxae contiguous and progressively reduced in sizes posteriorly.

Hood, Camerostome, and Cheeks.--Absent.

Capitulum.-Basis capituli contracted in front and behind, approaching a sphere in shape; surface irregular and with faint transverse rugae; a group of short spines on the sides, visible in ventral view.

Palpi-L Long, moderately heavy, article 2 much longer than article 1; article 1 in contact with the base of the hypostome; articles 2,3 and 4 free. Length of article 4 , three times its diameter.

Hypostome.-Short and large, rounded apically; denticles arranged 4/4 but it is not easy to distinguish the longitudinal files. Denticles a little larger in the lateral files. Length, 0.6.

Folds.- Supracoxal folds connected in front of the capitulum and terminating posteriorly at preanal groove. Coxal fold extending from coxa II to the preanal fold.

Grooves.-Dorso-ventral groove present and visible from above as a notch at the side. Preanal groove pronounced. Transverse postanal and median postanal grooves faint or absent.

Sexual opening.--At the level of the posterior ends of coxae I.

Eyes.-Two pairs of eyes present, all of about equal size.

Anus.- Small, in an elliptical pattern.

O. savignyi is readily distinguished from moubata, another African species, by the absence of eyes in the latter.

\section{HOSTS AND DISTRIBUTION}

This species is found in human habitations and is said to occur in loose, ciry soil in places frequented by animals or used as resting places for caravans. It occurs in Africa, Arabia, India, and Ceylon.

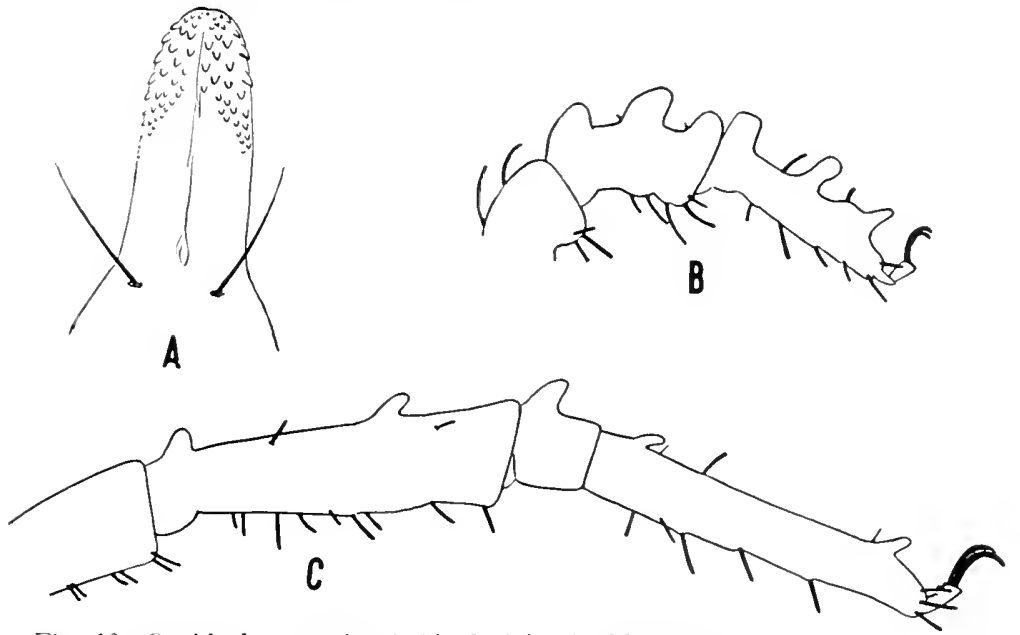

Fig. 13. Ornithodoros sarignyi (Audouin). A. Hypostome of adult. B. Leg 1 of adult. C. Leg IV of adult. 
Ornithodoros eremicus Cooley and Kohls, 1941

Plate 4 , Figs. 14 and 16

$19+1$ (b). Ornithodoros eremicus Cooley and Kohls, original description, pp. 588-589.

NYMPH

Body.-(Described from an early stage nymph.) Short oval, approaching circular, broadly rounded on both ends, tips of mouth parts visible from above. Size, $1.44 \times 1.11$.

Mammillae.-Numerous, small, and of about equal size in median and peripheral areas on both dorsal and ventral surfaces. Individual mammillae only a little elevated, flattened, with their surfaces smooth and shining. A few short hairs present, those on the anterior margin and above the anterior legs larger.

Discs.-Little in evidence, small and slightly depressed; not evident on the venter.

Legs.-Moderate in length and size. Surface smooth. Hairs few in number. Subapica! dorsal protuberance present on tarsi I, II, and III, absent on tarsus IV. Dorsal humps moderate; three on tarsus I, two on II, two on III, none on IV. Metatarsi I, II, and III, each with three dorsal humps; metatarsus IV, with two. Length of tarsus I, 0.3; metatarsus, 0.18. Length of tarsus IV, 0.42 ; metatarsus, 0.285 .

Coxae.-All coxae contiguous.

Hood, Camerostome, and Cheeks.-Absent.

Hypostome.-Moderate in length, sides parallel, apex rounded. Denticles arranged $2 / 2$ with two or three in each file and placed nat the distal end.
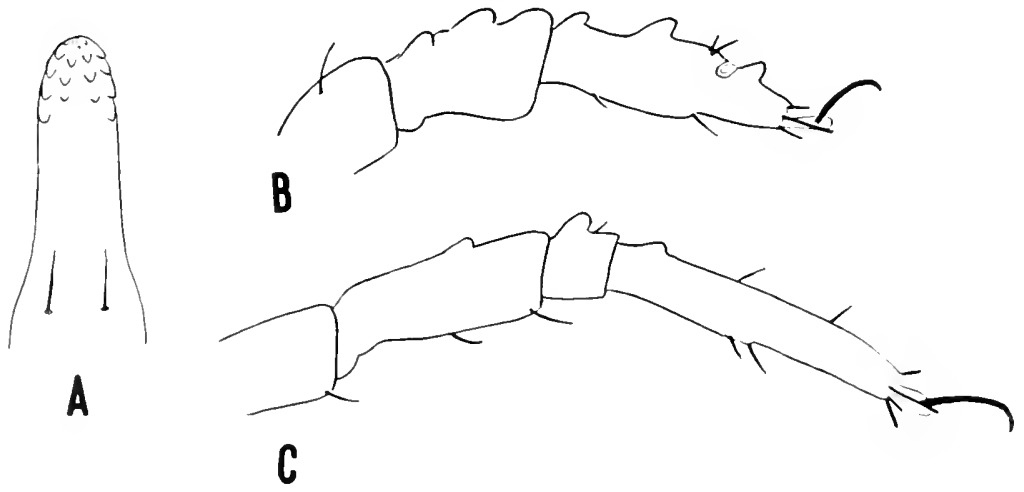

Fig. 14. Ornithodoros crimicus Cooley and Kohls. A. Hpostome of small nymph. B. Tarsus and metatarsus of leg I of small nymph. C, Tarsus and metatarsus of leg IV of small nymph. 
Length about 0.12. (Description and drawing made with the hypostome in sttu not mounted.)

Folds.-Coxal and supracoxal folds present.

Grooves.-Dorso-ventral and preanal grooves present. Median postanal and transverse postanal grooves absent.

Eyes.-Absent.

Anus.-In a nearly circular frame.

It is to be noted that although the specimen is in an early nymphal stage the dorsal humps on the tarsi are well developed. Since in all known American species the dorsal humps are poorly developed in the early nymphal stages and become progressively larger in successive stages, it appears likely either that the adult would be of a species of small size, or if of average size, the humps would be unusually prominent.

This tick resembles the African species, $O$. savignyi.

HOST AND DISTRIBUTION

Known only on Peromyscus maniculatus. The one nymph was collected rear Bluff, San Juan County, Utah. August 24, 1939. 
Ornithodoros Coriaceus Koch, 1844

Plate 5, Figs. 15 and 16

1844. Ornithodoros coriaceus Koch, original description, p. 219.

1847. Ornithodoros coriaccus Koch: Koch, redescribed, p. 31, with figures.

1888. Argas (Ornithodoros) coriaceus Koch: Berlese, p. 193.

1896. Ornithodoros coriaceus Koch: Neumann, redescribed, p. 31.

1901. Ornithodoros coriaceus Koch: Neumann, redescribed, p. 258.

1908. Ornithodoros coriaccus Koch: Banks, retescribed, p. 18-19, with figures.

1908. Ornithodoros coriaceus Koch: Nuttall, Warburton, Cooper, and Robinson, redescribed, pp. 55-56, with figures.

1911. Ornithodoros coriaeccus Koch: Neumann, redescribed, p. 124.

1930. Ornithodoros coriaccus Koch: Hoffman, redescribed, pp. 163-164.

1936. Ornithodoros coriaceus Koch: Brumpt, p. 1206.

Sexes similar; nymphs and adults similar.

\section{ADULT}

Body.-Sub-oval, somewhat pointed anteriorly and with the sides nearly parallel. Nuttall et al. (1908) give as the size of this tick, largest female 13.8 x 8.2, smallest, $9.5 \times 5.3$; largest male $8.6 \times 4.6$, smallest, $6.4 \times 3.4$. Specimens in the collections of the Rocky Mountain Laboratory are of intermediate sizes for the most part but one male measures $5.6 \times 3.4$.

Mammillae.-Numerous, moderate and variable in size, irregular in shape. In clean specimens ${ }^{5}$ the mammillae have the flattened tops ornate. Nuttall et al. (1908) state that the color is white in living and reddish in old preserved specimens. Living and freshly preserved specimens have the color reddish-gray, almost iridescent, with a few punctations interrupting the color. (Color is better seen in immersed specimens.) Interspersed in the mammillated areas are numerous large, deep pits independent of the discs, each with a conical, truncate elevation, bearing a hair.

Discs.-Large, depressed, with surface of the floors of the depressions irregular, resembling the mammillated areas. Discs less definite or absent on the ventral surface.

Legs.-Moderate in length; femur, tibia and metatarsus flared distally. Hairs few, short, and inconspicuous. Subapical dorsal protuberances pronounced on all tarsi; dorsal humps three or four on tarsi I to III: one at the base on tarsus IV. Length of tarsus I, 1.23; metatarsus, 0.96. Length of tarsus IV, 1.92; metatarsus, 1.5 .

Coxae-C Coxae I and II a little separated; all others contiguous.

Hood.-Separated from the anterior dorsal projection of the body wall

Camerostome.-Definite and deep.

Cheeks.-Absent.

Capitulum.-Basis capituli broader than long; surface very irregular with

5 Specimens of Ornithodoros collected in nature are often badly encrusted with dirt, and this is particularly true of coriaceus. 
coarse transverse wrinkles. Palpal article I with longitudinal wrinkles and with a thin flange extending over the base of the hypostome.

Hypostome. - With the sides nearly parallel. Denticles arranged 2,2 , with about four large ones in each file, all about equal in size. Length in the female, 0.57 ; male, 0.45 .

Folds.-Coxal and supracoxal folds present.

Grooves.-Dorso-ventral, preanal, transverse postanal, and median postanal grooves present; dorso-ventral groove visible in dorsal view as a marginal dent.

Sexual opening.- At the level of coxae I.

Eyes.-Two pairs of ocellus-like eyes present, those of the anterior pair nuuch larger.

Anus.-In an elliptical frame.
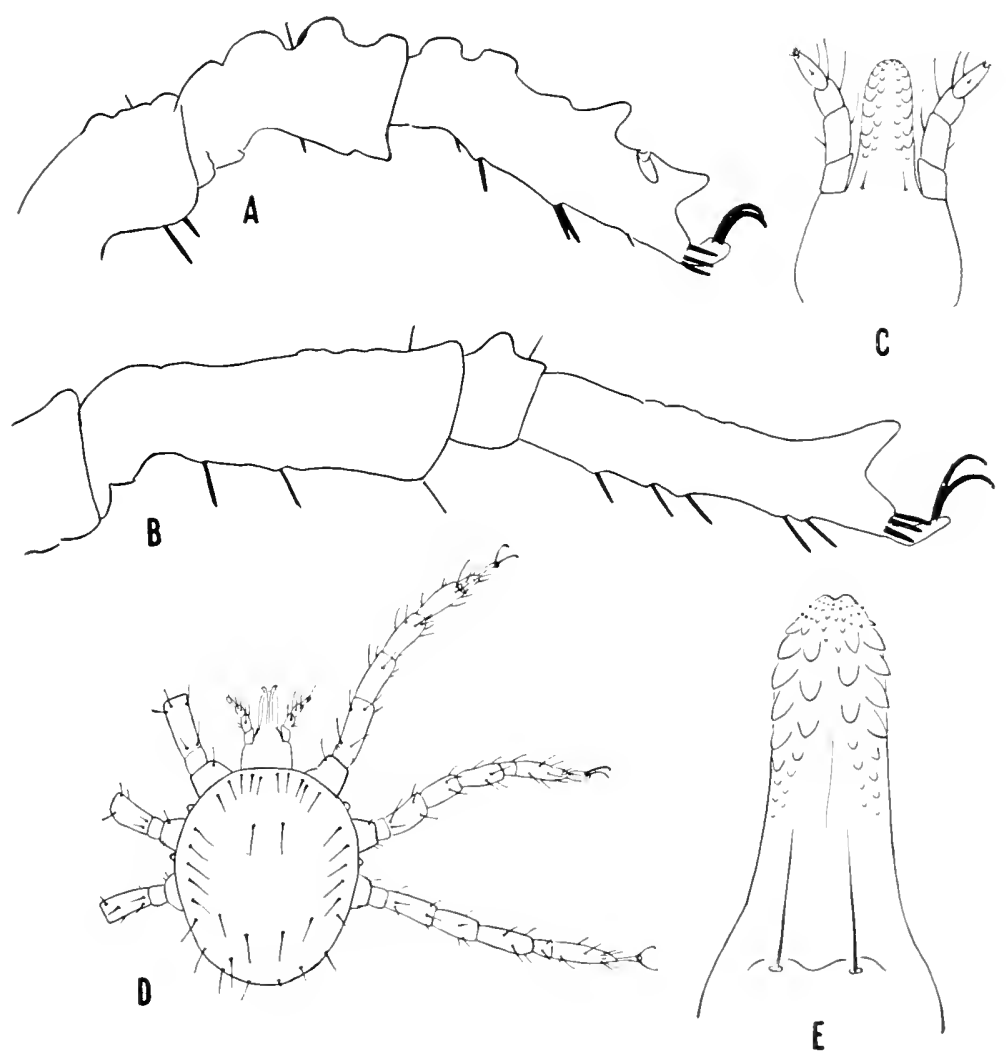

Fig. 15. Ornithodoros coriaceus Koch. A, Leg I of adult. B, Leg IV of adult. C. Capilulum of larva, ventral view. D. Larva, dorsal view. E. Hypostome of adult. 


\section{L.ARVA}

Oval, a little larger in front, with the entire capitulum visible from above; dorsal surface convex, with the sparse hairs arranged in a symmetrical pattern. Integument striated; dorsal plate absent. Two pairs of eyes present, the anterior ones about twice as large as the posterior. Length, not including the capitulum, 0.75; width, 0.6.

Legs long and slender. Length of tarsus I, 0.3; metatarsus, 0.2. Stalk of

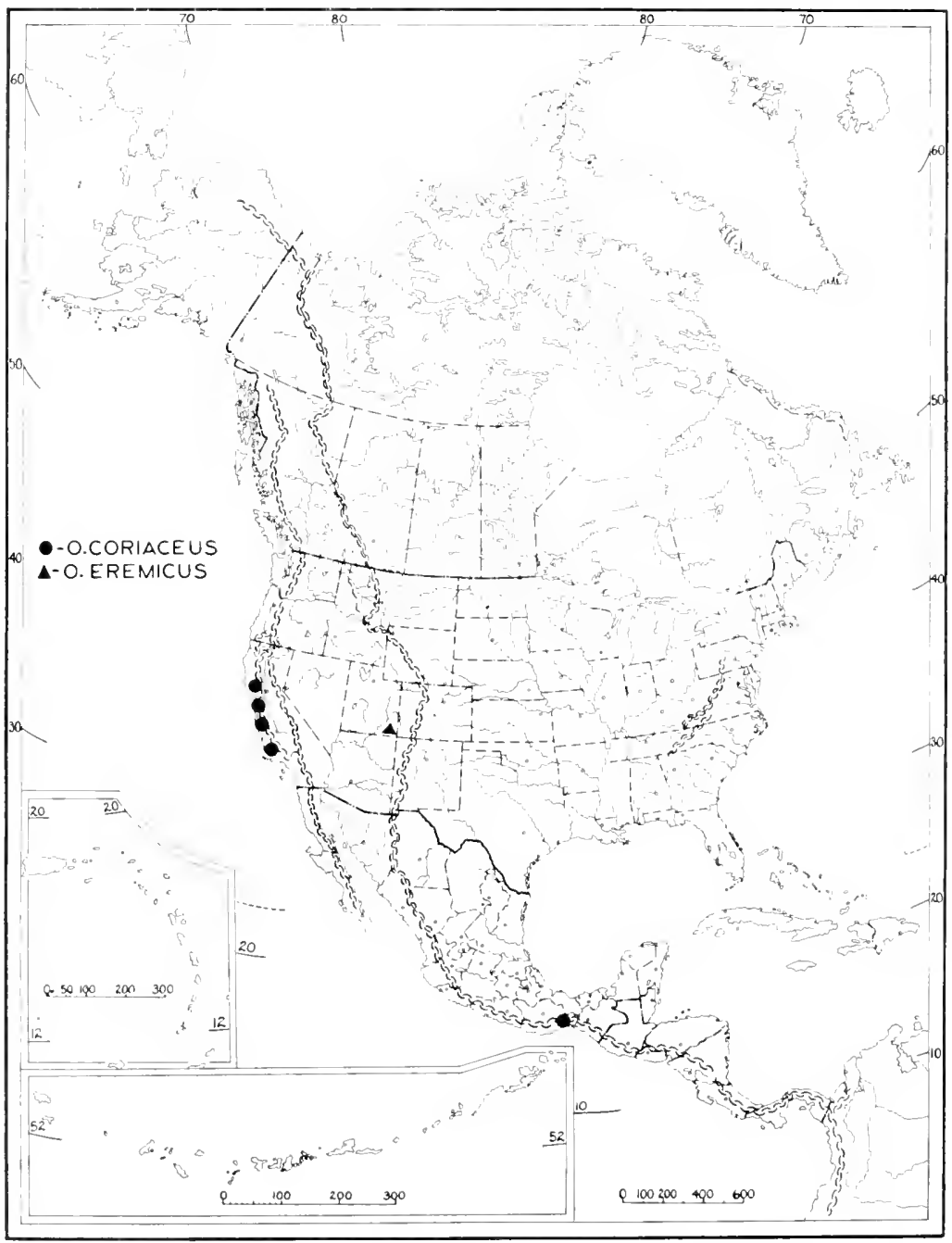

Fig. 16. Distribution of $O$. coriaceus Koch, and O. eremicus Cooley and Kohls. See also text. 
the pulvillus and claws long and slender. Palpi long and slender; terminal article about three times as long as wide.

Hypostome.-Long, and with the denticles arranged $\% / 2$, lateral denticles larger; denticles present for most of the length. Apex rounded, corona with a few very fine denticles. Length, 0.18.

Fed larvae are short-oval, measuring about $3.75 \times 2.75$. Leg I as distant from the capitulum as from leg II.

\section{HOSTS AND DISTRIBUTION}

The type specimens were from Mexico.

California-Banks (1908) saw specimens from San Francisco and Santa Clara County and stated that "it has been taken from cattle and cattlemen." Nuttall, ct al. (1908) mention specimens collected at Los Olivos (Santa Barbara County) in August, 1904. Herms (1939) stated that the species occurs in the more mountainous coastal counties and that he collected it on Mount Hamilton (Santa Clara County) in deer beds among the low scrub oaks (Quercus dumosa). Kohls collected 200 nymphs and adults on Mount Hamilton, May 15, 1940.

We have seen specimens as follows: 8692A, on ground, September 11, 1932, Mount Hamilton, Santa Clara County, 5 immature specimens (Heher Donohoe); 8607A, deer bed ground. Mount Hamilton, July 1932, Santa Clara County, several specimens; 12751, ground, October 1936, Monterey District, 1 adult (Joseph W. Burke); 5 lots, dates ranging from June 10, 1938 to January 30, 1940, Hastings Natural History Reservation, Monterey County, several specimens of all stages, (Dr. J. M. Linsdale); 16286, Monterey County, June 30, 1939, 1 nymph; 17338-39-41, host not stated, April, May, June, 1940, Calaveras Dam, Alameda County, 3 nymphs (Robert Holdenried); 17392, Cliff swallow's nest in cave, April 8, 1932, Mt. Diablo, Contra Costa County, 19 (Aitken and Howell); 17955, Odocoileus hemionus, August 8, 1940, Hastings Natural History Reservation, Monterey County, 29 nymphs (Dr. J. M. Linsdale); Odocoileus hemonicus columbianus September 8 and 9, 1941, Cobb Mt., Lake Co., 4 nymphs (J. E. Hare).

Mexico.-Nuttall et al. (1908) determined specimens collected in January 1908. They were found "whilst exploring some rock inscriptions near San Geronimo, on a hill in a sandy plain (Isthmus of Tehauntepec)."

Hoffman (1930) stated: "O. coriaceus is a native of the hot and temperate regions along the Pacific extending all the way from California to Chiapas. As to the eastern or Gulf region of Mexico, I am as yet uninformed." (Translation.) 
Ornithodoros hermsi Wheeler, Herms and Meyer, 1935

Plate 5, Figs. 17 and 18

1935. Ornithodorus hermsi Wheeler. Herms and Meyer, not intended to be the original May description but diagnostic differentiation is included, p. 1290-1292.

1935. Ornithodorus hermsi Wheeler, full description, pp. 435-438.

July

1936. Ornithodoros hermsi, Wheeler, Herms and Meyer: Brumpt, pp. 1206-1208.

Sexes similar; adults and nymphs similar.

\section{ADULTS}

Body.--Oval, wider behind, pointed anteriorly. The size of the female given by Wheeler was $5.0 \times 3.1$, and of the male, $3.8 \times 2.4$. Average sizes of numerous specimens in the Rocky Mountain Laboratory collections are, for females, $4.85 \times 3.01$ and for males, $3.42 \times 2.42$. The largest female measures $5.37 \times 3.24$ and the largest male, $3.69 \times 2.40$.

Mammillae.-Numerous and moderate in size with the individual mamnillae elongated, not conical, with sinuous, radiating ridges on the sides; longer axes longitudinal in the lateral area; and in the median areas with their longer axes tending to be concentric around the discs or groups of discs; of about equal size throughout on the dorsal surface, smaller in the median areas than at the sides on the ventral surface.

Hairs.-A few fine hairs usually visible.

Discs.-Definite, but shallow.

Legs.-Surface of legs smooth, not micromammillated, and with a few hairs present. Legs short and small. Length of tarsus I, 0.42; metatarsus, 0.3 . Tarsus IV, 0.48; metatarsus, 0.36. All tarsi without dorsal humps but with mild subapical dorsal protuberances.

Coxae.-Coxae I and II a little separated, all others contiguous.

Hood.-Well developed as an anterior projection above the capitulum and continuous with the anterior extension of the dorsal body wall.

Camerostome.-Deep posteriorly, shallow anteriorly. In fully fed specimens the camerostome is scarcely visible.

Cheeks.-Absent.

Capitulum.--Basis capituli with the length and width ahout equal. Surface irregular with interrupted transverse wrinkles and with a group of short hairs cn each side at the base.

Palpi.-Surface smooth. Article 1 with a narrow, knifeedge flange extending over the 'base of the hypostome; articles 2, 3, and 4 free

Hypostome.-Length from 0.21 to 0.27 . Denticles arranged $2 \%$ and limitcd to the distal one-third, about five in each file; denticles of all files of about equal size. Apically notched and the corona having numerous very fine denticles. Posthypostomal hairs long. 
Folds.-Coxal and supracoxal folds present.

Grooves.-Dorso-ventral groove present but faint. Preanal groove fronounced, sinuous; transverse postanal groove pronounced, interrupted at the median postanal groove which is deep and reaches from near the anus to near the posterior border.

Sexual opening.-At the level of the interval between coxae I and II.

Eyes.-Absent.

Anus.-In a long, oval pattern.

\section{LARVA}

Oval, broader behind; mouth parts short and capitulum visible from above. Integument thin and striated; hairs in a symmetrical pattern on dorsal and ventral surfaces.

Hypostome.-Sides nearly parallel, apically truncated or slightly notched; denticles $2_{2}$, with about four large ones in each file and occupying about twofifths of the distal portion. Posthypostomal hairs about three-fifths the length of the hypostome and arising from a prominent swelling. Length, about 0.08.

\section{HOSTS}

It has been assumed that $O$. hermsi bites man because of the known cases of relapsing fever originating from mountain cabins in which this species has collected. Until recently there have been no published, definite records of the hosts of this tick, but the account of Philip and Davis (1940) gives records of this tick biting man.
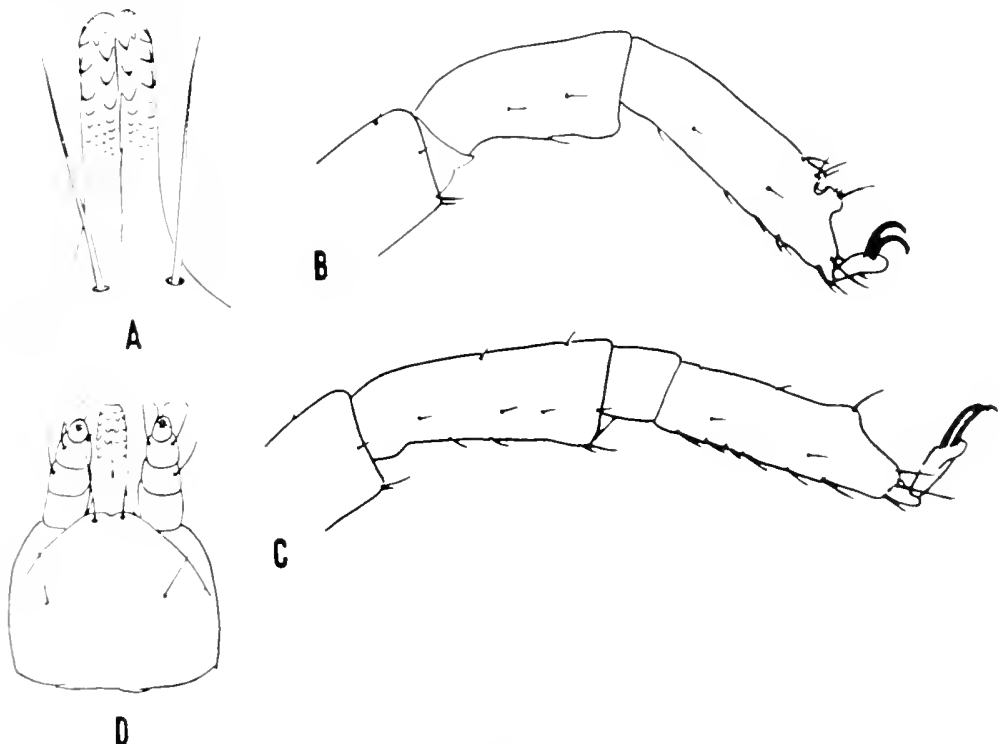

Fig. 17. Ornithodoros hermsi Wheeler. Herms and Meyer. A. Hypostome of adult. B. Leg I of adult. C. Leg IV of adult. D. Capitulum of larva, ventral view: 


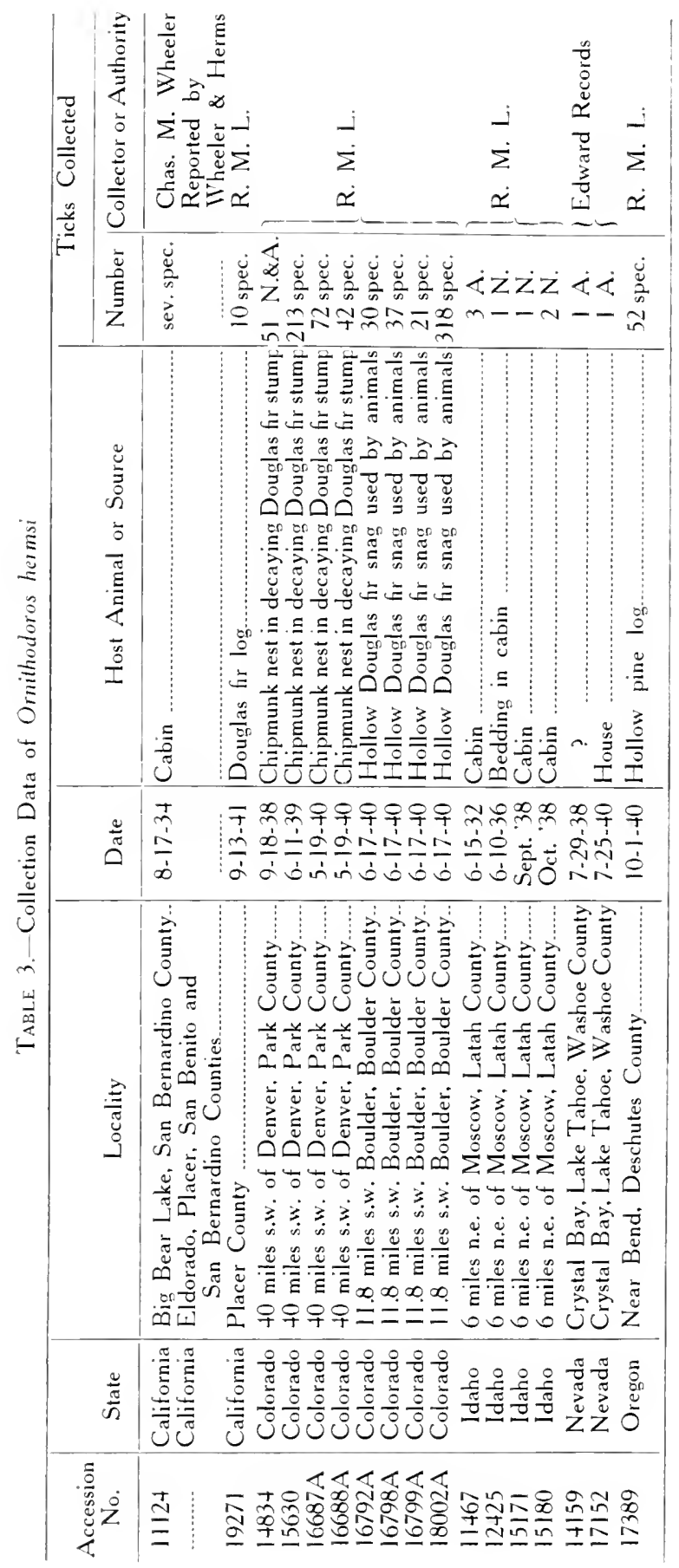


Dr. Gordon E. Davis, of the Rocky Mountain Laboratory, in connection with his studies on relapsing fever in Colorado in 1938, collected nymphs and adults from a chipmunk nest in an old, rotten stump of a Douglas fir tree. There were no animal burrow holes in the ground in this vicinity. When pushed over, the stump fell into numerous pieces and with extended search 51 specimens were recovered. The broken stump revealed a "cache" of corn in a hollow root, and nesting material of fine, dry grass well above the ground. The greater number of specimens was taken from the cracks and crevices of the stump material, and many of them had recently fed While the ticks were being collected a chipmunk hovered around "scolding." From these details it is assumed that the chipmunk was the host animal.

Again, on June 11, 1939, Dr. Davis took 213 specimens from the cracks and crevices of a rotten Douglas fir stump in Park County, Colorado. In this stump there was very extensive nest material.

The records show that this species has been taken only from higher elevations. Lake Tahoe has an elevation of 6225 feet. The cabin at Moscow, Idaho, has an elevation of about 3000 feet, and the mountainous area in Colorado where the species was taken has an elevation of approximately 8800 feet.

Briggs (1935) states that Mark F. Boyd in a personal communication had pointed out that $O$. talaje was identified as far back as 1914 from within a few miles of Polaris (near Lake Tahoe, California). The one remaining specimen of the lot from which the record had been made was kindly sent to Dr. Davis ard examined by Cooley, who found it to be a specimen of O. hermsi. Thus, this species was taken from near Lake Tahoe twenty years before the speries was described. The known records of collections of this species follow.

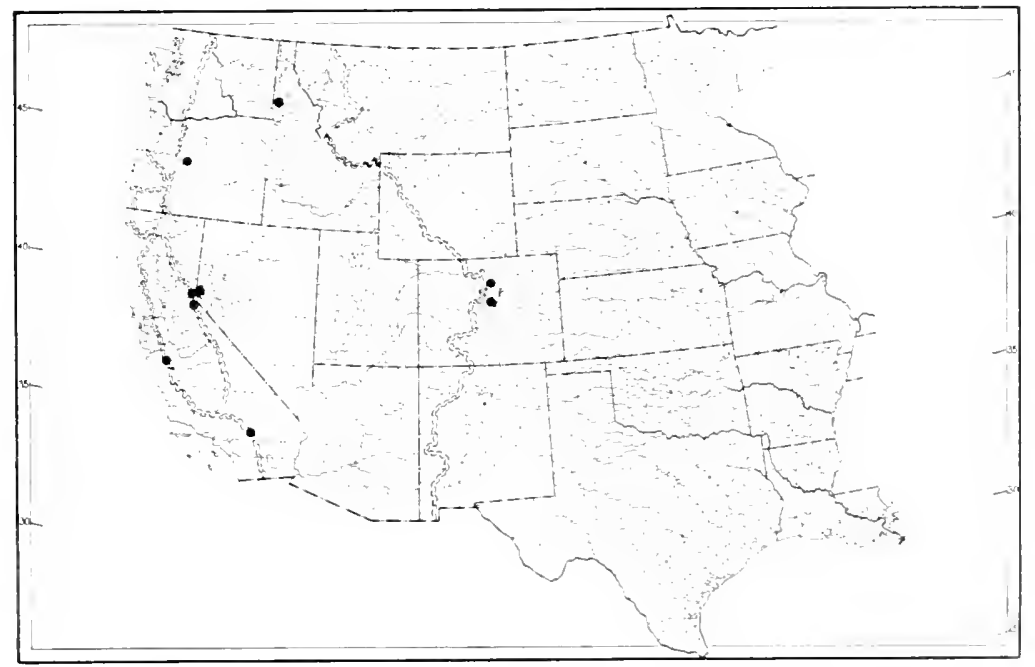

Fig. 18. Distribulion of Ornithodoros hermsi Wheeler. Herms and Meyer. 
Ornithodoros nicollei Mooser, 1932

Plate 6, Figs. 19 and 22

1932. Ornithodorus nicollei Mooser, original description, pp. 127-131, with figures.

1936. Ornithodorus nicollei Mooser: Brumpt, pp. 1210-1211.

Sexes similar; adults and nymphs similar.

\section{ADULT}

Body.-Broadly rounded at both ends, hood barely visible from above. Size of female, $7.0 \times 4.9$ to $10.3 \times 6.1$; male, $5.0 \times 3.5$ to $7.10 \times 4.2$.

Mammillae.-Numerous, moderate in size and on the dorsum about the same in size throughout; smaller on the venter except at posterior end. Individual mammillae sub-oval, conical, with their tops convex, smooth, and each with a few small pits; sides with radiating striae which reach nearly to the tops. Interspersed among the mammillae on both dorsal and ventral surfaces are conical elevations which are truncated and each bears : hair.

Dises.-Small, depressed and not conspicuous; absent or obscure on venter.

Legs.-Moderate in length and size, with the articles flared distally. All tarsi with a conspicuous subapical dorsal protuberance and all except IV with a prominent dorsal hump near the proximal end. Length of female tarsus I, 0.66; metatarsus, 0.57; length of tarsus IV, 0.72; metatarsus, 0.96 .

Coxae.-Coxae I and II slightly separated, all other contiguous.

Hood.-Moderate, not continuous with the anterior extension of the dorsal body wall.

Camerostome.-Shallow.

Cheeks.-Absent.

Capitulum.-Basis capituli wider than long, narrower in front; surface irregular, and with a group of short, heavy spines on each side behind. Palpi large, article 1 tumescent with a knife-edge flange overlying the base of the hypostome and with a row of spines on the median side.

Hypostome.-Large and long, sides parallel, apex rounded; denticles in a $\because$ arrangement, all of about equal size and confined to about three-fifths of the apical portion. Corona with numerous small denticles. Length, 0.6.

Folds.-Coxal and supracoxal folds present.

Grooves.-Dorso-ventral groove pronounced and visibie in dorsal view. Preanal, transverse postanal, and median postanal grooves pronounced; median postanal groove continuous from near the anus to near the posterior margin.

Sexual opening.--Placed at the level of the intervals between coxae I and II.

Eyes.-Absent.

Anus.-In an oval pattern. 
The subapical dorsal protuberances and the dorsal humps are smaller in the nymphs; small or negligible in the very small nymphs and become progressively larger in the stages up to the adult.

\section{HOSTS AND DISTRIBUTION} huts.

The type specimens were collected in Mexico, State of Guerrero, in native

Mexico.-Through the courtesy of Dr. Mooser, we have seen specimens, immature and adult, collected in nacive huts, Balsas River villages, State of Guerreto, April 1932.

Brumpt, Mazzotti and Brumpt (1939) mentioned specimens collected from Neotoma (Hodomys) alleni near Colima, State of Colima.

Missouri.-We have 1 adult and 23 nymphs collected from Florida diamond back rattlesnake, St. Louis Zoo, November 1933.

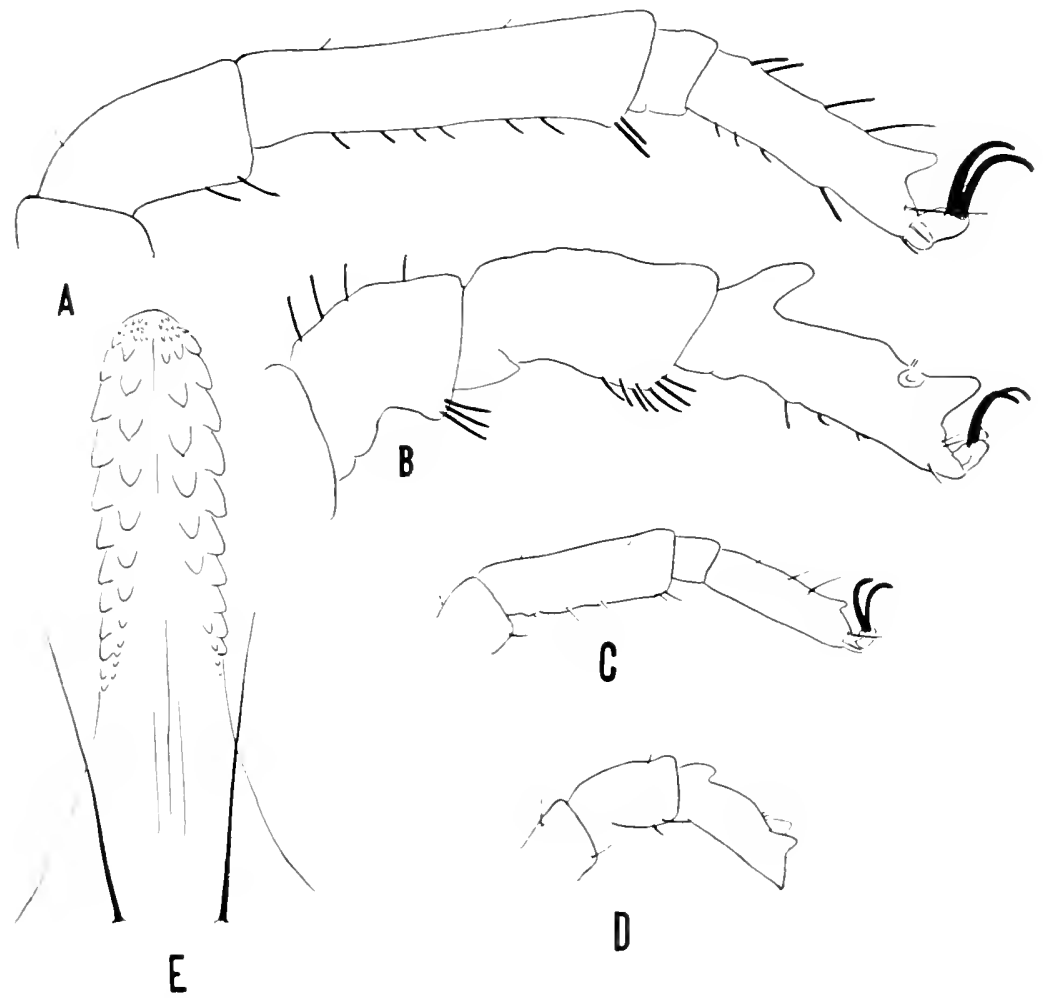

Fig. 19. Ornithodoros nicollei Mooser. A. Leg IV of femate. B. Leg I of female. C. Leg IV of a small nymph. D, Leg I of a small nymph. E. Hypostome if female. 


\section{Ornithodoros COOLEYI McIvor, 1941}

Plate 6. Figs. 20, 21, and 22

1941. Ornithodoros cooleyi McIvor, original description, with figures, pp. $435-436$.

Whether the sexes and adults and nymphs are similar or dissimilar is unknown.

\section{FEMALE}

Body-Sub-oval, sides nearly paraliel, anterior end bluntly pointed, posterior end broadly rounded. Length, 9.25; width, 4.5.

Mammillae.- Integument of the dorsal and the median posterior ventral surfaces in a reticulated pattern made up of numerous deep pits surrounded by continuous ridges of crowded mammillae of irregular shape. Surface of the floors of the pits irregular and each pit with a hair on an elevation placed on the anterior side of the pit. Reticulated surfaces continuous over the sides of the body with pits more shallow on the posterior ventral surface and indistinct or absent on the supracoxai folds, the inter-coxal area and in the vicinity of the mouth parts. Surface wrinkled posterior to the capitulum and at the side;

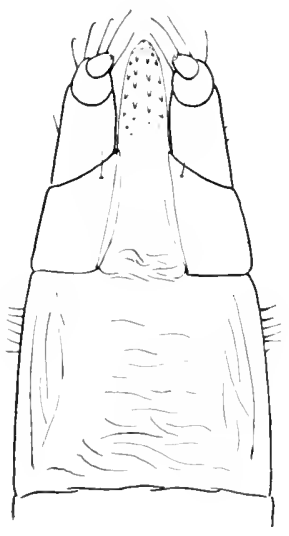

A
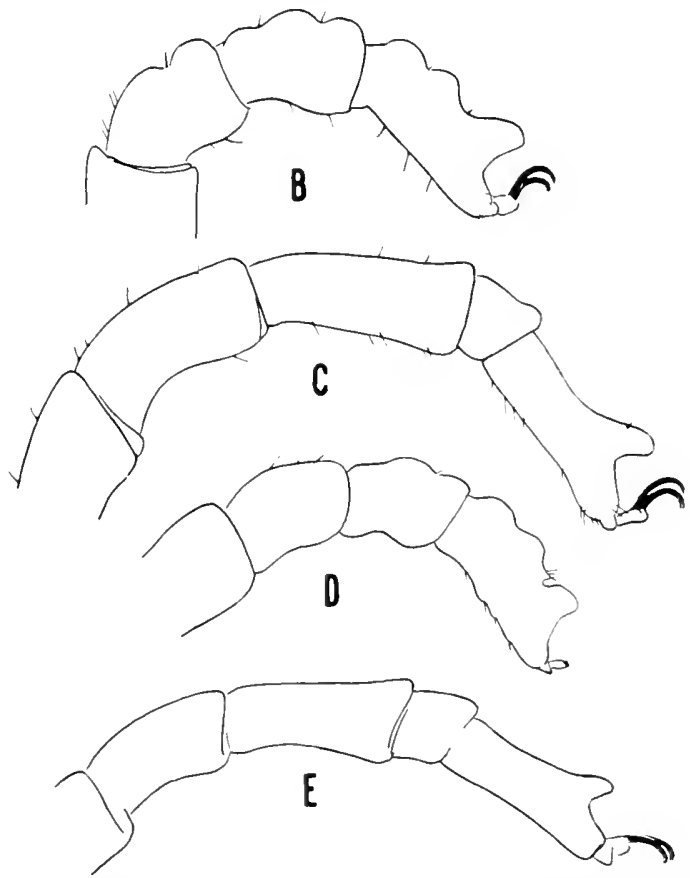

Fig. 20. Ornithodoros cooleyi Mclvor. A. Capitulum of nymph, ventral view. B, Leg I of adult. C. Leg IV of adult. D, Leg I of last stage nymph. E. Leg IV of last stage nymph. 
of the camerostome. Hairs absent in the median area between the coxal folds. few in number in the postero-lateral surfaces but more numerous and larger on the antero-lateral surfaces.

Discs.- Reticulated dorsal surface interrupted by depressed areas which include the discs. Dises large, distinct and their floors made irregular by elevations similar to the mammillae. Discs visible in the median postanal groove.

Legs.-Moderate in length and size and with a few inconspicuous hairs. Eemora a little flared distally. Subapical dorsal protuberance prominent on all tarsi. Two dorsal humps on tarsus I; a milder one near the articulation with the metatarsus on legs II, III, and IV. With two or three mild dorsal humps on metatarsi I and II. Length of tarsus I, 0.72; metatarsus, 0.54. Length of tarsus IV, 1.02; metatarsus, 0.84 .

Coxae.-Coxae I and II well separated; all others contiguous.

Hood.-No obvious hood present but in its place is a mild elevation in

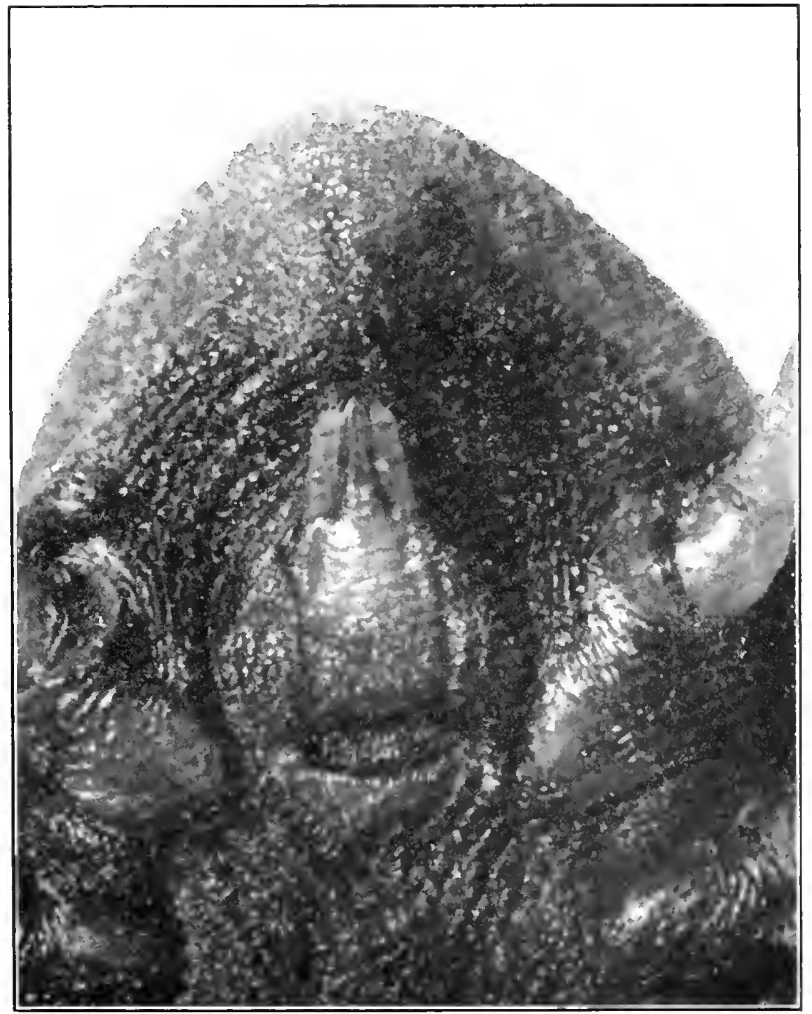

Fig. 21. Ornithodoros coolevi Mclvor. Anterior portion of female, ventral view. 
the shape of an inverted $Y$ with the mouth parts within the arms and the stem extending to the anterior margin.

Camerostome.-Distinct.

Cheeks.-Absent.

Capitulum.-Capitulum distant from the anterior margin. Basis capituli subquadrate, slightly narrower anteriorly. Surface irregular, wrinkled and with an elongated depression on each side parallel with the lateral 'border. With a

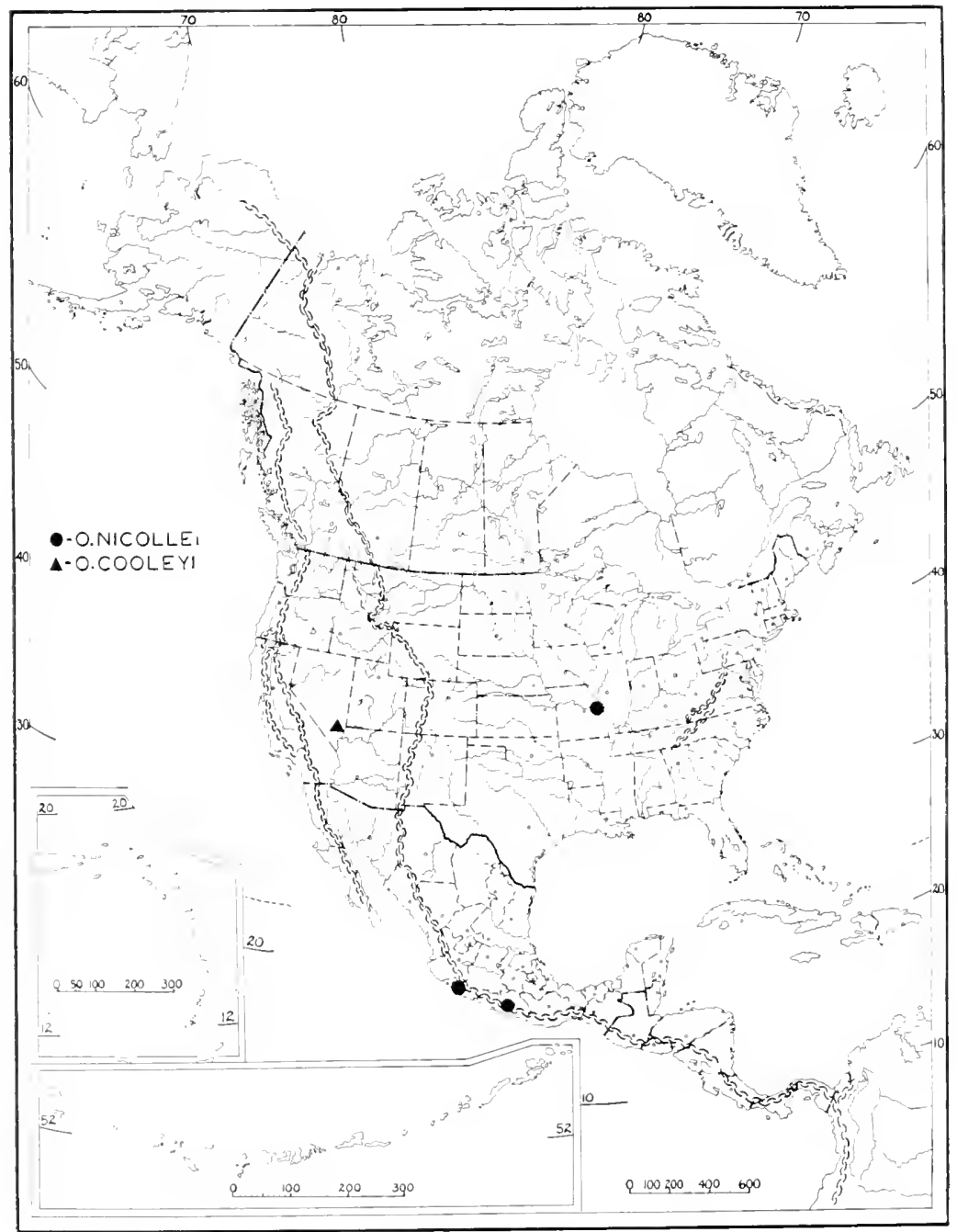

Fig. 22. Distribution of Ornithodoros nicollei Mooser and O. cooleyi McIvor. 
group of hairs on the margin on each side back of the palpi. Palpi moderate in length and with a few dorsal hairs. Article 1 with a narrow, knife-edge flange extending over the base of the hypostome; articles 2, 3, and 4 free.

Hypostome.-Long, with the apex broadly pointed. Denticles arranged $\because$, with about six in each file. Posthypostomal hairs, usually found in this genus, are absent. Length, 0.57 .

Folds.-Coxal and supracoxal folds are distinct.

Grooves.-True grooves are absent though a median elongated depression posterior to the anus suggests a median postanal groove.

Sexual opening.- Placed at the level of the posterior ends of coxae I.

Anus.-In an oval pattern.

Eyes.-Absent.

NYMPH

The single specimen from which this species was described was received by Miss McIvor as a living nymph. It was fed and in due course emerged as an adult. Thus, the cast skin was available for study and reveals some nymphal characters which differ mildly from the adult as follows: Reticulation and pits on the dorsum more shallow and less definite. Dorsal humps and subapical dorsal protuberances less prominent. Length of hypostome, 0.48. Length of tarsus I, 0.6; metatarsus, 0.42; length of tarsus IV, 0.84 ; metatarsus, 0.6.

\section{HOST AND DISTRIBUTION}

The single specimen was found by Dr. E. Raymond Hall, Museum of Vertébrate Zoology, University of California, Berkeley, in a shipment of skins sent by Mr. Frank Wilson, Rox, Nevada, which contained pelts of a striped skunk, swift foxes, and coyotes. The host of this tick is presumably one of these three animals. The specimen was given to Miss Barbara C. McIvor, The Medical Center, University of California, San Francisco, California, who has kindly given the authors full opportunity to study, figure, and photograph the specimen. 


\title{
Ornithodoros turicata (Dugès), 1876
}

\author{
Figs. 23, 24, 27, 28, 29, 30, 31, 33 and 34
}

1876. Argas turicala Dugès, original description in "Repertorio de Guanajuato," April 25.

1884. Argas turicata Dugès: Dugès, redescribed pp. 195-197, with figures.

1885. Argas turicata Alf. Dugès: Mégnin, redescribed, pp. $463-470$, with figures.

1895. Ornithodoros americanus G. Marx, figures only, p. 199. Marx obifuary notice.

1896. Ornithodoros turicata (Alf. Dugès): Neumann, redescribed, pp. 31-34.

1908. Ornithodoros turicata (Dugès): Banks, redescribed, p. 18, with figures.

1908. Ornithodoros turicala (A. Dugès): Nuttall, Warburton, Cooper and Robinson, redescribed, pp. 57-59, with figures.

1911. Ornithodoros lurnicala (Alf. Dugès) : Neumann, redescribed, p. 124.

1930. Ornithodoros turicata (Dugès): Hoffman, redescribed, pp. 155-160, with figures.

1936. Ornithodorus turicala (A. Dugès): Brumpt, pp. 1201-1203.

Sexes similar; nymphs and adults similar.

\section{ADULT}

Body.-Oval, slightly wider behind, anterior and posterior ends evenly rounded, hood visible from above. Size of female from $9.90 \times 6.80$ to $6.20 \times$ 4.6. Size of male from $6.3 \times 4.0$ to $5.4 \times 3.30$. Nuttall et al. (1908) give as average size of females $6 \times 4$, and of male, $3.5 \times 2.5$. Thus, there is evident an unusual range of sizes in the species.

Mammillae.-Moderately numerous and larger than in parkeri, distinctly larger at the posterior margin and smallest in the mid-ventral area. The individual mammillae are raised abruptly from the surface, ntarly hemispherical on top with small pits in the convexity and with radiating striae at the bases. Mammillae less crowded than in parkeri, and more elevated, with the radiating ridges at the bases more distinct. Interspersed with the usual mammillae are smaller conical, truncate elevations, each with a hair arising from a central papilla. Similar but larger hairs occur on the anterior body wall above the camerostome.

Discs.-Distinct, and depressed. Absent on the ventral surface except in the grooves where they are in lineal arrangement.

Legs.-Moderate in length and size, a little larger than in parkeri, with articles mildly flared distally. Surface smooth and shining (without micromammillae or granulations). Hairs on legs small, short. Tarsi I, II, and III with a mild subapical dorsal protuberance; absent on tarsus IV. Tarsus I with three or four dorsal humps; metatarsus I with four or five; absent on tarsus IV. Length of female tarsus I, 0.72; metatarsus, 0.60. Length of female tarsus IV, 1.08; metatarsus, 1.08. Length of male tarsus I, 0.84; metatarsus, 0.66. Length of male tarsus IV, 0.96; metatarsus, 1.05 .

Coxae.-Coxae prominent, progressively larger anieriorly. Coxae I and II slightly separated: all others contiguous.

Hood.-Large and prominent, not continuous with the dorsal body wall. Cheeks.-Absent.

Capitulum.-Basis capituli about as wide as long: a little smaller than in 
parkere. Surface irregular and with a few transverse wrinkles; with a few spines in a group on each side. Palpi long, longer than in parkeri, with surface of all articles smooth. Article 1 with a knife-edge flange for the entire length on the median side extending over the base of the hypostome; articles 2,3 , and 4 free.

Hypostome.-Long, sides nearly parallel and rounded apically. Denticles arranged $\%_{2}$, with the large teeth limited to about the distal two-fifth of the length and with teeth in lateral and median files about equal in size. Length
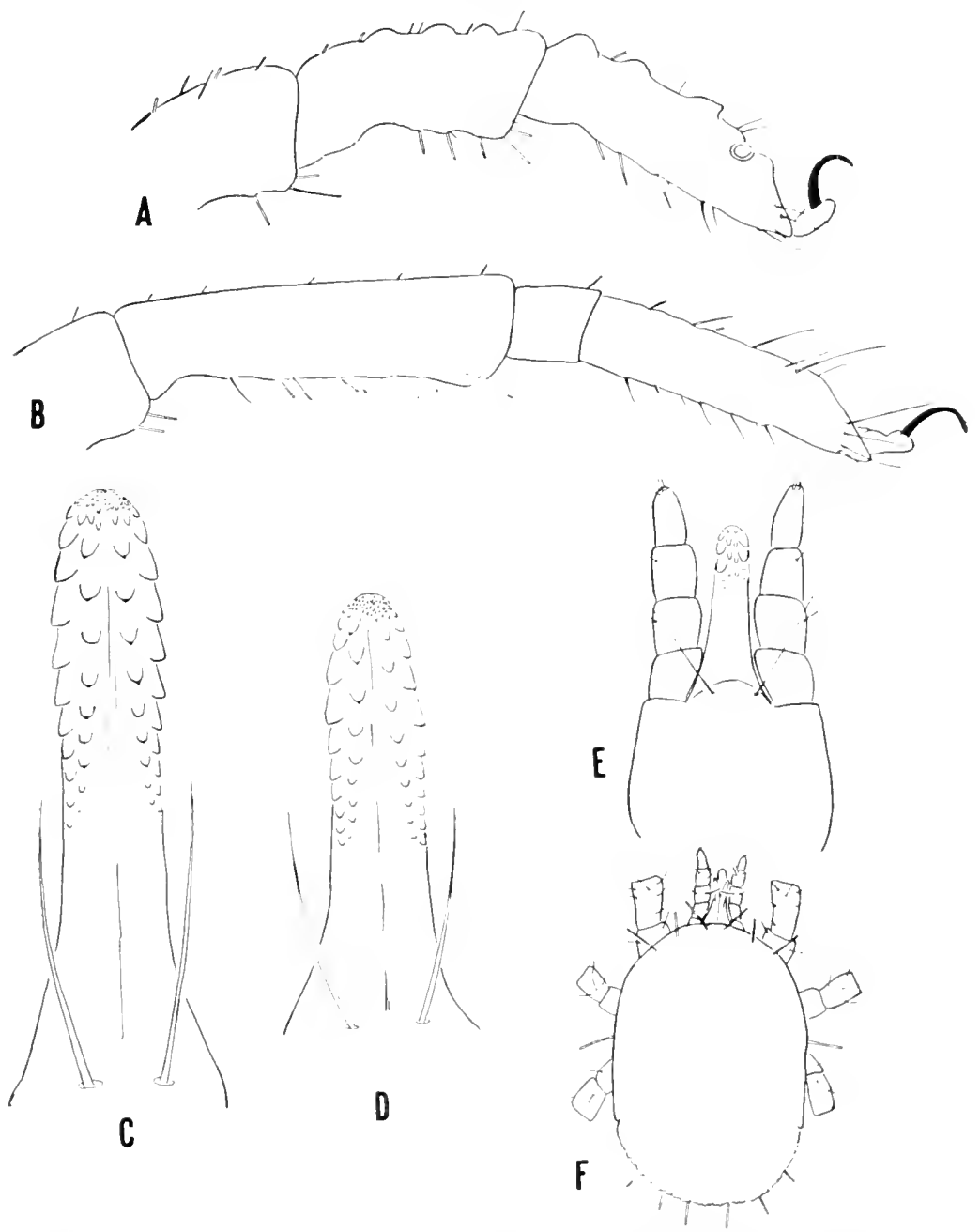

Fig. 23. Ornithodoros turicata (Duges). A, Leg I of female. B, Leg IV' of female. C. Hypostome of female. D. Hypostome of male. E. Capitulum of larva, ventral view. F, Larva, dorsal view. 
in the female, 0.60 to 0.69 , and in the male, 0.45 to 0.525 . Much longer than in parkeri.

Folds.-Coxal and supracoxal folds present.

Grooves.-Dorso-ventral groove present and visible on the dorsal surface at the sides. Preanal, transverse postanal and median postanal grooves pronounced.

Sexual opening.- At the level of the intervals between coxae I and II.

Eyes.-Absent.

Anus.-In an oval pattern.

\section{LARVA}

Oval, slightly wider behind, mouth parts visible from above. Integument thin, striated and with the sparse hairs in a symmetrical arrangement. Length, not including mouth parts, 0.84 , width, 0.57 .

Hypostome.-Long, sides nearly parallel, and rounded apically; denticles $2 / 2$ occupying about the apical two-fifths of the length, and with the lateral denticles larger. Posthypostomal hairs long. Length of hypostome about 0.135 .

\section{HOSTS}

O. turicata attacks a wide variety of hosts, including reptiles, birds, and mammals. Specimens have been collected from rattlesnakes, turtles, burrowing owls, ground squirrels, prairie dogs, kangaroo rats, woodrats. rabbits, pigs, cattle, horses, and man. In Kansas, Oklahoma, and Texas we have found it in large numbers in rodent burrows and burrows used by burrowing owls, Speotyto cunicularia. Davis (1936) reported the collection of eleven hundred and ninety-seven specimens from a single sand hole which contained 11 terrapins, Terrapene ornata, in Clark County, Kansas. The U. S. Bureau of Animal Industry has several records from pigs and from sinks frequented by pigs in Florida and according to Hoffman (1930) there have been many serious outbreaks of plagues among pigs in the central part of Mexico where enormous quantities of the species have been found on the ground in pig sties.

All stages attack man readily. According to our experience the bite is painless but is followed in a few hours by intense local irritation and swelling. Subcutaneous nodules often form which, accompanied by occasional itching, may persist for months. However, in Mexico, Hoffman (1930) states that the bite is painful and often followed by serious secondary consequences, characterized by the formation of gangrene in the skin. This latter effect he attributes to the filthy habitat of the species, i.e., pig sties, etc.

This species is the only known vector of human relapsing fever in portions of Kansas, Oklahoma, Texas, and possibly other areas in the Southwestern United States. Hoffman believes that $O$. turicata has little to do with the transmission of relapsing fever in Mexico since no cases have been found in the region where this tick occurs.

\section{DISTRIBUTION}

The localities for which there are definite records of the collection of $O$. turicata are shown in figure 24. In the United States the species is known from Utah, Colorado, Kansas, Oklahoma. Texas, New Mexico, Arizona, 
California, and Florida. According to Hoffman (1930), "O turicata is found in Mexico throughout about the same regions as $[O$. megnini $]$; that is to say, it prefers the dry sections of the Central and Western Coast States but has seldom been seen at altitudes of more than 2,000 meters. In the Valley of Mexico it has been found in some instances on pigs imported from the infested regions, but apparently cannot exist for any length of time in the climate of the valley. The species rathcr prefers the less cold regions between 1,000 and 1,800 meters." (Translation.)

The type locality is Guanajuato, Mexico.

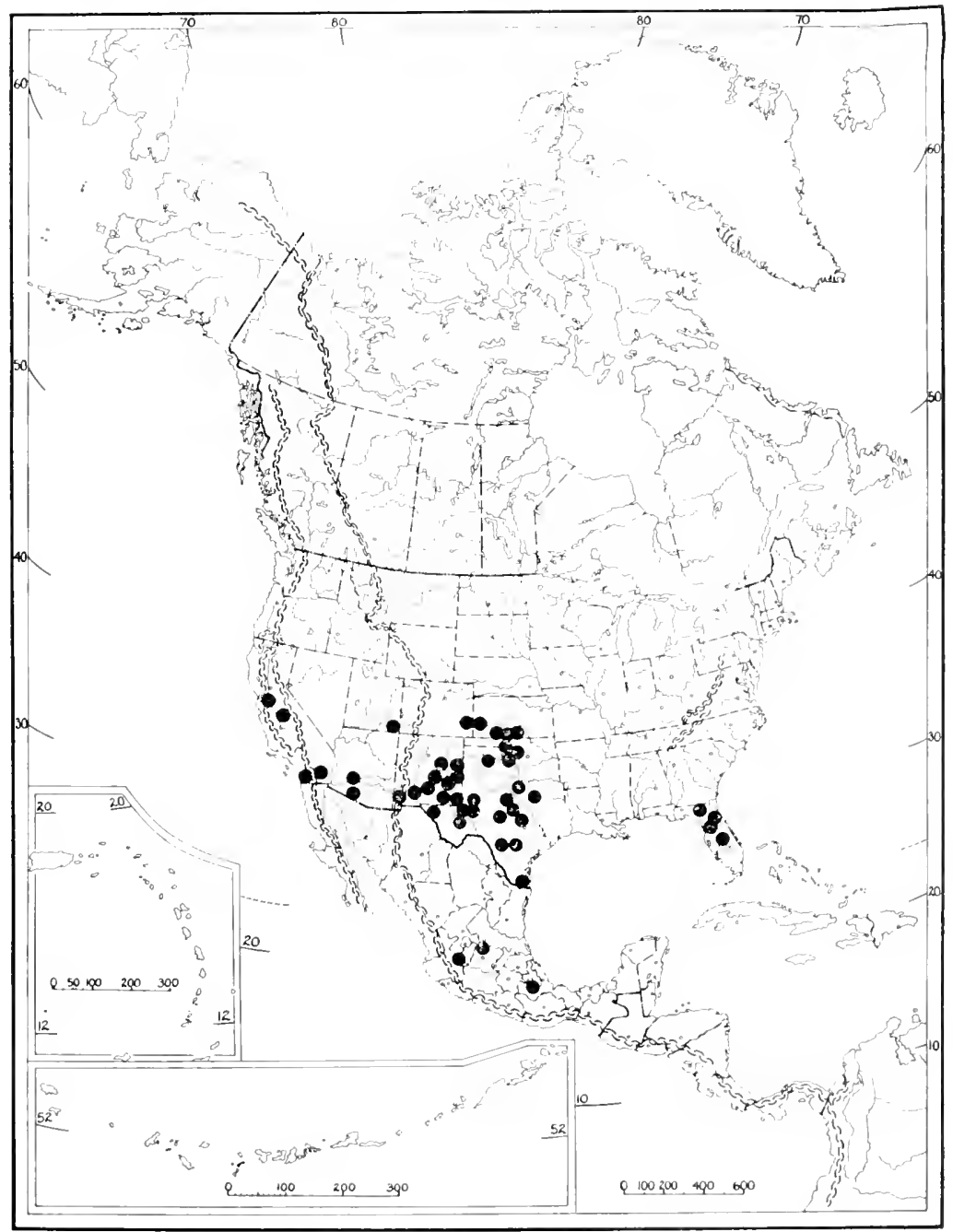

Fig. 24. Distribution of Ornithodoros turicata (Dugès). 


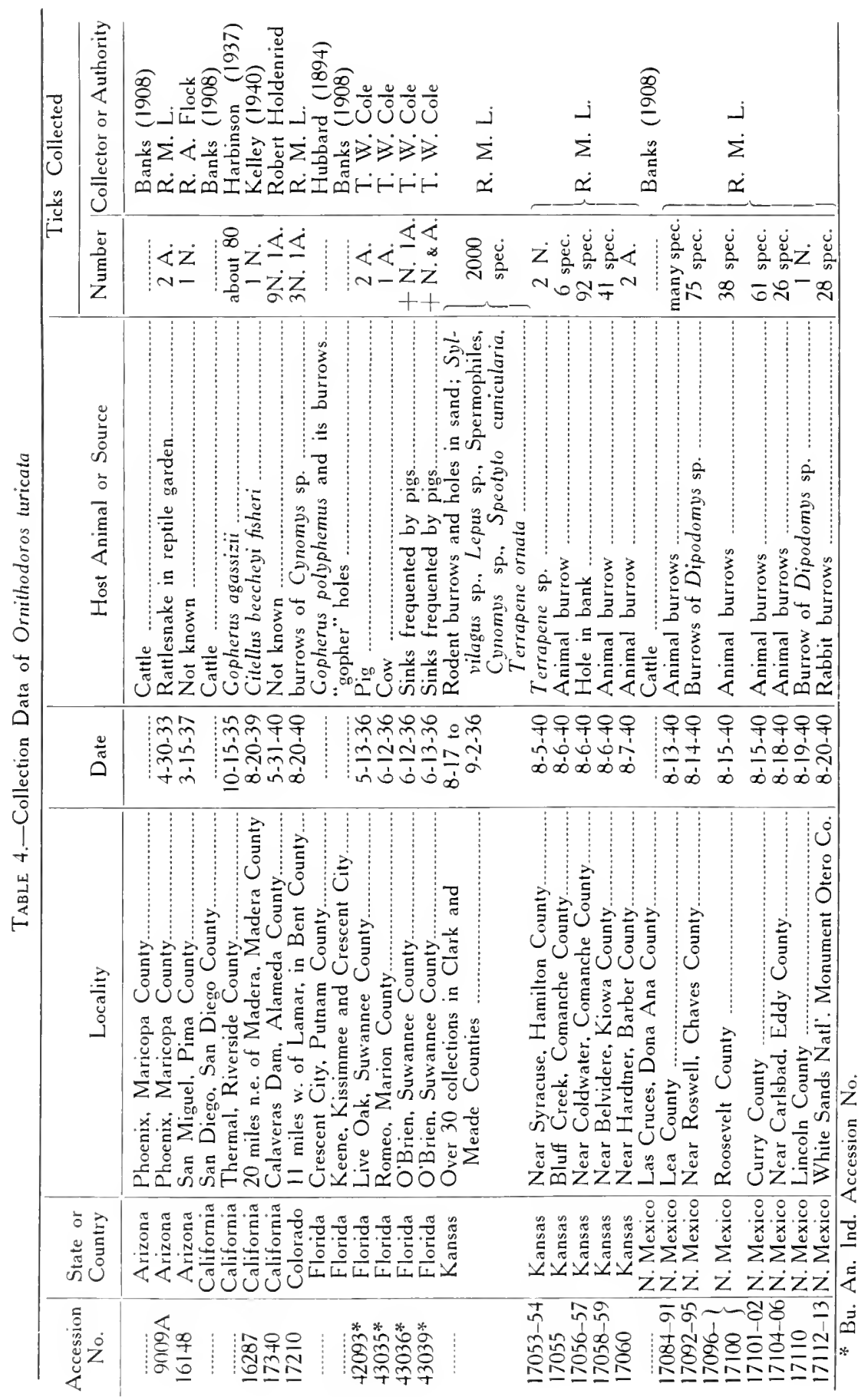




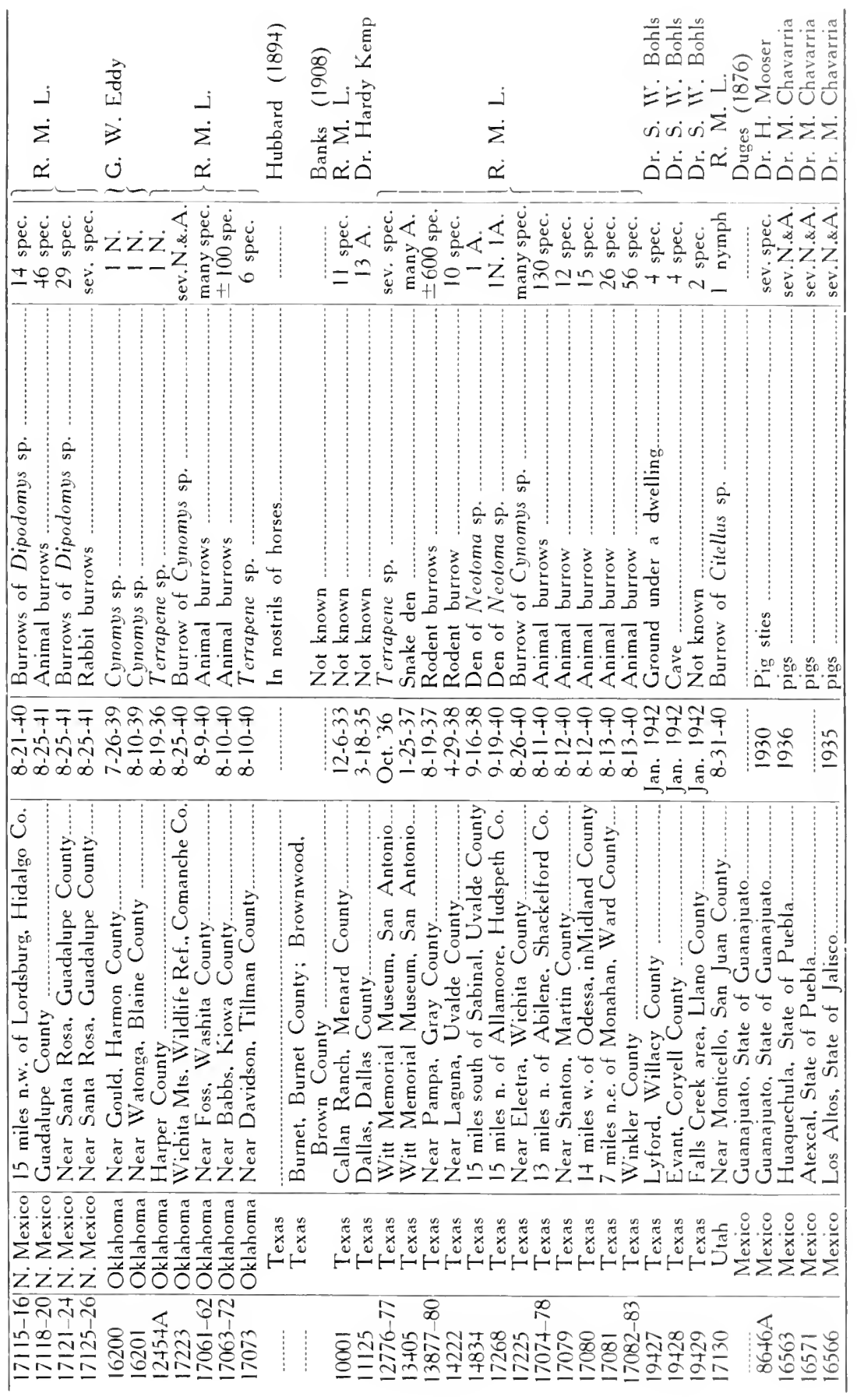


Ornithodoros parkeri Cooley, 1936

Figs. 25, 26, 27, 28, 29, 30, 32 and 34

1936. Ornithodoros parkeri Cooley, original description, pp. 431-433, with figures.

1937. Ornithodoros wheeleri McIvor, original description, pp. 365-367, with figures.

Sexes similar; nymphs and adults similar.

\section{ADULT}

Body.-Oval, a little broader posteriorly; hood visible from above. Size of female $7.10 \times 4.50$ to $5.82 \times 3.75$. Size of male $5.75 \times 4.00$ to $5.0 \times 3.25$.

Mammillae.-More numerous and smaller than in turicata, a little larger at the sides and largest of all at the posterior end, smallest in the mid-ventral region. The individual mammillae smooth, convex on top and in the convexity are usually present a few very small pits. Sides of the mammillae with radiating ridges. Mammillae more crowded together, less elevated and with the radiating ridges at their bases less visible than in turicata. Interspersed with the mammillae are smaller conical elevations, each with a hair arising from an apical pit. Hairs sparse or absent on the ventral surface.

Discs.-Discs distinct, small and depressed; absent on the ventral surface except in the grooves where they are in lineal arrangement.

Legs.- Long and moderate in size, a little heavier than in turicata, with articles mildly flared distally. Surface of the legs smooth (without micromammillae or granulations). Short hairs moderate in number. Tarsi I, II and III with moderate subapical dorsal protuberances; small or absent on tarsus IV. Tarsus I with three or four dorsal humps; metatarsus with four dorsal humps. Tarsus IV with no dorsal humps. Length of female tarsus I, 0.69; metatarsus, 0.57. Length of female tarsus IV, 0.96; metatarsus, 1.11. Length of male tarsus I, 0.6; metatarsus, 0.51 ; length of male tarsus IV, 0.75 ; metatarsus, 0.81 .

Coxae.-Coxae prominent, progressively larger anteriorly. Coxae I and II a little separated; all others contiguous. dorsum.

Hood.-Large, prominent, not continuous with the body wall of the

Cheeks.-Absent.

Capitulum.-Basis capituli about as wide as long, a little larger than in turicata; surface irregular and with transverse wrinkles; with a group of hairs cn each side. Palpi moderately long, longer than the hood; all articles smooth. Article 1 with a thin flange on the median side extending the full length of the article and projecting over the basal portion of the hypostome.

Hypostome. - Long, with sides about parallel, rounded apically. Denticles in a $2 \%$ pattern covering about the distal half, and with teeth in lateral and 
median files about equal in size. Length of female hypostome, 0.40; male, 0.33. Shorter than in turicata.

Folds.-Coxal and supracoxal folds present.

Grooves.-Dorso-ventral groove present and visible at the sides on the dorsal surface of the tick. Preanal, transverse postanal and median postanal grooves are present, pronounced.

Sexual opening.--At the level of the intervals between coxae I and II.

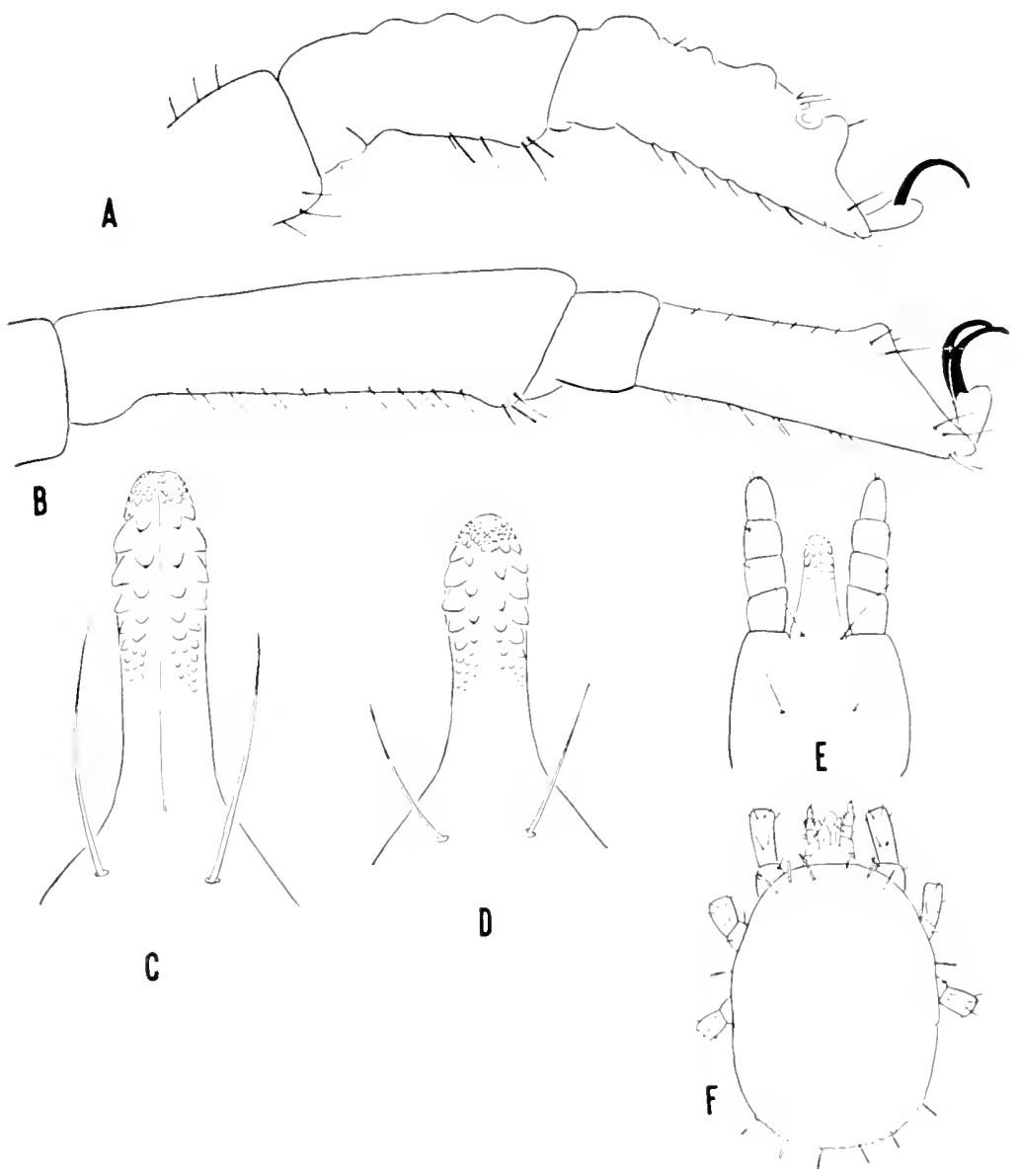

Fig. 25. Ornithodoros parkeri Cooley. A, Leg I of female. B, Leg IV of female. C. Hypostome of female. D. Hypostome of male. E. Capitulum of larva, ventral view. F, Larva, dorsal view. 
Eyes.--Absent.

Anus.--In an oval pattern.

\section{LARVA}

Oval, wider anteriorly, mouth parts visible from above. Integument thin, striated; with sparse hairs in a symmetrical pattern. Length, not including mouth parts, 0.66; width, 0.48 .

Hypostome.-Hypostome moderate in length, apically rounded: denticles $2 / 2$, occupying about the apical one-third and with the lateral teeth larger. Posthypostomal hairs long. Length of hypostome about 0.1 .

\section{HOSTS}

Ornithodoros parkeri was originally described from specimens that had been taken from Citellus sp., Lepus sp., and Cynomys sp., forty miles southwest of Casper, Wyoming. In our field experience it soon developed that while scattering specimens could be collected on animals away from their burrows, the tick was to be found more regularly and sometimes in abundance in the burrows.

Jellison (1940) examined 18 burrows and nests of the burrowing owl, Speotyto cunicularia, in Washington and nine were infested with $O$. parkeri. In nest 106 he took 491 ticks, and in nest 108, he took 360 ticks. Some of the nests containing fledglings had ticks that were fully fed, and microscopical examination showed that they contained avian blood. Thus it is evident that the burrowing owl is a natural host of $O$. parkeri.

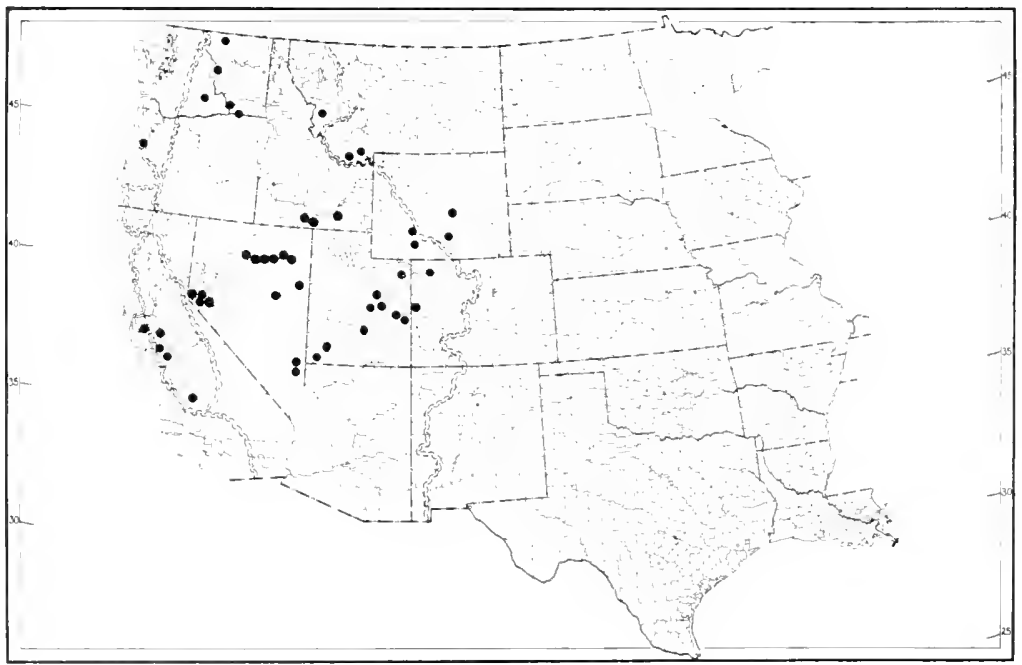

Fig. 26. Distribution of Ornithodoros parkeri Cooley. 
It is apparent that $O$. parkeri is less avid in attacking man than are some other species in the genus. Davis (1939) reported that this tick when placed on the bare arm feeds promptly. However, neither he nor his assistants, or Jellison, were bitten while collecting this species, though engaged in the work for hours at a time.

In summary, the known hosts of $O$. parkeri are: Citellus sp., $C$. columbianus, C. richardsoni, Cynomys sp., Cyn. leucurus, Marmota sp., Peromyscus sp., Lepus sp., Sylvilagus sp., Mustela sp., Speotyto cunicularia, and man.

\section{DISTRIBUTION}

Ornithodoros parkeri has been collected in widely separated areas in the following nine Western States: California, Colorado, Idaho, Montana, Nevada, Oregon, Utah, Washington, and Wyoming. Collection localities are shown in figure 26. 


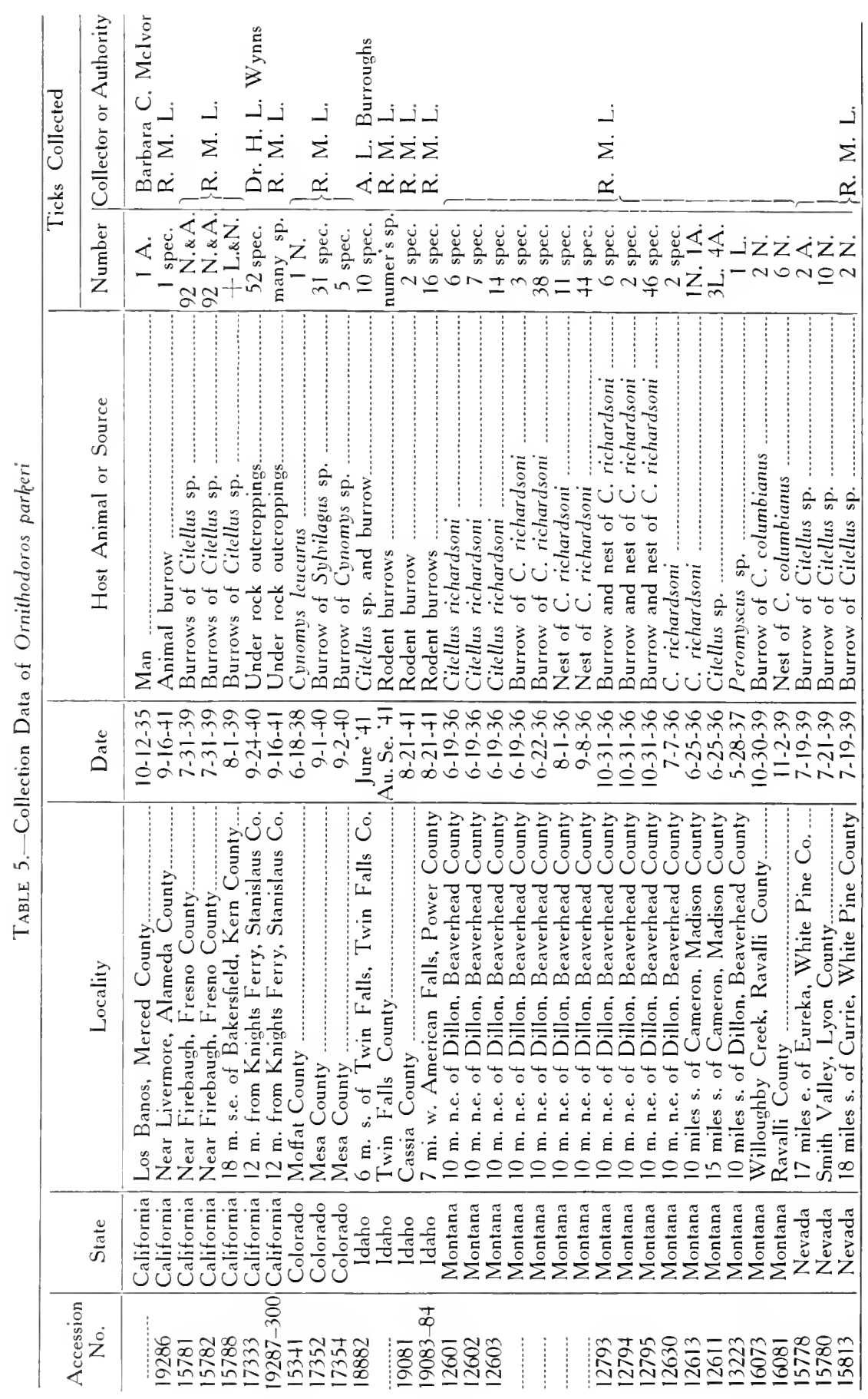




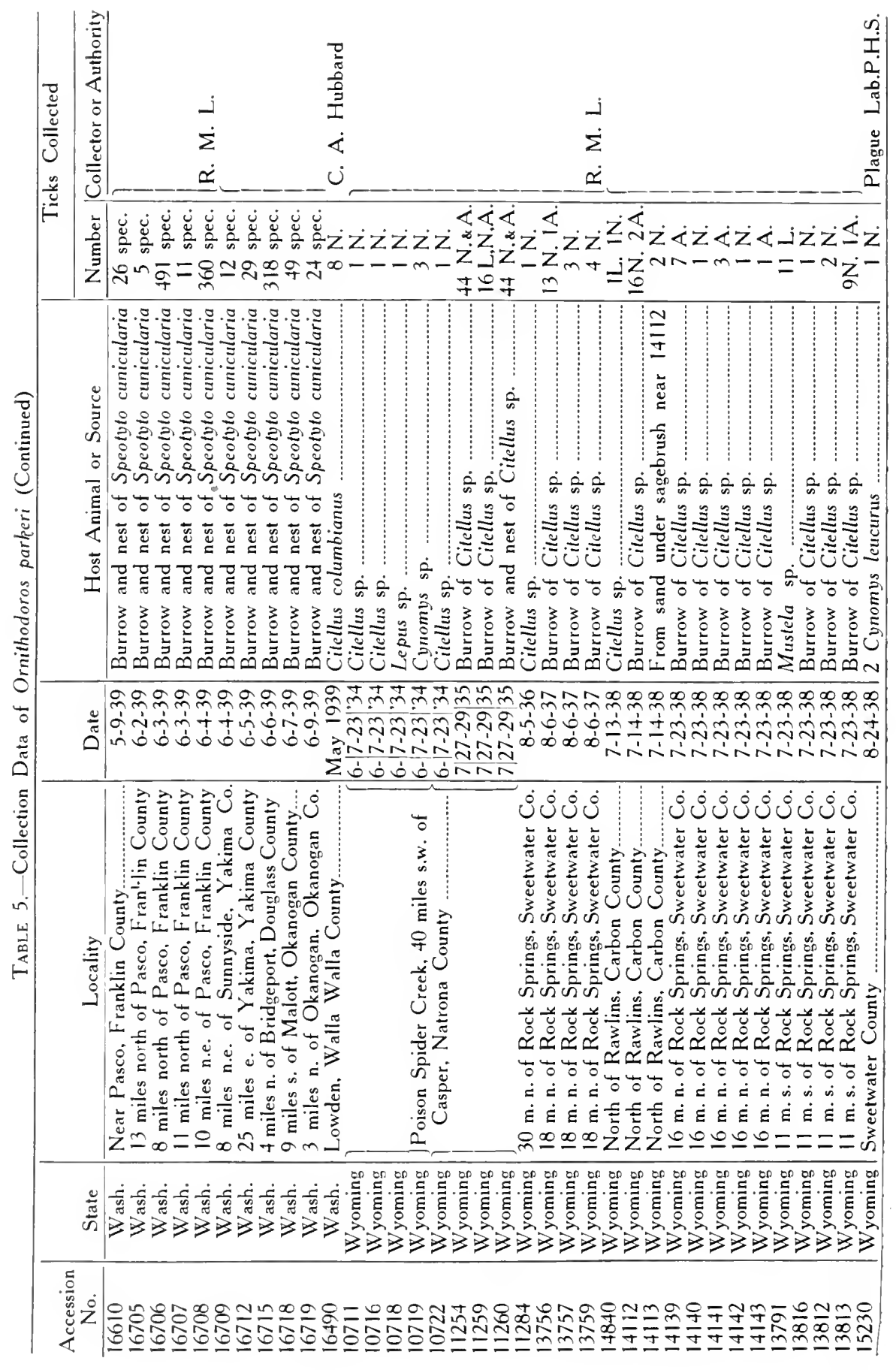


COMPARISON OF O. TURICATA AND O. PARKERI

Figs. 27, 28, 29, 30, 31, 32, 33, and 34

$O$. turicata and $O$. parkeri are rather closely related and yet in most in. stances are readily separated by their mammillae and hypostomes. In these

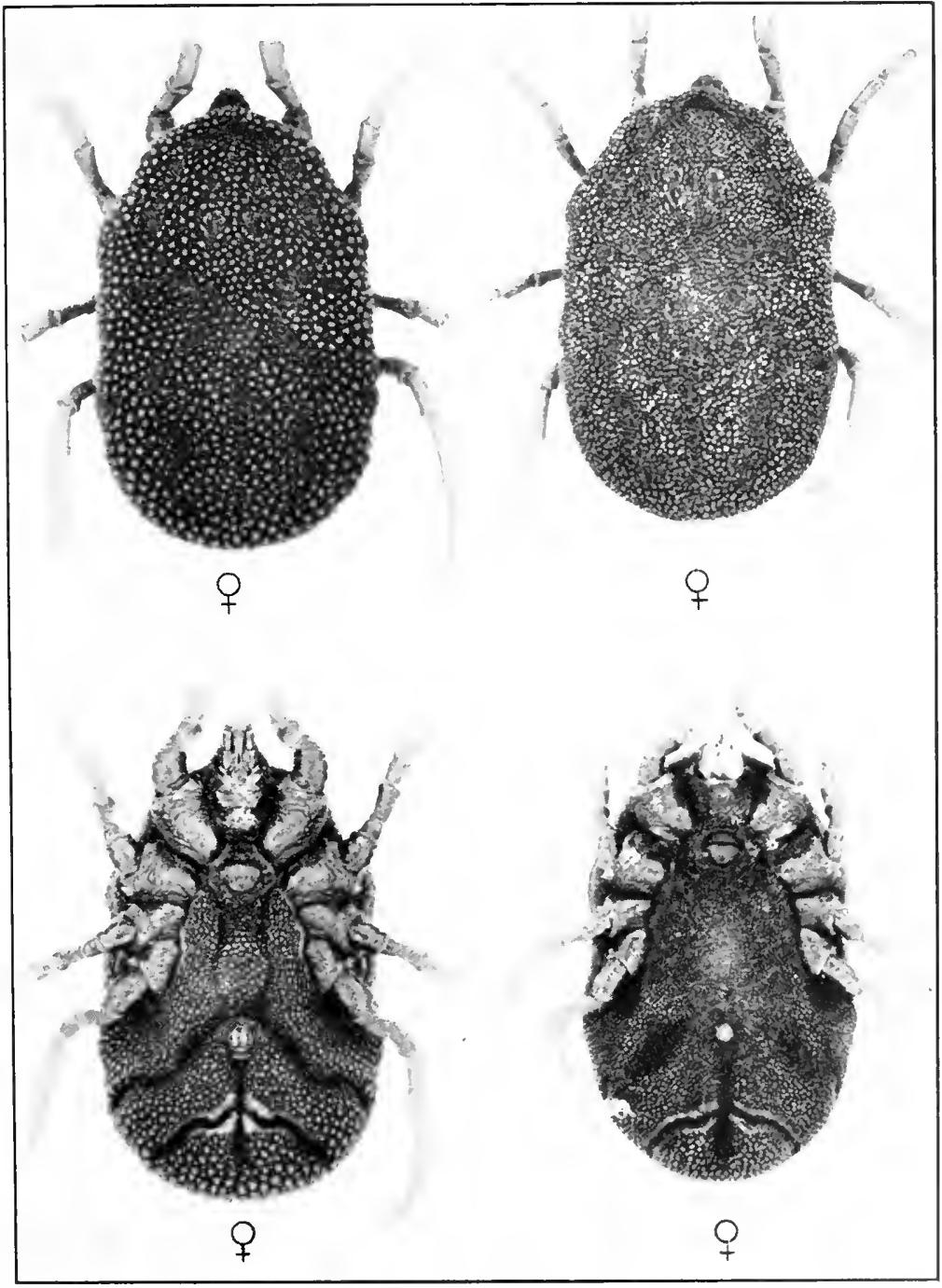

Fig. 27. Female of Ornithodoros turicata (Dugis) on the left, and female of $O$. parkeri on the right. 
species, as well as in others of the same genus, the characters of the mammillae may be less definite or distinct when the ticks are fully fed. Depleted specimens show the mammillae closer together and their elevation is at a maximum. The individual mammillae are then at their best as characters and show clearly the true shape and markings, and the folds and grooves are either normal or exaggerated. The length and width of the tick are but little in-

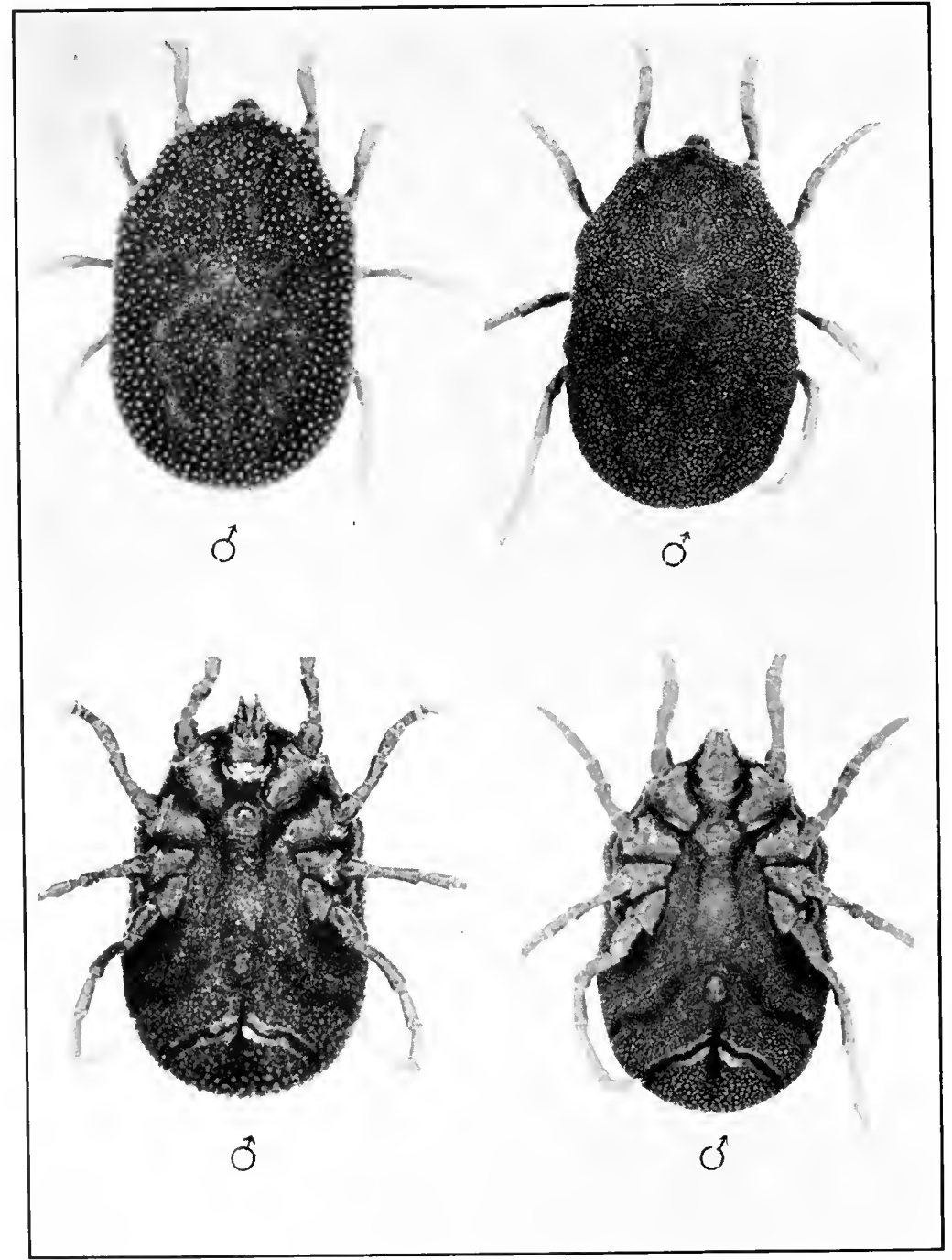

Fig. 28. Male of Ornithodoros turicata (Dugès) on the left, and male of O. parkeri Cooley on the right. 
creased by feeding but the mammillae become much flatened and in some species, including $O$. turicata and $O$. parkeri, are visible only as shining sclerites not agreeing with their descriptions. Similarly, the folds and grooves may disappear almost completely and be visible only as faint remnants. As specimens in Ornithodoros, the best ticks are those that have been depleted until the dorsal and ventral body walls are about parallel.

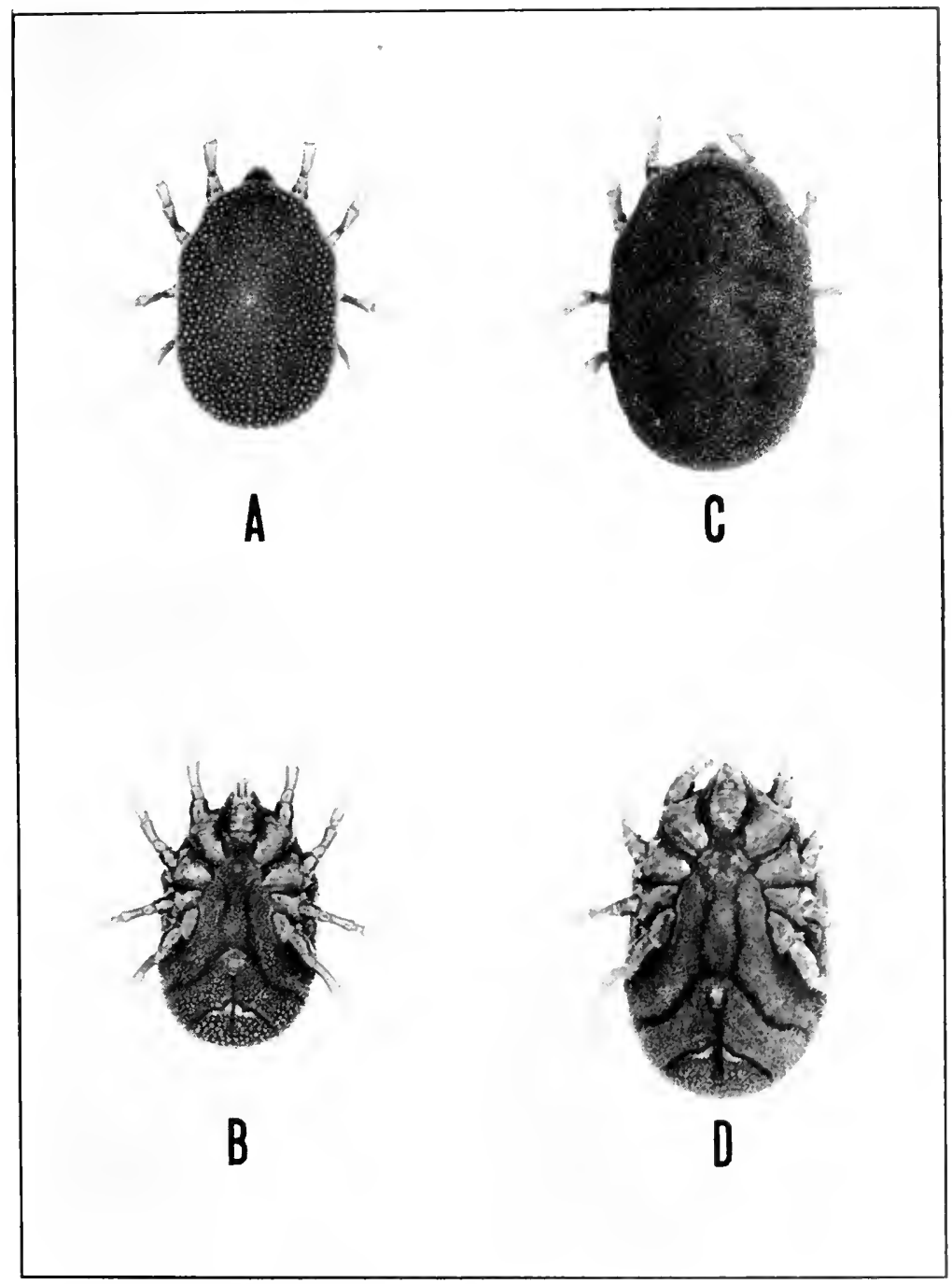

Fig. 29. A. Ornithodoros turicata (Dugès), fourth nymphal stage, dorsal view. B, Same, ventral view. C, O. parkeri Cooley, fourth nymphal stage, dorsal view. D. Same, ventral view. 
The two species occupy overlapping ranges (see maps). It should be realized too, that in the area where both species occur and use the same animals as hosts there is a possibility that $O$. turicata and $O$. parkeri may have hybridized. In fact, Dr. Davis has interbred these two species in the laboratory (unpublished) and certain field specimens from the overlapping area show intergraded characters.

Comparative studies have shown that other than the more definite characters which separate $O$. turicata and $O$. parkeri both as adults and nymphs, such as hypostome and mammillae, there is little of value for separating the two species. Both show the dorsal humps on the tarsi absent in N. 1, faint in N. 2, and progressively more prominent in the successive stages to the adults. $O$. savigny and eremicus show these humps to be very well developed in the early nymphal stages.

Photographs of all stages of both species are shown in figures 26, 27, 28, and 29, and pen drawings of the hypostomes and legs of all stages in figures

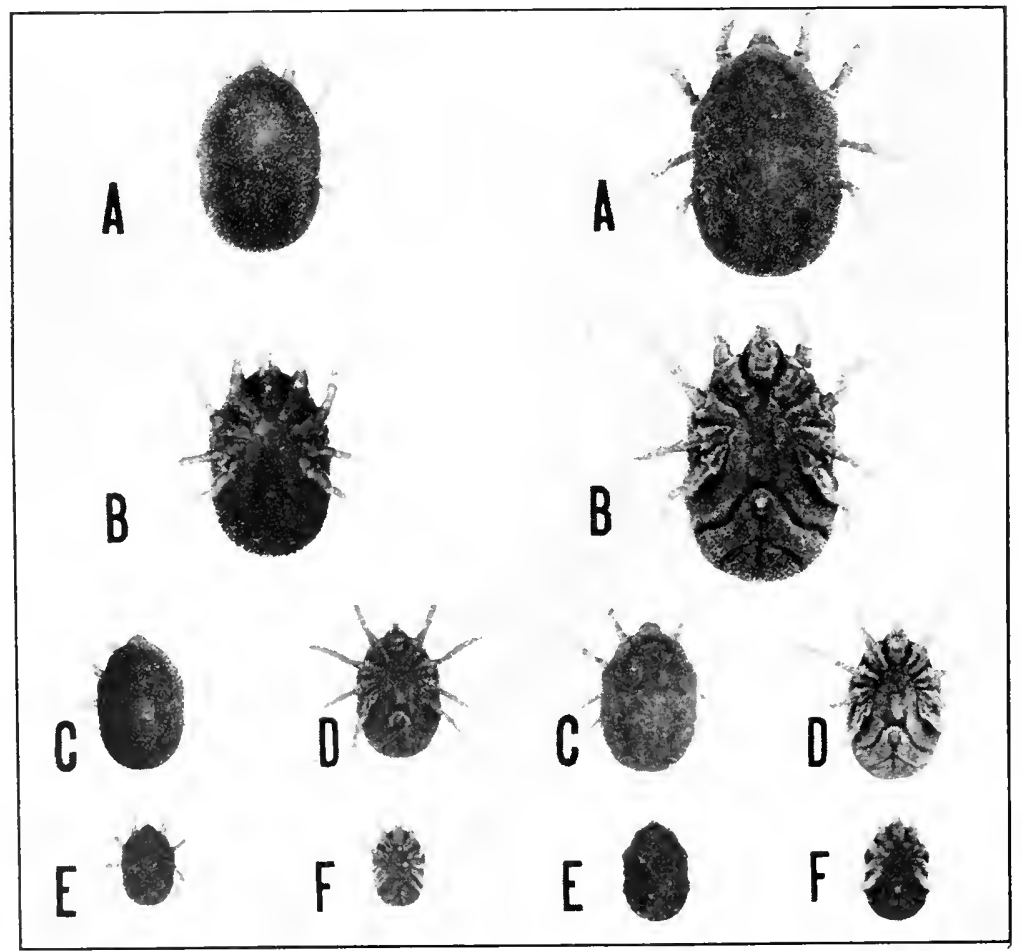

Fig. 30. Ornithodoros turicata (Dugès) on the left, O. parkeri on the right. $A$. Third stage nymph, dorsal view. B. Same, ventral view. C. Second stage nymph, dorsal view. D. Same, ventral view. E. First nymphal stage, dorsal view. F. Same, ventral view. 
$30,31,32$, and 33 . The drawings of the hypostomes show clearly that these characters are dependable even in the early nymphal stages. The same is true of all other species of Ornithodoros so far as we have studied them.
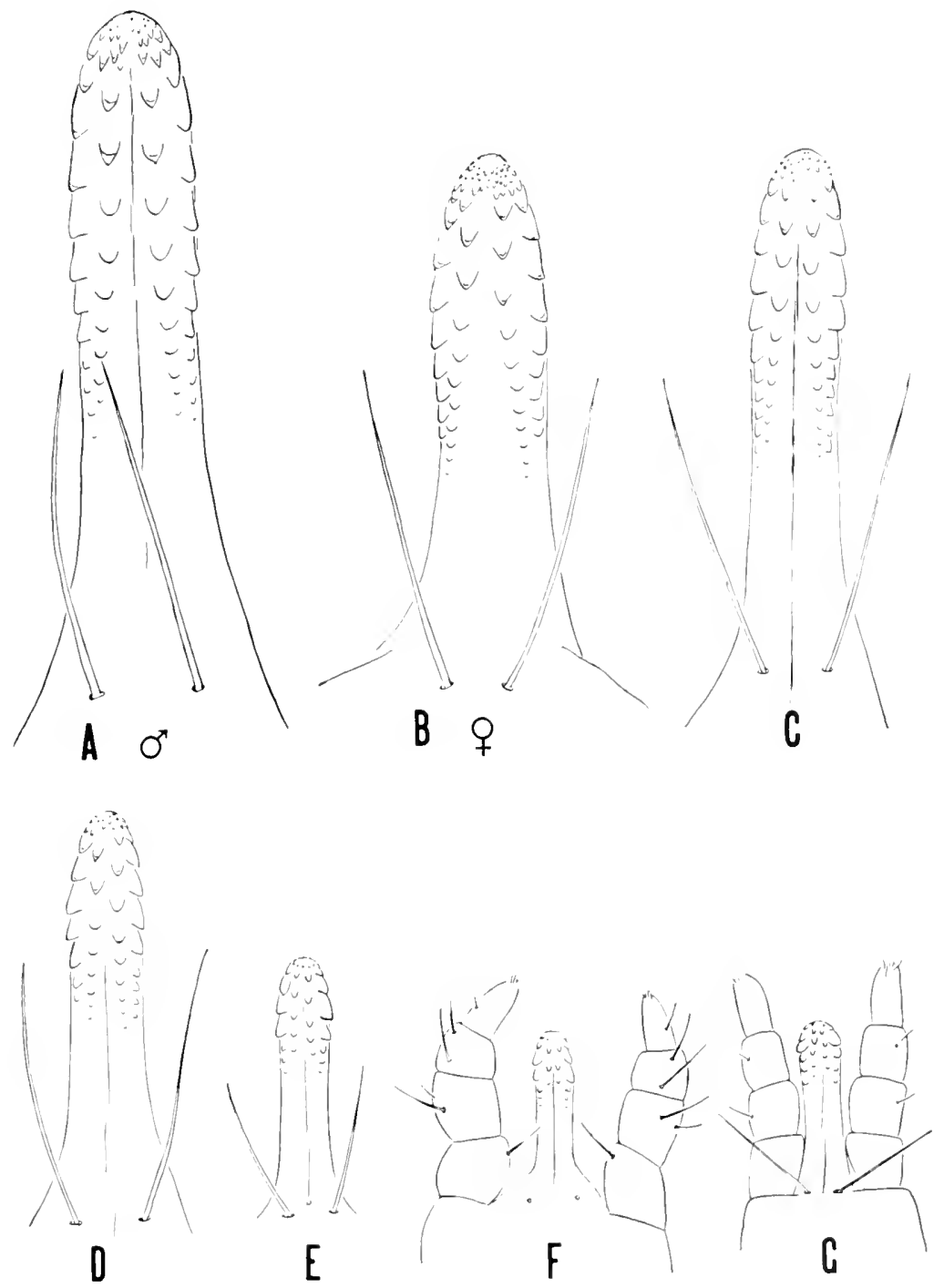

Fig. 31. Ornithodoros turicala (Dugès). A. Hypostome of female. B, Hypostome of male. C. Hypostome of fourth stage nymph. D. Hypostome of third stage nymph. E. Hypostome of second stage nymph. F, Hypostome and palpi of first stage nymph. G. Hypostome and palpi of larva. 
Ornithodoros yumatensis Cooley and Kohls, 1941

Plate 7. Figs. 35 and 36

1941b. Ornithodoros yumatensis Cooley and Kohls, original description, pp. 592-594, with figures.

Sexes mildly dissmilar; nymphs and adults similar.

FEMALE

Body.--Oval, sides nearly parallel, bluntly pointed in front and broadly
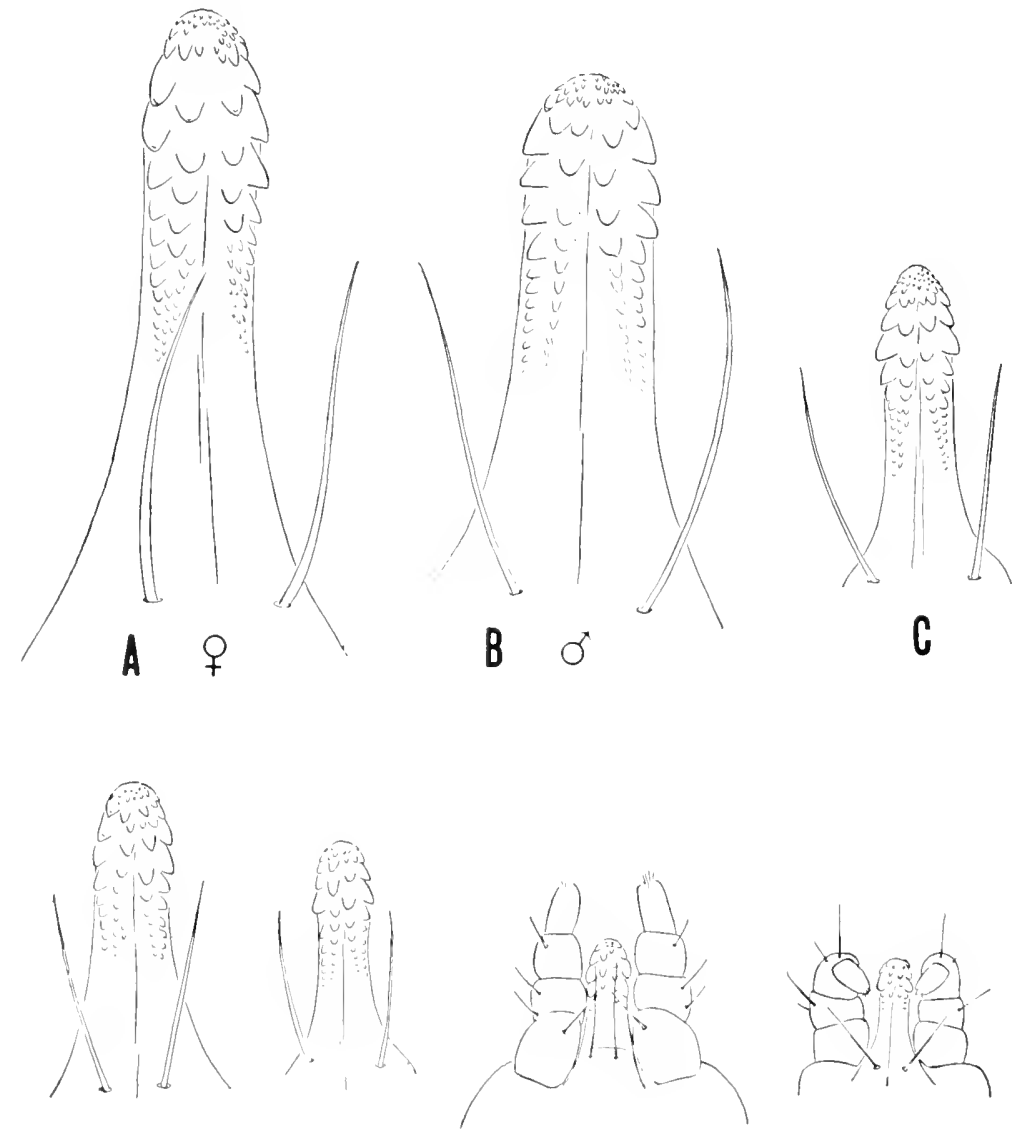

0

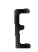

F

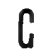

Fig. 32. Omithodoros parkeri Cooley. A. Hypostome of female. B. Hypostome of male. C, Ilypostome of fourth stage nymph. D. Hypostome of third stage nymph. E. Hypostome of second stage nymph. F, Hypostome and palpi of first stage nymph. G. Hypostome and palpi of İarva. 
rounded behind. Size of holotype female, $4.75 \times 3.25$. Size of allotype male, $3.8 \times 2.25$. Range of sizes of females, $5.6 \times 3.5$ to $4.1 \times 2.25$. Range of sizes of males, $4.8 \times 2.40$ to $3.6 \times 2.0$.

Mammillae.--Irregular in shape, moderate in size and number and about equal in sizes in median and peripheral areas on both dorsal and ventral surfaces; close together but not crowded. Individual mammillae have irregular surfaces on top and at the sides; those on the posterior ventral area bent back-
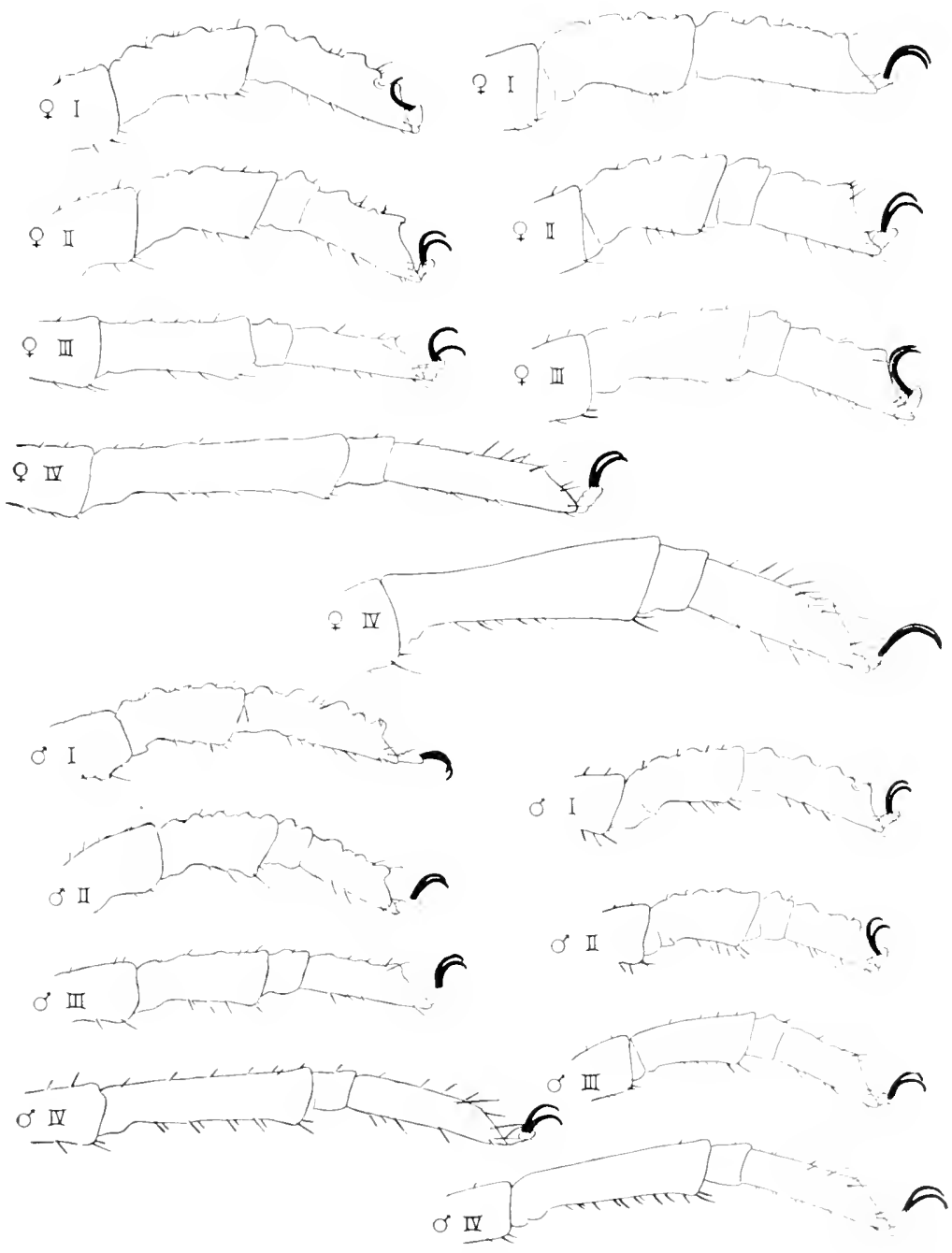

Fig. 33. Legs of adults. Ornithodoros turicata (Dugès) on the left and O. parkeri Cooley on the right. Leg numbers indicated by Roman numerals. 
ward mildly suggesting reptilian scales. Short hairs, few in number, present mainly on the posterior and lateral marginal areas.

Discs.-Moderate in size, superficial or mildly depressed, not conspicuous. On the venter present in lineal arrangement in the peranal, transverse postanal and median postanal grooves.

Legs.--Long and slender with their surfaces made irregular by very numerous granulations. Subapical dorsal protuberances and dorsal humps absent. Leg hairs numerous and small except on ventral and distal portions of the tarsi where they are larger. Length of female tarsus I, 1.02; metatarsus, 0.72 . Length of female tarsus IV, 1.17; metatarsus, 0.96. Length of male tarsus I, 0.66 ; metatarsus, 0.51 . Length of male tarsus IV, 0.87 ; metatarsus, 0.72 .
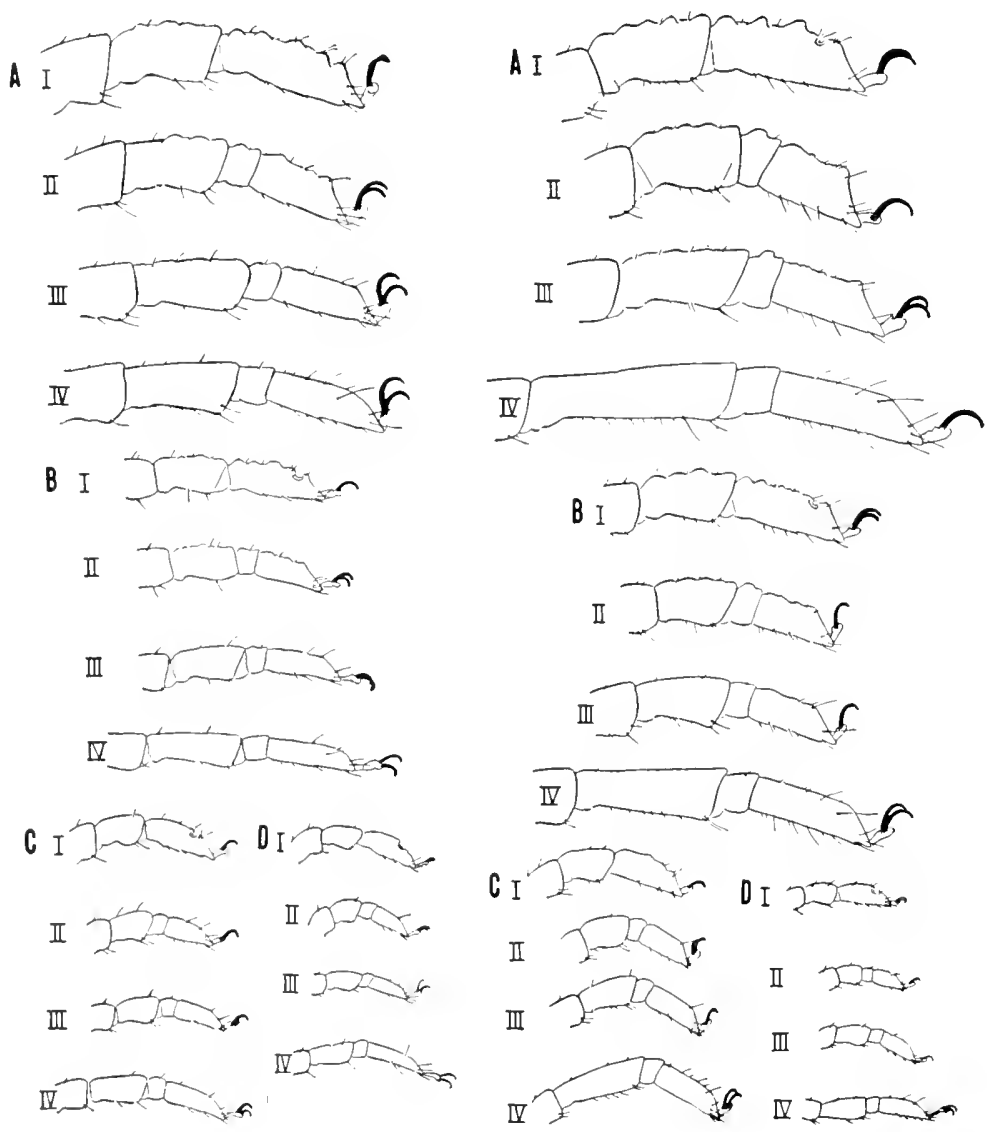

Fig. 34. Legs of nymphs, Ornithodoros turicata (Dugès) on the left, O. parkeri on the right. Leg. numbers indicated by Roman numerals. A, Fourth nymphal stage. B. Third nymphal stage. C. Second nymphal stage. D. First nymphal stage. 
Cuxae.- Coxae I and II a little separaced, all others contiguous.

Hood.--Indefinite.

Camerostome.-Indefinite.

Cheeks.-Large, about twice as long as wide, attached along one side, and with a very few short hairs.

Capitulum.-The capitulum is protrusile and when extended reaches beyond the anterior end of the body. When so extended the basis capituli is seen to be twice as long as wide and its length is about equal to the length of the soft membrane ("neck") which unites the capitulum with the body. Living specimens may show the capitulum either extended or withdrawn. Specimens preserved in alcohol usually have the capitulum withdrawn and give little evidence of extensibility. Basis capituli with the surface granulated as on the legs, and faintly wrinkled. Numerous hairs present on the sides on the anterior portion (not visible when the capitulum is withdrawn). Palpal article 1 swollen and with its surface granulated. Tip of hypostome reaching to articulation between articles 3 and 4 .

Hypostome. - With the sides subparallel, apex mildly notched. Denticles small or faint; larger in the lateral files and progressively smaller toward the median line. Length, female, 0.18 to 0.20 ; male, 0.16 to 0.17 .

Folds.-Coxal and supracoxal folds present, the latter reaching to the cheeks.

Grooves.-Preanal, transverse postanal, and median postanal grooves present. Dorso-ventral groove absent.

Sexual opening.-At the level of the interval between coxae I and II.

Eyes.-Absent.

Anus.--Large, in an elliptical pattern.

\section{MALE}

The male differs from the female principally in the hypostome. The male hypostome is smaller and has relatively smaller denticles.

\section{LARVA}

Large, sub oval. Length (including mouth parts), 1.20, width, 0.50. Dorsal plate, oval. Legs long, slender. Capitulum terminal, large, its length equal to about half the entire length of the larva. Basis capituli large, wider behind, visible from above. Hyposteme slender, long, pointed apically, and on a conical base which is about as long as the hypostome. Denticles apically, $3 / 3$, then $2 / 2$; those of the lateral (marginal) files large, those of the median files small. Length of hypostome, 0.24.

This species is rather closely related to O. brodyi Matheson but may be separated by the dentition of the adult hypostome and the character of the mammillae. 


\section{HOSTS AND DISTRIBUTION}

Known only from bats or bat retreats.

California.-17856, from rock crevices in mine tunnel, May 20, 1940, 15 miles northeast Yuma, Arizona, 1 male, 2 nymphs.

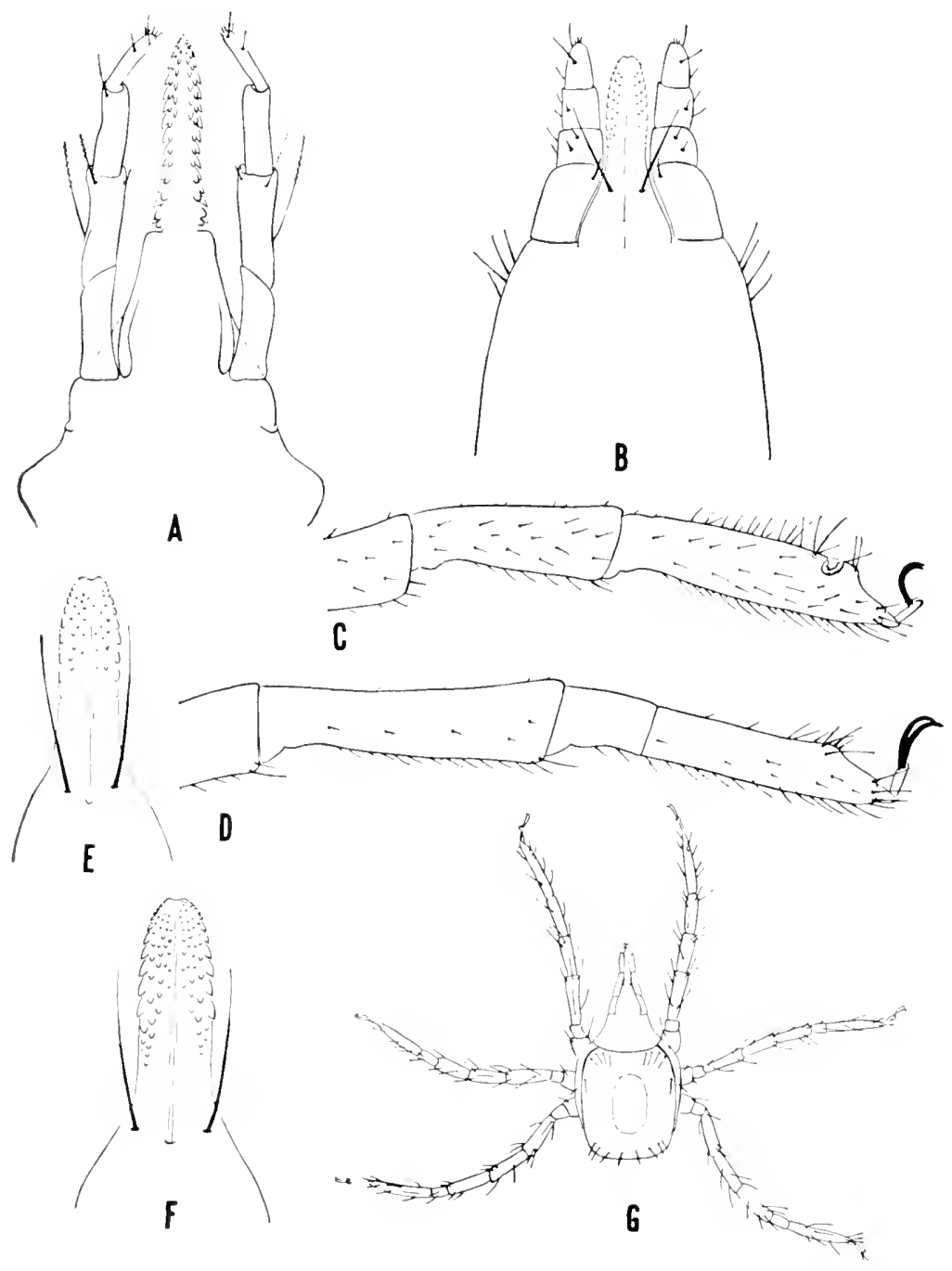

Fig. 35. Ornithodoros yumatensis Cooley and Kohls. A. Capitulum of larva, ventral view. B, Capitulum of male, ventral view. C, Leg I of adult. D. Leg IV of adult. E. Hypostome of male. F, Hypostome of female. G. Larva, dorsal view. 
Arizona.-17881, from rock crevices in Crystal Cave, June 2, 1940, 10 miles southeast Winkelman, numerous adults and nymphs, few larvae; 17882 from Myotis velifer velifer, in Crystal Cave, June 2, 1940, 10 miles southeast Winkelman, 6 adults and nymphs; 17046 from Myotis velifer, Picacho Peak near Picacho, July 23, 1940, 1 larva (R. A. Flock).

Texas.-17252, from rock crevices in Brehmer bat cave, September 11, 1940, near New Braunfels, 32 adults and nymphs.

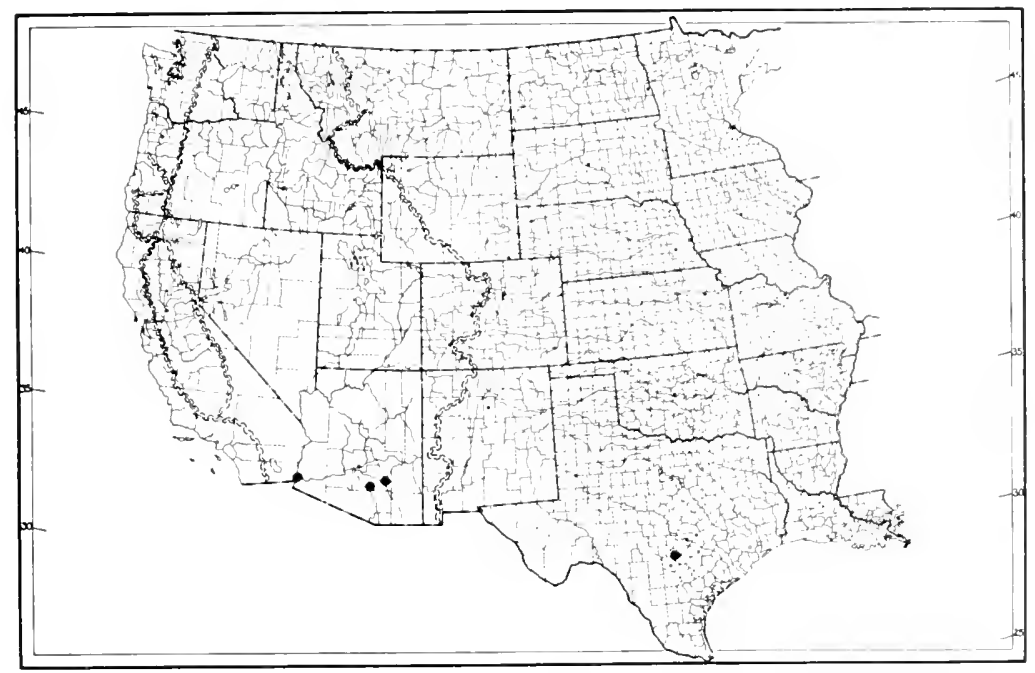

Fig. 36. Distribution of Ornithodoros vumatensis Cooley and Kohls. 


\section{Ornithodoros BRodyi Matheson, 1935}

Plate 7, Fig. 37

1935. Ornithodoros brodyi Matheson, original description, pp. 351-352, with figures.

Sexes similar; nymphs and adults similar.

\section{ADULT}

Body.-Oval, sides nearly parallel, a little pointed anteriorly and rounded behind; hood visible from above. Length, 6.0; width, 4.0 (Matheson).

Mammillae.-Moderate in size and number and about equal in size in the median and peripheral areas; by their shape and crowded arrangement resembling the scales of reptiles. Individual mammillae varying in size, flattened, smooth and shining; some with a few punctations in the flattered surface. A few hairs present arising from the integument between the mammillae. Mammillae smaller or absent on the supracoxal folds and in the intercoxal area; in other ventral areas, as large as on the dorsum.

Discs.-Moderate in size, superficial.

Legs.-Long and moderate in size, micromammillated and with numerous fine hairs. Subapical dorsal protuberance moderate on tarsus I, absent on all others; dorsal humps absent on all legs. Length of tarsus I, 1.02; metatarsus, c.78. Length of tarsus IV, 1.2; metatarsus, 1.14.

Coxae.-Small, with the surfaces granulated. Coxae I and II separated; all others contiguous.

Hood.-Well developed, a little depressed below the anterior extension of the dorsal body wall.

Cheeks.-Elongated, sides subparallel, reaching anteriorly beyond the line of attachment for about one-third the length.

Camerostome.-Well developed and together with the cheeks affording some protection for the mouth parts.

Capitulum.- Basis wider thian long, with the surface irregular and micromammillated. Palpi moderate in length; article 1 micromammillated and with a knife-edge flange extending over the base of the hypostome, 2, 3, and 4 free, smooth.

Hypostome.-Length, 0.125. Denticles in a $\% / 2$ patterr with the laterals larger and greater in number than those in the median files; corona large with numerous fine denticles, truncate or faintly notched.

Folds.-Coxal and supracoxal folds distinct.

Grooves.-Dorso-ventral groove absent. Preanal, transverse postanal, and median postanal grooves present, the latter extending only from the anus to the transverse postanal groove.

Sexual opening.-Placed between coxae I.

Eyes.-Absent.

Anus.-In an elliptical pattern.

Our redescriptions are from specimens kindly sent by Dr. Matheson. Descriptions of nymph and larva are quoted from Matheson (1935). 


\section{Nymph}

From the material before me there appears to be two nymphal stages. Fully gorged nymph (last nymphal stage) $4.5 \mathrm{~mm}$. in length by $2 \mathrm{~mm}$. in width. In general shape nymph closely resembles adult with no marked difference except size and absence of genital opening. Capitulum practically identical with that of adult except that at base of hypostome there are two very long spines that occupy the same position as the two short ones do in the adult.

\section{Larva}

Fully gorged larva practically spherical in shape, the long legs and capitulum projecting far beyond margins of body; length, exclusive of capitulum $2.3 \mathrm{~mm}$.; capitulum $0.64 \mathrm{~mm}$; ; extreme width $2.3 \mathrm{~mm}$. Hypostome of larva practically identical with that of O. azteci (Fig. 4, b). Integument of partially gorged larva with beautiful arrangement of fine parallel lines running in various directions on body.

\section{HOSTS AND DISTRIBUTION}

Types are in the collections of the Department of Entomology, Cornell University, Ithaca, N. Y.

Matheson (1935) states that the larvae of this species were taken on the short-tailed bat, Hemiderma perspicillatum aztecum (Saussure), March 30, 1931, by Mr. A. L. Brody and that the same collector found nymphs and adults in crevices of the walls and ceilings of the Chilibrillo Caves, Panama. Eggs were also found in association with the adults. No further collections of the species have been reported.
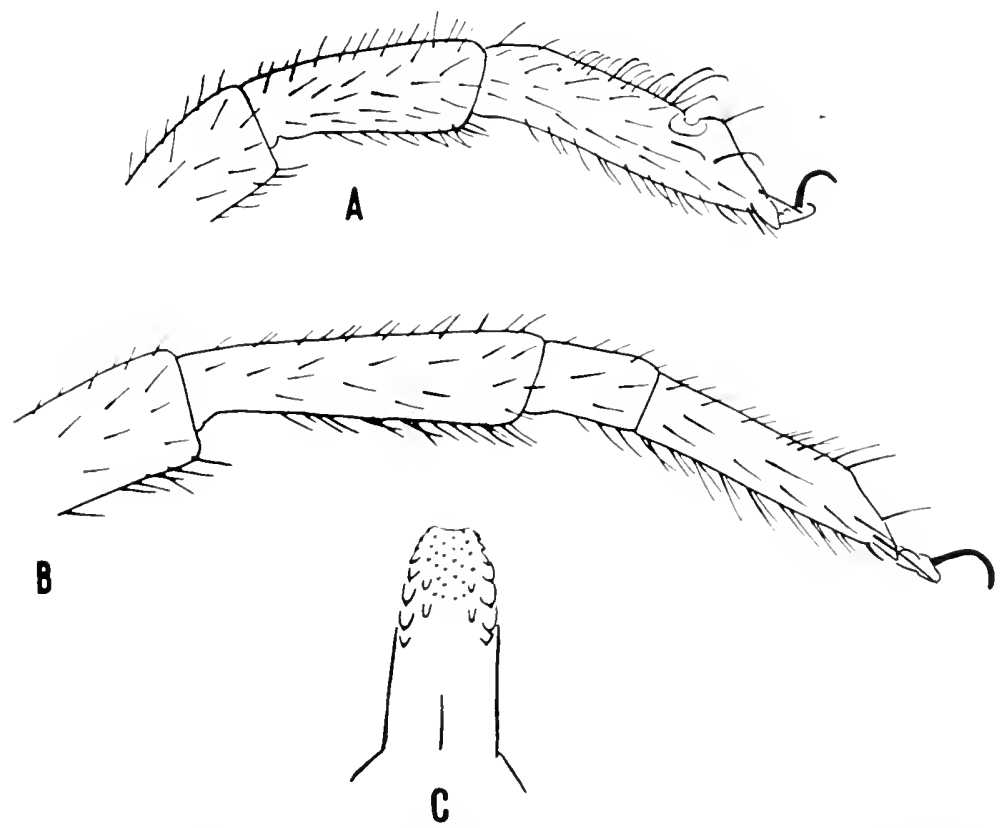

Fig. 37. Ornithodoros brodyi Matheson. A, Leg I of adult. B. Leg IV of adult. C. Hypostome of adult. 
Ornithodoros talaje (Guérin-Méneville), 1849

Plate 8 , Figs. 38 and 39

1849. Argas talaje Guèrin-Méneville, original description, pp. 342-343, with figures.

1885. Argas talaje Guérin-Méneville: Mégnin, redescribed, pp. $460-463$; 466, 470-472. with figures.

1896. Ornithodoros talaje (Guérin-Méneville): Neumann, redescribed, pp. 34-37.

1901. Ornithodoros talaje (Guérin-Méneville) : Neumann, made O. rudis Karsch 1880. a synonym, p. 259.

1907. Alectorobius talaje (Guérin-Méneville): Pocock, p. 189. New genus described, O. talaje type species.

1908. Ornithodoros talaje (Guérin): Banks, redescribed, p. 19, with figures.

1908. Ornithodoros talaje (Guérin-Méneville): Nuttall, Warburton, Cooper and Robinson, redescribed, pp. 59-61, with figures.

1911. Ornithodoros talaje talaje (Guér.): Neumann, redescribed, pp. 125-126, with figures.

1930. Ornithodoros lalaje (Guérin-Méneville): Hoffman, redescribed, pp. 161-163. with figures.

1936. Ornithodoros talaje (Guérin-Méneville): Brumpt, pp. 1197-1199.

Sexes similar; nymphs and adults similar.

\section{ADULT}

Body.-Oval, a little pointed anteriorly, the curve of the posterior border slightly flattened, sides nearly parallel. Margins more incurved opposite legs I, II, and III than in most species. Size of female from $7.25 \times 4.60$ to $4.20 \times$ 2.34. Size of male, $5.8 \times 3.40$ to $3.36 \times 1.75$.

Mammillae.-Large, close but not crowded, conical, with radial ridges on the sides reaching nearly to the tips; each mammillae witl one to three subapical excavations or pits. Mammillae larger at the sides and largest on the posterior border; small on the venter and indefinite on the supracoxal folds. Hairs absent on dorsal and ventral surfaces and even on the hood.

Discs.-Large, distinct, in large depressed areas which occupy much of the median area of the dorsum. Discs on the venter present in lineal arrangement in the preanal, transverse postanal, and the median postanal grooves and in three depressions posterior to the transverse postanal groove.

Legs.-Small, moderate in length, with the surface micromammillated Hairs small. Tarsus I with a mild subapical dorsal protuberance; absent on all other tarsi. Dorsal humps on the tarsi absent. Length of tarsus I, 0.72; metatarsus, 0.54. Length of tarsus IV, 0.87; metatarsus, 0645 .

Coxae.-Coxae I and II well separated; all other contiguous. Surfaces micromammillated and with large excrescences.

Hood--Small, reduced to a tongue-shaped flap which is bent downward and in contact with the cheeks with which it forms an enclosure covering the mouth parts. In lateral profile the hood and the anterio: extension of the dorsal body wall form a distinct notch. 
Camerostome.--Indefinite, obscured by the large cheeks.

Cheeks.-Oval, large (relatively larger than in any other known species) and when closed often covering the mouth parts. Surface irregular.

Capitulum. - Basis capituli wider than long with irregular transverse
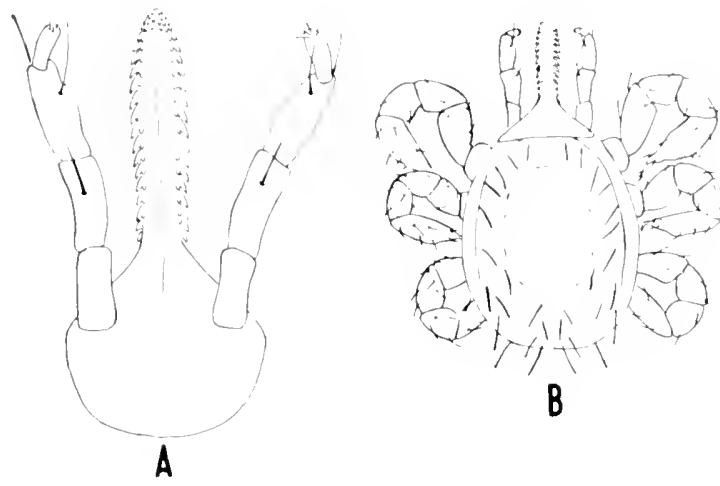

B
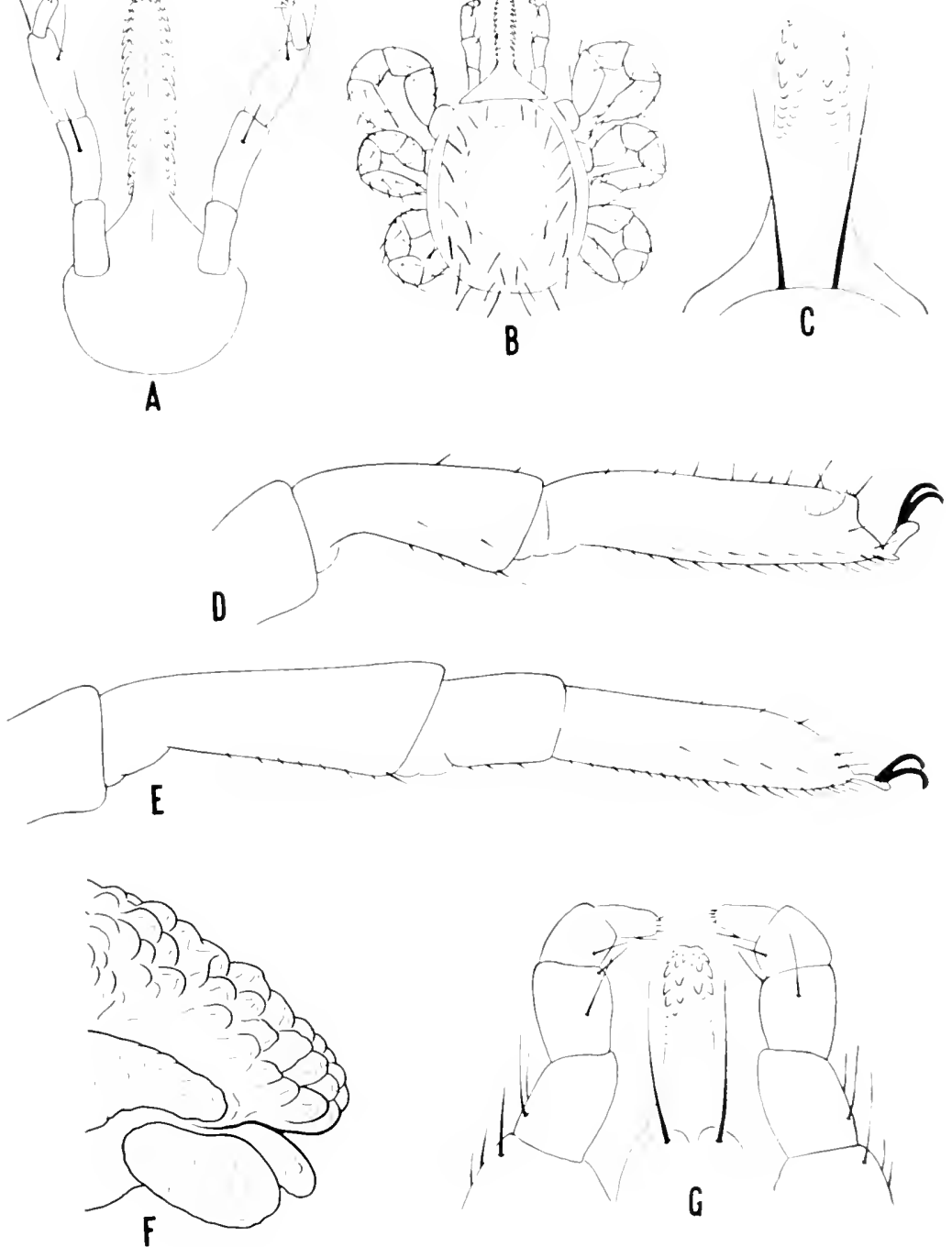

Fig. 38. Ornithodoros talaje (Guérin-Méneville). A, Capitulum of larva, ventral view. B. Larva, dorsal view. C, I Iypostome of adult. D, Leg I of adult. E, Leg IV of adult. F. Lateral view of anterior end of body. G. Hypostome and palpi of second stage nymph. 
wrinkles and micromammillae. Palpi moderate in size; article 1 micromammillated.

Hypostome.-Short and small, sides nearly parallel, notched apically. Denticles arranged $\% / 2$ with about four large ones in each file, and with those in the median and lateral files about equal in size. Length about 0.245.

Folds.-Coxal and supracoxal folds present, the latter extending forward tc near the hood.

Grooves.-Dorso-ventral groove absent. Preanal, transverse postanal, and median postanal grooves present, the latter terminating at the transverse postaral groove.

Sexual opening.-Between coxae I.

Eyes.-Absent.

Anus.-In an oval frame.

LARVA

Unfed larva sub-oval in shape; basis capituli triangular in dorsal view. Palpi very long, slender, and in life appressed against the hypostome. Length of body, including capitulum, 0.66. Length of capitulum (in ventral view), 0.33 .

Hypostome.-Very long and slender; denticles in a $2 / 2$ arrangement with the marginal denticles much larger than those in the next file which are not easily seen, even when mounted in balsam. Length about 0.21 .

$O$. talaje is rather closely related to $O$. kelleyi and $O$. concanensis, two bat-infesting species. From kelleyi it may be distinguished in the adult and late nymphal stages by a notch just above the hood when viewed in lateral profile. In these stages, concanensis is smaller, proportionately longer, more rounded on the posterior margin, the marginal projection opposite coxa II less pronounced, the hood shorter, and the depressed areas occupied by the discs less extensive. The larvae of concanensis are unknown. The latvae of talaje have the hypostone broad, with sides rounded, while in kelleyi the hypostome is long and narrow and the sides are nearly straight. Further, in talaje the base of the hypostome (from the insertion of the palpi to the denticles) is shorter than in kelleyi.

\section{DISTRIBUTION}

The range of $O$. talaje extends from California and Kansas to Argentina. The types were from Guatemala.

In the United States it is known from California, Arizona, Nevada, Kansas, Texas, and Florida. Hoffman (1930) stated that in Mexico this tick is a native of the hot country and that it is found on the Peninsula of Yucatan, Campeche, Tabasco, Chiapas, the Isthmus and State of Vera Cruz, extending along the Gulf Coast toward Texas; on the Pacific Coast the species 
thus far has not been found except to the north in the region of the Isthmus. According to Dunn (1933) the species apparently is widely distributed in Panama.

\section{HOSTS}

This species has been collected from a wide variety of hosts. In the United States it has been found only on wild rodents or in association with them.

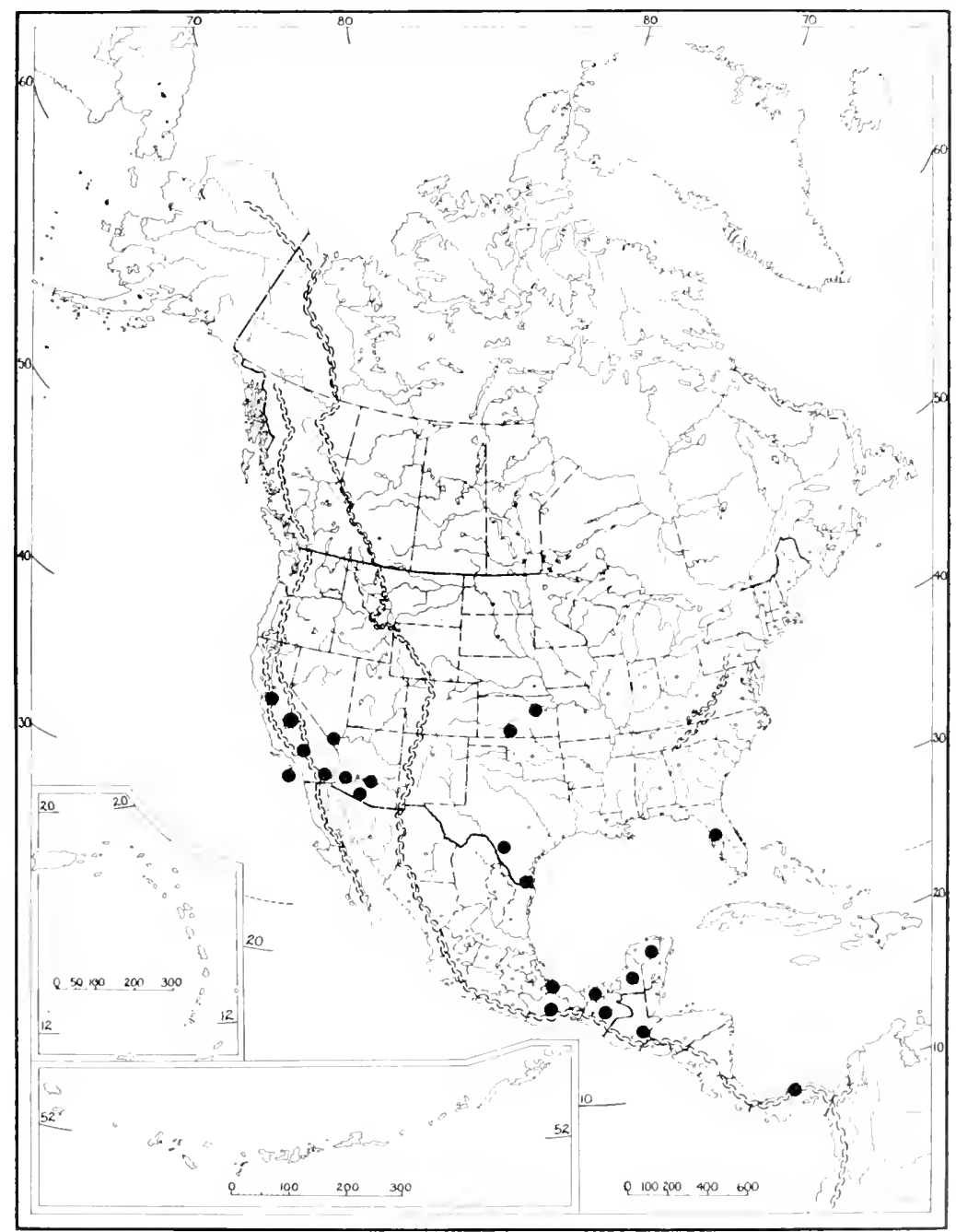

Fig. 39. Distribution of Ornithodoros talaje (Guérin-Méneville). 


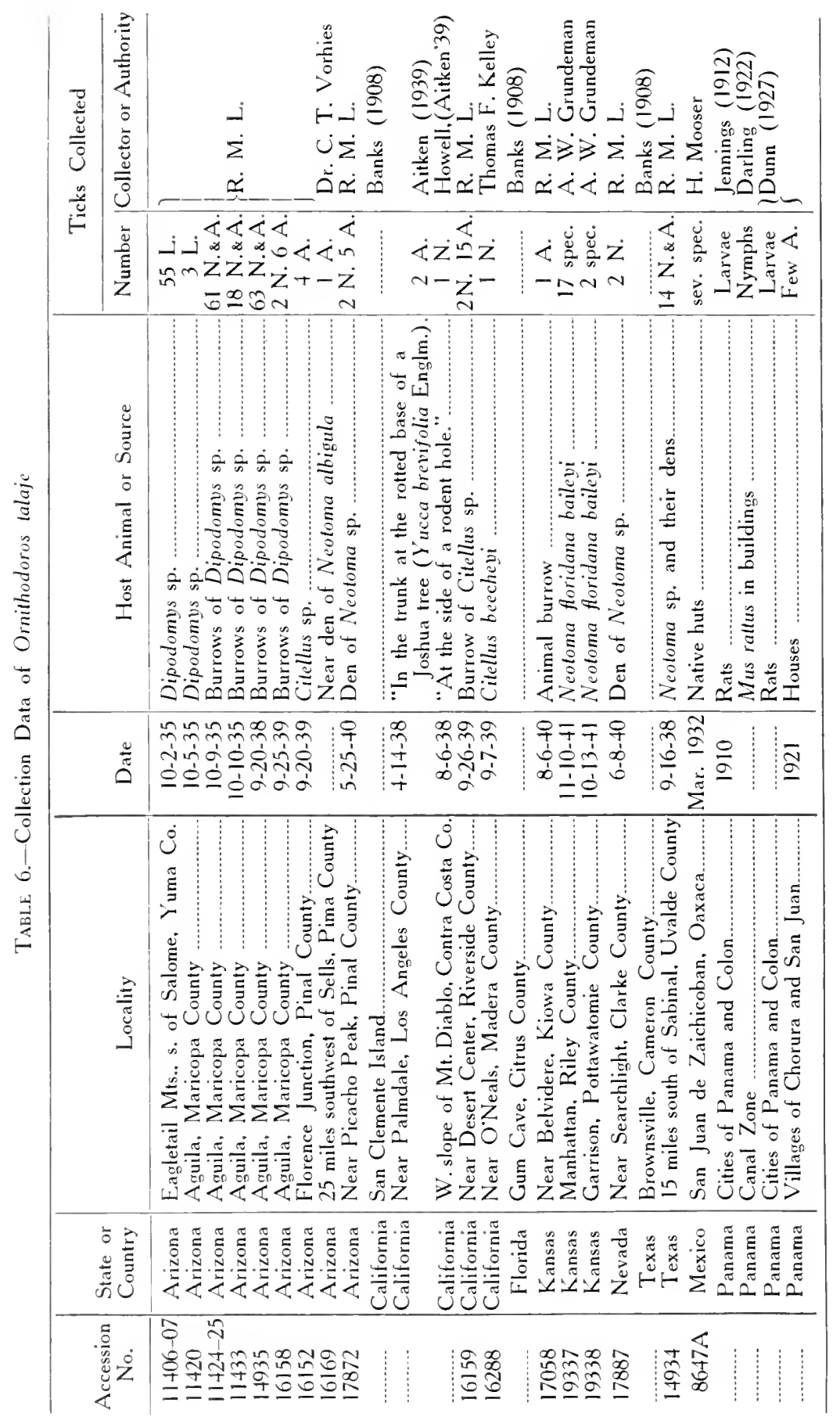




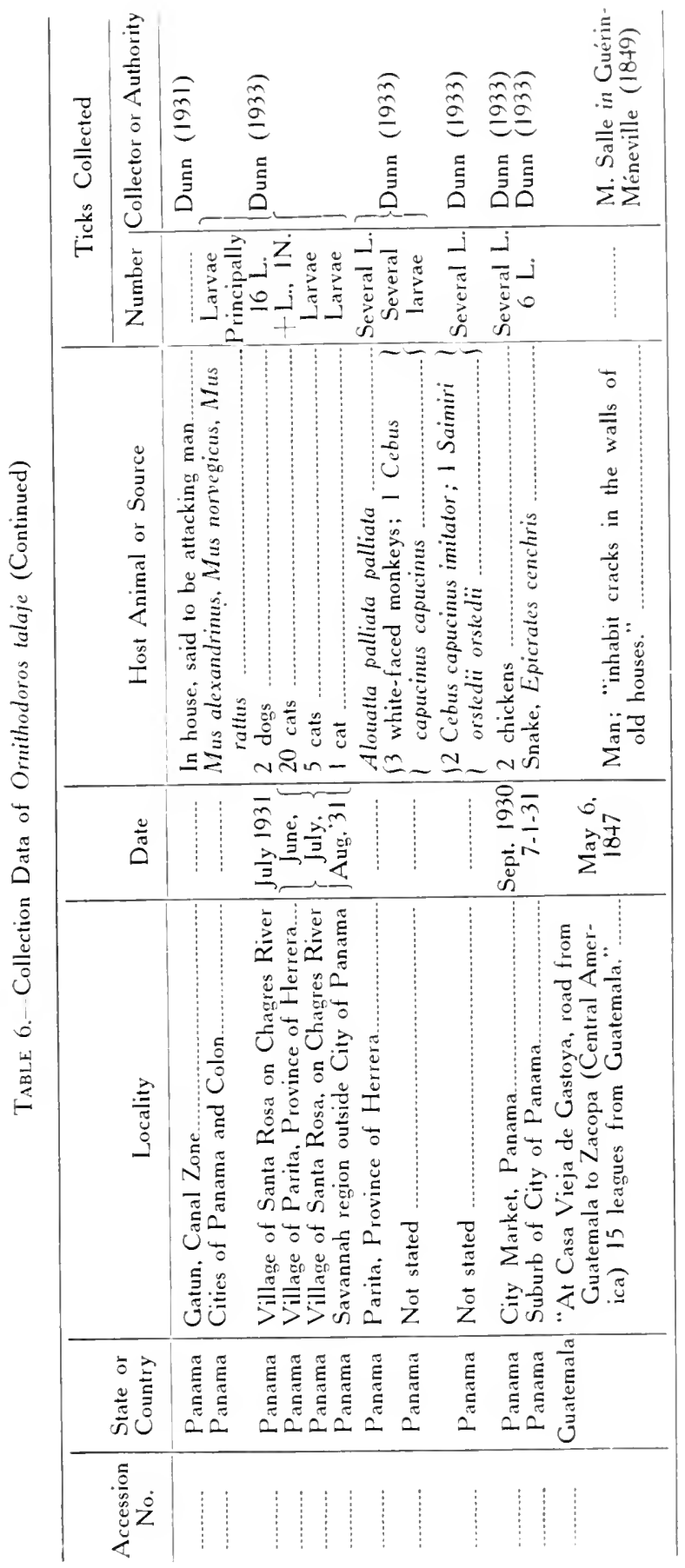


The rodents concerned were Dipodomys sp., Citellus sp., and Neotoma sp., including $N$. albigula and $N$. floridana baileyi. While reported from houses in Minnesota (Riley, 1935), Wisconsin (Herrick, 1935), and New York (Matheson, 1931) the species actually concerned was O. kelleyi Cooley and Kohls 1941.

In Mexico, Hoffman (1930) stated that the natural hosts are small, wild rodents and probably other mammals which inhabit holes and subterranean nests, and doubtless with the intervention of rats it is found in the houses of man, whom it attacks with preference when once establıshed in the habitation. As a true domestic parasite it has been observed only in the south of the Fepublic and never north of the region of San Andres Tuxtla. In the northern part of the State of Vera Cruz and in Tamaulipas it is quite rare and is found almost exclusively on wild animals (rodents). He stated that the bites were painful but not to the extent of those by $O$. turicata.

Among the hosts in Panama listed by Dunn (1933) were Mus alexandrinus, $M$. norvegicus, $M$. rattus, several species of monkeys, dogs, cats, chickens, and a snake, Epicrates cenchris. The ticks found were principally larvae. Dunn stated that adults were seldom observed in dwellings and he believed that they rarely attacked man.

Ornithodoros concanensis Cooley and Kohls, 1941

Plate 8 , Fig. 40

1941 (c). Ornithodoros concanensis Cooley and Kohls, original description, pp. 910-911, with figures.

Sexes similar; nymphs and adults similar.

\section{ADULTS}

Body.-Sub-oval, sides nearly parallel, anterior margin bluntly pointed, posterior margin rounded. Marginal projection opposite coxa II moderate. Size of female, $5.5 \times 3.0$; male, $4.20 \times 2.40$.

Mammillae.-Large, clcse but not crowded; sides and tops with a mixed pattern of ridges with but little appearance of radiation; the majority have one or two circular or crescentic pits on top, with a short, indistinct hair present in some of the pits especially in the peripheral areas. Sizes about equal in lateral and median areas of dorsum, slightly larger on posterior margin; on the venter somewhat smaller than those on the dorsum, but larger on the posterior margin; absent on supracoxal folds.

Discs.- Those on the dorsum depressed and with edges elevated. Venter with the discs in lineal arrangement in the preanal and median postanal grooves; present also in three depressions caudad of the transverse postanal groove. 
Legs.-Moderate in length and in diameter; surfaces micromammillated. Tarsus I with a mild subapical dorsal protuberance; absent on all others. Dorsal humps absent on all tarsi. Length of tarsus I, 0.6; metatarsus, 0.45; length of tarsus IV, 0.72; metatarsus, 0.6.

Coxae.-Coxae I and II well separated; all others contiguous. Surfaces micromammillated and also with mild excrescences.

Hood-Limited to a short, apical elevation which is separated from the anterior extension of the dorsal body wall by a depressed line.

Cheeks. - Oval, with the anterior end wider and free; attached by the side of the narrower portion.
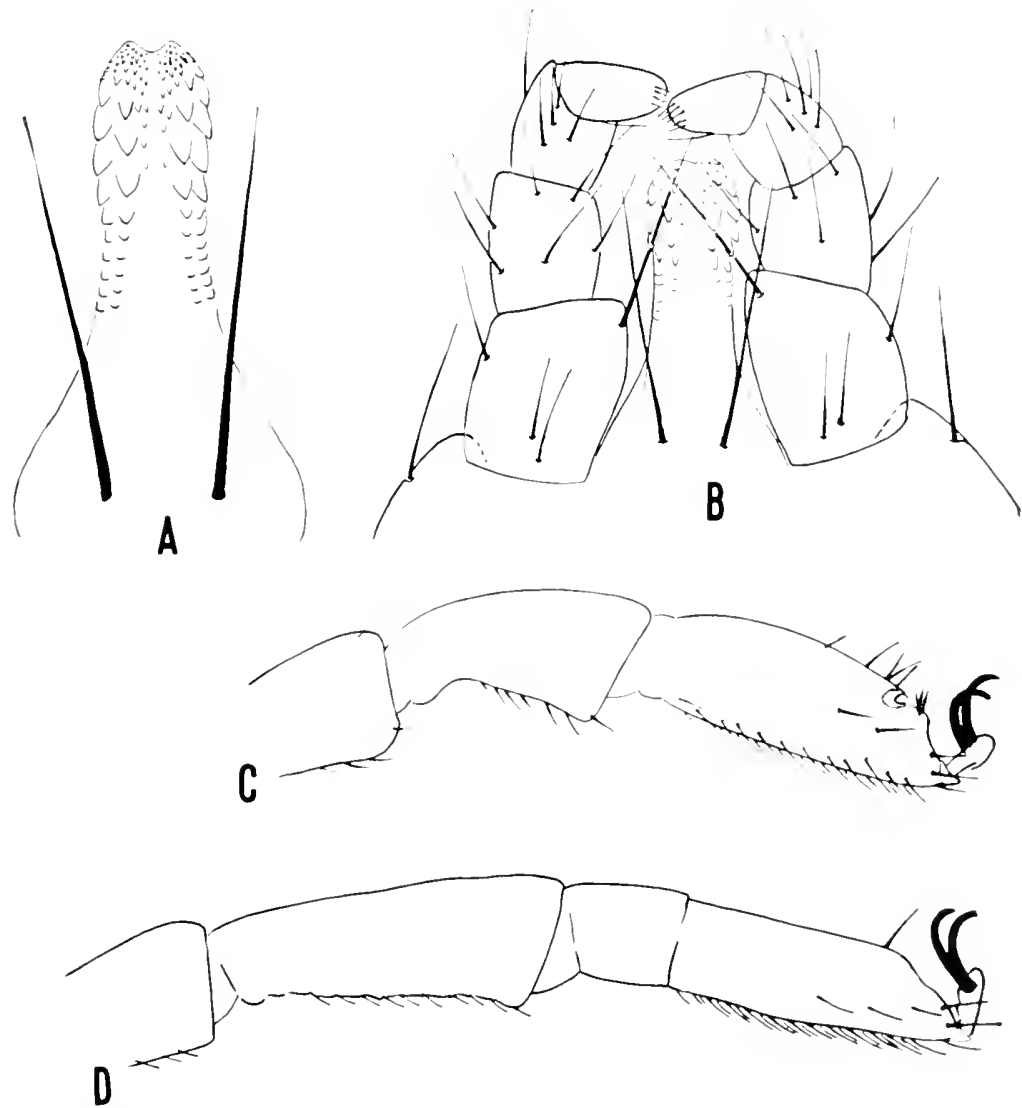

Fig. 40. Ornithodoros concanensis Cooley and Kohls. A, Hypostome of adult. B, Hypostome and palpi of second stage nymph, ventral view. C, Leg $\mathrm{I}$ of adult. D, Leg IV of adult. 
Capitulum.-Basis capituli about as wide as long, surface with transverse wrinkles and numerous micromammillae; with a pair of fine hairs posterior to the posthypostomal hairs and a group of smaller hairs on each side behind. Article 1 of palpus micromammillated.

Hypostome. - Wider beyond the middle, moderately long, notched apically. Denticles in a $\% 2$ pattern with about four in each file and limited to the distal one-third. Length about 0.21 .

Folds.-Coxal and supracoxal folds present. Supracoxal fold reaching anteriorly to the hood.

Grooves.-Preanal, transverse postanal and median postanal grooves present, the latter terminating at the transverse postanal groove. Dorso-ventral groove absent.

Sexual opening.-Placed at the level of the intervals between coxae I and II.

Eyes.-Absent.

Anus.-In an oval frame.

This speries resembles talaje and kelleyi. From talaje it is distinguished by being smaller, proportionately longer, more rounded on the posterior margin, the marginal projection opposite coxa II less pronounced, the hood shorter, and the depressed areas occupied by the discs are more shallow and less extensive. From kelleyi it is distinguished by being proportionately shorter and having the cheeks larger, as well as by having the hypostome wider beyond the middle and the palpi having more hairs.

\section{HOSTS AND DISTRIBUTION}

This species is known from bat retreats in Arizona and Texas as follows: Arizona.-17875, from rock crevices in a bat-inhabited mine tunnel, May 25, 1940, Las Guijas, Pima County, 2 males, 1 nymph.

Texas.-17261, from guano and rock crevices in bat cave, Sept. 16, 1940, near Concan, Uvalde County, several adults and nymphs. 
Ornithonoros stageri Cooley and Kohls, 1941

$$
\text { Plate 9. Figs. } 41 \text { and } 42
$$

1941 (b). Ornithodoros stageri Cooley and Kohls, original description, pp. 589-592, with figures.

Sexes dissimilar; adults and nymphs dissimilar.

\section{FEMALE}

Body.-Oval, wider behind, approaching a point in front; tips of the palpi often visible from above. Range of sizes from $5.3 \times 3.4$ to $3.3 \times 2.4$.

Mammillae.-Relatively large, few in number, and not crowded; irregular in shape, their tops convex, smooth, often with radial ridges on their bases. A few have a single, faint pit on the top which may or may not have a short, fine hair.

Discs.-Distinct, depressed, large, mostly circular. Present also on the venter where they are in a lineal arrangement in or near the preanal, transverse postanal, and median postanal grooves.

Legs.-Moderate in length and size; surface nearly smooth, shining, with hairs moderate in number and in length. Subapical dorsal protuberances and dorsal humps absent. Length of female tarsus I, 0.66; metatarsus, 0.48. Length of female tarsus IV, 0.84; metatarsus, 0.75 . (Length of male tarsus I, 0.45; metatarsus, 0.3. Length of male tarsus IV, 0.63; metatarsus, 0.54.)

Coxae I and II a little separated; all others contiguous.

Heod.-Negligible or absent.

Camerostome.-Faintly indicated.

Cheeks.-Small, and somewhat variable in shape; usually oval and attached along one side of the broader portion. (Absent in the male.)

Capitulum.-Basis capituli about as wide as long; surface irregular with transverse wrinkles. With two or three long, barbed hairs on each side on the lateral walls a short distance from the insertion of the palpi, and a pair of hairs back of the posthypostomal hairs, which are more seprated and smaller. Palpal article 1 with its surface a little roughened and with a narrow flange projecting over the base of the hypostome. Articles 2, 3 and 4 free.

Hypostome.-Notched in both sexes, narrower in the female than in the male, with the principal denticles arranged $2 / 2$ with the four files approximately equidistant. Length in both sexes about 0.22 .

Folds.-Coxal and supracoxal folds present, the latter continuous from side to side in front.

Grooves.-Preanal, transverse postanal, and median postanal grooves fresent; dorso-ventral groove absent.

Sexual opening.-Placed at the level of the intervals between coxae I and II. 
Eyes.-Absent.

Anus.-In an elliptical pattern.

\section{MALE}

The male differs from the female as follows: The male lacks the cheeks and has the hypostome wider and the denticles smaller with the two principal files separated by two shorter files of smaller denticles on each side of the median line.

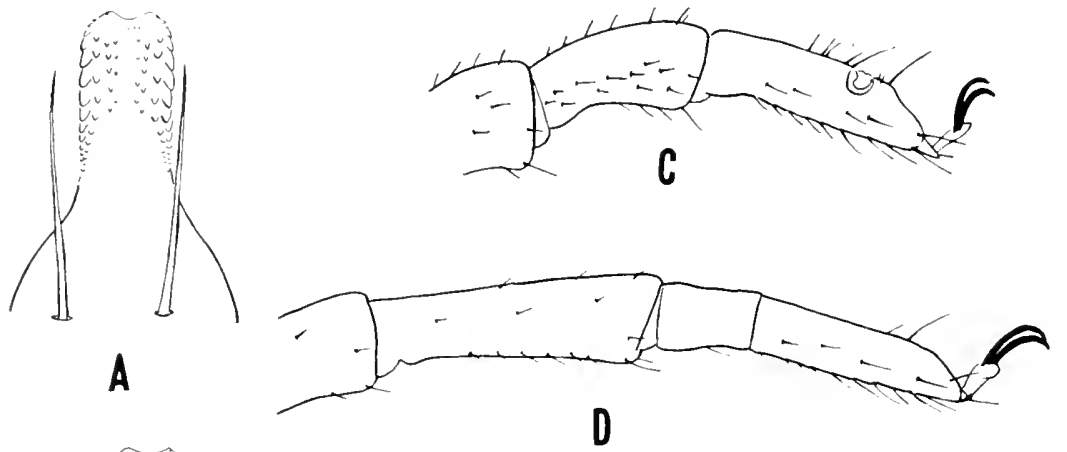

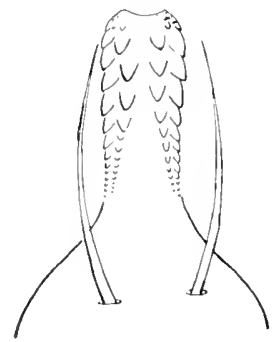

B

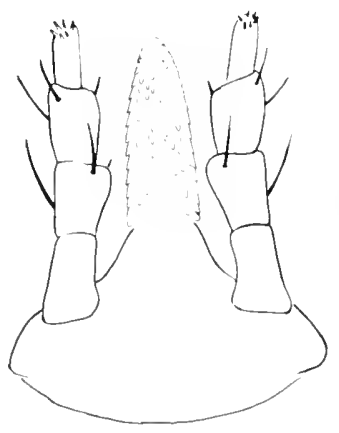

E

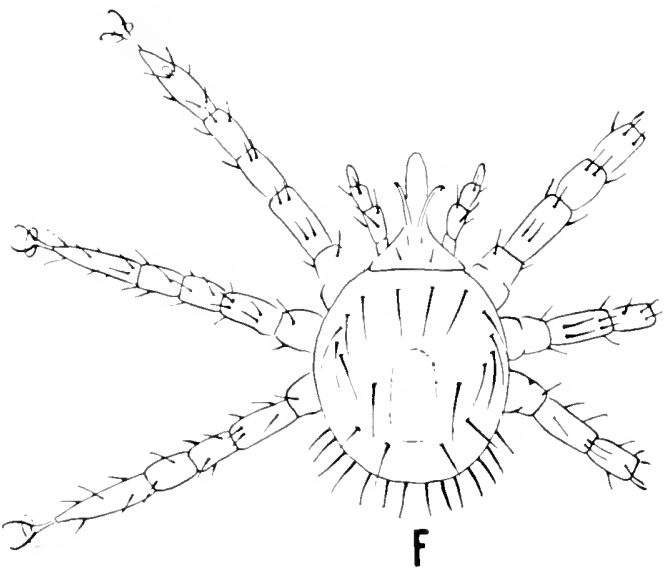

Fig. 41. Ornithodoros stageri Cooley and Kohls. A, Male hypostome. B, Female hypostome. C, Leg I of male. D, Leg IV of male. E, Capitulum of larva, ventral view. F, Larva, dorsal view. 
NYMPH

Early stage nymphs show no evidence of cheeks. Late stage nymphs show them much smaller than in the female. Smallest nymphs measure $1.35 \times 0.9$.

\section{LARVA}

Short-oval, moderate in size. Length including hypostome, 0.765; width, 0.48 . Dorsal plate shining and with faint pits (visible with reflected light in unmounted specimens). Legs about as long as the body. Capitulum terminal and visible from above; basis broad. Hypostome lacking the long conical base found in some species (see figure 35, A); sides a little converging anteriorly, bluntly pointed apically. Denticles apically $4 / 4$ then $3 / 3$, and finally $2 / 2$ at the base; those of the lateral files large, and those of the median files small. Length of hypostome about 0.2 .

\section{HOS'rS}

Ornithodoros stageri is known only from bats and bat-inhabited caves and mines. Adults have been found on Myotis velifer and Tadarida mexicana. Adults and nymphs have been found in abundance in rock crevices in bat caves and mine tunnels where bats hung and on guano deposits on the floors.

The species feeds promptly on man when it has opportunity as evidenced by Dr. Bequaert (in letter), and both of the present authors. One of us (G. M. K.) and his assistant received several bites while collecting the species in bat retreats.

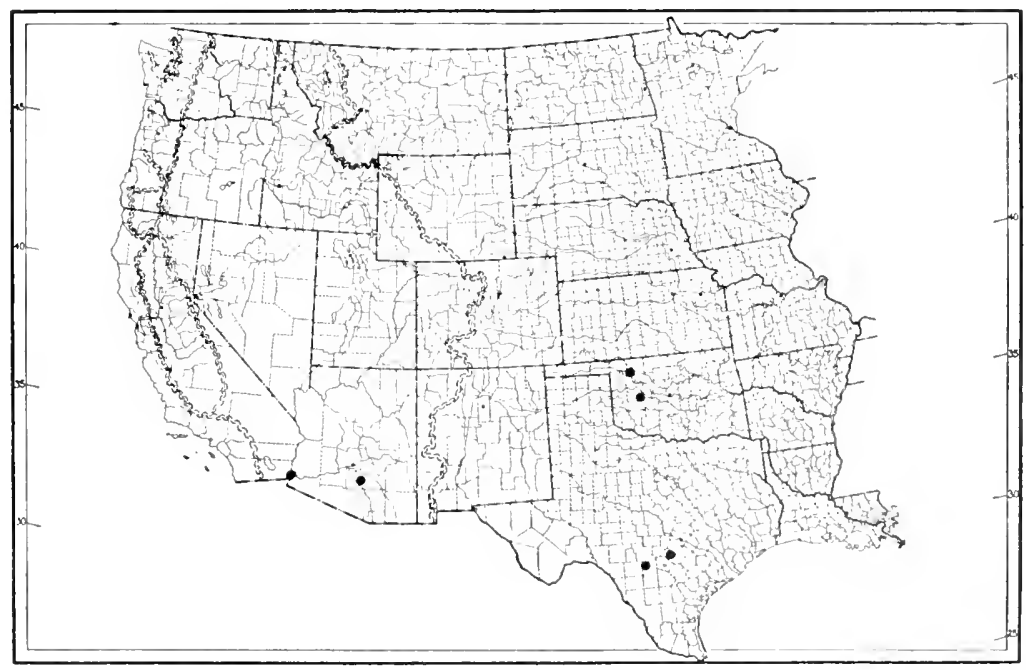

Fig. 42. Distribution of Ornithodoros stageri Cooley and Kohls. 
DISTRIBUTION

Califormia.-17859, bat guano in Senator Mine, May 21, 1940, 21 miles northeast of Yuma, Arizona, several adults and nymphs.

Arizona.-17868, rock crevices in mine tunnel, May 24, 1940, Picacho Peak near Picacho, numerous adults and nymphs; 17034, mine tunnel, July 23, 1940, Picacho Peak, near Picacho, 3 adults (R. A. Flock); 17166, Myotis velifer, July 1940, Picacho Peak, near Picacho, 1 adult (Dr. J. C. Bequaert).

Oklahoma.-17017, bat cave, July 2, 1940, near Freedom, 2 nymphs, 1 larva (Dr. D. E. Howell); 17221, bat cave, August 22, 1940, Selman Ranch, near Freedom, numerous adults and nymphs; 17393, bat cave, October 26, 1940, Weatherford, $10^{\star}$ (Dr. D. E. Howell).

Texas.-17798, Ney Cave, August 5, 1939, 20 miles north of Hondo, 1 male, 1 female, 1 nymph (Kenneth E. Stager); 17258, Ney Cave, September 14, 1940, 20 miles north of Hondo, numerous adults and nymphs; 17259, Tadarida mexicana, in Ney Cave, September 14, 1940, 20 miles north of Hondo, 2 adults; 17254, bat cave, September 12, 1940, near Bracken, about 150 adults and nymphs. 
Ornithodoros dyeri Cooley and Kohls, 1940

Plate 9, Figs. 43 and 44

1940. Ornithodoros dyeri Cooley and Kohls, original description, pp. 925-928, with figures.

Sexes similar; nymphs and adults similar.

\section{ADULT}

Body.-Length, 5.5, width, 2.1. Color (living) yellow-brown. Elongated, sides parallel, anterior end pointed, posterior end rounded. Flattened on top and marginated. Viewed in lateral profile the body is nearly straight. Entire dorsum bounded by two continuous ridges which are essentially parallel and with a third (inner) incomplete ridge on each side, plainer in early stage riymphs. Ridges less elevated in the later stage specimens. Within the ridges the surface is irregular due to short ridges and subcircular elevations. In the anterior dorsal area is a distinct median, smooth hump raised above the level of the lateral margins, and anterior to it a deep depression near the parallel marginal ridges.

Mammillae.-Indefinite or absent though there are present small, irregular elevations on the surface.

Hairs.-A few very fine, short hairs are scattered on dorsal and ventral surfaces.

Legs.-Moderate in length, small, micromammillated. Fine, short hairs scattered over the legs; those on ventral surface of the tarsi larger and in two parallel rows. All tarsi without subapical dorsal protuberances or dorsal humps. Stalk of the pulvillus and claws progressively longer on legs I to IV. Femur of leg IV notably long-longer than femur III. Length of femur IV, including trochanter, 1.08; that of leg III, 0.72. Length of tarsus I, 0.54; metatarsus, 0.48 . Length of tarsus IV, 0.69 ; metatarsus, 0.60 .

Coxae.-Coxae I and II separated; all others contiguous. Surfaces irregular and micromammillated. Hairs absent except a row near the articulation with trochanter on coxae II, III, and IV.

Hood.-A true hood absent but with a median ridge extending from the mouth parts to the anterior margin.

Cheeks.-Pyriform, attached along one side, with the broader end in front and together with the end of the ventral median ridge forming protection for the mouth parts.

Capitulum.-Basis large, broader than long; surface having micromammillae and distinct transverse wrinkles. Surface of palpal article 1 irregular and with a narrow, knife-edge flange on the median side overlapping the base of the hypostome; other articles free.

Hypostome.-Short, broad, truncate, with sides nearly parallel; posthypo- 
stomal hairs long, faintly barbed, reaching the tip of the hypostome. There is also a pair of shorter postpalpal hairs. Denticles short, U-shaped, arranged $5 / 5$, covering about the distal two-thirds of the hypostome. Length, 0.21 .

Folds.-Coxal and supracoxal folds present and also a supplemental pattern of folds as shown in figures 43, E. Supracoxal folds not joined anteriorly. In addition to the remarkable pattern of folds in this species is a fold or ridge above the supracoxal fold opposite legs III and IV, which is bent downward
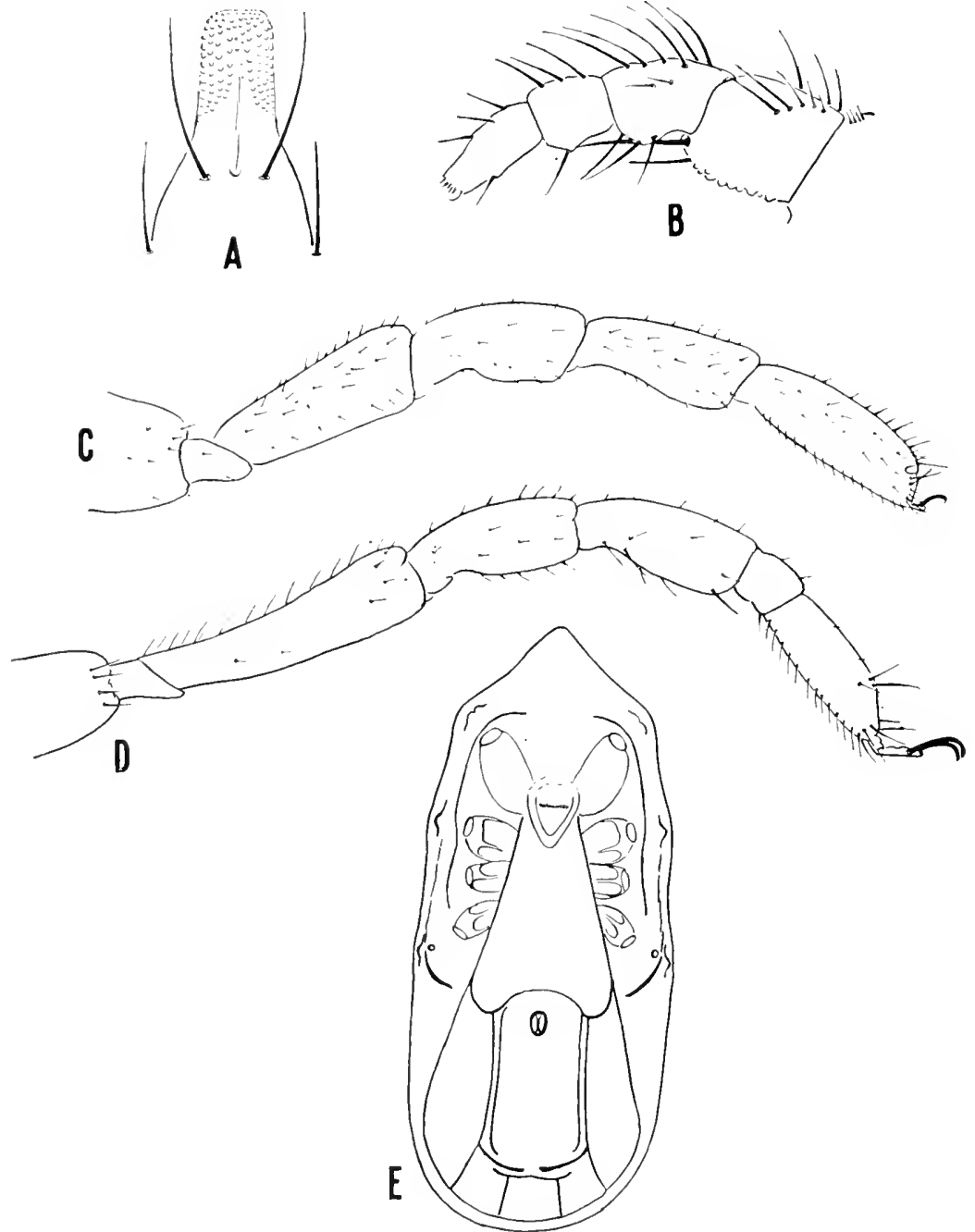

Fig. 43. Ornithodoros dyeri Cooley and Kohls. A, Hypostome. B. Palpus. C, Leg I. D, Leg IV. E. Diagram of venter. 
postcriorly and becorses an arc of a circle, the radial center of which would be the insertion of leg IV. The top of this arc is smooth while the surface of all other ridges is irregular. In living specimens leg IV in its movements is in contact with the smooth ridge, which is enough elevated to protect the spiracle placed just below it. Leg IV comes in coniact with this smooth arc at about the trochanter.

While in most Argasidae the spiracle is usually placed between coxae III and IV, in this species it is situated well back of coxa IV.

Grooves.- Only the deep, short, transverse postanal groove is present.

Sexual opening.--Placed at about the level of the posterior ends of coxae I. V-shaped depression, including the opening, present in the female, absent in the male.

Eyes.-Absent.

Anus.-Small, in an oval pattern, distant from the transverse postanal groove.

In this species the nymphs are remarkable in having a V-shaped depression in the position where the sexual opening is to appear, making it singularly difficult to distinguish between nymphs and adults. The original descriptions included both adults and nymphs, the authors believing that they had both before them. Dr. Mazziotti has recently sent us a male and a female specimen, the male being the first one we have scen. These specimens show the different male and female sex opening quite clearly and make it evident that the specimens before us at the time the species was described were nymphs. The $\mathrm{V}$ shaped depression is lacking in the male, while it is present, as in the nymph, in the female.

The above description is made from three large females from Mr. Flock (17189) and a male and female from Dr. Mazziotti. They differ from the nymphs in having the continuous submarginal ridge less elevated, the dorsal and ventral surfaces smoother and in having more spur ridges in the pattern of the folds on the venter. The smallest nymphs we have seen are shorter in proportion to the width than in adults and measure $1.98 \times 1.11$.

This remarkable tick is easily separated from other known species by its elongated body, the parallel marginal ridges, and the pattern of ridges on the venter as well as by other characters.

\section{HOSTS}

While this species has never been actually taken from bats, it has been found only on bat guano or on the walls of bat caverns.

\section{DISTRIBUTION}

Arizona.-16083, from bat guano from mine tunnel, November 3, 1939, Picacho Peak, near Picacho, 28 nymphs; 17863, from bat guano and rock crevices in mine tunnel, May 23, 1940, Picacho Peak, near Picacho, several nymphs; 17875, rock crevices in mine tunnel, May 28, 1940, Las Guijas, 1 
nymph; 17189, Tucson Mountains, September 16, 1940, 3 females (R. A. Flock).

Califormia.-17856, rock crevices in mine tunnel, May 20, 1940, 15 miles northeast of Yuma, Arizona, 3 nymphs; 17839, rock crevices in bat cave, June 14, 1940, 16 miles north of Needles, several nymphal cast skins.

Mexico.-Abandoned mine harboring numerous bats, 5 kilometers west of Coquimatlàn, Colima, November, 1940 (Mazziotti, 1941).

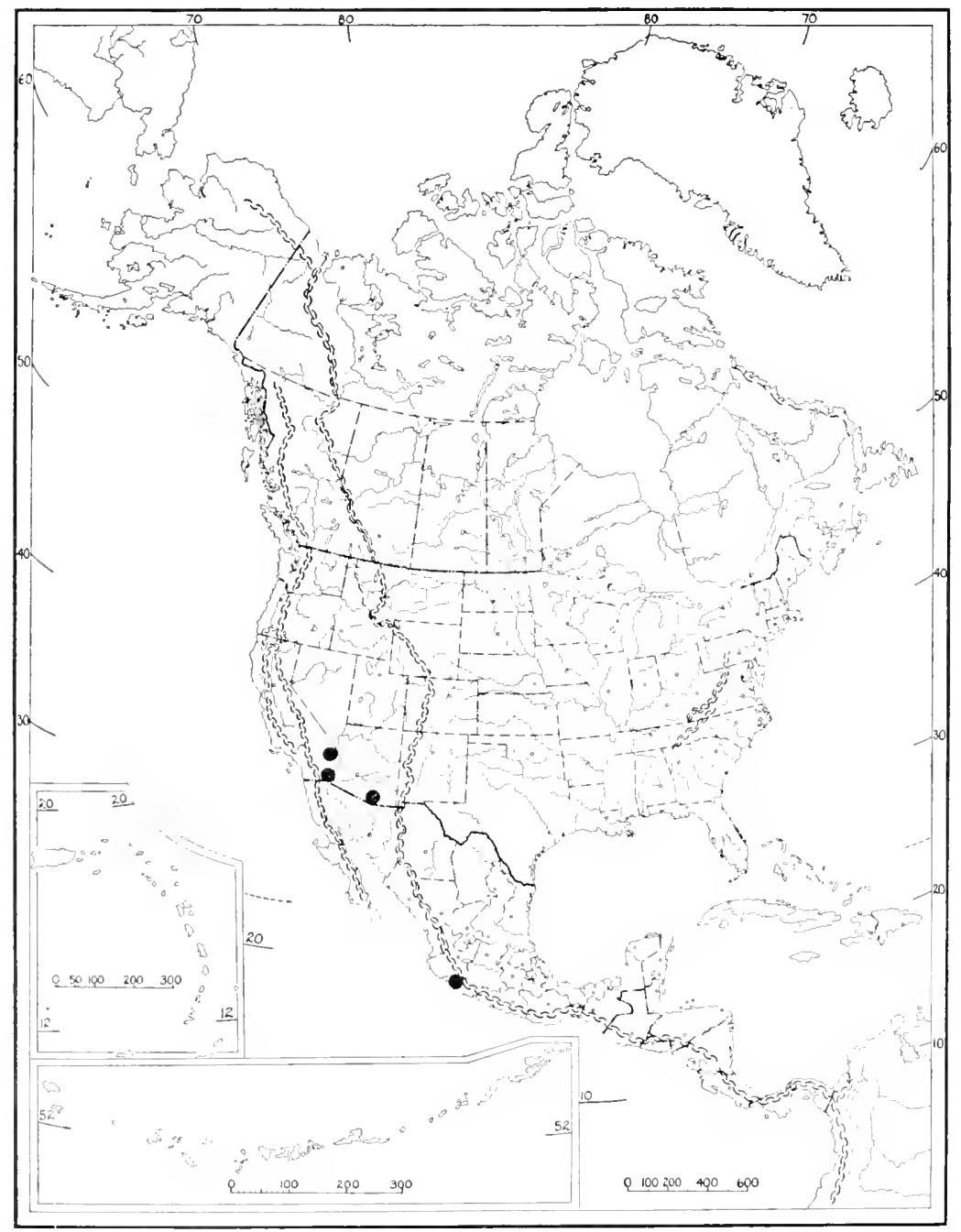

Fig. 44. Distribution of Ornithodoros dyeri Cooley and Kohls. 
Ornithodoros amblus Chamberlin, 1920

Plate 10, Fig. 45

920. Ornithodoros amblus Chamberlin, original description, pp. 43-44, with figure.

Sexes similar; adults and nymphs similar.

ADULT

Body.-Suboval, sides nearly parallel, anterior end a little pointed, posterior end broadly rounded. Mouth parts and hood not visible from above. Size, $6.45 \times 4.8$ to $5.0 \times 3.25$. Chamberlin (1920) gave the length as 7.2.

Mammillae.-Mammillae on the dorsum large, hemispherical, close but not crowded, those on the posterior border largest; tops convex with a few very small pits. Less elevated on the venter and some are oval or irregular in shape; absent or faint on the supracoxal folds.

Hairs.-Hairs few in number, more numerous on the anterior border and placed between the mammillae.

Discus.-Large and noticeable, mostly circular, a little depressed. On the venter present only in the grooves and in a median and two lateral depressions posterior to the transverse postana! groove.

Legs.-Moderate in length and size in the adults, relatively larger in the small nymphs, articles flared at their distal ends; trochanter thickened. Haller's organ notably distant from the distal end. Subapical dorsal protuberances and dorsal humps absent on all legs. Tarsus IV, long and tapering. Hairs few in number and of moderate length. Length of tarsus I, 0.78; metatarsus, 0.6. Length of tarsus IV, 1,2; metatarsus, 0.96 .

Coxae.-Coxae I and II separated; all other coxae contiguous.

Hood.-Very short and continuous with a short median elevation that connects it with anterior dorsal margin.

Camerostome.-Deep and terminating anteriorly in the short hood.

Cheeks.-Small, narrow and attached along their greatest dimension; not overlapping the mouth parts.

Capitulum.-Basis capituli wider than long; with a group of erect hairs on each side behind. Surface rough and with transverse wrinkles. Palpal article 1 swollen and with its surface similar to that of the basis capituli; with a knifeedge flange overlapping the base of the hypostome. Articles 2, 3, and 4 free and smooth.

Hypostome.-Sides nearly parallel; apex notched. Principal denticles in a $\%$ arrangement. Small denticles numerous in the corona and with a few small ones suggesting a third file on each side. Posthypostomal hairs reaching to about three-fourths the length of the hypostome.

Folds.-Coxal and supracoxal folds present.

Grooves.-Prenanal, transverse postanal and median postanal grooves present, broad and deep; the median postanal terminating at the transverse postanal groove. Dorso-ventral groove absent.

Eyes.--Absent.

Anus.-In a nearly circular frame. 
$O$. amblus resembles $O$. capensis from Africa, but the former is readily separated by several characters including the longer legs, the more numerous and more pointed denticles of the hypostome and in having the mammillae more nearly hemispherical on top and more regular at their bases.

\section{HOSTS AND DISTRIBUTION}

This species is known from guano islands off the coast of Peru, South America. Chamberlin (1920) states: "Dr. Murphy notes that these ticks are a type "extremely abundant on all the Peruvian guano islands. They live in the soil and the guano.' "Larval specimens were taken from the plumage of an adult penguin (Spheniscus humboldti).

Murphy (1925), p. 246, states:

Moreover, the ticks do not confine their attacks to the birds, but at times bite the skin of the native Indian laborers, usually upon the feet or legs, producing sores which are apt to be persistently troublesome.

Mr. Murphy in the same book (p. 245) states:

The most significant fact concerning the ground spiders is that they appear to subsist largely upon the native ticks, which are blood-sucking parasites of the birds. The spiders' dens are sometimes filled with shriveled remans of the ticks, for, since spiders eat only the body juices of their quarry, they take a remarkably heavy toll. Thus they become the chief natural agency in restricting the numbers of an important enemy of the guano birds.

While this species has not been collected in nature in North America, it is reported as very abundant on the guano islands and may be readily introduced with shipments of bird guano. In a recent letter Bequaert states: "It has been found recently in a port of the United States, in a shipment of guano."
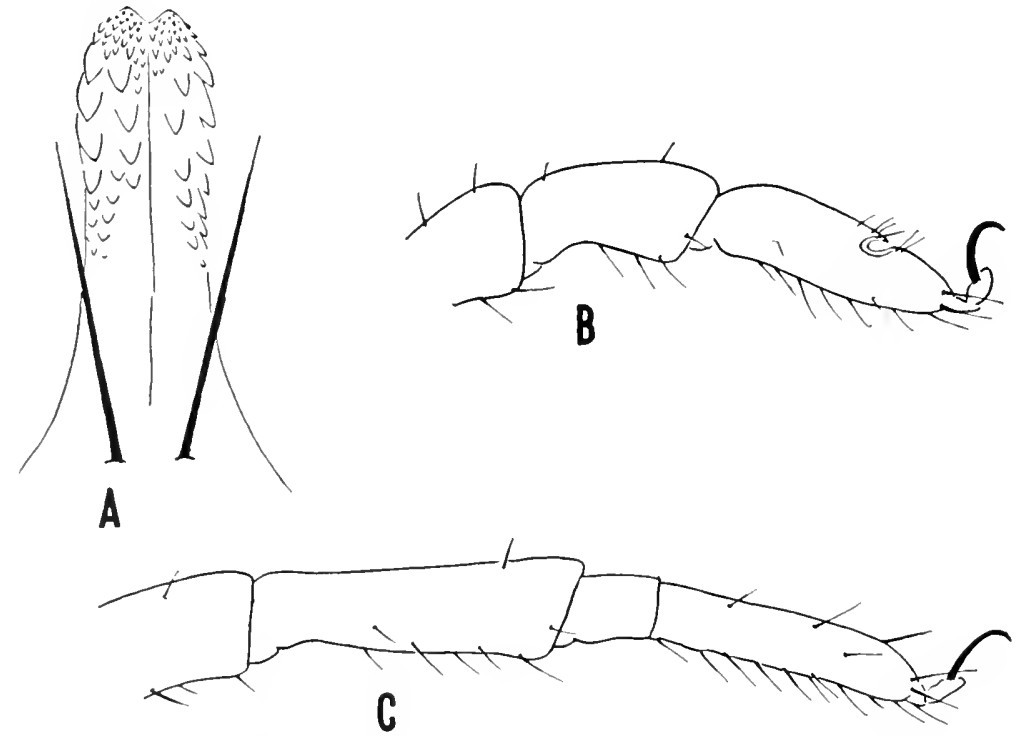

Fig. 45. Ornithodoros amblus Chamberlin. A, Hypostome of female. B, Leg I of female. C. Leg IV of female. 


\title{
ORNITHODOROS RUDIS Karsch, I880
}

\author{
Plate 10, Fig. 46
}

1880. Ornithodoros rudis Karsch, original description, p. $1+1$.

1901. Ornithodoros talaje (Guérin-Méneville): Neumann, p. 259.

1921. Ornithodorus venezucliensis [sic] Brumpt, in Neveu-Lemaire, p. 348.

1922. Ornithodorus venezuclensis Brumpt: Brumpt, redescribed, pp. 773-775, with figures.

1928. Ornithodoros venezuclensis Brumpt: Ruge, redescribed, pp. 406-409, with figures.

1936. Ornithodoros venezuelensis Brumpt: Brumpt, redescribed, pp. 1203-1205, with figures.

1936. Ornithodorus migonei Brumpt, pp. 1209-1210.

Sexes similar; adults and nymphs similar.

\section{ADULT}

Body.-Long-ovate, sides nearly parallel, anterior end pointed. Size of female, $5.5 \times 3.0$ to $3.95 \times 2.0$; male, $4.2 \times 2.2$ to $3.6 \times 2.1$.

Mammillae.-Moderate in number, convex and shining on top and with radiating striae on their bases; with one or more crescentic pits on the margin of each. On both the dorsal and ventral surfaces, short fine hairs arise from the crescentic pits at the sides of the mammillae, more abundant on the sides and at the posterior end. Mammillae a little larger in the marginal areas and largest of all at the posterior margin; smaller and less definite on the venter.

Discs.-Superficial and faintly differentiated from the mammillae; in a symmetrical pattern on the dorsum but on the venter visible only on the median postanal groove.

Legs.-Moderate in length and size, with numerous short hairs, those on the tarsi in two ventral rows. Surface of the legs micromammillated. Subapical dorsal protuberance small on tarsus I, very small or abcent on tarsus IV; dorsal humps absent. Length of male tarsus I, 0.585; metatarsus, 0.42. Length of male tarsus IV, 0.54 ; metatarsus, 0.435 .

Coxae.-Short and small, I and II a little separated but others contiguous; surfaces micromammillated.

Hood.-Continuous with anterior extension of the dorsal body wall; apically bent ventrad and together with the cheeks affords some protection for the mouth parts.

Cheeks.-Reniform with the free edges irregular.

Capitulum.-Basis a little wider than long; surface irregular, micromammillated, with faint transverse wrinkles and with short, fine hairs on each side behind. Palpi micromammillated; article 1 with a narrow flange extending over the base of the hypostome.

Hypostome--Moderate in length, sides nearly parallel, apex notched. 
Denticles arranged $\% / 2$ with only about four large ones in each file. Denticles placed on about the distal half. Length, 0.22 to 0.30 .

Folds.-Coxal and supracoxal folds present.

Grooves.-The dorso-ventral, preanal, transverse postanal and median fostanal grooves present.

Sexual opening.- At the level of the intervals between coxae I and II.

Eyes.-Absent.

Anus.-In an elliptical frame.

\section{HOSTS AND DISTRIBUTION}

The literature of this species reveals no hosts other than man and domestic fowls.

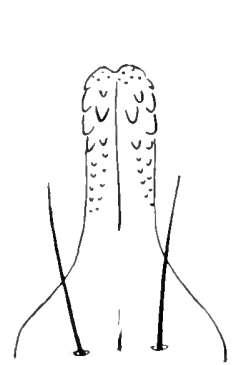

$\mathbf{A}$

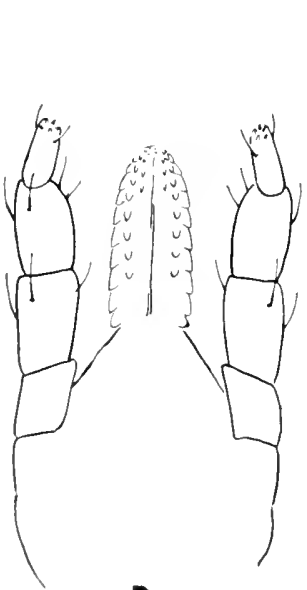

D
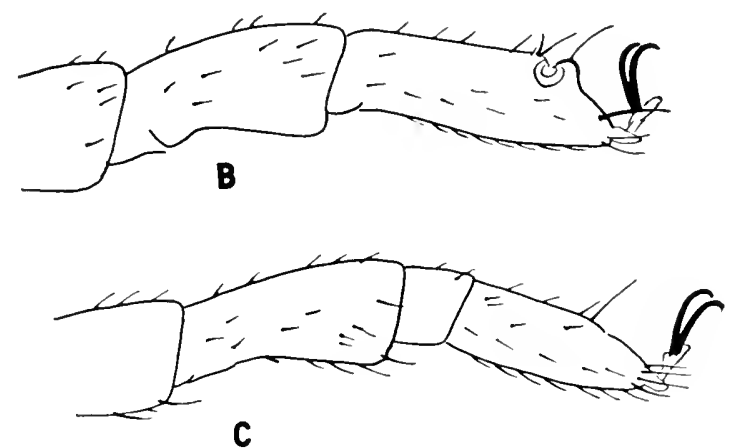

C

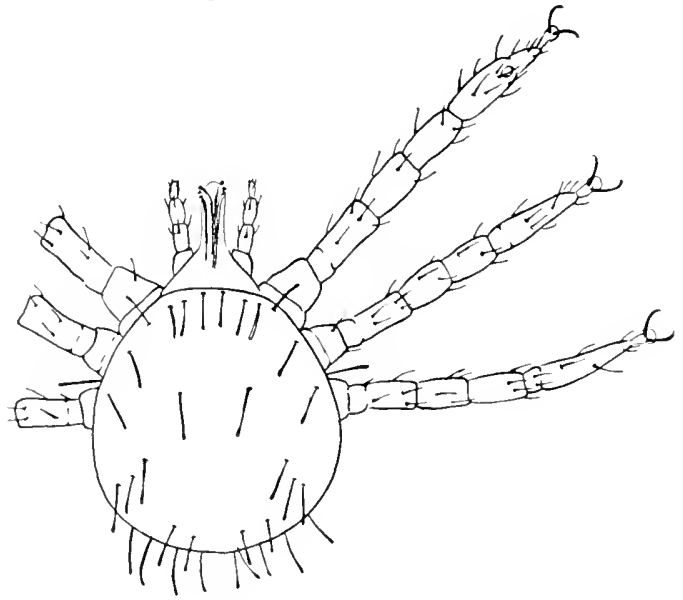

E

Fig. 46. Ornithodoros rudis Karsch. A, Hypostome of adult. B, Leg I of adult. C, Leg IV of adult. D. Capitulum of larva, ventral view. E, Larva, dorsal view. 
The type specimens came from "Nova Granada." Brumpt's specimens of renezuelensis were collected in Colombia and Venezuela; those of migonei were from Paraguay.

We have seen living specimens of $O$. migonei which came originally from Paraguay, and the Rocky Mountain Laboratory also has preserved specimens from Paraguay sent by Dr. Brumpt. These materials have supplied an abundance of specimens of all stages which have been compared with living and preserved specimens of $O$. rudis Karsch. The comparison shows no specific differences in adults, nymphs, or larvae and we find it necessary to make migonei a synonym of rudis, which has priority.

Dunn (1927) considers "this tick (O. venezuelensis) to be the one commonly found in houses in various parts of Panama, Colombia, and Venezuela, and possibly in some of the neighboring republics, and that this species accects man as its preferred host." In 1921 he received specimens from the native villages of Chorrera and San Juan in the Republic of Panama. In 1924, a total of 4,880 specimens was collected in Colombia from 68 houses in 20 villages, towns, and cities in various parts of the republic.

We have seen specimens from Panama, Canal Zone, Department of Bóyacá in Colombia, and Venezuela, as well as from Paraguay.

Ornithodoros dunni Matheson, 1935

Plate 11, Fig. 47

1935. Ornithodorus dunni Matheson, original description, pp. 347-349, with figures.

Sexes similar; adults and nymphs similar.

ADULT

Body.-Oval, a little pointed in front, wider and rounded behind; much flattened. Hood and mouth parts not visible from above. Matheson (1935) gives as the length 3.4; extreme width, 2.0. A single male before us measures $2.79 \times 1.71$.

Mammillae.-Relatively few in number, those in the margins smaller. It is difficult to distinguish between the mammillae and discs in the posterior areas near the margin on both dorsal and ventral surfaces. The individual mammillae are smooth and shining, only a little elevated and convex on top, usually with one or more small pits. Inconspicuous short hairs visible on the hood and around the entite margin on both dorsal and ventral surfaces.

Discs.-Large and conspicuous as elevated, shining areas which occupy much of the dorsal surface; a few are present also on the ventral surface, where they are in lineal arrangement in the grooves.

Legs.-Short and heavy with numerous shcrt hairs. Length of male tarsus 
I, 0.25; metatarsus, 0.25. Length of male tarsus IV, 0.42 ; metatarsus, 0.32 . With a mild subapical dorsal protuberance on tarsus I, absent on all others. Dorsal humps absent on all tarsi.

Coxae.-All coxae contiguous.

Hood.-This very small hood is separated from the anterior projection of the dorsal body wall.

Cheeks.-Small, oval and free on their anterior ends.

Capitulum.-Basis capituli wider than long, with the surface granulated. Article 1 of the palpus with a knife-like edge on the median side extending over the base of the hypostome; articles 2, 3 and 4 free.

Hypostome.-Short, with the sides nearly parallel; notched apically. Denticles arranged $\% / 2$ covering the distal half, with 3 or 4 large teeth in each file. Length about 0.18 .

Folds. - The supracoxal fold extends from the hood to behind coxa IV. Coxal fold extends from coxa III to near the posterior margin.

Grooves.-Transverse postanal groove present, all others absent.

Sexual opening.-Placed between coxae I.

Anus.-In an elliptical pattern.

\section{NYMPH}

The number of nymphal stages is not in evidence in the materials available. Matheson (1935) mentions two known nymphal stages and gives measurements as 1.5 and 2.0, respectively.

\section{LARVA}

Of the larva, Matheson (1935) gives the following:

Newly hatched larva $0.64 \mathrm{~mm}$. from tip of the hypostome to posterior end of body; remarkably elongated hypostome (Fig. 4, a) $0.2 \mathrm{~mm}$. in length; width of body $0.28 \mathrm{~mm}$. Hypostome narrowly elongate, sharply pointed at apex with a dentition of $2 \mid 2$; lateral teeth very long and apical portion lacks denticles; base of hypostome with two short spines; chelicerae slightly longer than hypostome: digit quite similar to that of adult though more elongate; palps free and with few spines. Full gorged larva extremely distended, $1.28 \mathrm{~mm}$. in length.

\section{HOSTS AND DISTRIBUTION}

\section{Matheson states:}

This tick was collected in the larval stage on the Little Bull Bat. Dirias albiventer minor (Osgood), which was captured in a mango tree in the yard of the Panama Hospital, Panama City, on March 17, 1931. The bat was placed in a bag and during the next few days 32 larvae dropped, full engorged. The larvae molted, and were carried through the nymphal stages to the adult. Larvae of this tick were also taken on the same species of bat at Summit Canal Zone, on Sept. 30. 1932. This tick appears to be restricted to this one species of bat. 
In addition to Panama and the Canal Zone, the known distribution as given by Matheson, we have received one female found "living in tree holes with bats" collected by Mr. R. Damasceno, and kindly sent by Dr. Emmanuel Dias. The specimen was taken on Marajó Island (mouth of Amazon), June 1941, Bélem, Para, Brazil.
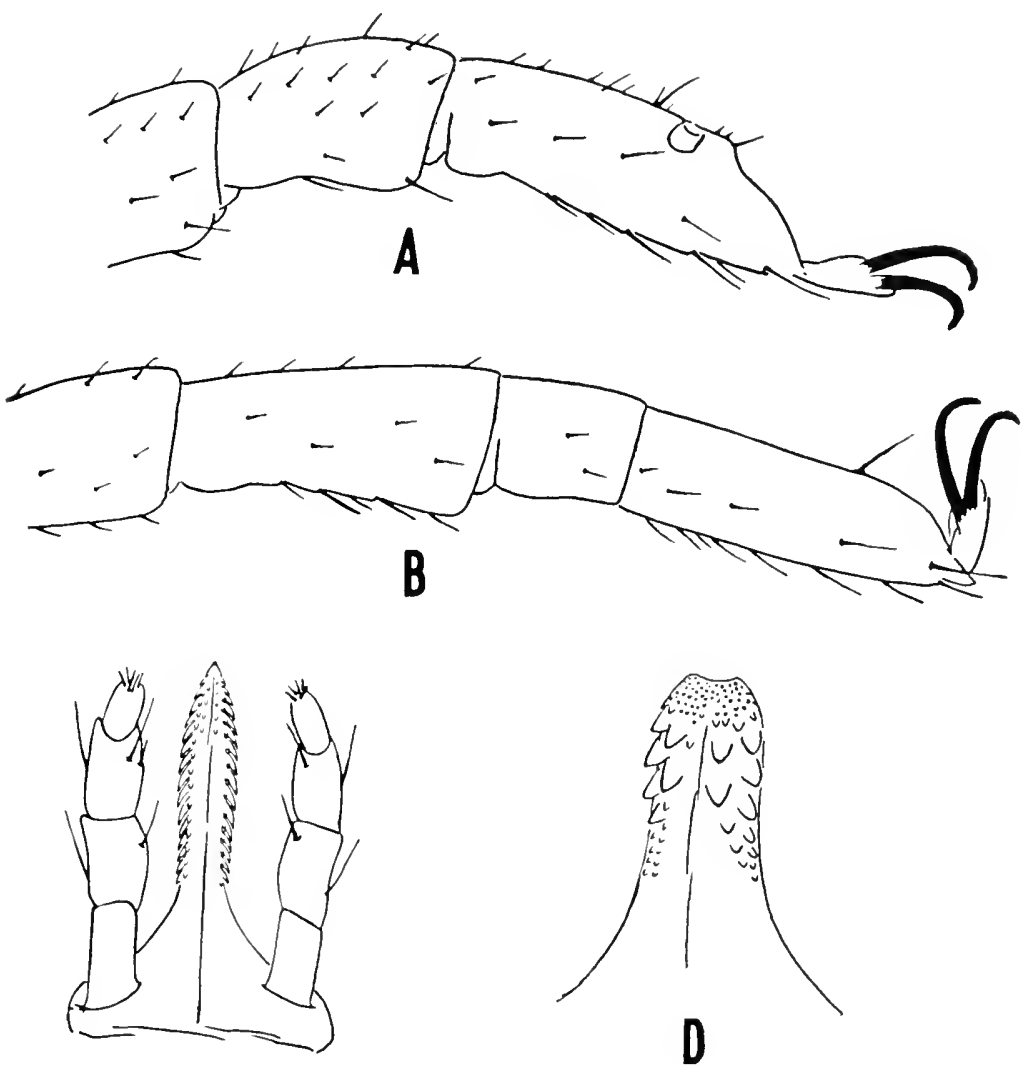

C

Fig. 47. Ornithodoros dunni Matheson. A, Leg I of nymph. B, Leg IV of nymph. C. Hypostome and palpi of larva, ventral view. D. Hypostome of adult. 


\section{Ornithodoros viguerasi Cooley and Kohls, 1941}

Plate 11, Fig. 48

1941a. Ornithodoros viguerasi Cooley and Kohls, original description, pp. 396-399. with figures.

Nymphs and adults dissimilar; whether sexes are similar or dissimilar is unknown.

\section{ADULT}

Body.-Sub-oval, broadest at about the middle, narrowly rounded behind, and a little pointed in front. Broad anterior point bent ventrad where it meets the anterior extensions of the supracoxal folds, from which it is separated by a depressed line. Size $3.12 \times 2.1$.

Mammillae.-Numerous and of various sizes and forms. Those in the median dorsal area large, crowded, of irregular shapes, flattened on top and each with a central pit which may bear a hair; those in the anterior marginal areas on the dorsum much as in the median area but smaller and with hairs more numerous; those in the dorsal posterior margin elongared, arranged radially, and only slightly elevated. Venter with a transverse band just posterior to coxae IV, extending from side to side, in which the mammillae are unique among mammillae of all known species. This band extends over the lateral margins becoming visible from above and also has extensions on the supracoxal folds and in the median area between the coxae. These mammillae at the margins are elevated, columnar, about twice as high as their diameters, convex on top and each with a single fine hair; height of the mammillae diminishing progressively from margins to the median area where they are only slightly elevated and yet retain a sharp margin of the convex top. The surface of the derm between these modified mammillae is finely and evenly pebbled.

Discs.-Large, distinct, a little depressed and with their surfaces shinirg; not apparent on the venter.

Legs.-With numerous barbed hairs which are shorter and more barbed on the dorsal surfaces, larger and less barbed on ventral surface. Surface shining and with transverse wrinkles. Subapical dorsal protuberances and dorsal humps absent. Length of tarsus I, 0.42; metatarsus, 0.3. Length of tarsus IV, 0.50 ; metatarsus, 0.4 .

Coxae.-Coxae I and II a little separated; all others contiguous.

Hood.-No well developed hood is present though the anterior projection of the dorsal body wall is bent downward and resembles a hood.

Cheeks.-Conical projections about as long as the diameter at the base and bearing a few short, fine hairs.

Capitulum.-Basis capituli with the surface irregular but shining; with a median longitudinal elevation. Only the anterior portion of the basis capituli is visible in the type female and it is not evident whether the capitulum is 
protrusile in the adult as in the nymph. Palpal article 1 long, about as long as articles 2 and 3 combined. Article 4, conical.

Hypostome.-Small, flattened, in the shape of an inverted V; denticles not evident when examined in situ. Posthypostomal hairs placed far behind the insertion of the hypostome and very long. Length from hairs to apex, about 0.18. (Described in situ.)

Folds.-Coxal and supracoxal folds present. Coxal fold with a shining, sclerotized plate bordering coxae II, III and IV. Suprocoxal fold similarly sclerotized from opposite coxa III to the anterior end. There is also a similar plate anterior to the sexual opening between coxae I.

Grooves.-Preanal groove distinct at the sides but interrupted in the middle. Transverse postanal groove deep and continous from the lateral margins. Median postanal groove deep and terminating at the transverse postanal groove. Dorso-ventral groove absent.

Sexual opening.-At the level of the intervals between coxae I and II.

Eyes.-Absent.

Anus.-In an elliptical pattern.

\section{NYMPH}

Body with shape much as in the adult. The late stagc nymphs measure $3.0 \times 1.95$ and differ from the adult in possessing a definite sclerotized plate posterior to the position of sexual opening and in lacking a transverse plate between coxae I anterior to the sex opening. The late nymphs differ from the adult also in having the mammillae in the margins of the transverse ventral band only about as elevated as the other mammillae of this species and in the first nymphal stage the band of modified mammillae is lacking. The nymph lacks the definite modification of mammillae in the median posterior margin of the dorsum as described in the adult.

In the nymphs the capitulum is very long, protrusile, and attached by a soft "neck." When so extended the capitulum reaches beyond the anterior point of the body.

Hypostome.-Pointed apically; the two posthypostomal hairs arising from the tumescent base. The faint denticles scarcely visible even in mounted specimens; those on the margins larger. Length about 0.15 .

Nymphs are misleading in appearing to have the sex opening present. This is due to the presence of a sclerotized semi-circular flap and just posterior to it a large, smooth sclerotized plate. Coxal folds have oval sclerotized plates bordering on coxae II, III and IV, but the supracoxal folds are mammillated and lack the long, definite sclerotized plates found in adults.

\section{LARVA}

Engorged larva (not necessarily fully fed) oval, widest in front of the middle, bluntly pointed in front, rounded behind. Length (not including the mouth parts) 2.64; width, 1.95. Larval integument striated as in other species 
but lacking a dorsal plate. Leg I distant from the insertion of the mouth parts. Legs II, III, and IV separated by about the same distance as that from leg I to the mouth parts.

Basis capituli long with a knob on each side and with two horns on the posterior corners. Mouth parts very long and slender; mounted in balsam, articulation between palpal articles 1 and 2 not visible.

Hypostome long and narrow, denticles $2 / 2$; principal denticles in the lateral files relatively long and sharp, except at the base where they are rounded and

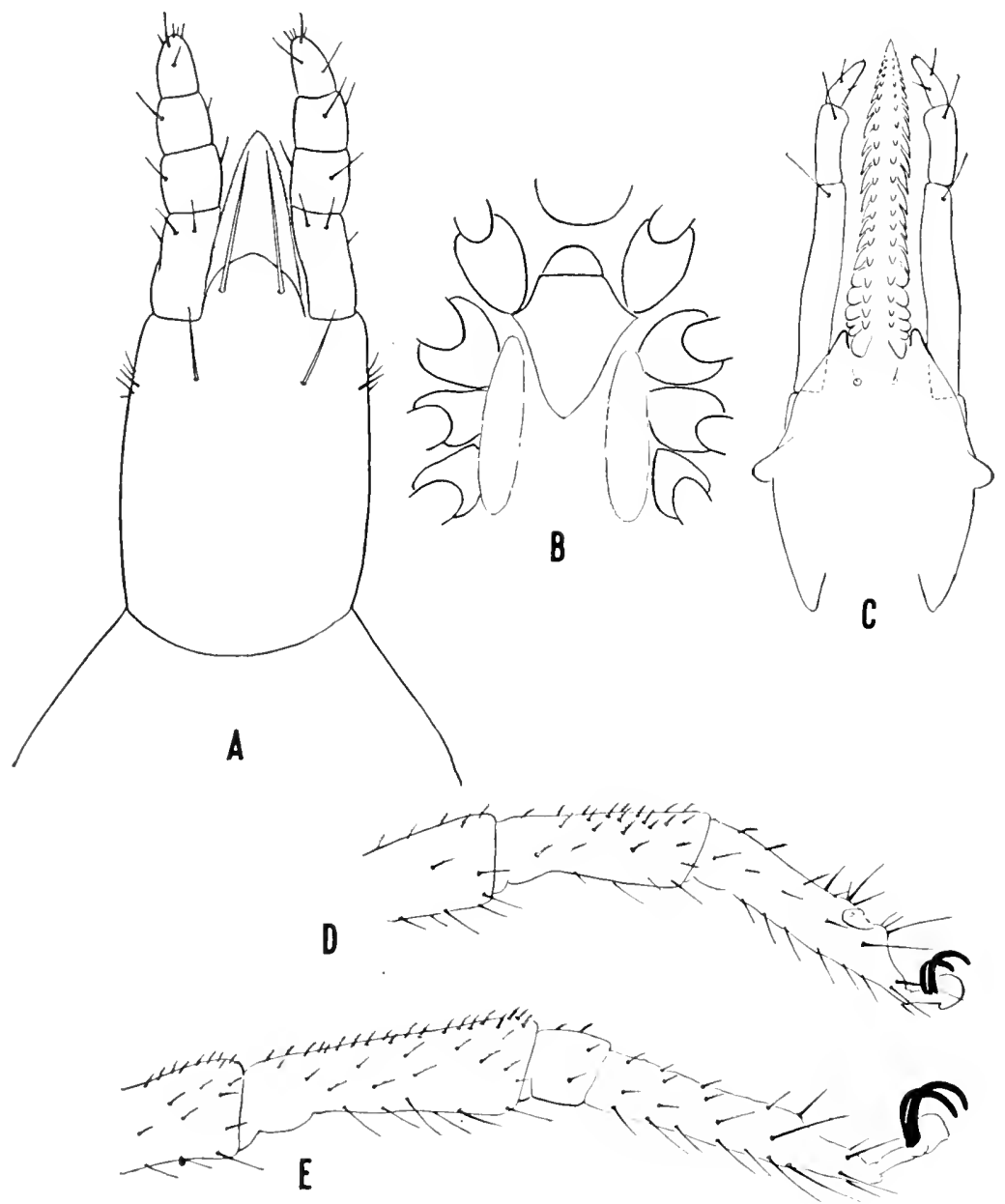

Fig. 48. Ornithodoros viguerasi Cooley and Kohls. A. Capitulum of adult, ventral view. B. Intercoxal area and coxae of nymph. C. Capitulum of larva, ventral view. D. Leg I of nymph. E, Leg IV of nymph. 
blunt, those of the median files small and short. Posthypostomal hairs very small and short. Length a'bout 0.27 .

It is notable that while the large, fed larva measures 2.64 in length, the adult measures only 3.12 .

\section{HOST AND DISTRIBUTION}

This species is known only from a bat cave, Cueva Somorrostro, Jamaica, Cuba, inhabited by Phyllonycteris poeyi Gundlach. One adult and several nymphs were collected from the walls of the cave; three nymphs and four larvae were from a bat. The collections were made in September, October, and November, 1940.

\section{Ornithodoros azteci Matheson, 1935}

$$
\text { Plate 12, Figs. } 49 \text { and } 50
$$

1935. Ornithodorus azteci Matheson, original description, pp. 349-351, with figures. 1941. Ornithodoros anduzei Matheson, original description p. 3.

Sexes similar; adults and nymphs similar.

Body.-Pyriform, broadly rounded behind and pointed in front, narrowing gradually from behind the third pair of legs. Size $4.5 \times 3.0$.

Mammillae.-Large and distinct in the marginal areas, small and not well formed in the median area. Individual large mammillat subhemispherical, with the surfaces of the sides irregular and with a few faint, radial striae; wsually with a crater and a short hair on top. On the venter mammillae faint or absent except in the peripheral areas; short hairs more abundant in the posterior area.

Discs.--Round or oval, faint, superficial, moderate in size, and evident only as modifications of the surface of the integument.

Legs.-Moderate in length and size; surface faintly micromammillated or granular, not shining. Hairs numerous, short except on the terminal articles where they are longer on the ventral side. Subapical dorsal protuberance moderate on tarsus IV, present but smaller on III. Dorsal humps absent on all legs. Length of tarsus I, 0.60; metatarsus, 0.54. Length of tarsus IV, 0.78; metatarsus, 0.66 .

Coxae.-Small, I and II separated, all others contiguous. Surfaces micromammillated or granular.

Hood.-Absent or negligible.

Cheeks.-Large, reniform with the convex side attached and with the anterior end free.

Camerostome.-Well formed and together with the cheeks and the overhanging anterior projection of the dorsal body wall forming protection for the mouth parts.

Capitulum.-Basis capituli about as wide as long; surface irregular, micromammillated or granulated. Palpi long, with article 1 very long, and with a 
flange projecting over the base of the hypostome. Stalks of the chelicerae very long and slender.

Hypostome.-Long, attenuated, pointed and with the very fine denticles limited to near the apex; denticles not in definite files; viewed in lateral profile, bent, with convex side ventrad.

Folds.-Coxal and supracoxal folds present.

Grooves.-Preanal, transverse postanal and median postanal grooves present; dorso-ventral groove absent.

Sexual opening.--Placed between coxae I.

Eyes.-Absent.

Anus.-Large, in an elliptical pattern.

Matheson (1935) describes the nymph and larva as follows:

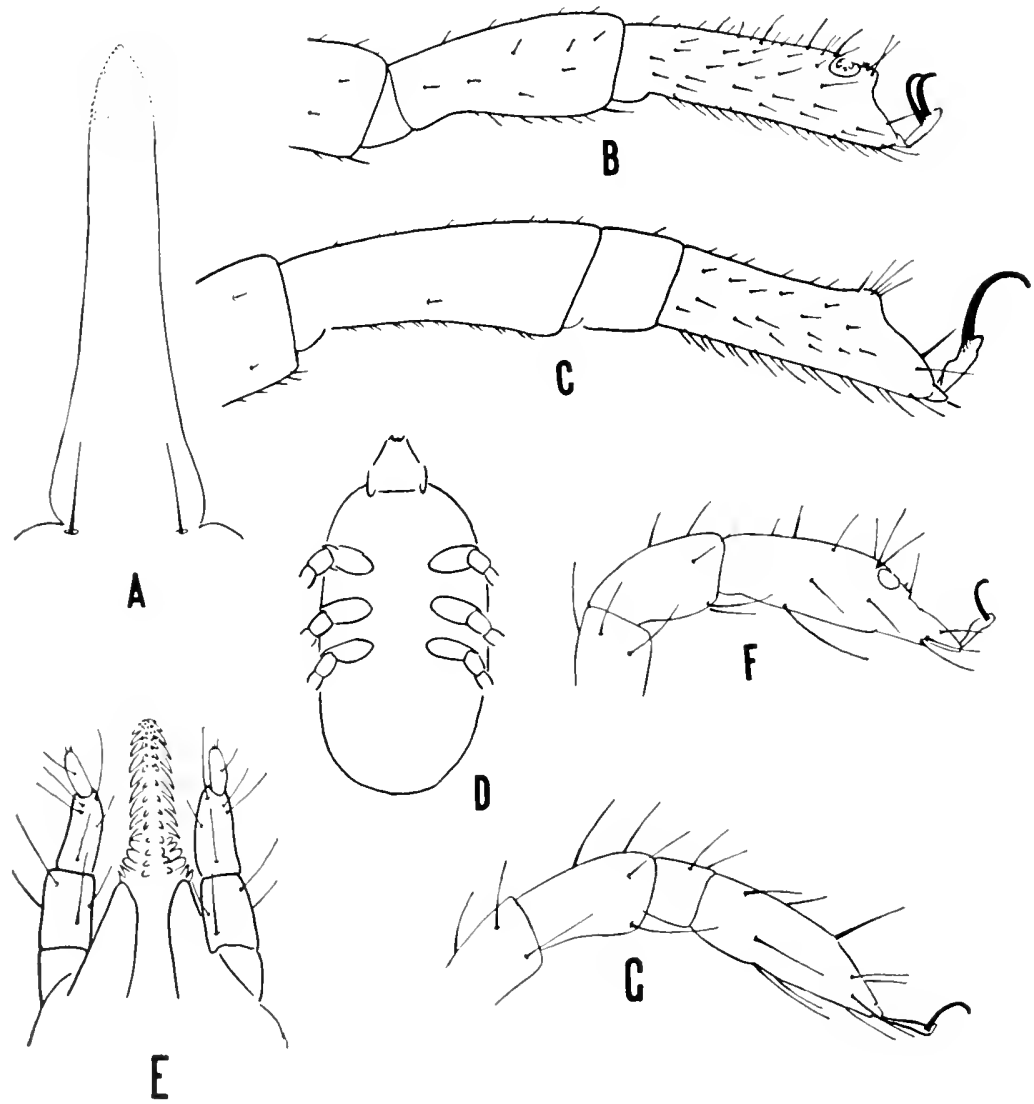

Fig. 49. Ornithodoros azteci Matheson. A. Hypostome of adult. B, Leg I of adult. C, Leg IV of adult. D, Engorged larva, ventral view. E. Hypostome and palpi of larva, ventral view. F, Leg I of larva. G, Leg III of larva. 


\section{Nymph}

From material before me there appears to be only one nymphal stage. Body elongate, sides subparallel, and strongly constricted in front. Length (unfed) $2.88 \mathrm{~mm}$; ; extreme width $1.6 \mathrm{~mm}$. Coxal and supra-coxal folds well developed; median and transverse post-anal grooves distinct; preanal groove present but not so well marked as in adult; integument has lost all indications of parallel transverse striations (so prominent in larvae) except at anterior end and now appears distinctly mammillated with minute spines between mammillae. Capitulum located in a deep camerostome as in adult; hypostome appears as a very thin, slightly chitinized membrane with only minute denticles arranged in transverse rows on apical portion (fig. $4, \mathrm{c}$ ); chelicerae elongate.

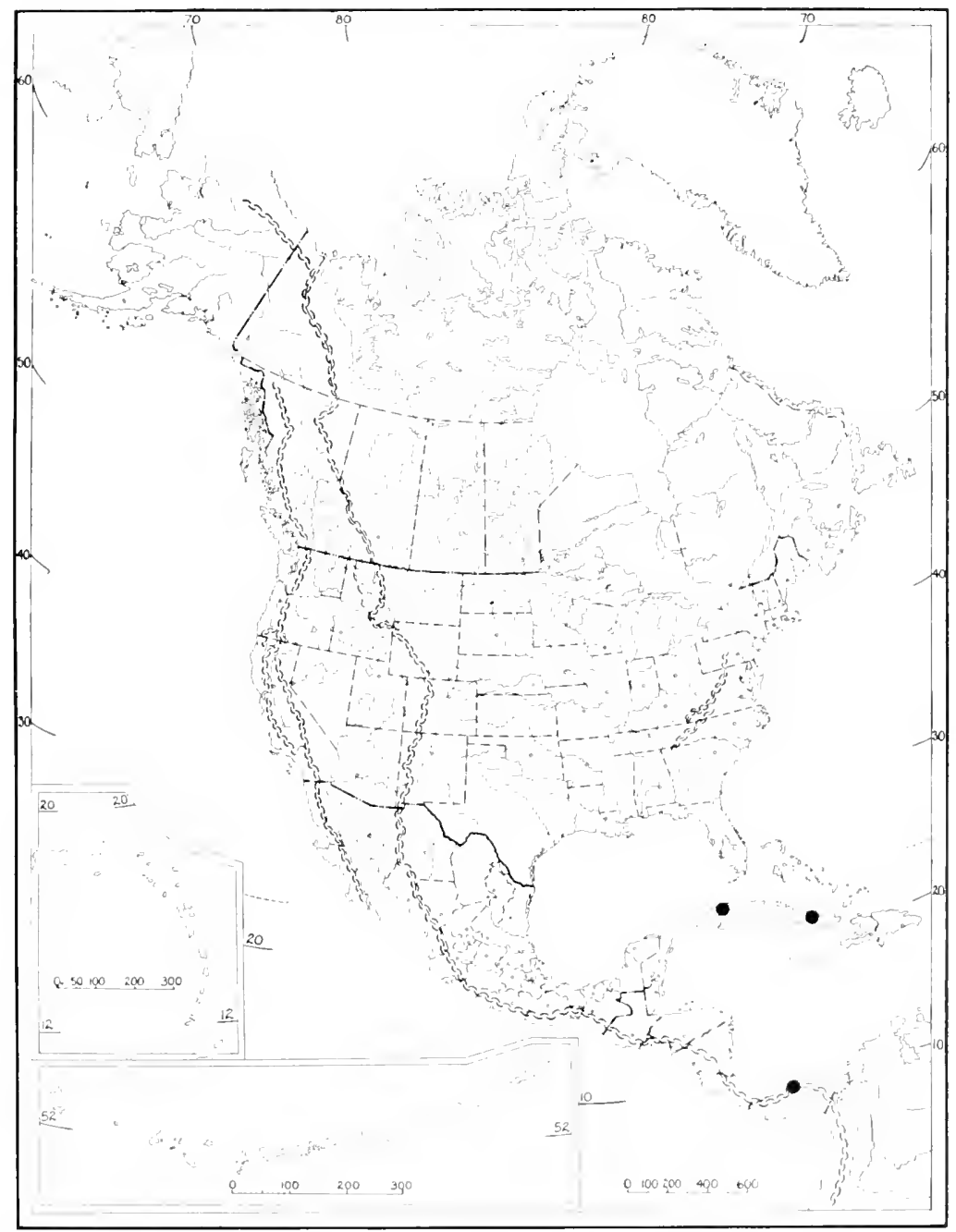

Fig. 50. Distribution of Ornithodoros azleci Matheson. 
sharply pointed shafts terminating in pointed digits (Fig. 2, 3); palps as long as hypostome; joint 1 about twice as long as 3; 2 shorter than 1; 4 short, pointed, with several apical spines.

\section{Larva}

Recently hatched larva narrowly elongate; length $0.88 \mathrm{~mm}$. as measured from apex of capitulum to posterior margin of body; capitulum measures $0.44 \mathrm{~mm}$. Body bears rather numerous stout hairs with minutely spinous margins; integument shows, under high magnification $(\times 400)$, very fine parallel lines running transversely, forming a more or less definite pattern; striate condition appears much more distinctly in mature larva and resembles that of $O$. megnini. Hypostome heavily toothed (Fig. 4, b); dentition $2 \mid 2$; apex with several rows of minute denticles; chelicerae as long as hypostome terminating in a two-toothed article; palps as long as the hypostome; joints 1 , 2 and 3 of about equal length; joint 4 is very short and bears numerous short, pointed spines; scattercd spines present on joints 2 and 3. Fully gorged larva measures 1.68 $\mathrm{mm}$. in length.

To the above it should be added that in the fed larva the capitulum is plainly visible from above and the coxae are remote from the capitulum. Hypostome on a conical base which is about as long as the hypostome itself. Denticles of the lateral files much larger than the medians and both files extend the entire length of the hypostome; basal denticles crowded and deformed.

\section{HOSTS AND DISTRIBUTION}

From Matheson (1935) we quote as follows:

Bats, Hemiderma perspicillatum aztecum (Saussure); Summit, Canal Zone, Nov. 12, 1930; this bat was found to be heavily infested with larvae and the nymphs and adults were present in the cracks and crevices of the culvert where the bats roosted in masses. Also taken on this same bat in a cave at Taboga lsland. Panama Bay and on the vampire bat, Desmodus rolundus murinus Wagner. This tick has also been taken in the cracks and crevices of Chilibrillo Caves and in other caves and culverts in Panama and the Canal Zone.

Cuba.-Through the kindness of Dr. I. Pérez Vigueras, University of Havana, Havana, we have received other specimens as follows: 17158, 1 adult from walls of a bat cave, Holguin, Santiago de Cuba; 17497, 4 adults, 2 nymphs, 9 larvae, Cueva del Barro, Loma Blanquizar, Guanajay.

Venezuela.-In 1941 Dr. Matheson of Cornell University kindly sent us specimens of this species taken from bat caves in Venezuela. 
Ornithodoros kelleyi Cooley and Kohls, 1941

Plate 12. Figs. 51 and 52

1941c. Ornithodoros kelleyi Cooley and Kohls, original description, pp. 912-914, with figures.

Sexes similar; nymphs and adults similar.

ADULT 5

Body.-Oval, pointed anteriorly and rounded posteriorly; sides more curved and with the excavations at legs I, II, and III less pronounced than in talaje. Size of female, $7.35 \times 4.0$.

Mammillae.-Large, close but not crowded, rounded on top and with the radial ridges reaching nearly to the top. Equal in sizes in lateral and median areas and larger at the posterior margin where they are elongated with the longer axes transverse; small on the venter, and indefinite on the supracoxal folds. Hairs absent on both dorsal and ventral surfaces, even on the hood.

Discs.-Large, conspicuous, in depressed areas which occupy much of the median area of the dorsum. On the venter, discs in lineal arrangement in the preanal and transverse postanal grooves and in three depressions caudad of the transverse postanal groove.

Legs.-Small and moderate in length; surface micromammillated; hairs small. Tarsus I with a mild subapical dorsal protuberance; absent on all others; dorsal humps absent. Tarsus I notably large (wide when viewed laterally). Length of female tarsus I, 0.66; metatarsus, 0.51. Length of tarsus IV, 0.9 ; metatarsus, 0.66 .

Coxae.-Coxae I and II well separated; all others contiguous. Surfaces micromammillated and with excrescences.

Hood.-Very small and short, placed close to the anterior poitit of the body and separated from it only by a depressed line. Not tongue-shaped as in talaje.

Camerostome.-Negligible and obscured by the large cheeks.

Cheeks.-Large, reniform, with the anterior portion free.

Capitulum.-Basis capituli about as wide as long; surface with irregular. transverse, deep wrinkles and numerous micromammillae; with a pair of inconspicuous fine hairs posterior to the posthypostomal hairs and with a few fine, short hairs on each lateral margin behind. Palpal article 1 micromammil. lated. Hairs on the palpi moderate in number and in length.

5 Described from specimens from houses in New York, Minnesota, and Illinois. The species was originally described from larvae and nymphs from bats in Utah and Colorado. 

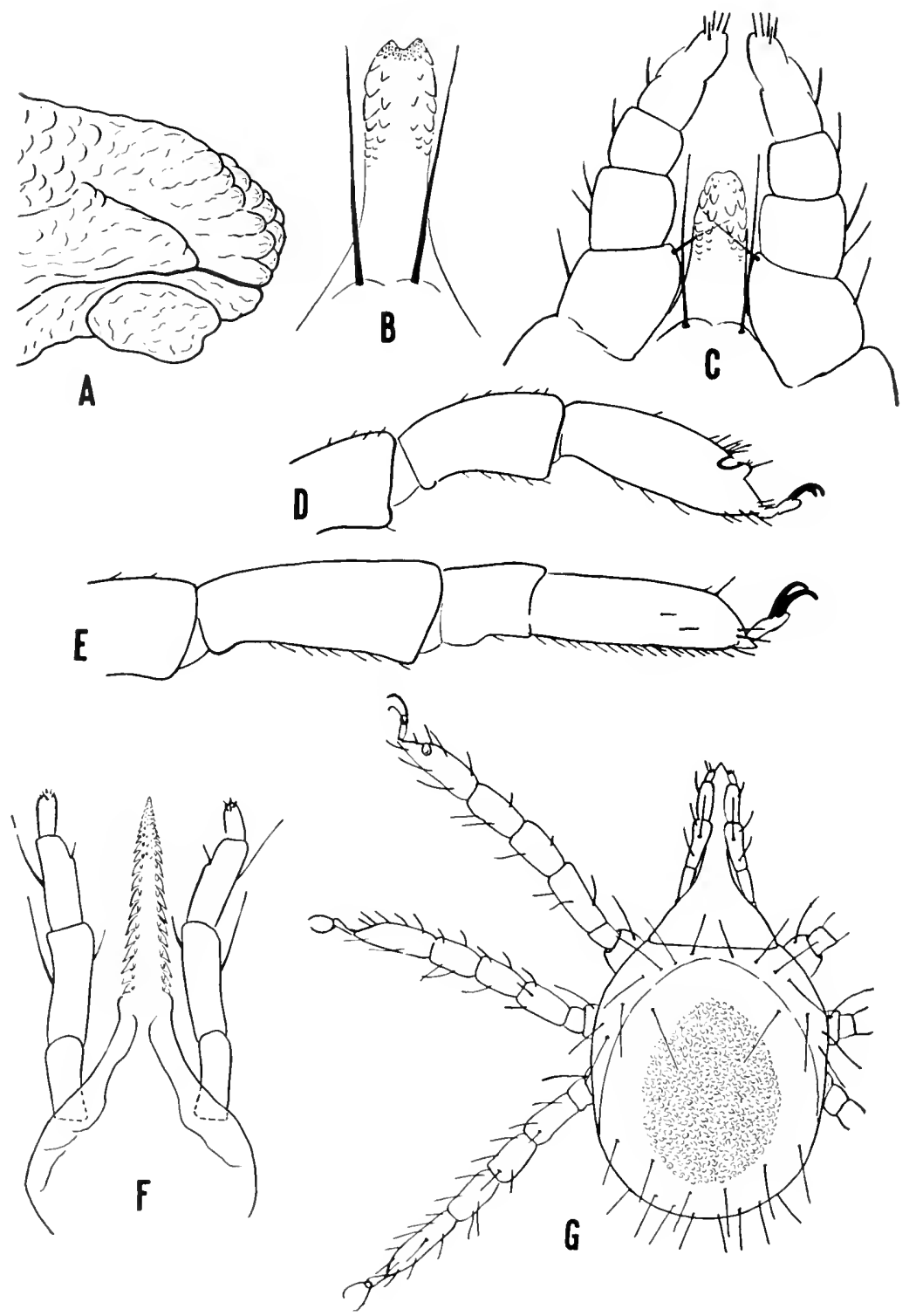

Fig. 51. Ornithodoros helleyi Cooley and Kohls. A, Lateral view of anterior end of body. B, Hypostome of female. C. Hypostome and palpi, ventral view of second stage nymph. D, Leg I of adult. E, Leg IV of adult. F, Capitulum of larva, ventral view. G, Larva, dorsal view. 
Hypostome.- Short and small, sides subparallel, a little wider at the denticles than at the middle; apically notched. Denticles $\% / 2$ with about 4 in each file. Corona with many very fine denticles. Length of female hypostome, 0.21 .

Folds-Coxal and supracoxal folds present, the latter extending forward to near the hood.

Grooves.-Preanal, transverse postanal, and median postanal grooves present, the last terminating at the transverse postanal groove. Dorso-ventral groove absent.

Sexual opening.-Between the posterior ends of coxae I.

Eyes.-Absent.

Anus.-In an oval frame.

\section{LARVA}

Unfed larva sub-oval in shape. Length of body including capitulum, 0.96; length of capitulum (in ventral view), 0.42. Palpi very long, slender, and in life closely appressed on the mouth parts.

Hypostome.- Long and slender and with a basal portion without denticles about one-third as long as the apical portion with denticles; sides converging to the pointed apex. Principal denticles $\% / 2$, extending the full length; apically $3 / 3$; lateral denticles much larger and sharper. Length about 0.195 (measured from beginning of the basal teeth to the apex).

$O$. kelleyi is related to talaje and concanensis. Nymphs and adults of kelleyi may be separated from talaje by the absence of a tefinite notch just above the hood, visible when viewed in lateral profile. The unfed larvae of talaje are only about two-thirds as long as those of kelleyi. From concanensis

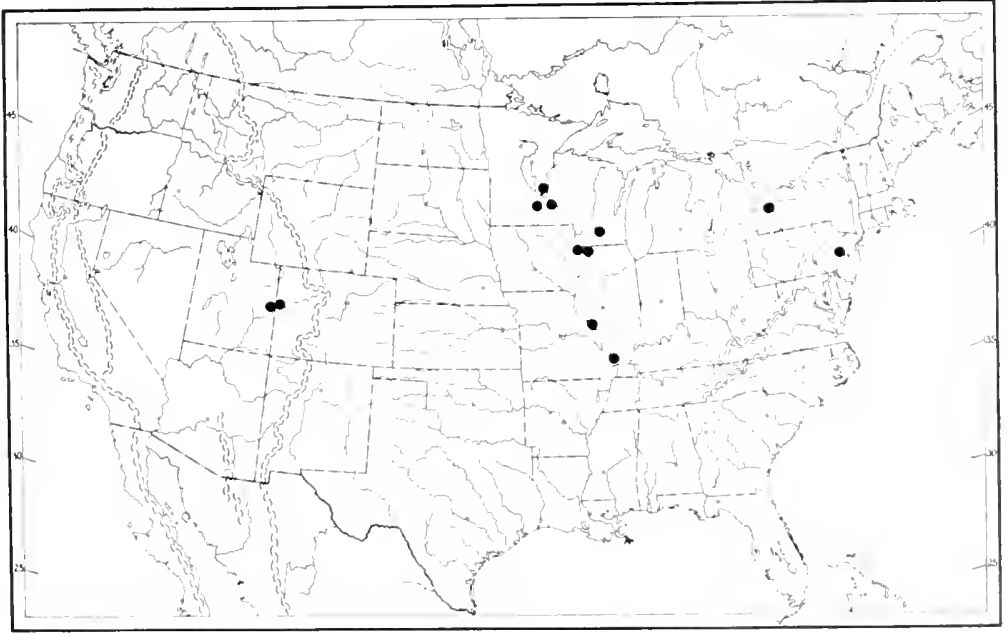

Fig. 52. Distribution of Ornithodoros kelleyi Cooley and Kohls. 
it is distinguished by being proportionately longer and in having the cheeks smaller, as well as by having the sides of the adult hypostome about parallel. $O$. concanensis is known only from bats and bat retreats and kelleyi from bats and from houses, some of which harbor bats. $O$. talaje has not been recorded on bats. The resemblance of this species to $O$. talaje led to its having been reported as talaje in houses in New York, Wisconsin, and Minnesota, by Matheson, 1931, Herrick, 1935, and Riley (1935), respectively. Other records (unpublished) are from houses in Pennsylvania, Illinois, and Iowa. Collection data are summarized in table 7. 


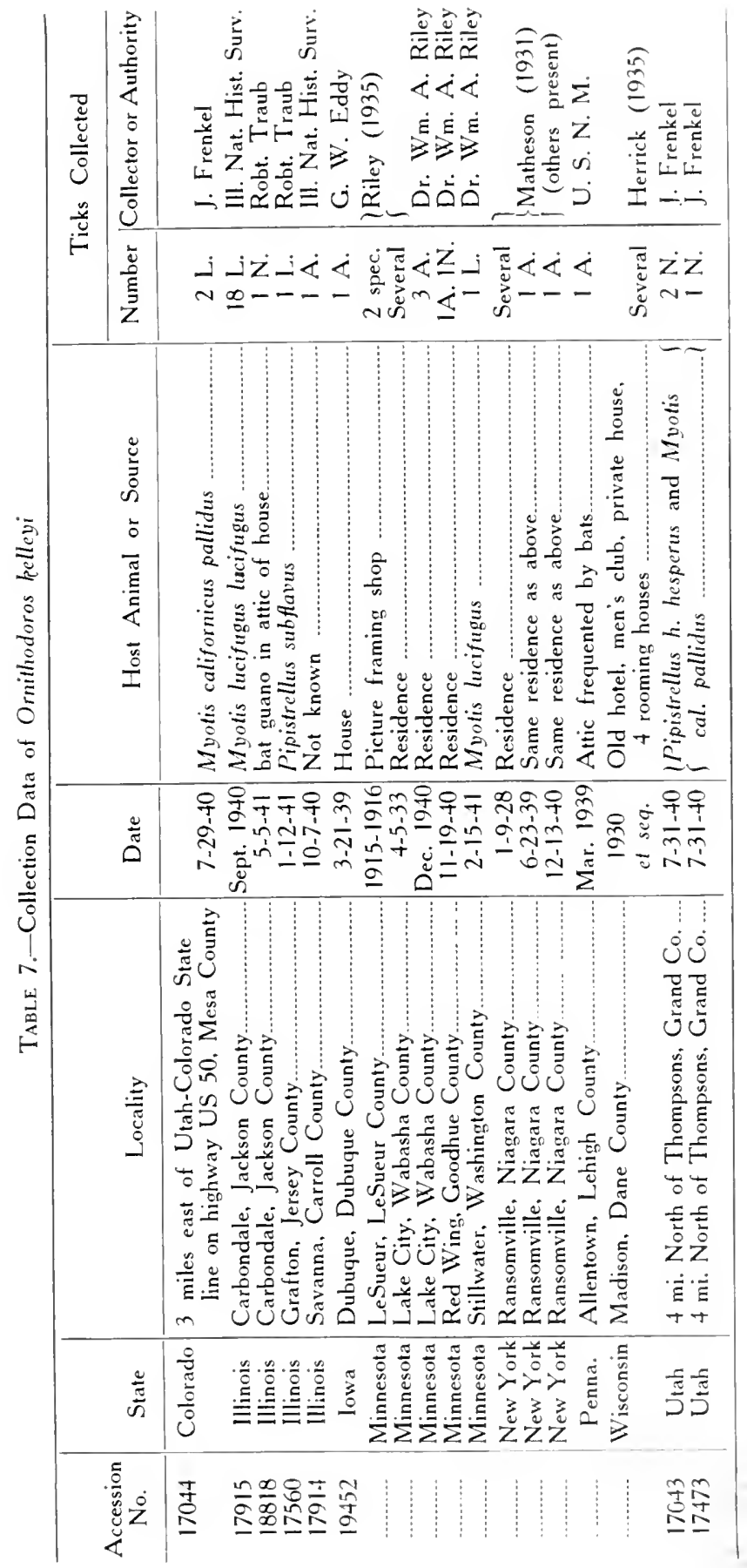




\section{Genus Antricola Cooley and Kohls, 1942}

Dorsal walls flattened and marginated; below the flattened dorsum the body convex and deep. Integument semi-translucent and the surface smooth, shining, and with tubercles. Discs absent on the venter. Mouth parts adapted for quick feeding and not for clinging to the host; hypostome convex ventrally, concave dorsally and lacking effective denticles; chelicerae large and effective. Anal ring large. Eyes absent. Eggs small and the small larvae with bulbous pulvillae in place of claws.

Genotype: Ornithodoros coprophilus McIntosh, 1935.

\section{Key to Species of Antricola}

1. Margin of body of adults and nymphs wiith finger-like projections, each having several hairs

2. Margin of body of adults and nymphs lacking projections marginalus (p. 123)

Antricola Coprophilus (McIntosh), 1935

Plate 13, Figs. 53, 54, and 55

1935. Ornithodoros coprophilus Mclntosh, original description, pp. 519-522, with figures.

Sexes dissimilar; adults and nymphs similar.

\section{FEMALE ${ }^{6}$}

Body.-Length about 6.0; greatest width about 3.3. Color light tan. Shape in dorsal view approching pyriform, tapering to a point in front which is bent ventrad; with two mild, marginal projections above the spiracles and two submarginal elevations above legs II, visible from above. Lateral margins mildly excavated back of leg IV. The marginated dorsal surface, while flattened in general, is irregular and has deep, broad submarginal furrows which unite in front. Also with deep, short, marginal furrows in the postero-lateral areas near the excavations.

Tubercles.- Tubercles large, moderate in number, of various shapes and sizes, those in the median area approaching a hemisphere, those on the margins fused and directed outward at an angle; absent in the furrows except for a few in the marginal furrows. Many of the tubercles with one to three hairs on their curved tops; such hairs longer in the median area. Tubercles absent on the lateral walls above the legs but present back of the legs, on the ventral surface, and in the inter-coxal area where they are smaller and less definite.

Discs.-Discs present in a continuous series in the deep, dorsal furrows; absent on the venter.

Coxac.-All coxae contiguous, smooth, shining, and with a few hairs.

6 In this species the depleted adults are usually much shrunken and misshapen. Males are less misshapen than the females. Specimens for describing were selected out of many for being what we may call "normal." 
Legs.- Long and slender and with numerous barbed hairs; surface smooth, shining. Claws large. All tarsi lacking subapical dorsal protuberances and dorsal humps. Length of tarsus I, 0.66; metatarsus, 0.78. Length of tarsus IV, 1.02; metatarsus, 1.02 .

Hood.- No true hood is present, though there is an anterior projection of the body wall.

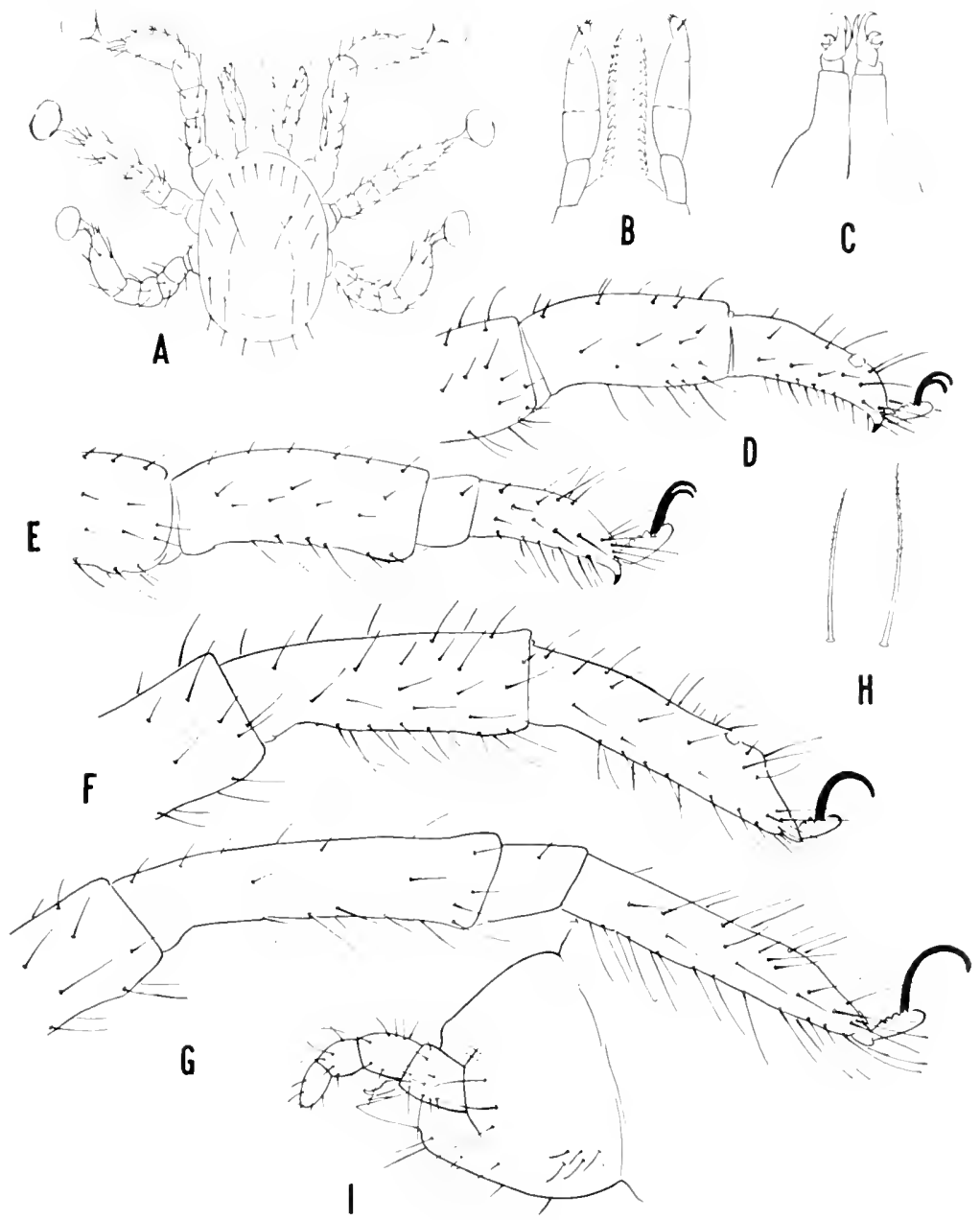

Fig. 53. Antricola coprophilus (McIntosh). A, Larva, dorsal view. B, Hypostome and palpi of larva, ventral view. C, Chelicerae of adult. D, Leg I of male. E, Leg IV of male. F, Leg 1 of female. G, Leg IV of female. H, Barbed hairs. I, Capitulum of nymph, lateral view. 
Camerostome.-Well developed as a depression to receive the capitulum when not extended.

Cheeks.-Cheeks absent but near their position are five to seven finger-like projections each bearing one or two barbed hairs.

Capitulum.-Basis capituli tumescent, with the sides rounded over into the lateral walls which are plainly visible. Surface smooth and shining and

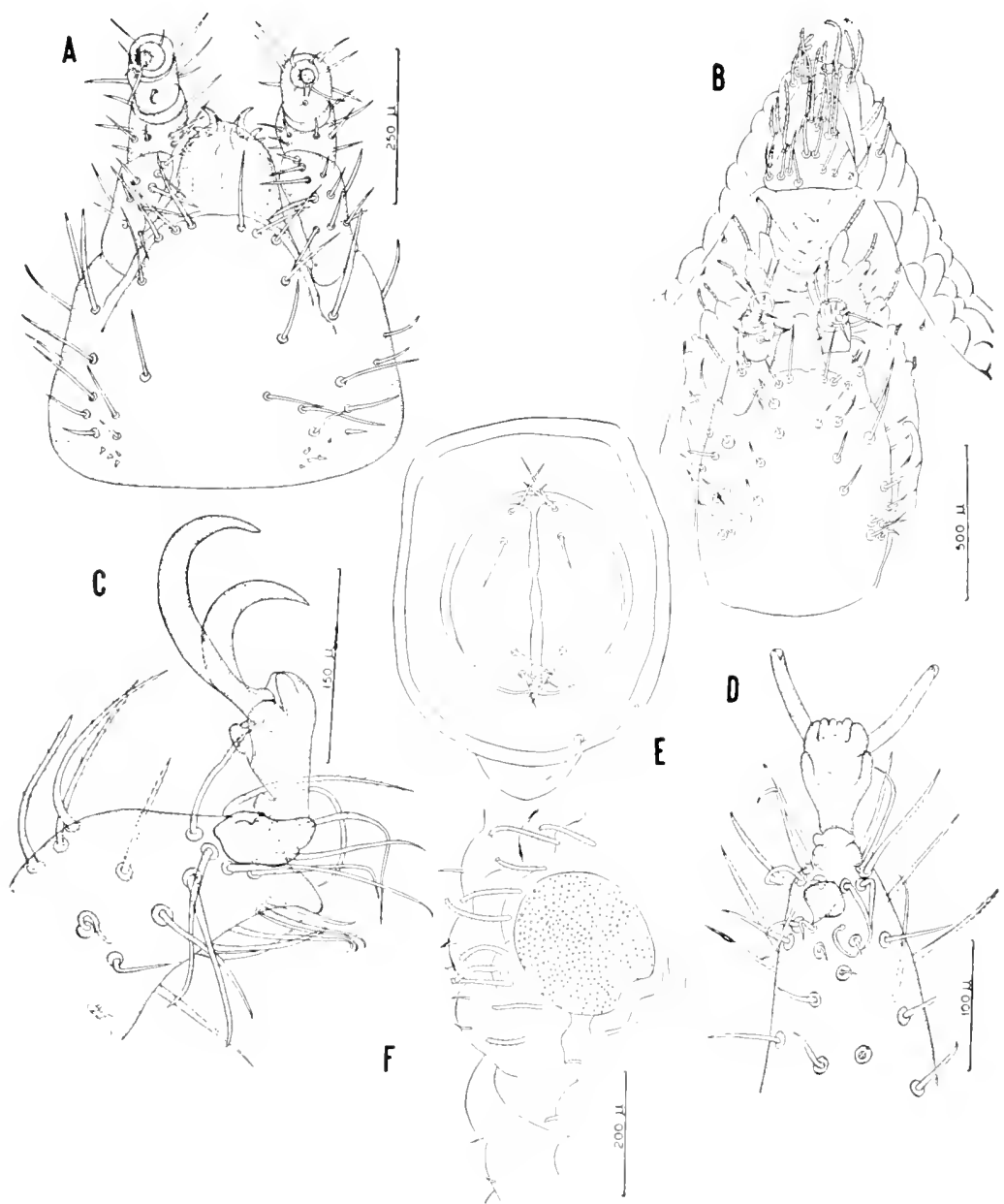

Fig. 54. Antricola coprophilus (McIntosh). A. Capitulum of male, ventral aspect. $\mathrm{B}$, Anterior end of female, showing capitulum, anterior portion of hood, and finger-like appendages of camerostome, ventral aspect. C, Distal portion of left tarsus IV of male, lateral aspect. D, Distal portion of right tarsus I of male, ventral aspect. E. Anal valves of male showing arrangement of hairs. F, Right stigmal plate of male and blunt hairs surrounding same. From Mclntosh (1935). 
with a few scattered, long barbed hairs. Palpi of moderate length; article 1 closely appressed on the base of the hypostome; articles 2, 3 and 4, free.

Hypostome-Short, broad, and rounded apically; convex ventrally and concave dorsally (scoop-like); with very fine teeth on the anterior lateral margins (better seen in a balsam mount under a microscopt).

Chelicerae.-Very large and effective.

Folds.-Coxal and supracoxal folds present.

Grooves.-The transverse postanal groove present, short; all others indefinite or absent.

Spiracles.-Spiracles an oval, globular protuberance, free on all sides except at the smaller attached end.

Sexual opening.- At the level of the intervals between coxae I and II.

Anus.-Very large, in an elliptical frame.

\section{MALE}

Body.-Length about 4.44; greatest width (at the spiracles) about 2.75 . Color light tan. Some specimens are as small as $4.0 \times 2.57$ (McIntosh). Shape pyriform, tapering in front to a point which is bent ventrad.

Dorsal surface in general flattened and marginated as in the female, and with mild sub-marginal grooves which unite in front but lacking both the excavations in the margins at the sides behind the middle and the deep marginal furrows near them.

Tubercles-As in the females, but with the hairs absent or few in number.

Discs.-Essentially as in the female.

Legs.-Legs shorter and larger than in the female; tarsi shorter and with well-developed ventral spurs (absent in the female). Length of tarsus I, 0.45; metatarsus, 0.57; length of tarsus IV, 0.54; metatarsus, 0.66.

Coxae.-As in the female.

Hood.-Absent as in the female.

Cheeks. - Cheeks absent; finger-like projections near the position of cheeks smaller and fewer in number than in the female.

Grooves, folds, spiracles, and anus essentially as in the female.

Sexual opening.-Placed between coxae I (a little anterior to its position in the female).

\section{NYMPH}

With many specimens of all stages before us the sexes as well as the late stage nymphs which are to become either male or female are readily separable. Thus we have in this species nymphs which we may speak of as pro-male or pro-female. Their potential sex is indicated by their size, shape, relative length over width, legs, as well as by the absence in the pro-male of the postero-lateral emarginations and the deep marginal grooves near them.

First and second stage nymphs measure $1.8 \times 1.14$ and $2.2 \times 1.35$, respec- 
tively. The very early stage nymphs have the elongated tubercles lying horizontally or at an angle at the margins and with one or more hairs projecting from their tops, thus resembling the tubercles or "protuberances" found on adult marginatus.

\section{LARVA}

Small, oval. Length (including mouth parts) 0.44 , width 0.25 . Legs short and with large, bulbous pulvilli; claws absent; leg 1 the longest and only about twice as long as the mouth parts. Capitulum terminal, with basis capituli short, scarcely visible from above. Dorsal plate large, oval. Hypostome long, sides

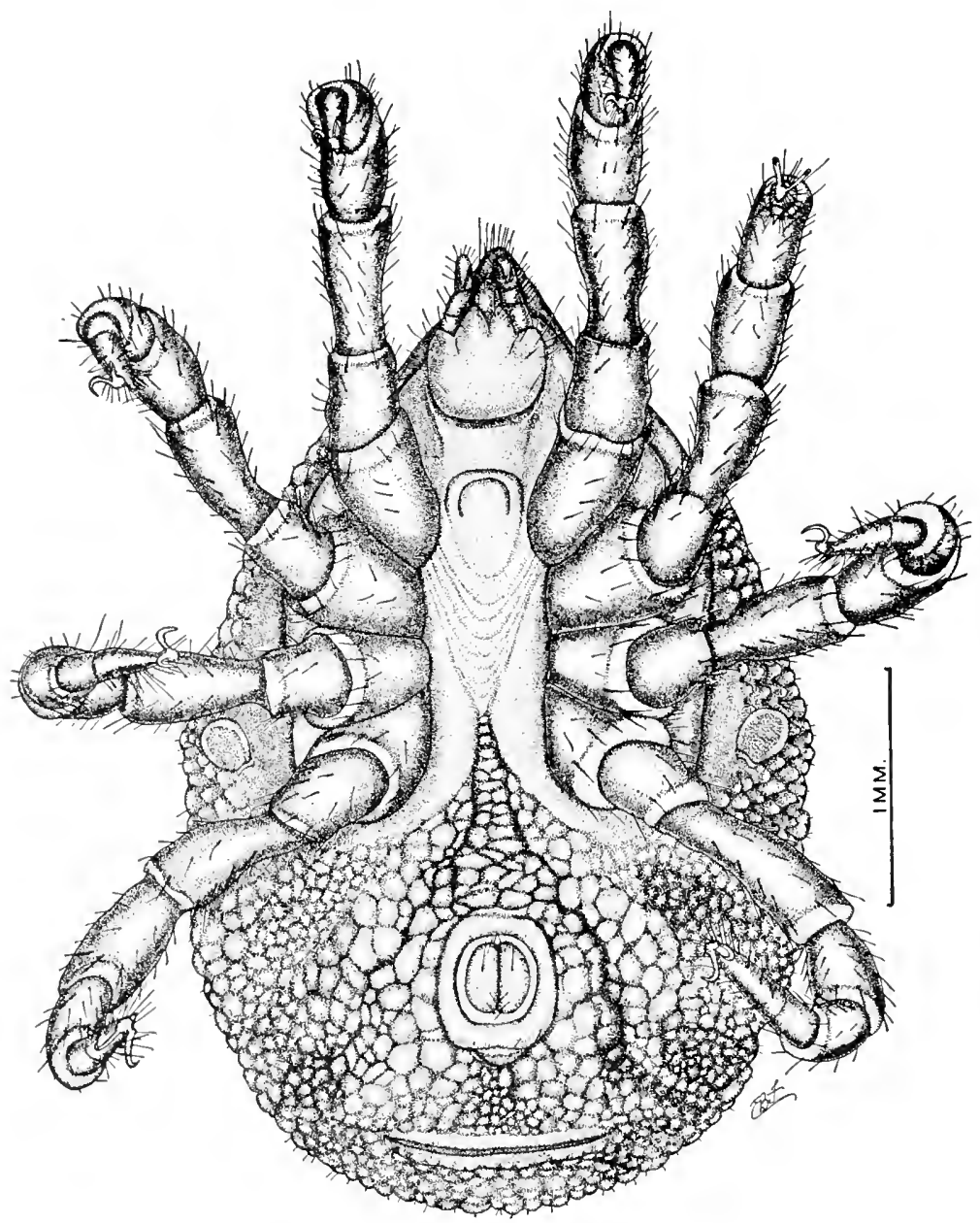

Fig. 55. Antricola coprophilus (McIntosh). Male, ventral view. From McIntosh (1935). 
subparallel, apex pointed. Denticles apically $3 / 3$, then $2 / 2$, those of the marginal files largest; those of the median files very small and not easily seen even when mounted in balsam. Length of hypostome, 0.12 .

\section{HOSTS}

While $A$. coprophilus is known to be associated with bats, the species has not been observed feeding on these animals. The junior author when at the Picacho Mine tunnel in Arizona, having 'both living coprophilus and living bats, attempted to feed the ticks on bats confined in a bag but was not successful. While the ticks in all stages may be found in abundance on the bat guano, they are at times numerous on the walls of the retreat. In one instance, a fomale was found laying eggs in a crevice near where the bats were hanging.

The type specimens were found in a carload of bat guano in October 1934, originating at Linares (Nuevo Leon), Mexico, and held in quarantine at Metamoros, Mexico; also in bat guano, May 29, 1931, at Tucson, Arizona, by Dr. L. P. Wehrle.

\section{DISTRIBUTION}

In addition to the localities noted above, the species has been collected as follows:

Arizona.-16083 and 16156, bat guano, September and October, 1939, mine tunnel, Picacho Mountain, Pinal County, several hundred nymphs and adults (Philip, 1940) ; 17863, 17866, locality as above, May 23, 1940, several hundred nymphs and adults.

Texas.-17258, bat guano, September 14, 1940, Ney Cave, Hondo, Medina County, several nymphs and adults; 17261, bat cave, September 16, 1940, Concan, Uvalde County, numerous nymphs and adults.

Mexico.- "Cueva de la Chepa" harboring numerous bats (Leptonycteris nivalis and Pteronotus davyi fulvus), near Tuxtla Gutierrez, Chipas, October, 1940 (Mazzotti, 1940); abandoned mine harboring numerous bats, 5 kilometers west of Coquimatlàn, Colima, November, 1940 (Mazzotti, 1941).

\section{Antricola marginatus (Banks), 1910}

Plate 14 . Figs. 56 and 57

1910. Ornithodoros marginatus Banks, original description, p. 6, with figures.

\section{FEMALE}

Body.-Size $6.62 \times$ 4.70. Banks (1910) gave the length as 5.0 to 8.0. Color light tan. Shape in dorsal view sub-oval, widest at about the middle, thence tapering to the anterior point which is bent ventrad; broadly rounded posteriorly. Dorsal surface flattened or even depressed (frd specimens would probably show the surface about level with the margin). Margin with a continuous row of large tubercles which follows the entire periphery, each bearing 
a tuft of long, barbed hairs. Body wall thin, semi-translucent, smooth and shining.

Tubercles.-In addition to the large, tufted tubercles which accentuate the margins are numerous small ones with one to four small lairs on each, scattered over the dorsal surface. They are absent or faint on the lateral walls above the legs. There is a large one above leg I and another above leg II. Anterior to the mouth parts on the venter, tubercles small and each with a single hair.

Discs.-Evidenced only by faint depressions in symmetrical areas which lack tubercles; absent on the venter.

Legs.-Long and large, with the surfaces smooth and shining and with numerous long, barbed hairs. All tarsi lack subapical dorsal protuberances and humps. Claws large. Length of tarsus I, 0.9; metatarsus, 1.02. Length of tarsus IV, 1.56; metatarsus, 1.20. (Measurement from a late nympha! stage which is about as large as the adult.)

Coxae--All coxae contiguous, smooth, shining, and with hairs as on the legs.
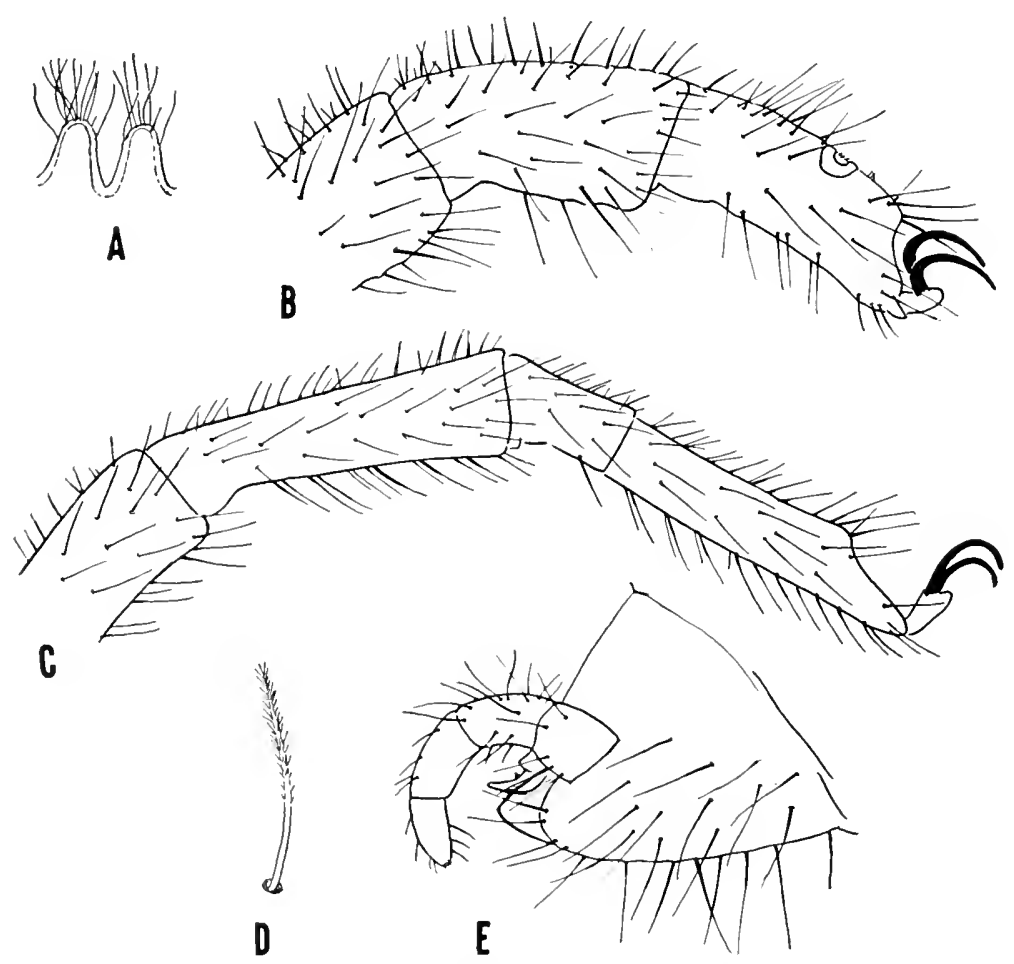

Fig. 56. Antricola marginatus (Banks). A. Tubercles from the margins. B, Leg 1 of nymph. C, Leg IV of nymph. D, Barbed hair. E, Capitulum of nymph, lateral view. 
Hood, camerostome and cheeks.-Absent.

Capitulum.--Large, a little flattened on the ventral side. Surface smooth and shining and with numerous long, barbed hairs. Palpi of moderate length; articles 2,3 and 4 free.

Hypostome.-Short, broad and rounded apically; convex ventrally and concave dorsally, thin and scoop-like; with numerous very fine denticles near the rounded edge.

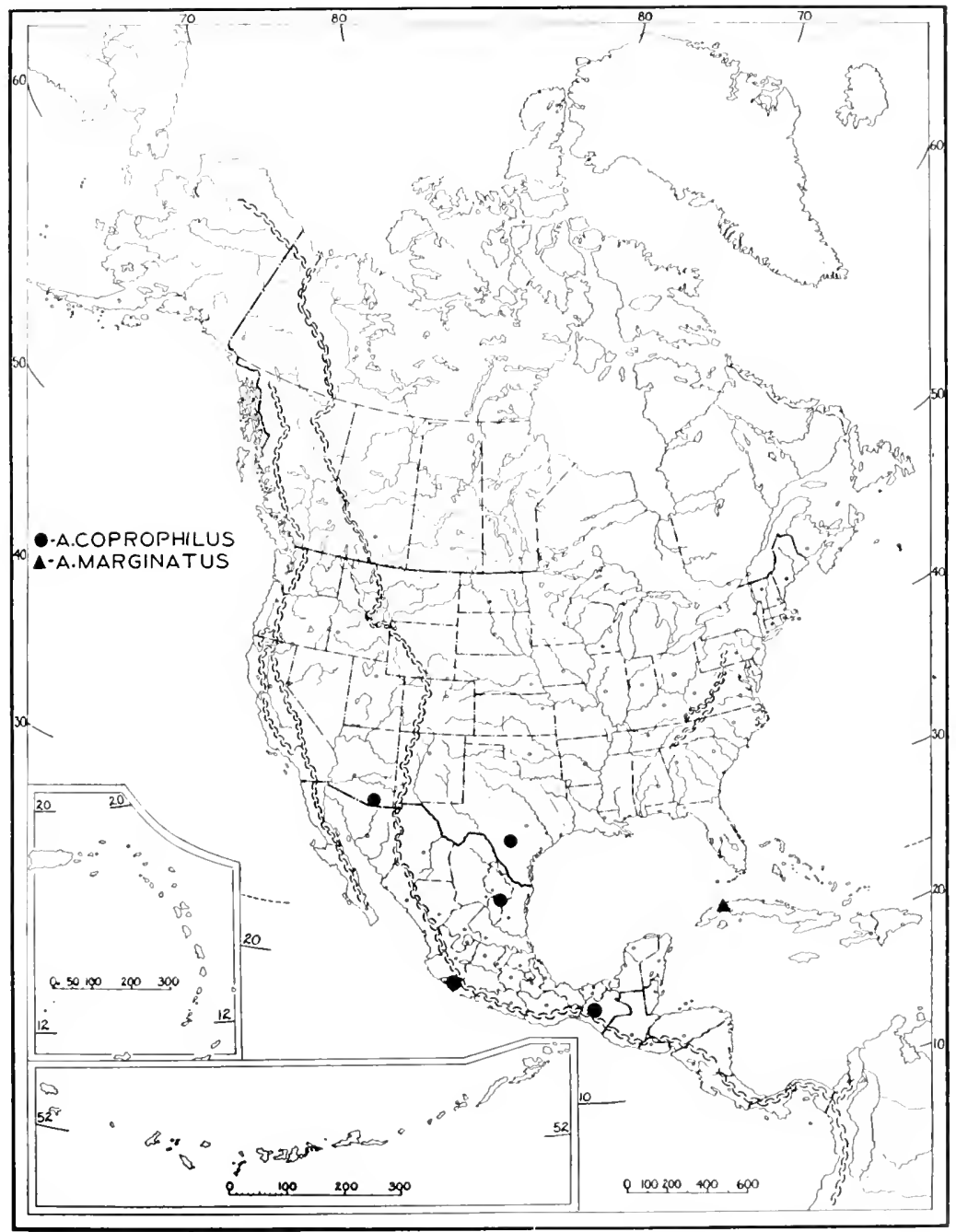

Fig. 57. Distribution of Antricola coprophilus (Mclntosh) and A. marginatus (Banks). 
Chelicerae.-Very large and long, with very effective digits.

Folds.-Coxal and supracoxal folds present.

Grooves.-Transverse postanal groove short and deep; all others absent or indefinite.

Spiracle.-A flattened, globular protuberance, free on all sides except on the attached smaller end.

Sexual opening.-Between coxae $\mathbf{I}$.

Anus.-Large, in an elliptical frame placed well back on the venter.

\section{NYMPH}

With the specimens before us it is evident that the nymphs differ from the adults only in their smaller size, absence of sex openings, and in having the marginal tubercles longer.

Male unknown.

HOST AND DISTRIBUTION

The type specimens were from a cave in Guanajay Mountains in Cuba; "also from a West Indian bat probably from Porto Rico." (Banks, 1910.)

Vigueras (1934) stated that Eumops glaucinus (Wagner) is a host and reported the collection of two females from bats, Nycticeius cubanus (Gundlach), captured in Santiago de las Vegas.

It is evident that this species is closely related to coprophilus (McIntosh) but the two are readily separated by the characters mentioned in the key to species. The original collection has been divided, part being in the National Museum and part in the collections of the Bureau of Animal Industry, U. S. Department of Agriculture, and neither lot contained a type label. The senior author has ssen all of the specimens. One female from these has been placed in the collections of the Rocky Mountain Laboratory, Hamilton, Montana. The combined lot contains 2 females and 18 nymphs of vatious sizes. Having available only one sex, we cannot determine at present whether the sexes are dissimilar in this species. In the relatively few specimens available and in view of their relatively small size it was not possible to determine whether the eventual sex would be indicated in late stage nymphs.

In the lot now in the collections of the Bureau of Animal Industry there is one small, probably a first stage, nymph which differs in having the tubercles on the margin smaller in diameter and relatively much longer than in the larger nymphs. It is possible either that $A$. marginatus makes this remarkable change during its development, or that it represents an early stage of ais undescribed species.

The single female in the lot in the National Museum was separated and labelled as the lectotype of the species. 
Cooley \& Kohls: Argasidae of N. Americ 4, Etc.

Plate 1

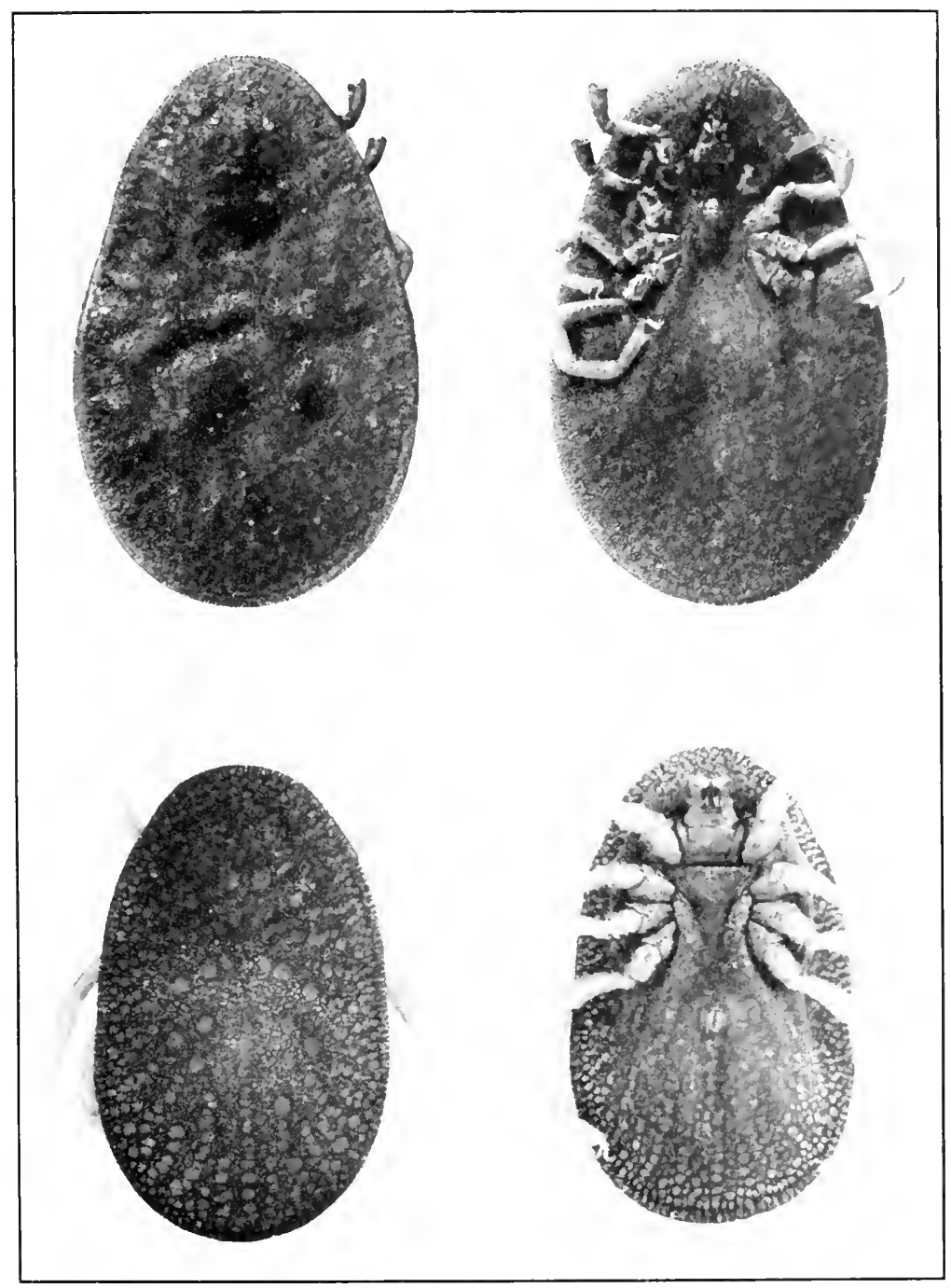

Argas reflexus (Fabricius)

Argas persicus (Oken) 
Plate 2

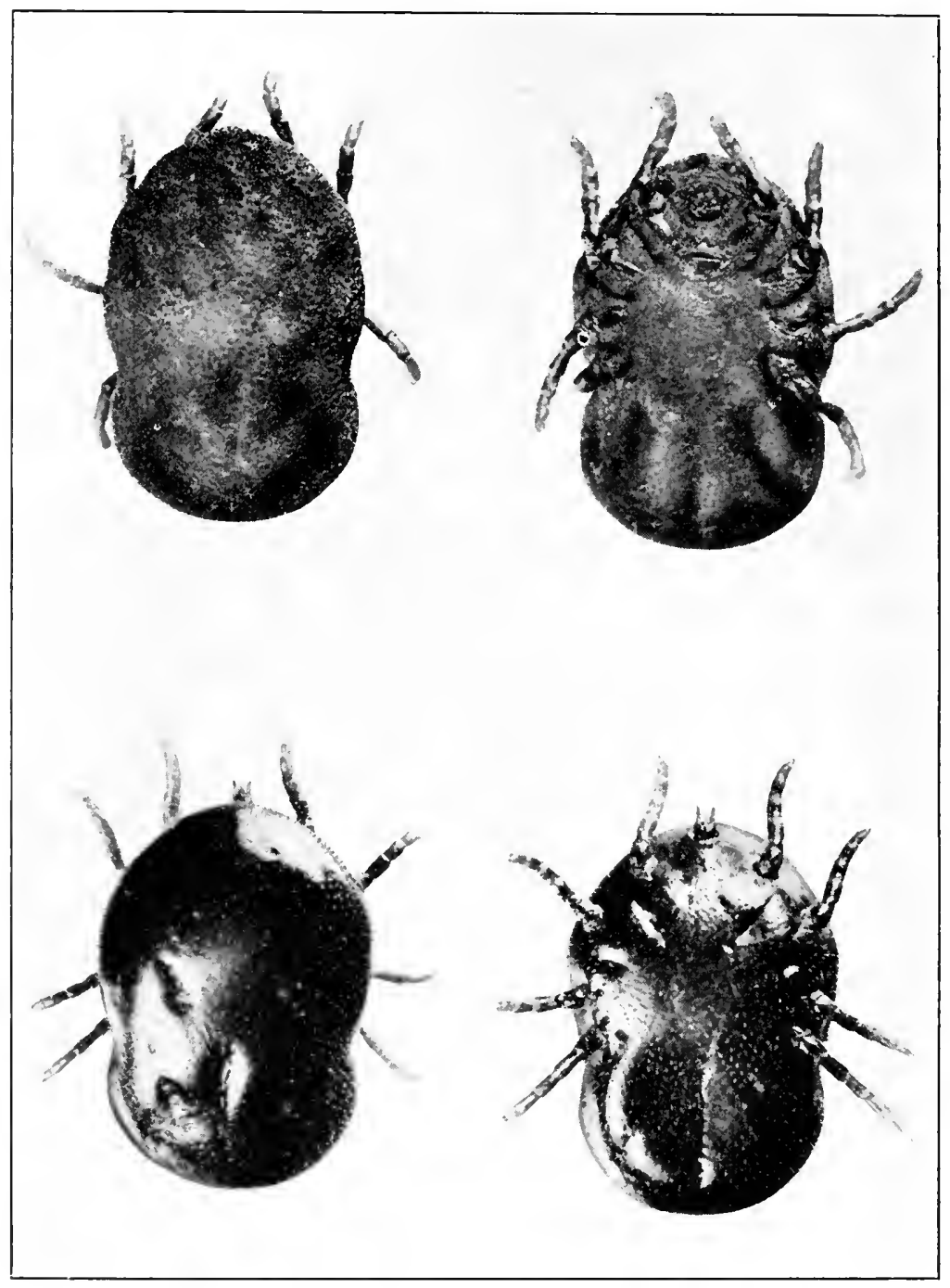

Otobius megnini (Dugès). Adult

Otobius megnini (Dugès). Nymph 


\section{Plate 3}

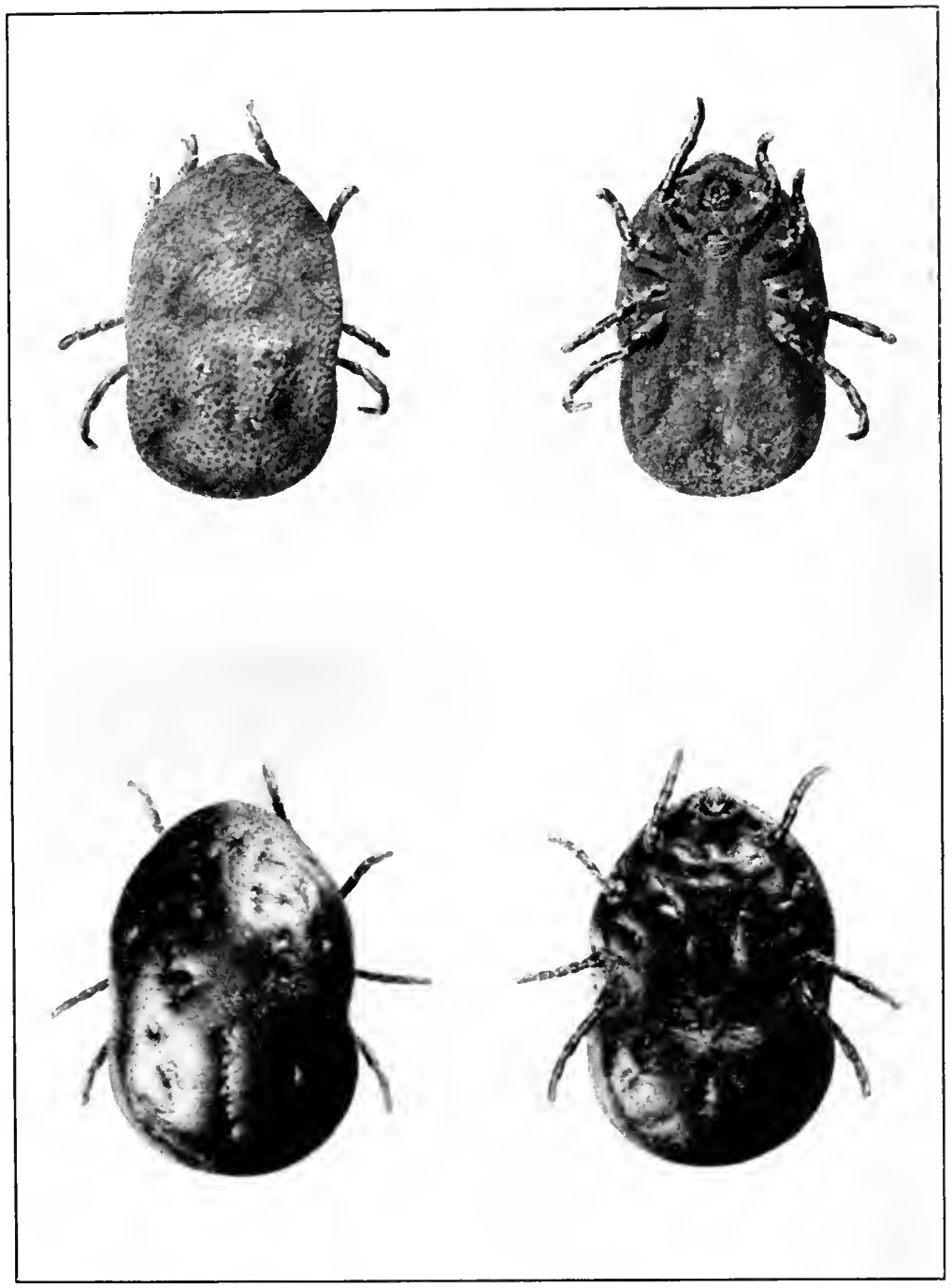

Otobius lagophilus Cooley and Kohls. Adult Otobius lagophilus Cooley and Kohls. Nymph 


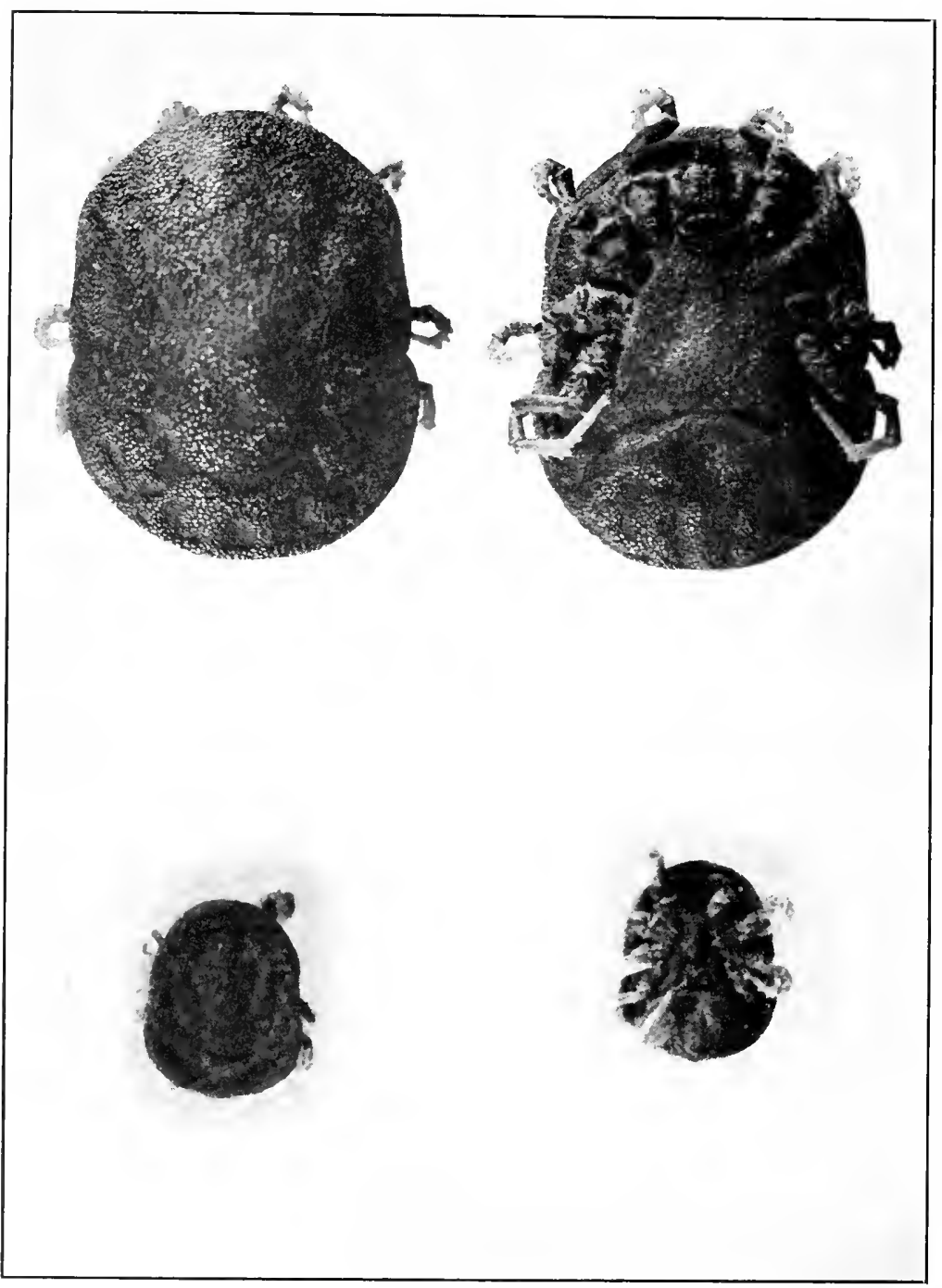

Ornithodoros savignyi (Audouin)

Ornithodoros eremicus Cooley and Kohls 
Plate 5

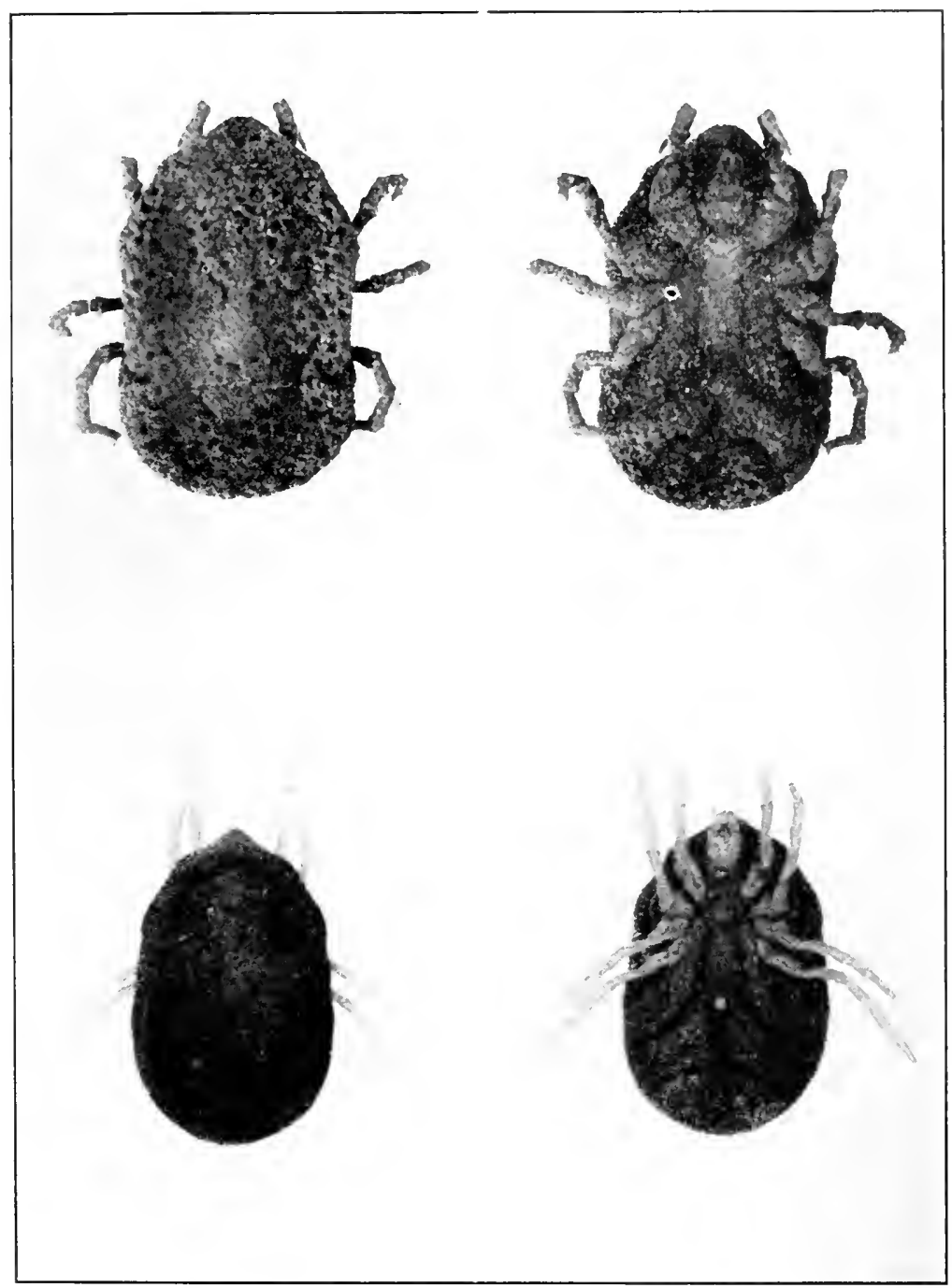

Ornithodoros coriaceus Koch

Ornithodoros hermsi Wheeler, Herms, and Meyer 
Plate 6

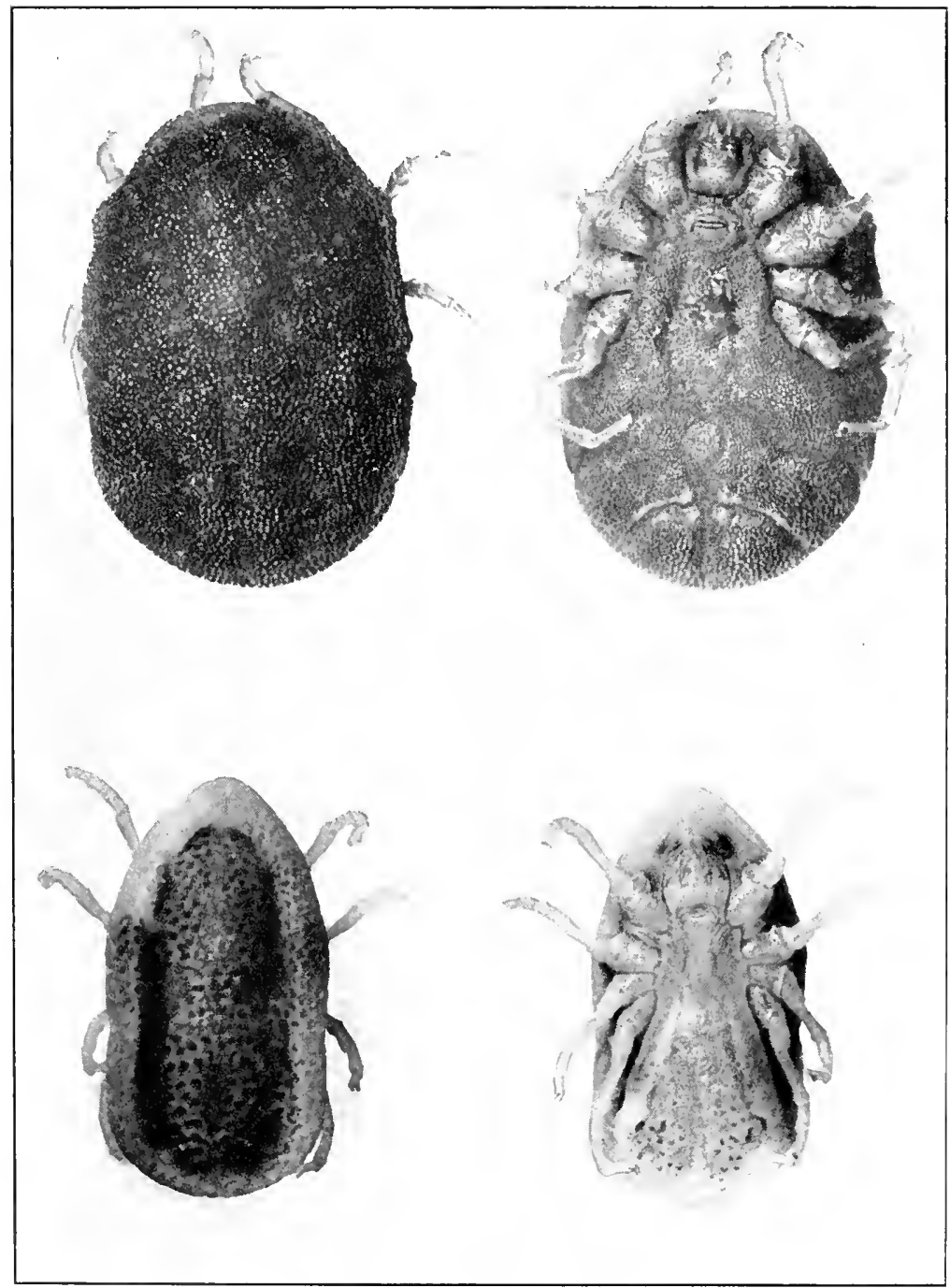

Ornithodoros nicollei Mooser

Ornithodoros coolevi McIvor 
Plate 7

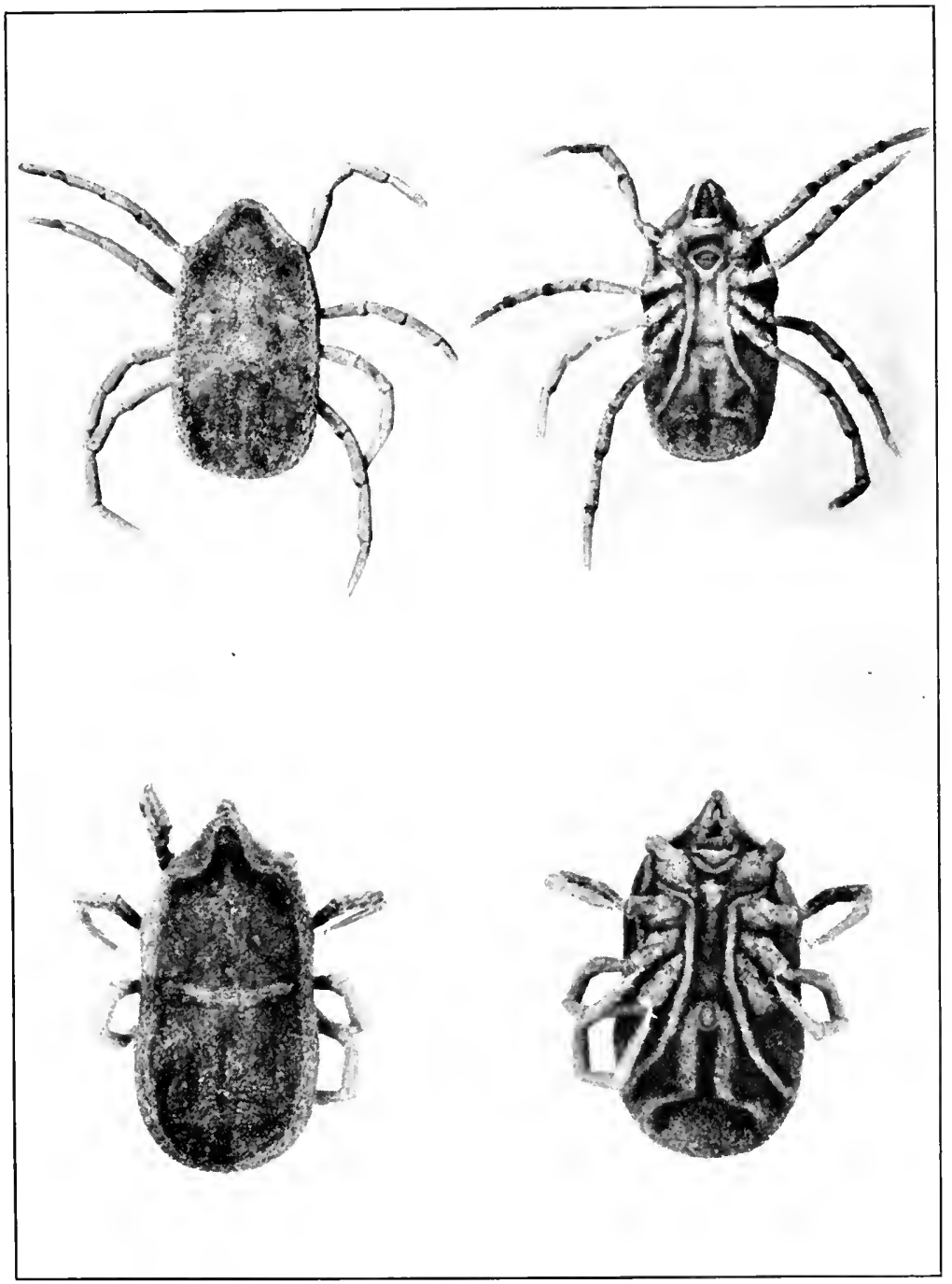

Ornithodoros yumalensis Cooley and Kohls

Ornithodoros brodyi Matheson 


\section{Plate 8}

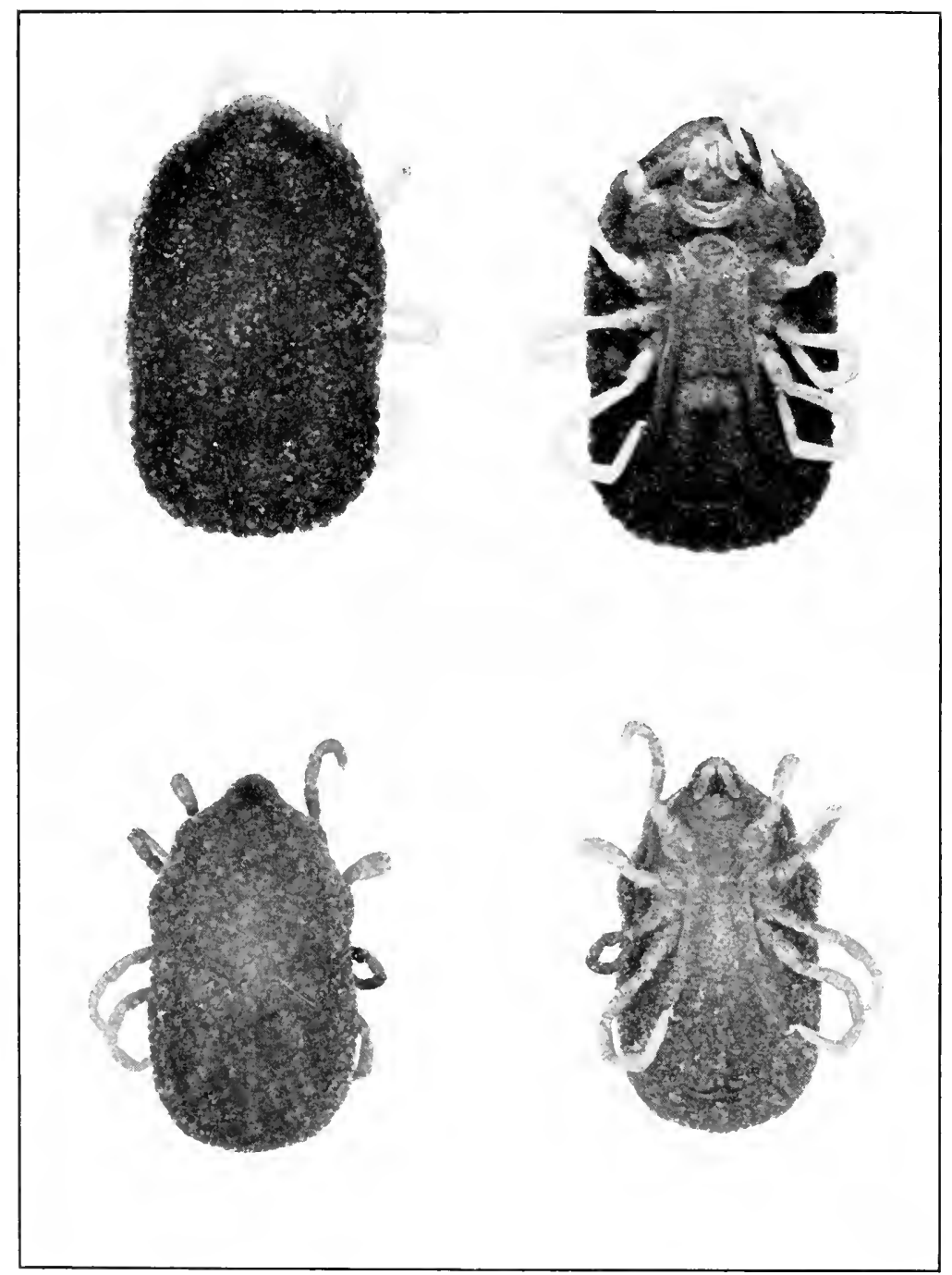

Ornithodoros talaje (Guérin-Méneville)

Ornithodoros concanensis Cooley and Kohls 
Coolly \& Kohls: Argasidae of N. Amfrica, etc.

Plate 9

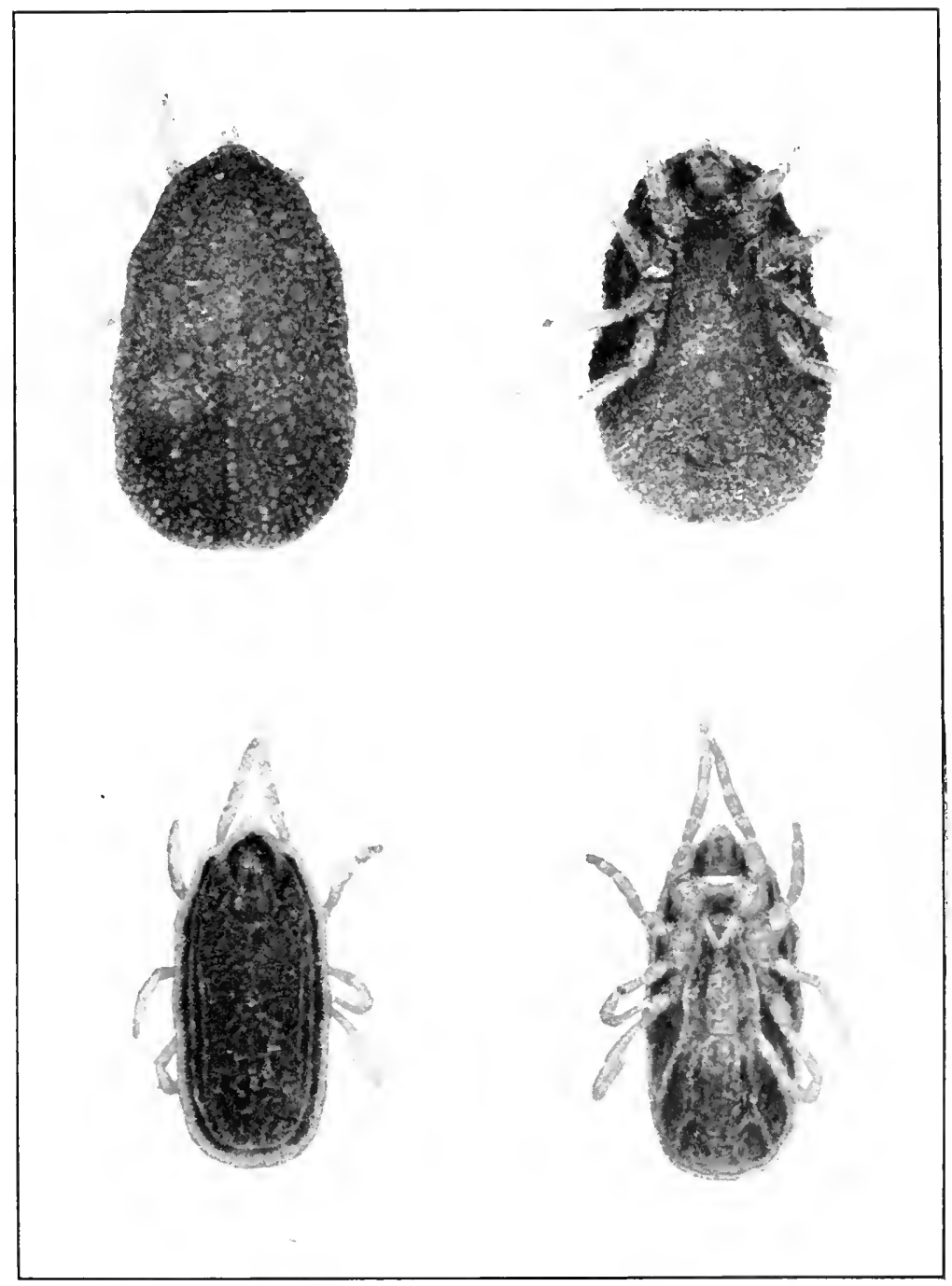

Ornithodoros stageri Cooley and Kohls

Ornithodoros dyeri Cooley and Kohls 
Plate 10

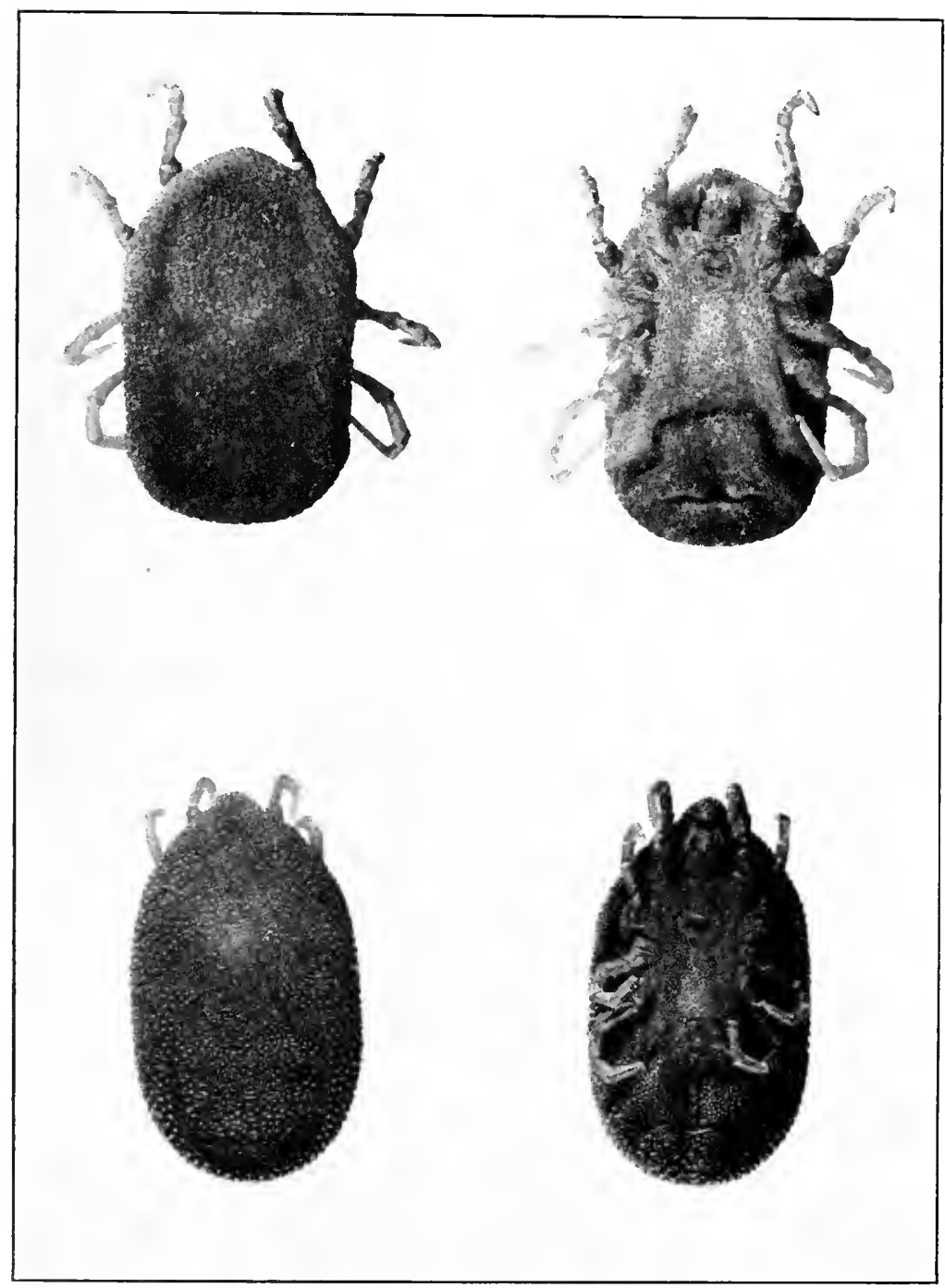

Ornithodoros amblits Chamberlin

Ornithodoros rudis Karsch 
Plate 11

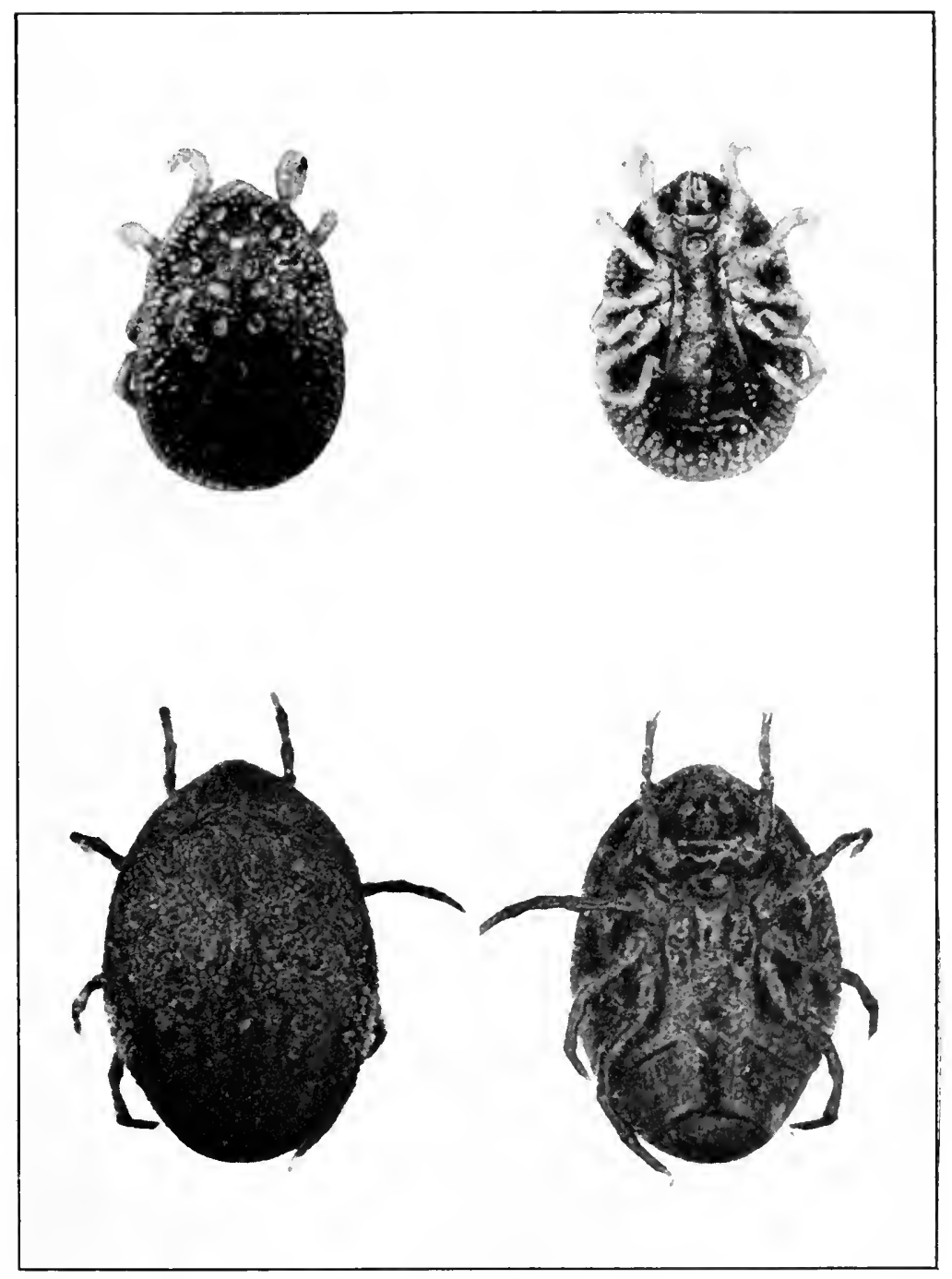

Ornithodoros dunni Matheson

Ornithodoros vigucrasi Cooley and Kohls 
Plate 12

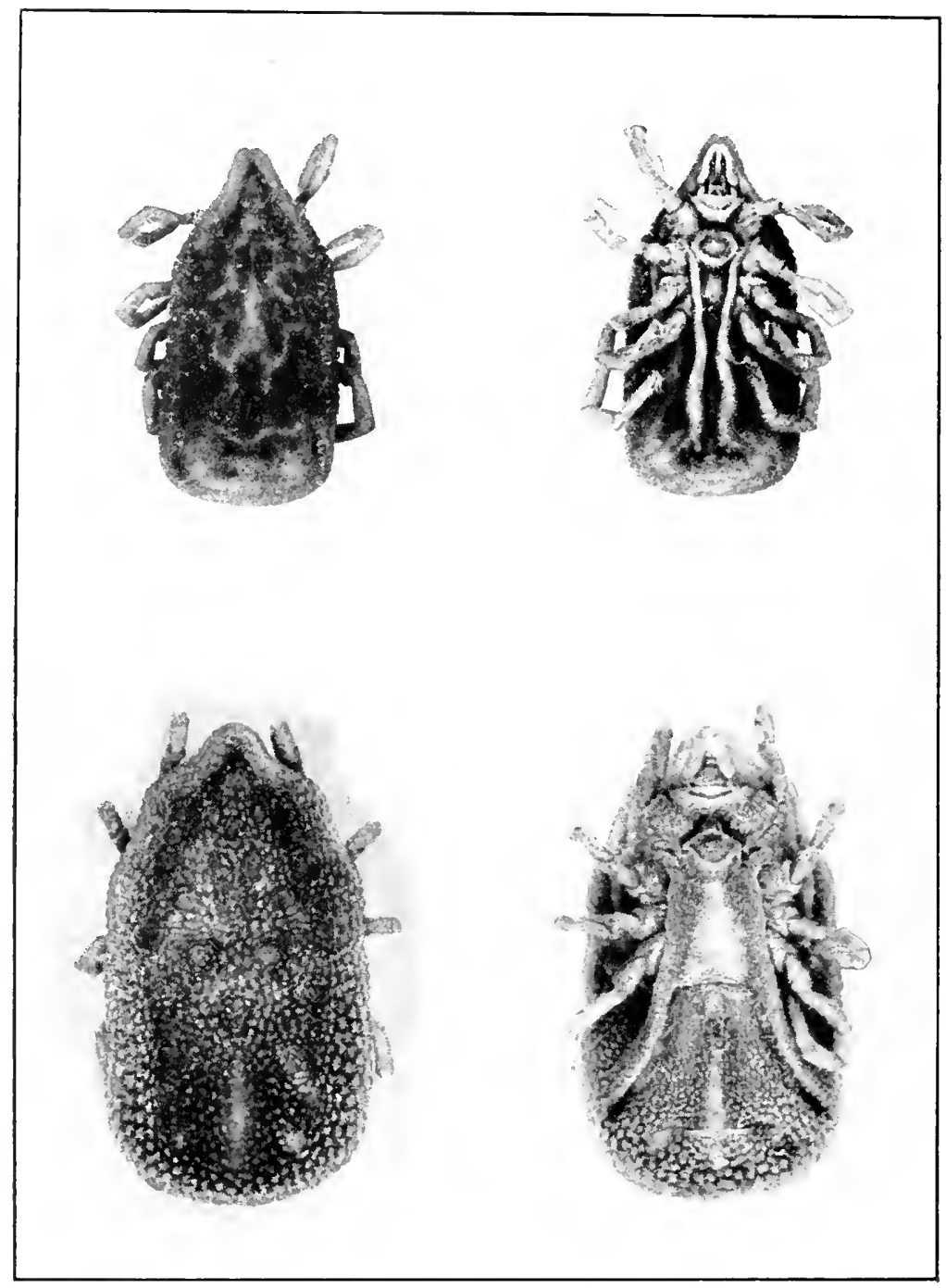

Ornithodoros azleci Matheson

Ornithodoros kelleyi Cooley and Kohls 
Plate 13

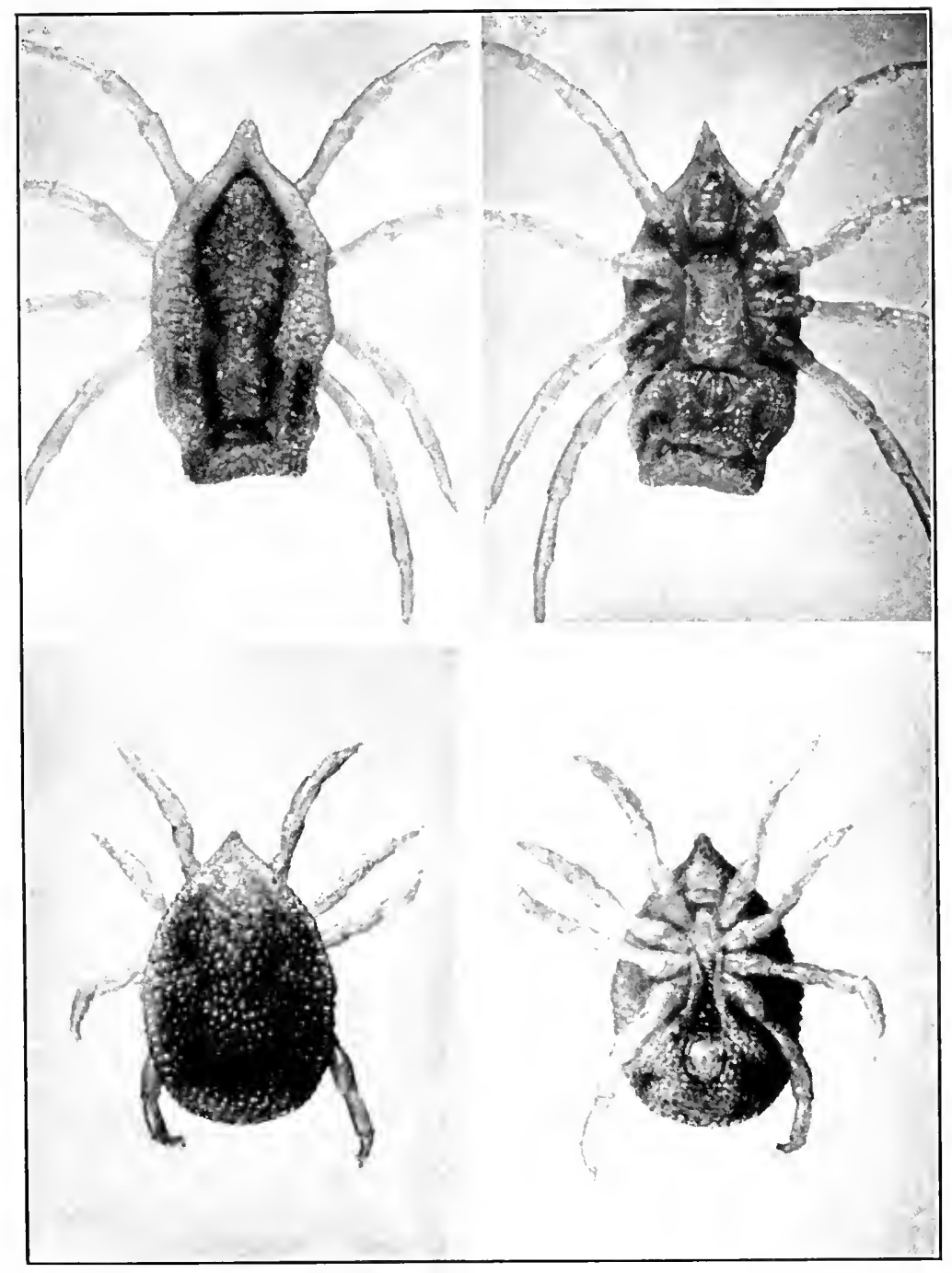

Antricola coprophilus (McIntosh). Female

$\therefore$ it ic is c prcphilus (Mclntosh). Male 
Plate 14

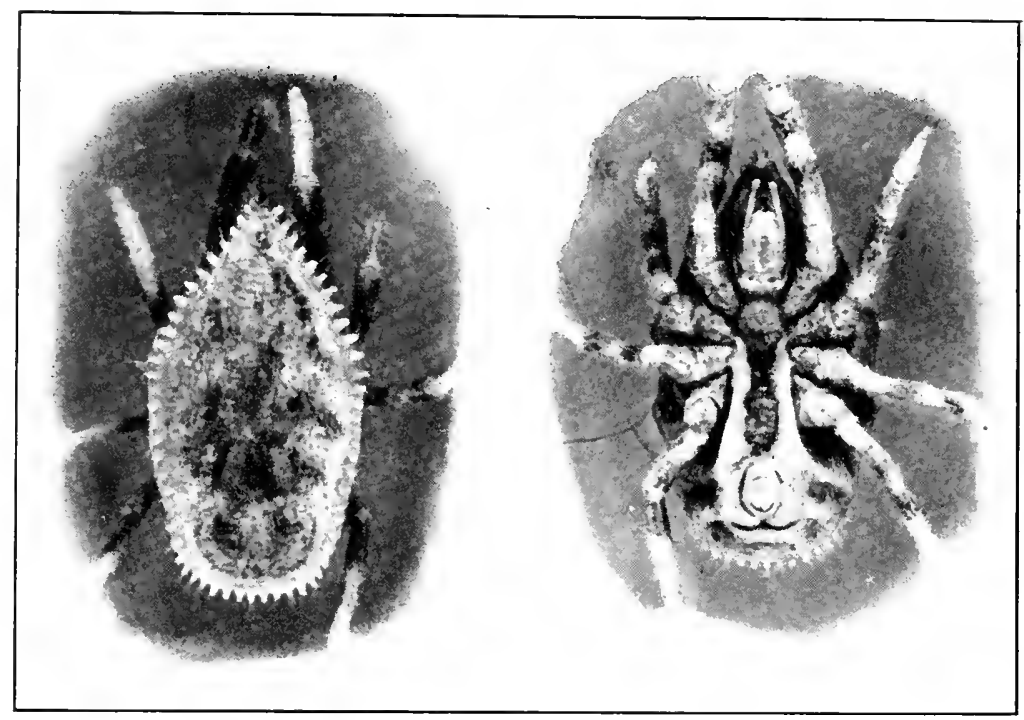

Antricola marginatus (Banks) 


\section{Classified List of Hosts}

Vertebrata

\section{Reptilia}

Serpentes

Boidae
Epicrates cenchris
Ornithodoros talaje

Crotalidae

"Florida diamond-back rattlesnake"

Ornithodoros nicollei

"Rattlesnake"

Ornithodoros turicata

\section{Testudinata}

\section{Testudinidae}
Terrapene ornata
Ornithodoros turicata
Terrapene sp.
Ornithodoros turicata
Gopherus polyphemus
Ornithodoros turicata
Copherus agassizii agassizii
Ornithodoros turicata

\section{Aves}

Struthioniformes

Struthionidae
Struthio australis (South Africa)
Struthio australis (South Africa)
Argas persicus
Otobius megnini

Spheniscidae

Spheniscus humboldti

SPHENISCIFORMES

Sulidae

Sula nebouxi

Ornithodoros amblus

Pelecaniformes

Ornithodoros talaje

ANSERIFormes

Anatidae

Anser domestica (Europe)

$$
\text { Argas reflexus }
$$

FaLCONIFORMES

Cathartidae

Gymnogyps californianus Argas reflexus

Sagittariidae

Sagittarius serpentarius (South Africa) Argas persicus

Perdicidae

"Quail"

Galliformes

Phasianidae

Gallus domesticus (Europe)

Gallus domesticus (Europe)

Gallus domesticus (Europe)

Argas persicus

Argas reflexus

Argas persicus

Ornithodoros talaje (?)

Numididae

Numida papillosa transvaalensis

(South Africa)

Argas persicus

Meleagrididae

Meleagris gallapavo

Argas persicus 
Columbidae

Columba livia (Europe)

Zenaidura macrura

Strigidae

Speotyto cunicularia

Speodyto cunicularia

Otus asio inyoensis (Nesting hole of)

Otus asio inyoensis (Nesting hole of)
Columbiformes

Argas reflexus

Argas persicus

\section{STRIGIFORMES}

Ornithodoros parkeri

Ornithodoros turicata

Argas reflexus

Argas persicus

\section{PAsseriformes}

Hirundinidae

"Cliff swallow's nest in cave."

Fringillidae

Zonotrichia coronata

Didelphiidae

Didelphis marsupialis etensis

Noctilionidae

Dirias albiventor minor

Phyllostomidae

Hemiderma perspicillatum aztecum

Hemiderma perspicillatum aztecum

Phyllonycteris poevi

Desmodontidae

Desmodus rolundus murinus

Vespertilionidae

Myotis californicus pallidus

Myotis lucifugus lacifugus

Myotis lucifugus subsp.

Myotis velifer velifer

Myolis velifer subsp.

Pipistrellus hesperus hesperus

Pipistrellus subflavus

Nycticeius cubanus

Molossidae

Tadarida mexicana

Eumops glaucinus
Ornithodoros coriaceus

Argas persicus

\section{Mammalia}

\section{Marsupialia}

Ornithodoros talaje

\section{Chiroptera}

Ornithodoros dunni

Ornithodoros azteci

Ornithodoros brodyi

Ornithodoros viguerasi

Ornithodoros azteci

Ornithodoros Rellevi

Ornithodoros kellevi

Ornithodoros kellevi

Ornithodoros yumatensis

Ormithodoros stageri

Ornithodoros kellevi

Ornithodoros kelleyi

Antricola marginatus

Ornithodoros stageri

Antricola marginatus

\section{Carnivora}

Mustelidae

Mustela sp.

Ornilhodoros parkeri

Canidae

Canis familiaris

Canis familiaris

Canis sp. (coyote)

Otobius megnini

Ornithodoros talaje

Otobius megnini

Felidae

Felis catus

Otobius lagophilus

Felis catus

Ornithodoros talaje 


\section{Primates}

"White faced monkey"

Alouatidae

$$
\text { Alonatla palliata palliata }
$$

Cebidae

Cchus capucinus capucinus

Cebus capucimus initator

Saimiridae

Saimiri orstedii orstedii

Hominidae

Homo sapiens

\author{
Ornithodoros talaje \\ Ornithodoros talaje \\ Ornithodoros talaje \\ Ornithodoros talaje \\ Ornithodoros talaje \\ Argas reflexus \\ Argas persicus \\ Ototius megnini \\ Ornithodoros coriacens \\ Ornithodoros hermsi \\ Ornithodoros nicollei \\ Ornithodoros parteri \\ Ornilhodoros rudis \\ Ornithodoros stageri \\ Ornithodoros talaje \\ Ornithodoros turicata
}

\section{Rodentia}

Sciuridae

Marmola sp.

Citellus sp.

Citcllus sp.

Citcllus sp.

Citellus teecheyi

Citellus beechevi fisheri

Citellus columbianus

Citellus richardsoni

Cynomys sp.

Cynomys sp.

Conomys leucurus

Eutamias sp. (nest of)

Heteromyidae

Dipodomys sp.

Dipodomys sp. (burrows of)

Dipodomys sp. (burrows of)

Cricetidae

Peromyscus sp.

Peromyscus maniculatus

Neotoma floridana hailevi

Neotoma sp.

Neotoma sp. (den of)

Hodomys alleni

Muridae

Rattus norvegicus

Rattus rallus

Raltus raltus alexandrinus

Leporidae

Lepus sp. (jack rabbits)

Lepus sp. (jack rabbits)

Lepus sp. (jack rabbits)
Ornithodoros parkeri

Ornithodoros talaje

Ornithodoros turicata

Ornithodoros parkeri

Ornithodoros talaje

Ornithodoros turicata

Ornithodoros parkeri

Ornithodoros parkeri

Ornithodoros parleri

Ornithodoros turicata

Ornithodoros parkeri

Ornithodoros hermsi

Ornithodoros talaje

Ornithodoros turicata

Ornithodoros parleri

Ornithodoros parkeri

Ornithodoros eremicus

Ornithodoros talaje

Ornithodoros talaje

Ornithodoros turicata

Ornithodoros nicollei

Ornithodoros talaje

Ornithodoros talaje

Ornithodoros talaje

\section{LAGOMORPHA}

()rnithodoros iuricala

()tobius lagophilus

()tohius megnini 
Lepus californicus

Lepus californicus deserticola

Lepus californicus nalla nalla

Lepus tomnsendii

Sylvilagus sp.

Sylvilagus sp.

Sylvilagus sp.

Sylvilagus sp.

"Rabbit"
Otobius lagophilus

Otobius lagophilus

Otobius megnini

Otobius lagophilus

Otobius lagophilus

Otobius megnini

Ornithodoros parteri

Ornithodoros turicata

Otobius lagophilus
Suiidae

Sus scrofa

Cervidae

Odocoileus hemionus subsp.

Odocoileas hemionus subsp.

Odocoilcus hemionus columbianus

Odocoileus virginianus

"Deer"

Bovidae
Bos taurus
Bos taurus
Bos taurus
Ovis aries
Ovis canadensis
Capra hircus

Equidae

Equus caballus

Equus caballus

Equus caballus (Rumania)

Equus asinus

Mule
Artiodactyla

Ornithodoros turicata

Otobius megnini

Ornithodoros coriaceus

Ornithodoros coriaceus

Otobius megnini

Otobius megnini

Otobius megnini

Ornithodoros turicata

Ornithodoros coriaceus

Otobius megnini

Otobius megnini

Otobius megnini

Perissodactylla

Otobius megnini

Ornithodoros luricata

Argas reflexus

Otobius megnini

Otobius megnini

\section{Geographical Distribution of Species}

\section{CANADA}

Argas persicus :

Otobius lagophilus:

British Columbia

Otobius megnini:

Alberta

British Columbia

\section{United States}

Argas reflexus

California, Montana

Argas persicus:

Widespread

Otobius lagophilus:

California, Colorado. Idaho, Montana, Nevada, Oregon, Wyoming.

Otobius megnini: Widespread

Ornithodoros amblus: In "seaport" in guano shipment from Peruvian islands.

Ornithodoros concanensis: Arizona, Texas

Ornithodoros cooleyi: Nevada

Ornithodoros coriaceus:

California

Ornithodoros dyeri: Arizona, California

Ornithodoros

eremicus:

Utah 
Ornithodoros hermsi:

Ornithodoros belleyi:

Ornithodoros ricollei:

Ornithodoros parteri:

Ornithodoros stageri:

Ornithodoros talaje:

Ornithodoros turicata:

Ornithodoros vumatensis :

Antricota coprophilus:
California, Colorado, Idaho, Nevada, Oregon. Utah, Colorado, Illinois, lowa, Minnesota, New York, Pennsylvania, Wisconsin.

Missouri (in Zoo).

California, Colorado, Idaho, Montana, $\mathrm{Ne}$ vada, Oregon, Utah, IV ashington, Wyoming. Arizona, California, Oklahoma, Texas.

Arizona, California, Florida, Kansas, Nevada. Texas.

Arizona, California, Colorado, Florida, Kansas, New Mexico, Oklahoma, Texas, Utah. Arizona, California, Texas.

Arizona, Texas.

\section{MeXico}

Argas persicus:

Widespread.

Otobius megnini:

Widespread.

Ornithodoros coriaceus:

Widespread.

Ornithodoros dyeri:

Ornithodoros nicollei:

Ornithodoros talaje:

Ornithodoros turicata:

Antricola coprophilus: State of Colima.

States of Guerrero and Colima.

Widespread.

Widespread.

States of Nuevo Leon. Chiapas and Colima.

\section{Guatemala}

Ornithodoros talaje:

Probably widespread.

\section{Panama}

Argas persicus:

Widespread.

Ornithodoros azteci:

Ornithodoros brodyi:

Ornithodoros dunni:

Ornithodoros rudis :

Ornithodoros talaje:

Widespread.

Chilibrillo Caves.

Panama City; Summit, Canal Zone.

Widespread.

Widespread.

\section{CuBA}

Argas persicus:

Provinces of Havana, Matanzas, and Santa Clara.

Otobius megnini: Province of Havana.

Ornithodoros azteci: Holguin, Guanajay.

Ornithodoros viguerasi: Cueva Somorrostro (near Jamaica).

Antricola marginatus: 


\section{BIBLIOGRAPHY}

Aitken, Thomas H. G. 1939-Ornithodoros talaje on the California mainland. PanPacific Entomol. 15:12-13.

Aragao, H. DE B. 1935-Observacoes sobre os Ixodideos da Republica Argentinia. Mem. Inst. Osw. Cruz, Rio de Janeiro 30:519-533, I pl.

Audoun, J. V. 1826-Expl. somm. d. Pl. d. Moll.-Arachnides,- de l'Egypte-. p. J. C. Savigny.-Extr. d. 1. Desc. de l'Egypte, Paris, 2nd ed., 1:182-186, pl. 9. (Cited by Oudemans, 1936.)

Banks, N. 1904-Some Arachnida from California. Proc. California Acad. Sci. $3: 331-369$. Pl. 38-41.

-1908-A revision of the Ixodoidea, or ticks of the United States. U. S. Dept. of Agri.. Bur. of Entomol. Tech. Ser. 15:1-61, 10 pls.

1910 New American Mites. Arachnoidea, Acarina. Proc. Entomol. Soc. Washington $12: 2-12,3$ pls.

1912-New American mites. Proc. Entomol. Soc. Washington 14:96-99.

Bedford, G. A. H. 1912-A tick new to South Africa. Rept. Dir. Vet. Res. Union S. Africa $2: 343-344$, pl. 37.

1932-A synoptic check-list and host-life of the ectoparasites found on South African Mammalia. Aves, and Reptilia. 2nd. ed., 18th Rep. of the Dir. of Vet. Serv. and An. Ind., Union of South Africa; 223-523.

1934-South African ticks. Onderstepoort Journ. Vet. Sci. and An. Ind. $2: 49-99$.

Berlese, A. 1888-Acari Austro-Americani. Boll. della Soc. Entomol. Italiana $20: 171-223$.

1889-Acari africani tres illustrati. Atti della Soc. veneto- trentina di sc. naturali 10:289-300, pl. 7, figs. 2-4. (Cited by Nuttall et al., 1908.)

Bishopp, F. C. 1927-The fowl tick and how premises may be freed from it. U. S. Dept. Agri. Farmer's Bull. 1070:1-13.

Brebisson, L. A. DE. 1827 -Catal. Arachn. Myr. Ins. Apt. Calvados. Mém. Soc. Linn. Normandie $3: 265-268$. (Cited by Oudemans, 1936.)

Briggs, LeRoy H. 1935-Relapsing fever. California and West. Med. 42:350-354.

Brown, J. C. And J. C. Cross. 1941-A probable agent for the transmission of fowl paralysis. Science 93:528.

Brumpt, E. 1922-Précis de Parasitologie, 3rd ed., 2, Paris. 1936 - Précis de Parasitologie, 5th ed., 2. Paris.

1936-Contribution à l'étude de l'évolution des ornithodores. Biologie et longévité de l'Ornithodorus megnini. Ann. de Parasit. Humaine et Comparée 14:647-651.

Brumpt, E., Mazzotti, L., and L. C. Brumpt. 1939-Étude épidémiologique de la fièvre récurrente endémique des hauts plateaux Mexicains. Ann. de Parasit. Humaine et Comparée 17:275-286.

Chamberlin, R. V. 1920 -South American Arachnida, chiefly from the guano islands of Peru. Brooklyn Mus. Sci. Bull. 3:35-44, pl. 4. 
Chamberlin, W. J. 1937-The ticks of Oregon. Oregon Agri. Expt. Station Bull. $349: 1-34,11$ figs.

Cooley, R. A. 1936 Ornithodoros parkeri, a new species on rodents. Pub. Health Rept. $51: 431-433, \mathrm{pl} .1$.

Cooley, R. A. And G. M. Kollls. 1940-Two new species of Argasidae (Acarina: Ixodoidea). Pub. Health Rept. 55:925-933, pl. I, figs. 1-3.

1941a-Ornithodoros vigucrasi, a new species of tick from bats in Cuba (Acarina: Ixodoidea). Pub. Health Rept. 56:396-399. pl. I, I fig.

1941b-Three new species of Ornithodoros (Acarina: Ixodoidea). Pub. Health Rept. 56:587-594, pl. 1-2, figs. 1-4.

1941 - Further new species of Ornithodoros from bats (Acarina: Argasidae). Pub. Health Rept. 56:910-914, pl. 1, figs. 1-3.

-1942-Antricola new genus, Amblyomma gertschi new species, and notes on lxodes spinipalpis. (Acarina: lxodoidea). Pub. Health Rept. 57:1733-1736. 1 pl.. 1 fig.

DARLiNg, S. T. 1922- The rat as a disseminator of the relapsing fever of Panama. Journ. Am. Med. Assoc. 79:810-812.

Davis, Gordon E. 1936-Ornithodoros turicata: The possible vector of relapsing fever in southwestern Kansas. Pub. Health Rept. 51:1719.

1939-Ornithodoros parkeri: Distribution and host data; spontaneous infection with relapsing fever spirochetes. Pub. Health Rept. 54:1345-1349.

-1939-Relapsing fever: Ornithodoros hermsi a vector in Colorado. Pub. Health Rept. 54:2178-2180.

Davis, Gordon E. ANd M. E. Walker. 1940-Ornithodorus hermsi: Feeding and molting hapits in relation to the acquisition and transmission of relapsing fever spirochetes. Pub. Health Rept. 55:492-504.

Dugès, Alf. 1876-Turicata de Guanajuato. El Repertorio de Guanajuato, April 25. (Newspaper.) (Cited by Mégnin, 1885.)

1884-Turicata y garrapata de Guanajuato. La Naturaleza, periodico cientifico de la sociedad Mexicana de historia natural, 6(1882-1884):195-198, pl. 4. Mexico. (MS dated Nov. 1882.)

1891-Argas sanchezi-nobis. La Naturaleza, periodico scientifico de la sociedad Mexicana de historia natural, Ser. 2, $1: 20$. Mexico.

DunN, L. H. 1923-The ticks of Panama, their hosts, and the diseases they transmit. Am. Jour. Trop. Med. 3:91-104.

1927a-Notes on two species of South American ticks, Ormithodoros talaje Guerin-Mene. and Ornithodoros venezuclensis Brumpt. Journ. of Parasitol. $13: 177-182$.

1927b-Studies on the South American tick. Ornilhodoros venezuelensis Brumpt. in Colombia, its prevalence, distribution, and importance as an intermediate host of relapsing fever, Jour. Parasitol. $13: 249-255$.

1931-Notes on the tick Ornithodoros talaje (Guer.) infesting a house in the Canal Zone. Psyche 38:170-173.

1933-Observations on the host selection of Ornithodorus talaje Guern., in Panama. Am. Journ. Trop. Med. 13:475-483.

Erichson, G. F. 1845-Arachnidae. In: Agassiz. Nomenclatoris zoologici, etc. 
Fabricius, J. C. 1794-Entomologia systematica, etc. Vol. 4 Ticks, 425-434. Hafniae. (Cited by Nuttall et al., 1908.)

1805-Systema antliatorum secundum ordines, etc. Brunsvigiae. (Cited by Nuttall, et al., 1908.)

Fischer de Waldheim, G. 1823-Notice sur l'Argas de Perse (Mallèh de Mianèh) décrit par les voyageurs sous le nom de punaise venimeuse de Miana. Mém. Soc. Imp. de nat. de Moscou 6:269-283, pl. 23, figs. 1-I1. (Cited by Nuttall et al., 1908.)

Gerstaecker, C. E. A. 1873-Gliederthiere Ostafrika's von C. v. d. Decken's Reise; 464-470. (Cited by Nuttall et al., 1908.)

Gervais, P. 184t-Acarídes, In Walckenaer's Histoire naturelle des Insectes, Aptères, 3:1-476. (Argas chinche Goudot, pp. 462-463.) (Cited by Oudemans, 1936.)

Guérin-Míneville, F. E. 1828-Hist. nat. Ins. 1. Paris. (Cited by Oudemans, 1936.) 1844-Iconographie du règne animal, de G. Cuvier, 16-17, pl. 6. (Cited by Nuttall et al., 1908.)

1849-Description de l'Argas talaje. In: Rev. et Mag. de Zool. 1:342-344, pl. 9.

Harbinson, Charles F. 1937-The adobe tick on Gopherus agassizii. Herpetologica. $1: 80$.

Hearle, Eric. 1938-The ticks of British Columbia. Sci. Agri. 18:341-354.

Hermann, J. F. 1804-Mémoire Aptérologique, An. XI1, 63-71. Strasbourg. (Cited by Nuttall et al., 1908.)

Herms, W. B. and C. M. Wheeler. 1936 -Ornithodoros hermsi Wheeler as a vector of relapsing fever in California. Journ. Parasitol. 22:276-282.

Herms, Wm. B. 1939-Medical entomology with special reference to the health and well-being of man and animals. 3rd ed., 582 pp., 196 figs. Macmillan, New York.

Herrick, C. A. 1935-The tick Ornithodoros talaje in Wisconsin houses. Journ. Parasitol. $21: 216-217$.

Hxon, H. 1932-'The life history and habits of Ixodes sculptus Neumann (Ixodidae). lowa State Journ. Science 7:35-42.

Hoffman, Carlos C. 1930 -Monographias para la entomologia medica de Mexico. Monografia Núm. I, Los Argasidos de Mexico. An Inst. Biol. 1:135-164, figs.

Hooker, W. A., Bishopp, F. C., ANd H. P. Wood. 1912-The life history and bionomics of some North American ticks. U. S. Dept. Agri. Bur. of Entomol. Bull. 106:239 pp., figs.

JELLISON, WM. L. 1940--The burrowing owl as a host to the argasid tick, Ornithodorus parkeri. Pub. Health Rep. 55:206-208.

Jennings, A. H. 1912-Some notes on the tick Ornithodoros talaje Guerin. Proc. Entomol. Soc. Washington 14:77-78.

Karsch, F. 1880-Vier neue Ixodiden des Berliner Museums. Mittheil. d. Münchener entomol. Vereins $4: 141-142$.

Kelley, Thomas F. 1940 - Ornithodoros turicala in California (Arachnida, Acarina). Pan-Pacific Entomologist 16:106-107.

Kingston, J. S. 1936-Spinose ear tick in India. Journ. Royal Army Vet. Corps $7: 1+2-1+3$. 
Kocri, C. L. 1844 -Systematische Uebersicht uber die Ordnung der Zecken. Arch.f. Naturgeschichte 10(I):217-219.

1847-Uebersicht des Arachnidensystems. Nürnberg, 4:136 pp., pl. 1-30.

Kohls, Glen M. And R. A. Coolex. 1936- Notes on the occurrence and host relationships of the tick Ornithodoros talaje in Arizona. Pub. Health Rept. $51: 512-513$.

Latreille, P. A. 1795-Observations sur la variété des organes de la bouche des Tiques, etc. Mag. encyl. ou Journ. d. Sciences des Lettres et des Arts 4:15-20.

- 1796 Précis des caractères génériques des insectes disposés dans un ordre naturel. xiv + 202 pp. 8 vo. Brive. An V (lssued in 1796).

1802-Histoire naturelle, générale et particulière, des Crustacés et des Insectes, etc. $3: 66$. Paris. (Cited by Oudemans, 1929.)

1829-Crustacés, arachnides et partie des insectes. In Cuvier's Le règne animal, 4:584. Paris.

Mclntosh, A. 1935-Description of a tick, Ornithodoros coprophilus n. sp., from bat guano. Parasitol. $27: 519-522$, pl. 18, fig. 1-2.

MCIvor, Barbara C. 1937-A new species of Ornithodoros tick from California (Acarina, lxodoidea). Journ. of Parasitol. 23:365-367, pl. 1, fig. 1.

- 1941-A new Ornithodoros tick from Nevada (Acarina: Ixodoidea). Journ. Parasitol. $27: 435-436$, figs. 1-4.

MARX, G. 1895-Obituary notice of his work. Proc. Entomol. Soc. Washington $3: 195-201,1 \mathrm{pl}$.

Matheson, R. 1931-Note on the tick Ornithodorus talaje (Guerin-Men.). Parasitology $23: 270$.

1935-Three new species of ticks, Ornithodorus (Acarina, lxodoidea). Journ. Parasitol. $21: 347-353$, I pl., figs. 1-7.

1941-A new species of tick, Ornithodoros anduzei, (Ixodoidea, Argasidae) from bat caves in Venezuela. Bol. de Entomologia Venezolana 1:3-5.

Mazzotti, L. 1940 Ornithodoros coprophilus McIntosh, en el estado de Chiapas. Mexico. Ciencia $1: \$ 05-406$.

1941-Ornithodoros dyeri en Mexico. Revista Medicina de Mexico 21 :313-314.

Mŕgnin, P. 1885-Les Argas du Mexique. Journ. de l'Anat. et de la Physiol. $21: 460-474$, pl. $20,21$.

Mooser. H. 1932-Ornithodorus nicollei spec. nov. Anal. del Inst. de Biol. Univ. Nac. de Mexico 3:127-131, figs. 1-6.

Murphy, Robert C. 1925-Bird Islands of Peru. 362 pp. G. P. Putnam's Sons, New York.

Murray, A. 1877-Economic Entomology; Aptera. Ixodoidea: 180-204. London.

Neumann, L. G. 1896 -Révision de la famille des Ixodidés. I. Argasines. Mém. Soc. Zool. de France 9:1-4t. figs. 1-36.

-1901-Révision de la famille des Ixodidés. te Mémoire. Mém. Soc. Zool. de France $14: 249-372,18$ figs.

1905-Notes sur les Ixodidés, III. Arch. de Parasitol. 9:225-241.

1911-Ixodidae. In: Das Tierreich, herausg. v. T. E. Schulze, im Auftrage der K. Preuss. Akad. d. Wiss. zu Berlin. Berlin: R. Friedländer \& Sohn. 26. Lieferung; $x v i-169$ pp., 70 figs.

Neviu-Lemaire, M. 1921-Parasitologie humaine, 5th ed. 
Nuttall, G. H. F., Warburton, C., Cooper, W. F., and L. E. Robinson. 1908 Ticks. A monograph of the Ixodoidea, Part 1, The Argasidae, 1-104, Cambridge Univ. Press.

Oken, L. 1815-Lehrb. d. Naturg. 3, Zoologie I. Jena. (Cited by Oudemans, 1936.) 1818-Sogenannte giftige Wanze in Persien. Isis, 1567-70, pl. 19, figs. 1-4. (Cited by Nutall, et al., 1908.)

Olfers, Ign. Fra. Mar. von. 1816-De vegetativis et animatis corporibus in corp. Anim. rep. \& Berlin, 75, pl. 1. (Cited by Oudemans, 1936.)

Osborn, H. 1896-Insects affecting domestic animals: an account of the species of importance in North America, with mention of related forms occurring on other animals. U. S. Dept. Agri. Div. of Entomol. Bull., New Series, 5:302 pp.

Oudemans, A. C. 1929-Kritisch Historisch Oversicht der Acarologie, 2:135-1+1. Amsterdam.

1936- Kritusch Historisch Overzicht der Acarologie. 3:746-797. Amsterdam.

PACKARD, A. S. 1872 - "Arachnida" in : Rept. U. S. Geological survey of the territories 6:740, fig. 68 .

Philip, C. B. 1940 - Ticks (Ornithodoros spp.) in Arizona bat "caves" Pub. Health Rept. $55: 680-682$.

Philip. C. B. And Gordon E. Davis. 1940-Relapsing fever: Data implicating Ornithodorus hermsi as a vector in northern ldaho. Pub. Health Rept. 55:504-507.

Pinto, C. 1930 - lxodideos. Arthrópodes Parasitos e Trans-missores de Doenças, 1:29-97. (Tratado de Parasitologia 4). Rio de Janeiro.

Pocock, R. I. 1907-Ticks. In: A system of medicine by many authors. Edited by Allbut and Rolleston, 2:187-203. Macmillan, London.

Railliet, A. 1893-Traité de zoologie médicale el agricole, 1:1-736.

Riley, WVM. A. 1935-Minnesota records of Ornithodoros talaje. Journ. Parasitol. $21: 217$.

Ruge. H. 1928-Kurze Beschreibung des Ornithodorus venezuelensis (Brumpt, 1921). Archiv für Schiffs-und Tropenhygiene 32:406-409, figs. 1-7.

Salmon, D. E. And C. W. Stiles. 1901-The cattle ticks (Ixodoidea) of the United States. 17th An. Rep. Bur. An. Ind., U. S. Dept. of Agri.: 380-488, Washington.

Shaw, G. and F. P. Nodder. 1793-Viv. Nat. or the Nat. Misc. 4: pl. 128. (Cited by Oudemans, 1929.)

Townsend, C. H. T. 1893-Ticks in the ears of horses. Journ. N. Y'. Entomol. Soc. $1: 49-52$.

Valdez, S. Macias. 1923-Ensayo de una Monografia sobre Ixodidos Mexicanos vulgo garrapatas. Me. de la Soc. "Alzate" 41 :197-216, pl. 44-54.

Vigueras, I. Pérez. 193 ta-Sobre un nuevo hospedero de Ornithodoros marginalus Banks, 1910. Revista Universidad de la Habana 1:127.

1934b-On the ticks of Cuba with description of a new species, Amblyomma torrei from Cyclura macleavi Gray. Psyche 41:13-18.

Whiceler. Charles M. 1935-A new species of tick which is a vector of relapsing fever in California. Am. Journ. Trop. Med. 15:435-438.

Wheeler, C. M., Herms, IW. B., ANd K. F. Meyer. 1935-A new tick vector of relapsing fever in California. Proc. Soc. Exptl. Biol. and Med. 32:1290-1292. 


\section{INDEX}

Synonyms in italics

abbreviations

Acarus (Argas)

Alectorobius (Ornithodoros)

amblus (Ornithodoros)

American $Q$ fever...

americana (Argas)

americanus (Ornithodoros)

anduzei (Ornithodoros)

anterior projection

Antricola key to species of Antricola anus frame of

apical ventral spur

Argas

key to species of Argas

Argas (Ornithodoros)

Argasidae key to genera of Argasidae article

attenuated

azteci (Ornithodoros)

barbed hairs

basis capituli

brevipes (Argas)

brodyi (Ornithodoros)

buttons

camerostome

capituli, basis

capitulum

characters (Fig. 1)

cheeks

chelicerae

chinche (Argas)

cleaning

clubbed hairs

color

columbarum (Argas)

concanensis (Ornithodoros)

cooleyi (Ornithodoros)

coprophilus (Antricola)

coriaceus (Ornithodoros)

corona

coxae

denticles

depletion

discs

dissecting microscope

dissection

dorsal humps

dorsal plate dorsum ..................... 5

dunni (Ornithodoros) 103

dyeri (Ornithodoros) .... $\quad 95$

eremicus (Ornithodoros) . _... . . 40

espagnol (Ixodes) …............................. 14

explanation of terms …................... 4

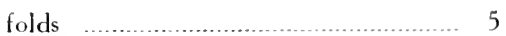

frame of the anus ...................... 5

granulations …................................. 5

grooves .......................................... 5

hairs ……....................................... 5

barbed hairs ........................... 4

clubbed hairs

hermsi (Ornithodoros) ….................... 46

hood

hosts, classified list of .....................14]

humps, dorsal ................................... 5

hypostome …………...................... 5

introduction .................................. 1

Ixodes (Argas) ................................... 14

kelleyi (Ornithodoros) ….................113

lagophilus (Otobius) ........................ 32

legs ................................................ 5

lighting ........................................... 7

magnus (Argas) ................................. 14

mammillae

marginatus (Argas) …........................ 14

marginalus (Acarus) ........................... 14

marginatus (Antricola) …….............. 123

mauritianus (Argas) …........................ 17

measurements ……............................ 6

medical importance ........................... 3

megnini (Otobius) ............................ 21

methods ….................................... 7

micromammillae …............................. 6

microscope, dissecting ........................... 7

migonei (Ornithodoros) ……............ 101

millimeters (see measurements) ........... 6

miniatus (Argas) …........................... 17

morbillosus (Ornithodoros) _............. 38

nicollei (Ornithodoros) .................... 50

ornate .................................................... 7

Ornithodoros _..................................... 37

key to species of Ornithodoros..... 37 


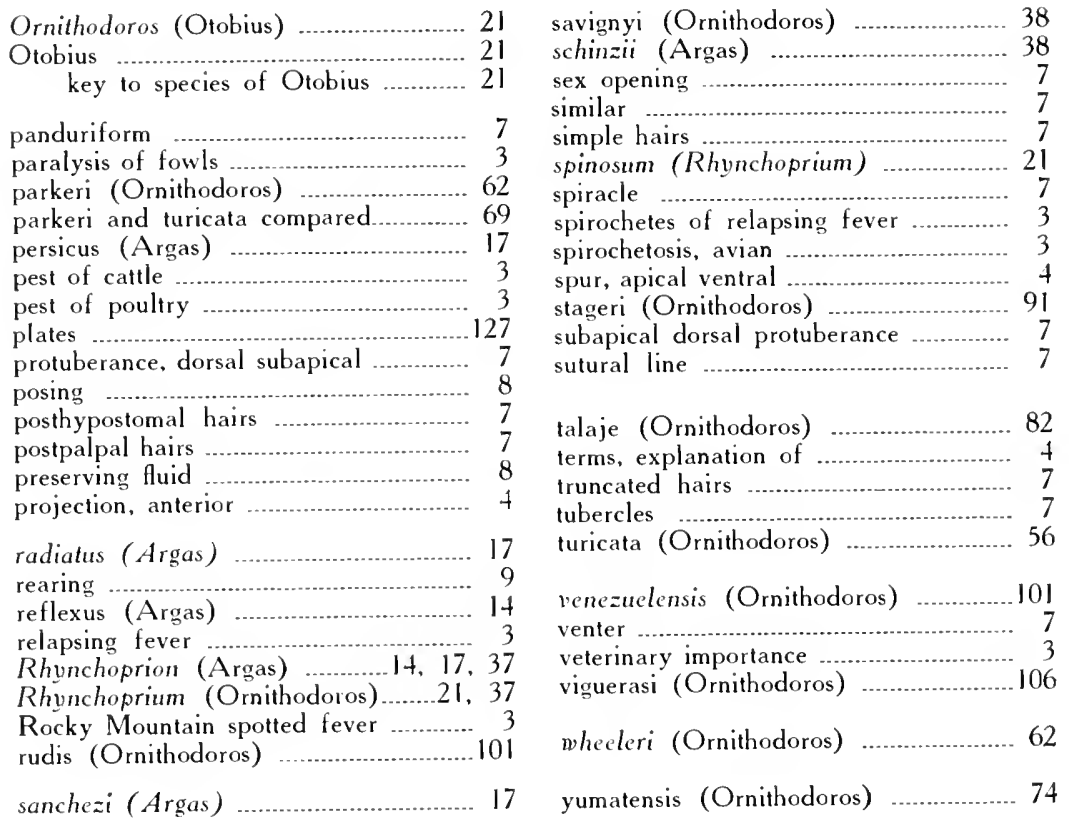







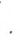


- 


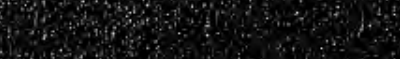

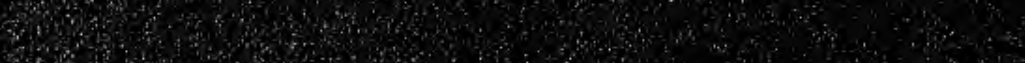

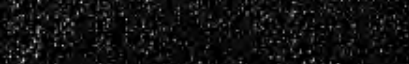

